UMTA - 83-50

\title{
Development of an Extruded Tunnel Lining System
}

of Transportation

Urban Mass

Transportation

Administration

Joseph S. Boyce

Kenneth R. Maser

Douglas W. Ounanian

Foster-Miller, Inc.

350 Second Avenue

Waltham MA 02254

December 1983

Final Report

This document is available to the public through the National Technical Information

Service, Springfield, Virginia 22161.

\section{UMTA Technical Assistance Program}




\section{NOTICE}

This document is disseminated under the sponsorship of the Department of Transportation in the interest of information exchange. The United States Government assumes no liability for its contents or use thereof.

\section{NOTICE}

The United States Government does not endorse products or manufacturers. Trade or manufacturers' names appear herein solely because they are considered essential to the object of this report. 


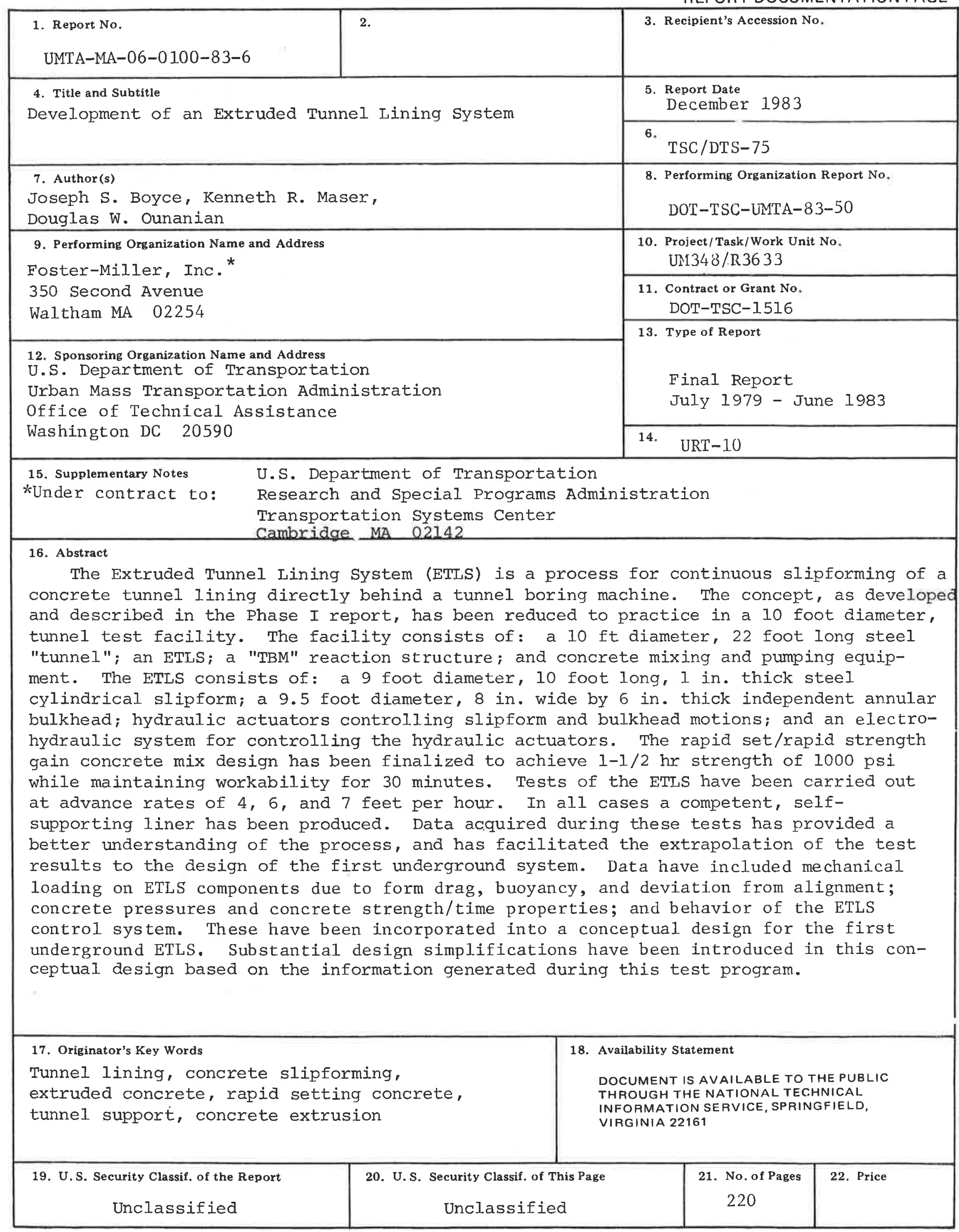




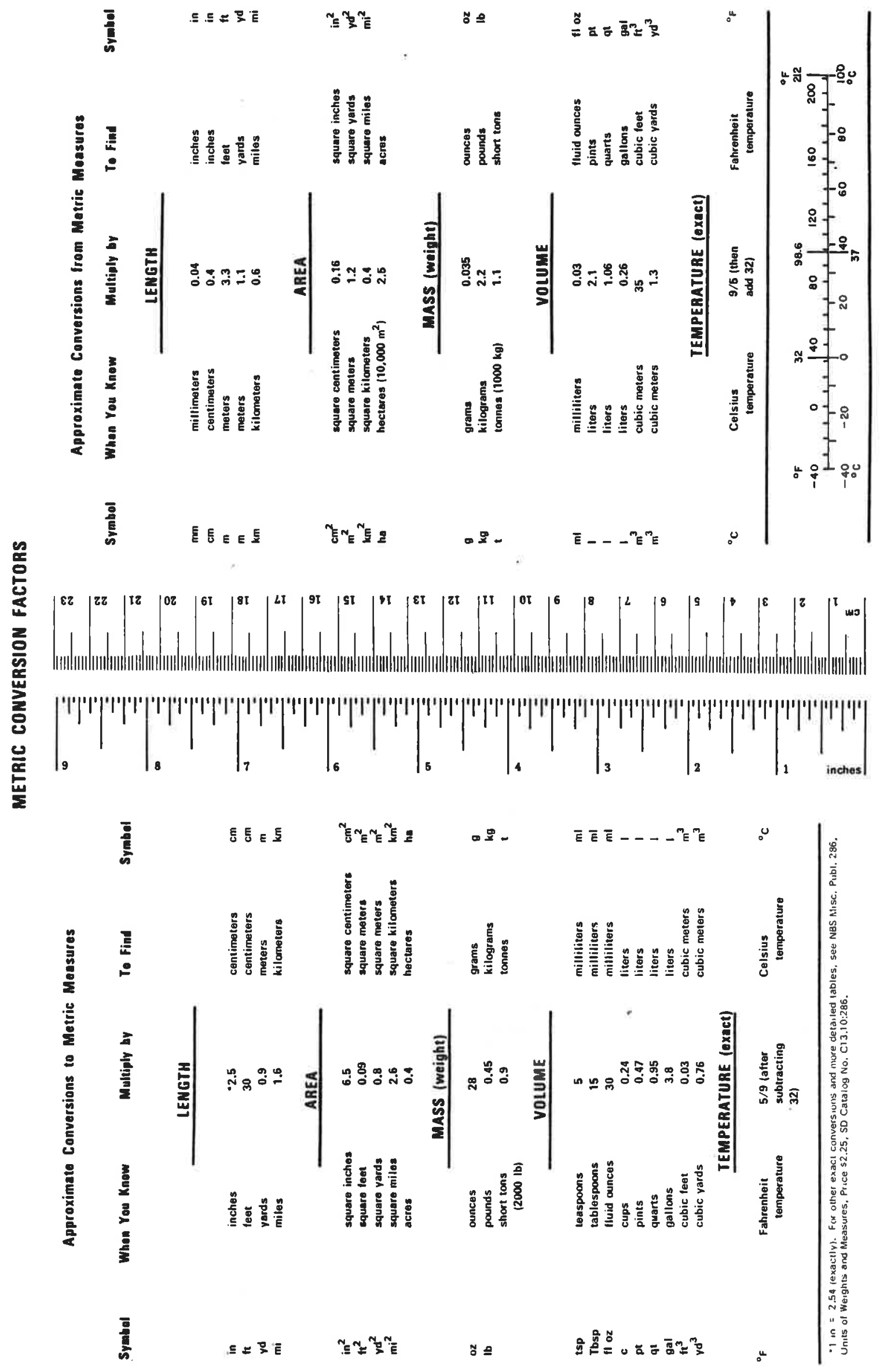


PREFACE

This report was prepared by Foster-Miller, Inc., Waltham, Massachusetts under Contract DOT-TSC-1516 to the U.S. Department of Transportation/Transportation systems Center (TSC), Cambridge, Massachusetts. The contract was sponsored by the Urban Mass Transportation Administration, Office of Technical Assistance. Mr. G. Saulnier of TSC was the contract technical monitor.

The objective of the contract was to design, develop, fabricate, test and demonstrate a system for placing a continuously extruded tunnel liner. The program was carried out in three phases. This report describes the results of the work conducted during Phase II and III (July 1979 - June 1983). It includes the design, fabrication and evaluation of a full-scale, 10-ft diameter prototype in an above ground test facility.

The program manager for the effort described herein was Mr. Joseph Boyce. The project was carried out in the Materials and Structures Division of Foster-Miller under the overall direction of Dr. Kenneth R. Maser. Development efforts in concrete technology, and a majority of the test program, were carried out under the supervision of $\mathrm{Mr}$. Douglas Ounanian. 
The authors would like to acknowledge the support and cooperation of the following individuals in the execution of this contract:

Mr. Gilbert Butler, of UMTA, for his support in initiating and encouraging the pursuit of this work.

Mr. Gerald Saulnier, of TSC, for his patience and guidance throughout the duration of this effort.

Dr. Eugene Foster, President of UTD Corporation, for his contributions to the economic and implementation evaluation of the ETLS concept.

Mr. Adi Guzdar, Vice President, Foster-Miller, for providing enthusiastic corporate support to this effort.

In addition, we would like to acknowledge the following individuals for their technical contribution.

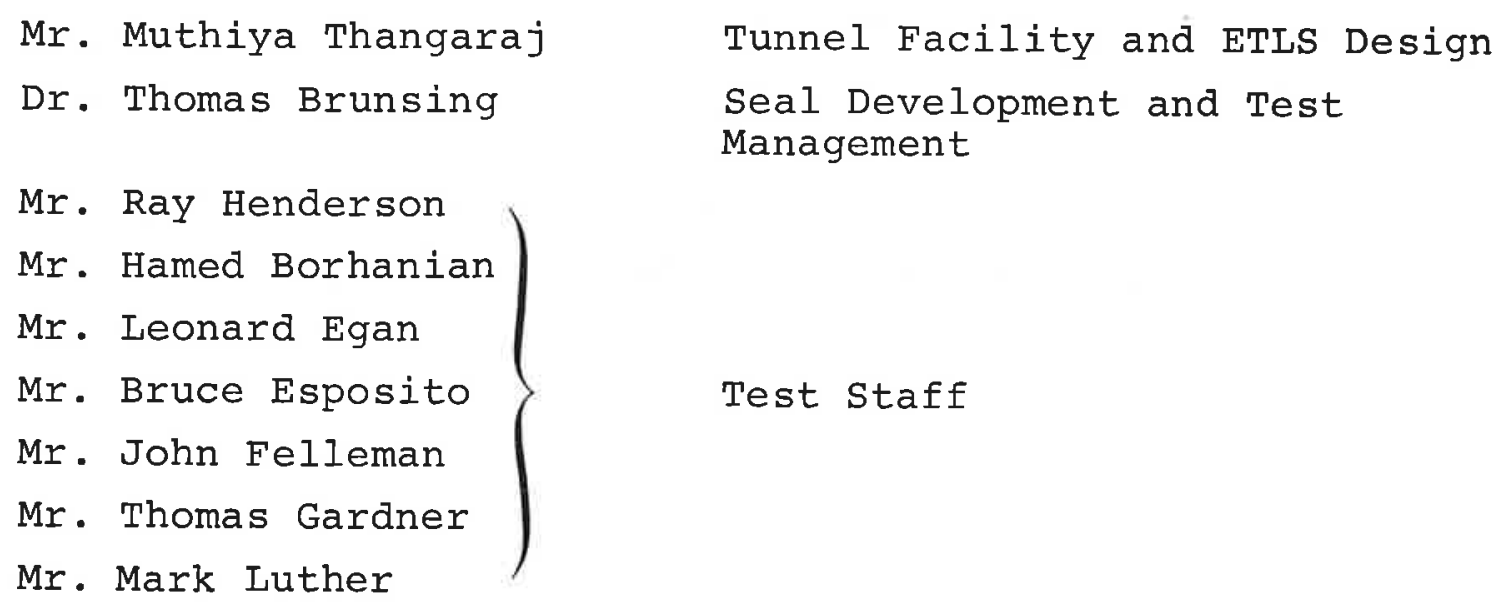

Furthermore, we would like to thank the individual members of the Peer Review Committee for their efforts in evaluating the program. 
INTRODUCTION . . . . . . . . . . . . . . . . . 1-1

1.1 Background . . . . . . . . . . . . 1-1

1.1.1 Rationale. . . . . . . . . . . . 1-1

1.1.2 Historical Perspective . . . . . . . 1-4

1.2 ETLS Concept Description . . . . . . . 1-5

1.3 Program Structure............. 1-10

1.3.1 Phase I - Technology Development. . 1-10

1.3.2 Phase II - Ful1-Scale Laboratory

1.3.3 Phase III - Design for

1.3.4 Implementation . . . . . . . . . . . . . $1-11$

1.4 Report Organization . . . . . . . . . . 1-16

2. PHASE II PROGRAM OBJECTIVES. . . . . . . . . . . 2-I

2.1 Develop a Concrete Mixing System. . . . . 2-1

2.2 Demonstrate Consolidation In a 2-I

2.3 Demonstrate Self-support. . . . . . . . 2-2

2.4 Evaluate Advance Rate Limitations . . . . . 2-2

2.5 Evaluate Slipform Drag. . . . . . . . 2-2

2.6 Develop a Bulkhead Seal . . . . . . . 2-3

2.7 Evaluate Quality of Finished Iiner. . . . . 2-3

2.8 Develop a Placing Line Purging System . . 2-3

3. TEST APPROACH. . . . . . . . . . . . . . 3-1

3.1 Laboratory Tests. . . . . . . . . . 3-1

3.1.1 Concrete Tests. . . . . . . . 3-1

3.1.2 Prebatch Tests......... . . 3-2

3.1.3 Slide Valve and Go-Devil Tests. . . 3-3

3.2 Tunnel Tests. . . . . . . . . . . 3-4 
CONTENTS (Continued)

$\underline{\text { Section }}$

Page

3.2.1 Series I (Preliminary) Tests . . . 3-6

3.2.2 Series II (Final) Tests. . . . . . 3-6

3.2.3 Series III (Critical) Tests. . . . 3-7

3.3 Bulkhead Seal Tests . . . . . . . . 3-8

3.3.1 Bench Top Seal Tests . . . . . . 3-8

3.3.2 Full Scale Seal Tests. . . . . . . 3-9

4 .

ETLS TEST FACILITY . . . . . . . . . . . 4-1

4.1 Shop and Concrete Laboratory. . . . . . . 4-1

4.1 .1 shop . . . . . . . . . . . . . 4-1

4.1.2 Concrete Laboratory Facility . . . 4-3

4.2 Test Tunnel . . . . . . . . . . . . 4-5

4.2.1 Test Tunnel. . . . . . . . . . 4-5

4.2.2 Tunnel Skid. . . . . . . . . . . 4-5

4.2.3 Reaction Structure . . . . . . . . 4-5

4.3 ETLS Prototype. . . . . . . . . . . . 4-7

4.3.1 Concrete Process Subsystem .. . . 4-7

4.3.2 Mechanical Hardware Subsystem. . . 4-20

4.3.3 Hydraulic Power Unit (HPU)

Subsystem. . . . . . . . . . . 4-23

4.3.4 Instrument and Control Subsystem . .4-27

5. TEST METHOD AND TEST RESULTS . . . . . . . . 5-1

5.1 Laboratory Testing. . . . . . . . . . . 5-1

5.1.1 Concrete Mix Design and Material

Properties . . . . . . . . . . 5-1

5.1.2 Prebatch Test. . . . . . . . . . 5-16

5.1.3 Slide Valve and Purge Systems

Tests. . . . . . . . . 5-25

5.2 Series I Tunnel Tests . . . . . . . . . 5-32 
CONTENTS (Continued)

Section

$\underline{\text { Page }}$

5.2.1 Mixer-Pump Tests. . . . . . . 5-32

5.2.2 Distribution Tests. . . . . . 5-35

5.2.3 Slipform Tests. . . . . . . . 5-48

5.2.4 Conclusions of the Series I Test

Program .. . . . . . . . . . 5-55

5.3 Series II Tunnel Tests... . . . . . 5-59

5.3.1 Modifications to the ETLS..... 5-59

5.3.2 Slipform Tests at $6 \mathrm{ft} / \mathrm{hr} . . .5 .5-64$

5.3.3 Laboratory Testing of Concrete . . 5-66

5.3.4 Auger-Mixer Tests ....... . 5-70

5.3.5 Conclusions from Auger-Mixer

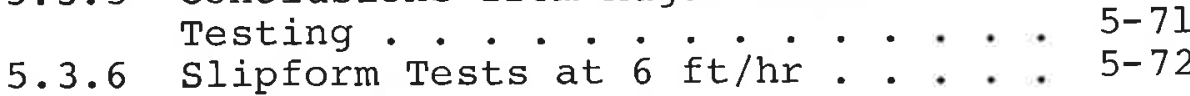

5.4 Series III Tunnel Tests - Critical Tests . 5-79

5.4.1 Prebatch Production Trials. . . . 5-80

5.4.2 Auger-Mixer Trials. . . . . . 5-81

5.4.3 Critical Tunnel Tests SIII-1 and 5-86 SIII-2 . . . . . . . . . . . . .

5.5 Extruded Tunnel Lining System Seal

Development Program. . . . . . . . 5-90

5.5.1. Background. . . . . . . . . 5-90

5.5.2 Seal Concepts.......... . 5-94

5.5.3 Prototype Seal Design... . . . 5-95

5.5.4 Test Results. . . . . . . . . . 5-97

6. CONCLUSIONS OF TEST PROGRAM AND IMPACT ON

ETLS DESIGN . . . . . . . . . . . . . . . . . 6-1

6.1 Conclusions on the Concrete. . . . . . . 6-1

6.2 Conclusions on the Process . . . . . . . 6-4

6.3 Conclusions on the Mechanical Hardware . . 6-6

6.3.1 Eliminate Independent Bulkhead. . . 6-6

6.3.2 Eliminate Purge System. . . . . 6-10

6.3.3 Design of Slipform. . . . . . 6-10

6.3.4 Joints in the Liner... . . . . 6-11 
CONTENTS (Continued)

Section

Page

6.4 Conceptual Design of an Underground ETLS . . 6-11 6.5 Slipform Design Study. . . . . . . . . 6-12

6.5.1 Circumferentially segmented

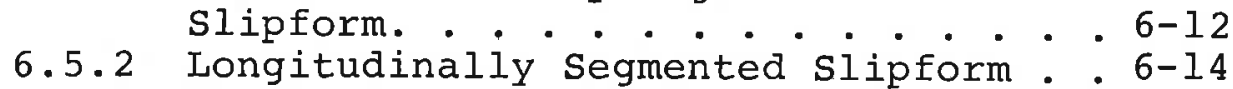

6.5.3 Conclusions of slipform Design study .. . . . . . . . . 6-16

6.6 Integration of ETLS with TBM . . . . . . 6-18

6.6.1 Rock Conditions . . . . . . . . . 6-18

6.6.2 ETLS Materials Handling. . . . . . 6-18

6.6.3 Rail Laying Operations... . . . . 6-18

6.7 Integration of ETLS with Other Tunneling

Machines . . . . . . . . . . . 6-20

6.7.1 ETLS with Shielded TBM. . . . . . . 6-20

6.7.2 ETLS with Two Piece Shield with

6.7.3 ETLS with Rotary Mechanical Shield. $\cdot 6-22$

7. PROGRAM EVALUATION AND RECOMMENDATIONS. . . . . 7-I

7.1 Program Evaluation . . . . . . . . . 7-1

7.1.1 The IPA Review. . . . . . . . . . 7-1

7.1.2 The "Peer Review" . . . . . . . 7-5

7.1.3 Summary of Reviews. . . . . . . 7-10

7.2 Recommendations. . . . . . . . . . 7-11

References. . . . . . . . . . . . . 7-14 
Figure

Page

1-1 CONCEPTUAL EXTRUDED LINER SYSTEM (ㅁ) PROPOSEL

BY UNIVERSITY OF ILLINOIS (1971) . . . . . . . 1-7

1-2 ETLS CONCEPT PURSUED DURING THE FOSTER-MILLER

PROGRAMS $(\underline{8}) \cdot . \cdot$. . . . . . . . . . . . . 1-8

1-3 HARD ROCK ETLS CONCEPT PROPOSED AT THE CONCLUSION

OF THE FOSTER-MILLER PROGRAM . . . . . . . . . . 1-9

1-4 ETLS DEPLOYMENT PLAN PHASING AND SCHEDULE

3-1 PLAN FOR TUNNEL TESTING • . . . . • . . • • • 3-5

4-1 FLOOR PLAN OF BUILDING 2 SHOP . . . . . . . . . 4-2

4-2 TEST TUNNEL, TUNNEL SKID, AND REACTION STRUCTURE 4-6

4-3 SCHEMATIC OF CONCRETE SUBSYSTEM • . • . . • • . 4-8

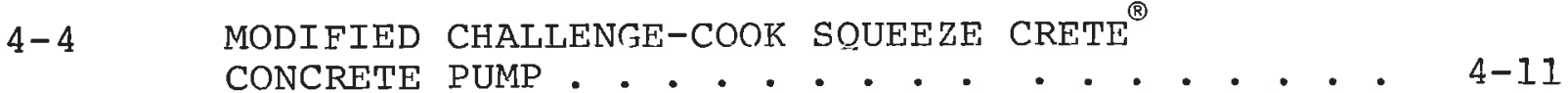

4-5 MODIFIED REMIX-HOPPER . . . . . . . . . . . . 4-12

4-6 SCHEMATIC OF MODIFIED CONCRETE PUMP
HYDRAULIC SYSTEM . . . . . . . . . . . . . . . . . . . $4-13$

4-7 CONCRETE PUMP CONTROL PANEL • • • • • • • • • • $\quad$ - 4-14

4-8 FIOW DIAGRAM OF ADMIXTURE SYSTEM • • • • • • • • 4-16

4-9 SCHEMATIC OF PLACING AND PURGING EQUIPMENT • • • 4-17

4-10 SIIDE VALVE AND GO-DEVIL WINCH . • . • • • • • • 4-18

4-11 SLIPFORM AND BULKHEAD . . . . . . . . . . • . 4-20

4-12 EXTRUDED TUNNEL LINING SYSTEM ELECTROHYDRAULIC

CONTROL SYSTEM • • • • • • • • • • • • • • • • • 4-25

4-13 SCHEMATIC OF INSTRUMENT AND CONTROL SUBSYSTEM - 4-29 
LIST OF ILLUSTRATIONS (Continued)

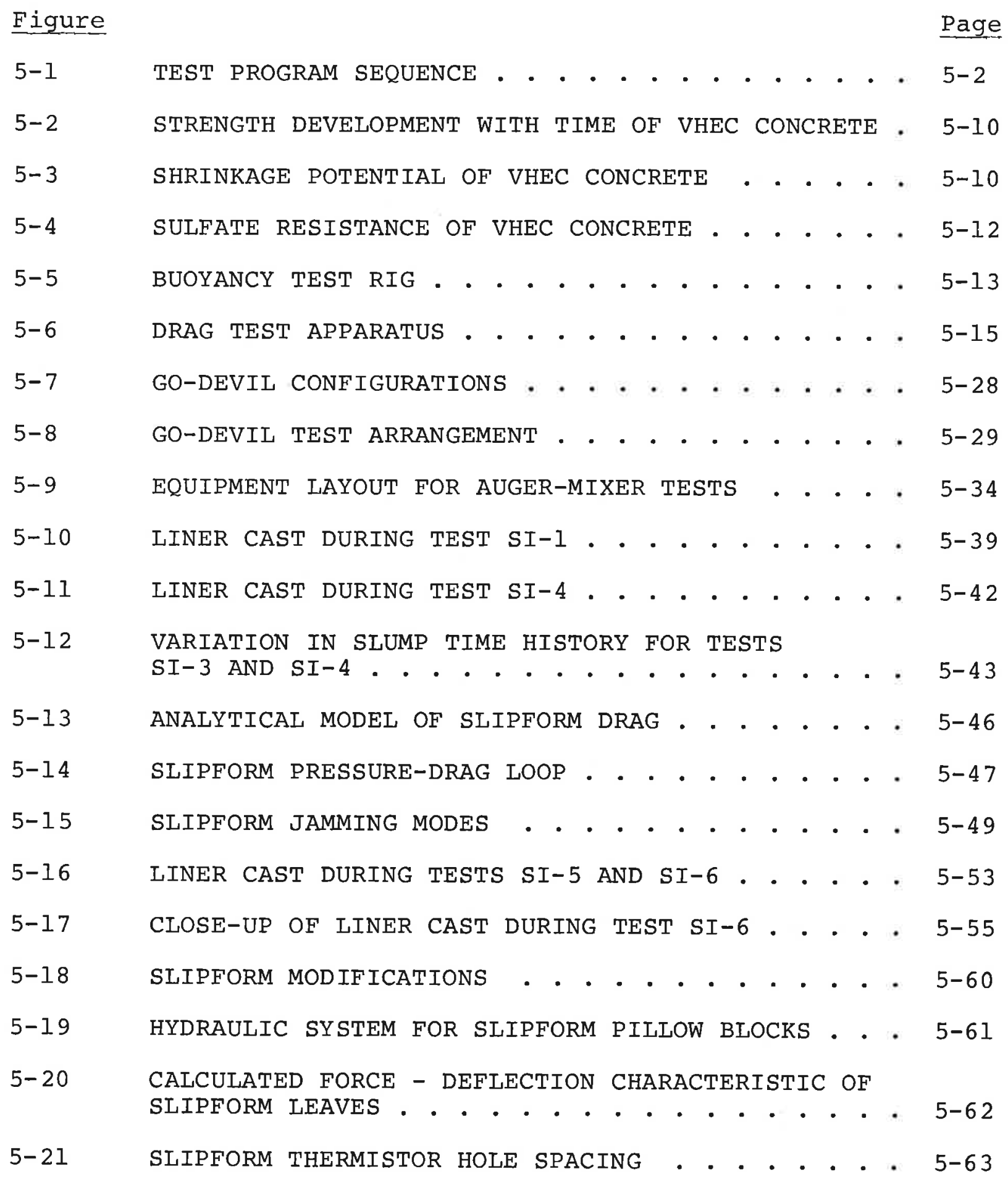




\section{LIST OF ILLUSTRATIONS (Continued)}

Figure

Page

5-22 CONCRETE TEMPERATURE DISTRIBUTION AT TIME OF FIRST EXPOSURE (TEST SII-3) . . . . . . . . . 5-77

5-23 DRAG-TEMPERATURE RELATIONSHIP FOR TESTS SII-3 AND SII-4 . . . . . . . . . . . . . . . 5-78

5-24 BULKHEAD SEAL REQUIREMENTS . . . . • • . • • . . . 5-91

5-25 DESIGN OF SEAL TESTED IN THE LABORATORY • • • • • 5-96

5-26 DESIGN OF SEAL TESTED IN THE CSL PROTOTYPE • • . 5-98

5-27 FULL-SCALE SEAL TESTING . . . . . . . . . . . 5-99

5-28 RESULTS OF TESTING USING THE 4-LEAF SEAL

ARRANGEMENT ON THE DEEPER AND LARGER

SLOUGH ZONE . . . . . . . . . . . . . . 5-101

6-1 VARIABLE LENGTH SLIPFORM . . . . . . . . . . . . 6-8

6-2 CONTROL OF CONCRETE PRESSURE USING CONCRETE PUMP. 6-9

6-3 CIRCUMFERENTIALLY SEGMENTED SLIPFORM • • • • • • 6-13

6-4 LONGITUDINALLY SEGMENTED SLIPFORM • • • • • • • . 6-15

6-5 LONGITUDINALLY SEGMENTED SLIPFORM WITH HYDRAULIC CYLINDERS . . . . . . . . . . . . 6-17

6-6 ETLS INTEGRATED WITH HARD ROCK TBM . . . . . . . 6-19

6-7 ETLS WITH SHIELDED HARD ROCK ROTARY TBM . . . . . 6-21

6-8 ETLS WITH TWO PIECE SHIELD EXCAVATING MACHINE • • 6-23

6-9 ETLS WITH ROTARY MECHANICAL SHIELD. . • . . . . 6-25 


\section{LIST OF TABLES}

Table

$\underline{\text { Page }}$

1-1 COST BENEFIT ANALYSIS OF ETLS CONSIDERING

AN APPLICATION PERIOD OF 1983-1993 . . . . . . . . 1-3

1-2 ETLS SPECIFICATIONS. . . . . . . . . . . . . 1-12

1-3 PHASE DEFINITIONS FOR THE ETLS DEPLOYMENT PLAN . - 1-15

4-1 HPU COMPONENT SPECIFICATIONS . . . . . . . . . . 4-28

5-1 RESULTS OF MIX DESIGN VERIFICATION TESTS . . . . . 5-6

5-2 RESULTS WITH TYPE B AGgREGATES . . . . . . . . . 5-7

5-3 FINAL MIX DESIGN . . . . . . . . . . . . . 5-8

5-4 LONG-TERM COMPRESSIVE STRENGTH DEVELOPMENT * • • . 5-9

5-5 RESULTS OF UPIIFT TEST FOR CONCRETE OF VARYING

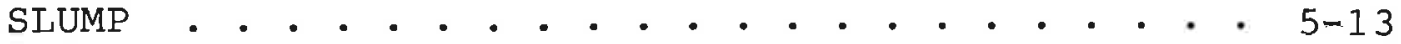

5-6 RESULTS OF SIEVE ANALYSES PERFORMED ON SAMPLES OF PREBATCH TAKEN FROM TRANSIT

MIXER DISCHARGE. . . . . . . . . . . . . 5-18

5-7 RESULTS OF SIEVE ANALYSIS AND MOISTURE CONTENT TESTS FOR SOURCE B AGGREGATES (60 Percent) . . . . 5-21

5-8 RESULTS OF SIEVE ANALYSIS AND MOISTURE CONTENT TESTS FOR SOURCE B AGGREGATES (50 Percent) . . . . 5-22

5-9 RESULTS OF SIEVE ANALYSIS AND MOISTURE CONTENT TESTS FOR SOURCE B AGGREGATES (30 Percent) . . . 5-23

5-10 MEASURED ACCURACIES OF METERING PUMPS AND AUGERMIXER METERING AUGERS. . . . . . . . . . . 5-33

5-11 MINIMUM SLUMP VALUES AT THE TIMES INDICATED. . . . 5-67

5-12 OUTER BULKHEAD SEAL PERFORMANCE SPECIFICATIONS * . 5-93

6-1 SUMMARY OF TEST RESULTS . . . . . . . . . . . . . 6-2 


\section{LIST OF TABLES (Continued)}

Table

Page

$7-1$

PEER REVIEWERS

$7-6$

$7-2$

QUESTIONNAIRE FOR ETLS PEER REVIEW COMMITTEE . . 7-7

$7-3$

SUMMARY OF PEER REVIEWER'S RESPONSES

$7-9$ 



\section{INTRODUCTION}

\subsection{BACKGROUND}

\subsubsection{Rationale}

In the late $1960^{\prime}$ s and early 1970 's, a number of federallysponsored studies were conducted to address various issues related to tunneling technology, and to recommend approaches for reducing the costs of tunneling. These studies were motivated in a large part by a concern for the increased demand for tunnel construction required to address the nation's urban transportation needs. Three significant studies addressing this concern were sponsored by Housing and Urban Development (HUD) (1968) (1), Urban Mass Transportation Administration (UMTA) (1970) (2), and National Science Foundation (NSF) (1974) (3). Each of these studies recommended, among other things, that a continuous, castin-place, slipform technique be developed to place a final concrete tunnel lining directly behind a tunnel boring machine (TBM) . The Extruded Tunnel Lining system (ETLS), discussed herein, is such a lining system.

The rationale behind this recommendation is that most tunnels require two support systems - a primary support system which stabilizes the opening during construction, and a secondary lining which becomes part of the permanent structure. The installation of the final lining directly behind the boring machine eliminates the primary lining system. Primary linings represent a costly element in tunneling in poor quality rock and soft ground. In competent rock, primary lining requirements are reduced. However, the delayed completion due to the second step of lining will incur costs to the project that could be avoided if the final liner were placed directly behind the TBM. 
The above rationale has been tempered over the past few years by the increasing acceptance of precast concrete liners in the United States. Precast liners represent a system which places the final lining segmentally directly behind the boring machine. In spite of this, a continuous slipformed system retains significant potential cost advantages over a precast system, including:

1. Elimination of precasting costs such as high tolerance form work, and reinforcement for handling

2. Elimination of bolting and gasketing

3. Elimination of backpacking and grouting.

A cost analysis carried out during this program by The Transportation Systems Center (TSC) (4) indicated that the ETLS could result in a cost savings of $\$ 500$ per linear foot vs. a precast system under equivalent conditions for an $18 \mathrm{ft}$ diam tunnel.

The rationale for the investment in a program to develop a continuous lining technique can be seen from the figures taken from a 1981 National Academy of Sciences (NAS) report (ㅁ), shown in Table 1-1.

Figures related to projected lengths of mechanically excavated tunnels are shown in Part 1 of Table 1-1. The second part of the table represents estimates which account for projected cutbacks in federal spending that have been implemented since the NAS report. While tunneling may be replaced by other less costly alternatives for urban transportation, other areas of urban and national infrastructure, such as water, sewage, and national defense, have few alternatives. Thus, the demand for tunneling will continue to exist. Assuming that the ETLS is applicable to as little as 20 of the $300 \mathrm{~km}$ projected for the $1983-1993$ period and that $\$ 1,320 /$ meter is saved with this system, the present value of the benefit to the tunnel owners is 15 million dollars. 
TABLE 1-1. COST BENEFIT ANALYSIS OF ETLS CONSIDERING AN APPLICATION PERIOD OF 1983-1993

1. Estimate of $\mathrm{km}$ of Tunnels which could use ETLS (5)
a) Army
$-16.5 \mathrm{~km}$
(both rock and soil are included)
b) Hydro
$-29 \mathrm{~km}$
c) Sewage
$-94.6 \mathrm{~km}$
d) Transportation
$-140 \mathrm{~km}$
e) Water
$-290 \mathrm{~km}$

2. How many will really be built considering current economic conditions?
a) Army
- probably most - say
$-14 \mathrm{~km}$
b) Hydro
- say half
- $15 \mathrm{~km}$
c) Sewage
- limited alternatives - say half -
$47 \mathrm{~km}$
d) Transportation
- many alternatives - say few
$25 \mathrm{~km}$
e) Water
- Iimited alternatives - say
$\underline{200} \mathrm{~km}$

Total estimated ETLS market $=300 \mathrm{~km}$

- Assume that ETLS is used on 20 of the $300 \mathrm{~km}$

- Assume ETLS cost savings of $\$ 1,320 /$ meter

Present value of the accumulated benefit ( $12 \%$ discount rate)

$=\$ 14.92$ million 


\subsubsection{Historical Perspective}

The concept of such a continuous lining system is not new. A tunnel under the Riachuela River in Buenos Aires is reported to have been constructed by such a method in 1942. Other tunnels have been reported to have been constructed in this manner in Toronto and Mexico. It is difficult to assess the degree of success that was achieved in these endeavors since contractor innovations are not widely published in the literature. However, the fact that the technique did not become widespread and the verbal descriptions gathered on these experiences suggest that they encountered problems that could not be overcome with the resources at hand.

In consonance with the recommendations discussed in subsection 1.1.1, a development program was initiated in 1969 by the Department of Transportation (DOT) to develop innovative tunnel support techniques. One of these was an Extruded Tunnel Lining System (ETLS) which would slipform a concrete lining directly behind a tunnel boring machine. A conceptual study of the ETLS was complete in 1971 (6) . This led to definition of the requirement for a rapid-set, high early strength pumpable concrete to support the ETLS concept. Subsequent research programs were carried out at the University of Illinois between 1971 and 1975 to develop and evaluate concrete formulations meeting these specifications. The final results of these investigations were published in 1975 (7). The results confirmed the feasibility and applicability of specific mix designs to meet the ETLS requirements.

Subsequent to these findings, DOT issued a procurement for the development of equipment to demonstrate the feasibility of the ETLS concept. This procurement led to the award of a contract to Foster-Miller, Inc. (FMI), in January, 1978. The Foster-Miller contract, which this report covers, had three overall objectives. 
1. Identify and develop specific technologies required to support the ETLS concept

2. Design, build, and test equipment to demonstrate the ETLS concept

3. Recommend equipment configurations for underground testing.

At the time of this procurement, it was known by DOT that a system for continuous placement of concrete behind a tunnel boring machine was being developed by the Soviet Union. This was a mechanized jumpform system using a series of form elements about $2 \mathrm{ft}$ in length each. A review of the material covering this system indicated that it had very limited advance rate potential, and that it did not meet the overall objectives of DOT.

In 1981, a consortium of German companies, funded by the German Federal Republic, demonstrated a system very similar in concept to the soviet system $(\underline{9}, \underline{10})$. The German system utilized fiber-reinforced concrete and was specifically configured to operate in conjunction with a slurry shield. A similar system was also developed by the Japanese (ㅍ1). The maximum advance rate of the German system is reported to be $3 \mathrm{ft} / \mathrm{hr}$, and the maximum advance rate potential of the Japanese system is reported to be $1 \mathrm{ft} / \mathrm{hr}$. Given the low advance rate and the specific integration with a slurry shield, FMI believes that the Japanese and German systems do not overlap the market which the ETLS was intended to serve. This market will be described in the next section.

The details of the ETLS program structure are discussed in Section 1.3. To better appreciate the program, the next section presents a description of the ETLS concept and its basic features.

\subsection{ETLS CONCEPT DESCRIPTION}

The ETLS is conceived as a system applicable to hard or soft ground. It is understood that its most attractive 
economic potential would be in soft ground, where the cost of the primary support is high. However, it was also understood that soft ground is a difficult environment for first attempts at new lining systems, and early experiences with slipformed liners in soft ground supported this position. Consequently, the initial ETLS was configured for application to competent rock. It was believed that once the system could be successfully demonstrated in this environment, its acceptance and adaptation to soft ground would follow more easily.

The ETLS concept has evolved from the initial thoughts proposed in 1971 to the current concept, presented in section 6.4, and supported by extensive testing. Figures 1-1, 1-2 and 1-3 show three stages of the evolution of the ETLS concept. As the concept has evolved with additional thought and supporting data, certain features have remained fixed. These are the following:

1. Use of short form - Early attempts to slipform tunnel linings used forms that were 50-100 ft in length. The ETLS form is short (length is less than the tunnel diameter) to permit maneuverability around curves, to reduce drag and to minimize and deal with possible binding.

2. ETLS advance rate equals average TBM rate - With the current state-of-the-art in mechanized excavation equipment this could range from 2 to $12 \mathrm{ft} / \mathrm{hr}$.

3. Use of rapid set, rapid strength gain concrete - The combination of short form, rapid advance rates, and final lining requirements demand that the concrete be both self-supporting and able to withstand shortterm rock loads immediately upon exiting from the slipform. 


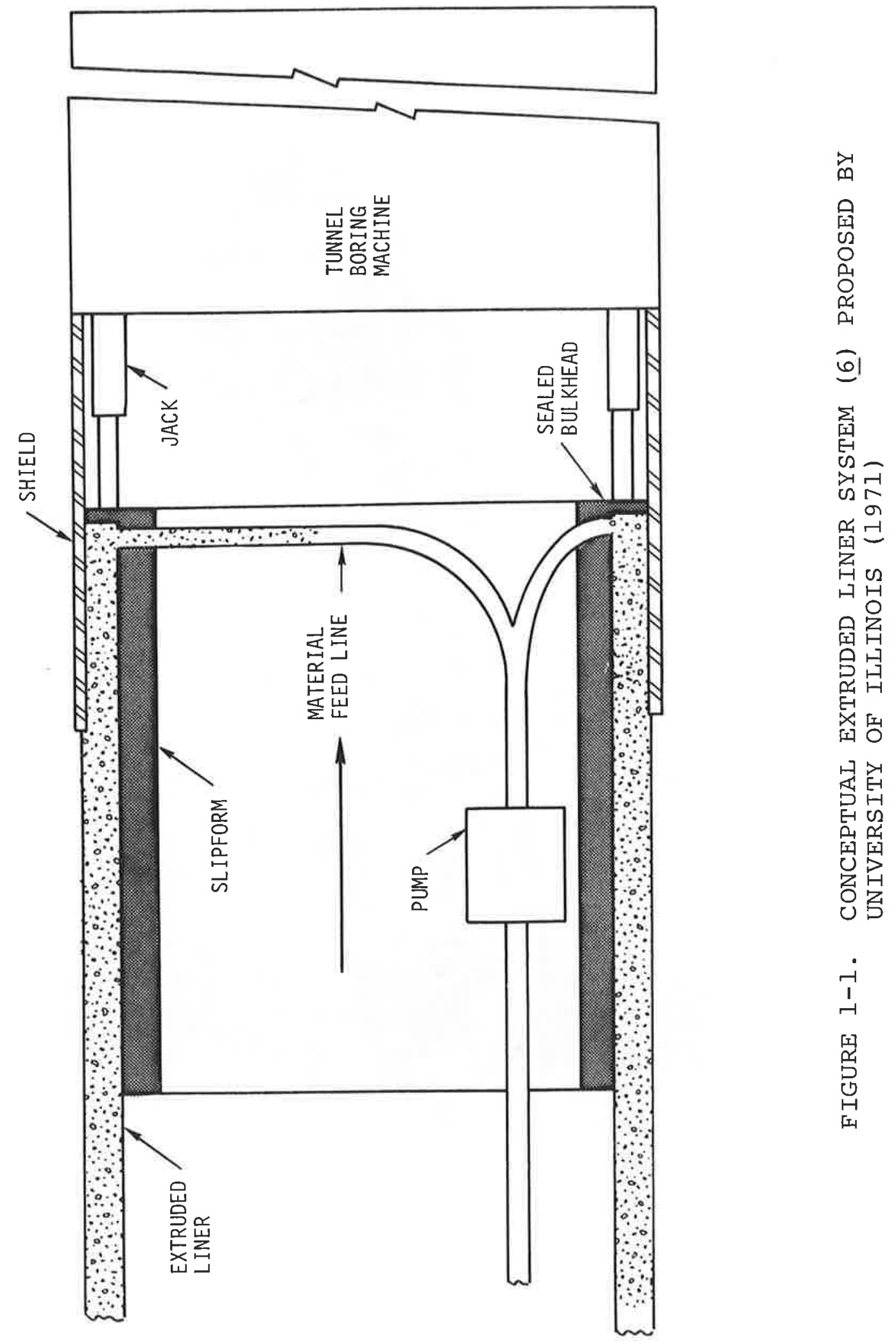


क्ञ।

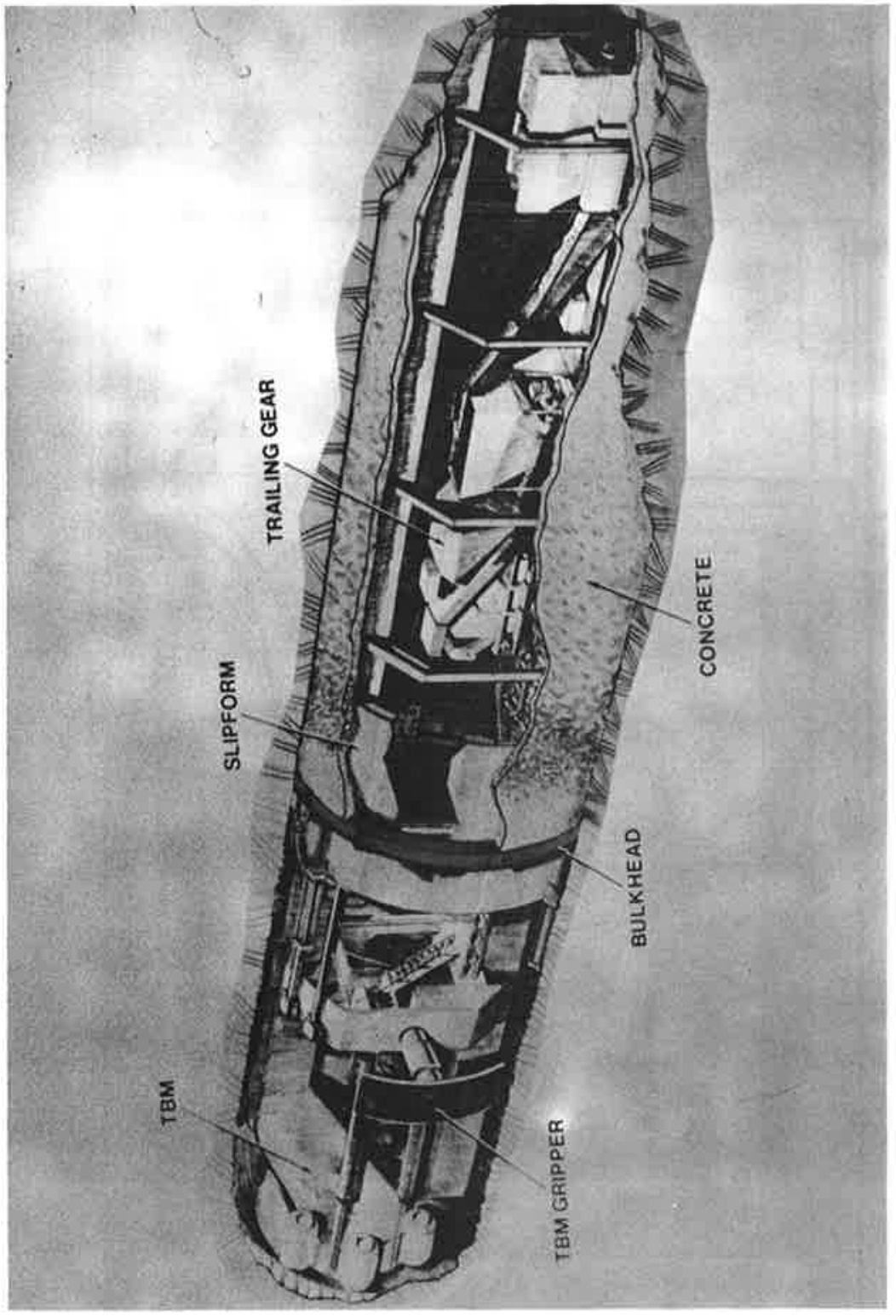

傊

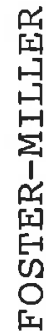

点

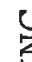

台

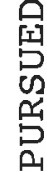

$E$
望
U
0
0

告

굴 


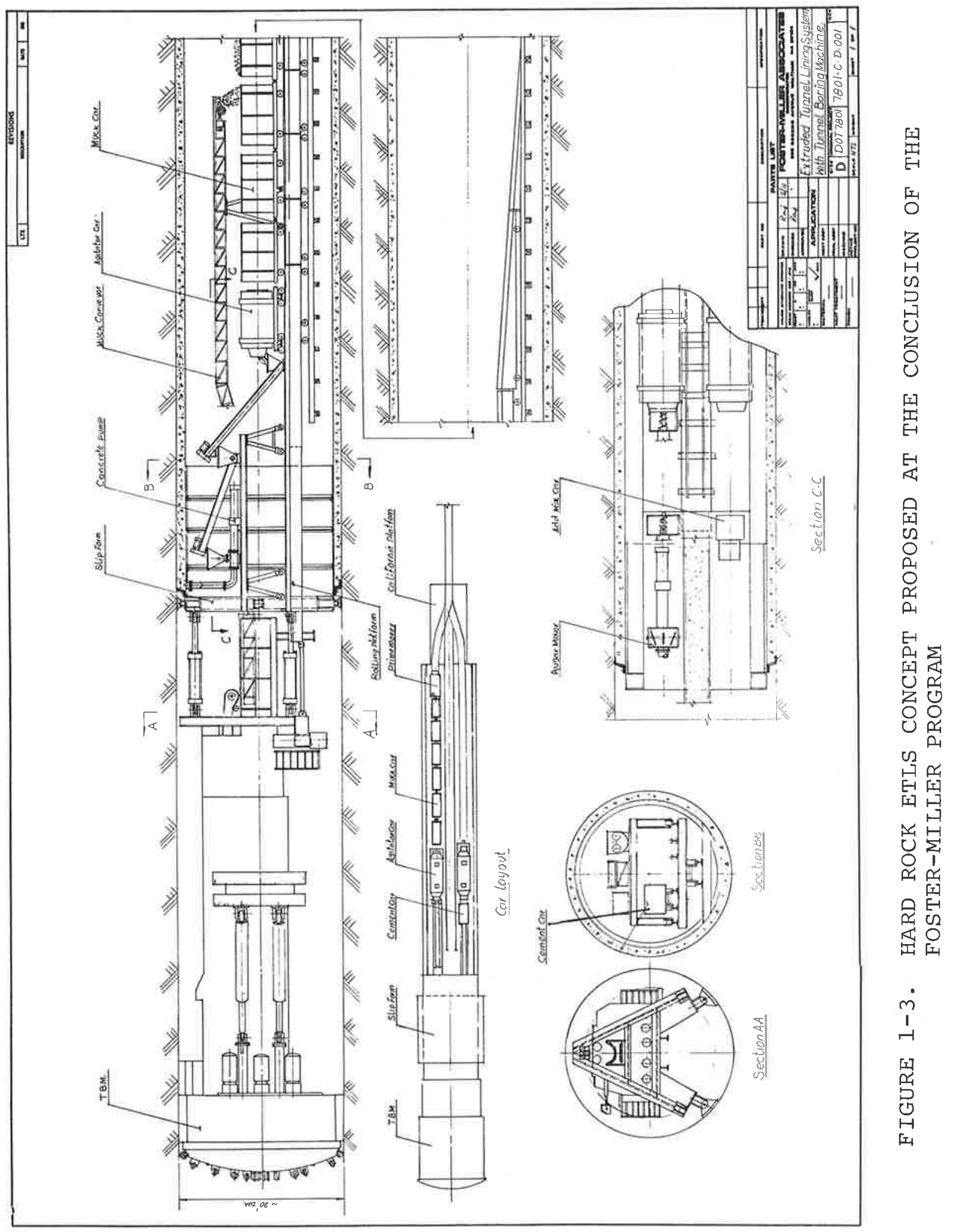


4. Use of pumping - Pumping is the only feasible means of introducing the concrete into the slipform.

5. Requirement for short term workability - Not only must the concrete be designed for pumpability, but it must remain fluid for a sufficiently long time to distribute itself within the closed annular void bounded by the rock surface, the slipform, and the bulkhead.

6. Integration with the tunneling system - It is recognized that the ETLS system must complement the tunnel boring operation, and must adapt to the space constraints imposed by that operation.

The overall development program has been designed to conform to these overall features. The following section describes the structure of the ETLS development program.

\subsection{PROGRAM STRUCTURE}

The Foster-Miller ETLS development program was divided into three phases as follows:

Phase I - Technology development

Phase II - Full-scale laboratory testing

Phase III - Design for implementation

The following paragraphs discuss the content of these phases in further detail.

\subsubsection{Phase I - Technology Development}

The objective of Phase I was to identify and resolve the critical technical issues associated with the ETLS for which 
there was no prior resolution. Following a review of the stateof-the-art in related construction practices, these issues were identified as follows:

1. Development of a concrete formulation which was pumpable and workable during the first 20 min after mixing, and which would gain substantial strength within 45 to $60 \mathrm{~min}$

2. Development of a concrete mixing and placement technique which would guarantee uniform concrete distribution in the closed annular void

3. Development of a slipforming system which would produce self-supporting concrete upon exiting from the form.

The above issues were successfully addressed in an extensive laboratory program. Phase I concluded with a set of specifications for the ETLS system. These are presented in Table 1-2. A detailed description of the activities and results generated during Phase I can be found in the Phase I report (12).

\subsubsection{Phase II - Full-Scale Laboratory Testing}

The overall objective of Phase II was to develop full-scale equipment capable of demonstrating the ETLS concept. Due to considerations of cost and space, a $10 \mathrm{ft}$ diam system was considered to be an adequate representation of full-scale. The detailed objectives, activities and results of the Phase II effort are the subject of the subsequent chapters in this report.

\subsubsection{Phase III - Design for Implementation}

The objective of Phase III was to develop a conceptual design for the first underground ETLS system to serve as a basis for a subsequent development and field testing. In parallel with the conceptual design activity was a critical test program to resolve any 
TABLE 1-2. ETLS SPECIFICATIONS

\begin{tabular}{|c|c|}
\hline \multicolumn{2}{|c|}{ TUNNELING CONDITIONS } \\
\hline $\begin{array}{l}\text { Rock Type and Quality } \\
\text { Depth of Cover } \\
\text { Water Inflow } \\
\text { Maximum External head for a Water Tight } \\
\text { tunnel } \\
\text { Nominal Bore Diameter } \\
\text { Bore Diameter Variation } \\
\text { Bore Surface Roughness } \\
\text { Rock Temperature } \\
\text { Ambient Temperature } \\
\text { Minimum Tunnel Radius of Curvature }\end{array}$ & $\begin{array}{l}\text { Any that can be machine bored } \\
\text { one diameter to any depth where squeezing ground is } \\
\text { not encountered } \\
\text { Any that can be handled in a TBM operation } \\
100 \mathrm{ft} \text { on final liner } \\
15 \text { to } 21 \mathrm{ft} \\
-11 / 2 \mathrm{in.} \mathrm{to} 100 \mathrm{ft} \\
1 / 2 \mathrm{in.} \text { to } 1 \mathrm{in} \text {. maximum pitch } \\
50^{\circ} \text { to } 70^{\circ} \mathrm{F} \\
55^{\circ} \text { to } 90^{\circ} \mathrm{F} \\
750 \mathrm{ft}\end{array}$ \\
\hline \multicolumn{2}{|c|}{ TUNNEL BORING MACHINE } \\
\hline $\begin{array}{l}\text { Type } \\
\text { Maximum Advance Rate } \\
\text { Gripper Slip } \\
\quad \text { Longitudinal } \\
\quad \text { Circumferential } \\
\text { TBM Deviation from Alignment Bullseye } \\
\text { TBM Backup for Cutter Replacement } \\
\text { Shove Length } \\
\text { Routine Shutdown Period }\end{array}$ & $\begin{array}{l}\text { Any } \\
12 \mathrm{ft} / \mathrm{hr} \\
1 \text { to } 2 \mathrm{in.} \\
1 / 4 \text { to } 1 / 2 \mathrm{in} . \\
3 \mathrm{in.} \\
48 \mathrm{in.} \mathrm{maximum} \\
2 \mathrm{to} 6 \mathrm{ft} \\
15 \mathrm{~min} \text { to } 2 \mathrm{hr}\end{array}$ \\
\hline \multicolumn{2}{|c|}{ LINING SYSTEM } \\
\hline $\begin{array}{l}\text { Lining Thickness } \\
\text { Variation in Lining Thickness } \\
\text { Across Tunnel Section } \\
\text { Maximum Lining Rate } \\
\text { Minimum Lining Rate } \\
\text { Lining System to TBM Travel }\end{array}$ & $\begin{array}{l}6 \mathrm{to} 12 \mathrm{in} . \\
\pm 3 \mathrm{in} . \\
12 \mathrm{ft} / \mathrm{hr} \\
2 \mathrm{ft} / \mathrm{hr} \\
8 \mathrm{ft}\end{array}$ \\
\hline \multicolumn{2}{|c|}{ LINING MATERIAL } \\
\hline $\begin{array}{l}\text { Concrete Workability } \\
\text { Tolerance on Concrete set Time } \\
\text { Final Concrete Strength }\left(f_{C}^{\prime}\right)\end{array}$ & $\begin{array}{l}20 \text { to } 25 \mathrm{~min} \\
40 \text { to } 60 \mathrm{~min} \\
4000 \text { to } 6000 \mathrm{lb} / \mathrm{in}^{2}\end{array}$ \\
\hline
\end{tabular}


issues supporting the conceptual design which were not resolved during the Phase 2 test program. The results of the conceptual design and critical test efforts are described in this report.

\subsubsection{Programmatic Events}

Throughout the program, a number of major events took place which strongly influenced the course of the program.

At the conclusion of Phase I, a major program review was conducted by TSC. The purpose of the review was to determine whether the findings of Phase I justified continuation of the program. On the occasion of this review, it was the opinion of the UMTA sponsor that a review by selected individuals outside of the program and sponsor team should be conducted. This review was conducted by the Institute for Public Adminitration (IPA) (13) in November, 1979, and is described in further detail in section 7.1.

Following the general recommendations of the IPA reviewers, TSC, under the direction of UMTA, prepared a deployment plan for the implementation of the ETLS system within the tunneling industry (li4). The result was a five phase plan, Phase 2 of which included the program that is described in this report. Figure 1-4 shows the overall deployment plan schedule that resulted and Table 1-3 describes the content of each phase.

Following the general recommendation of the IPA reviewers, Foster-Miller presented an ETLS paper ( $(\underline{8})$, and Foster-Miller and TSC jointly set up a booth and display at the 1981 Rapid Excavation and Tunneling Conference (RETC) in San Francisco. 


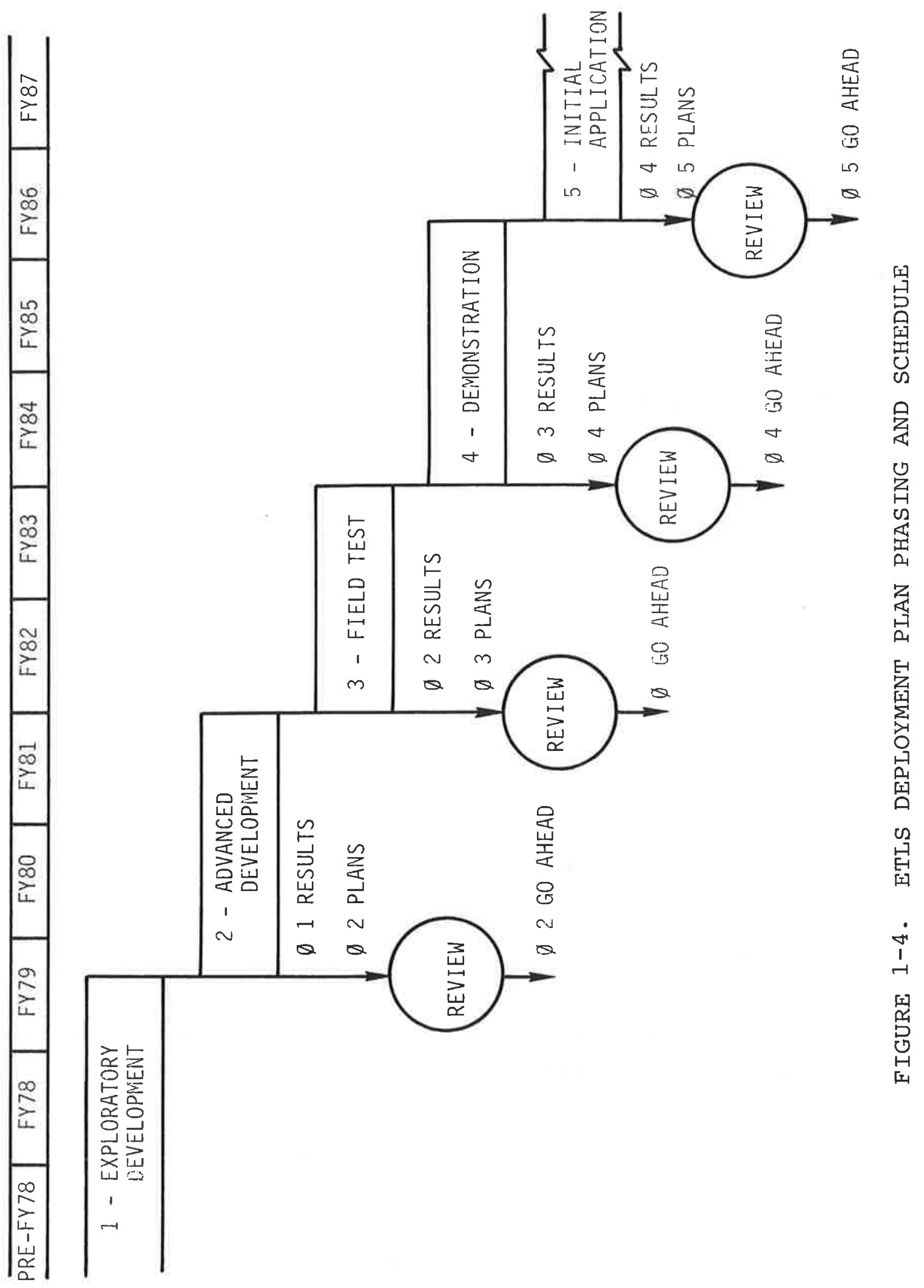




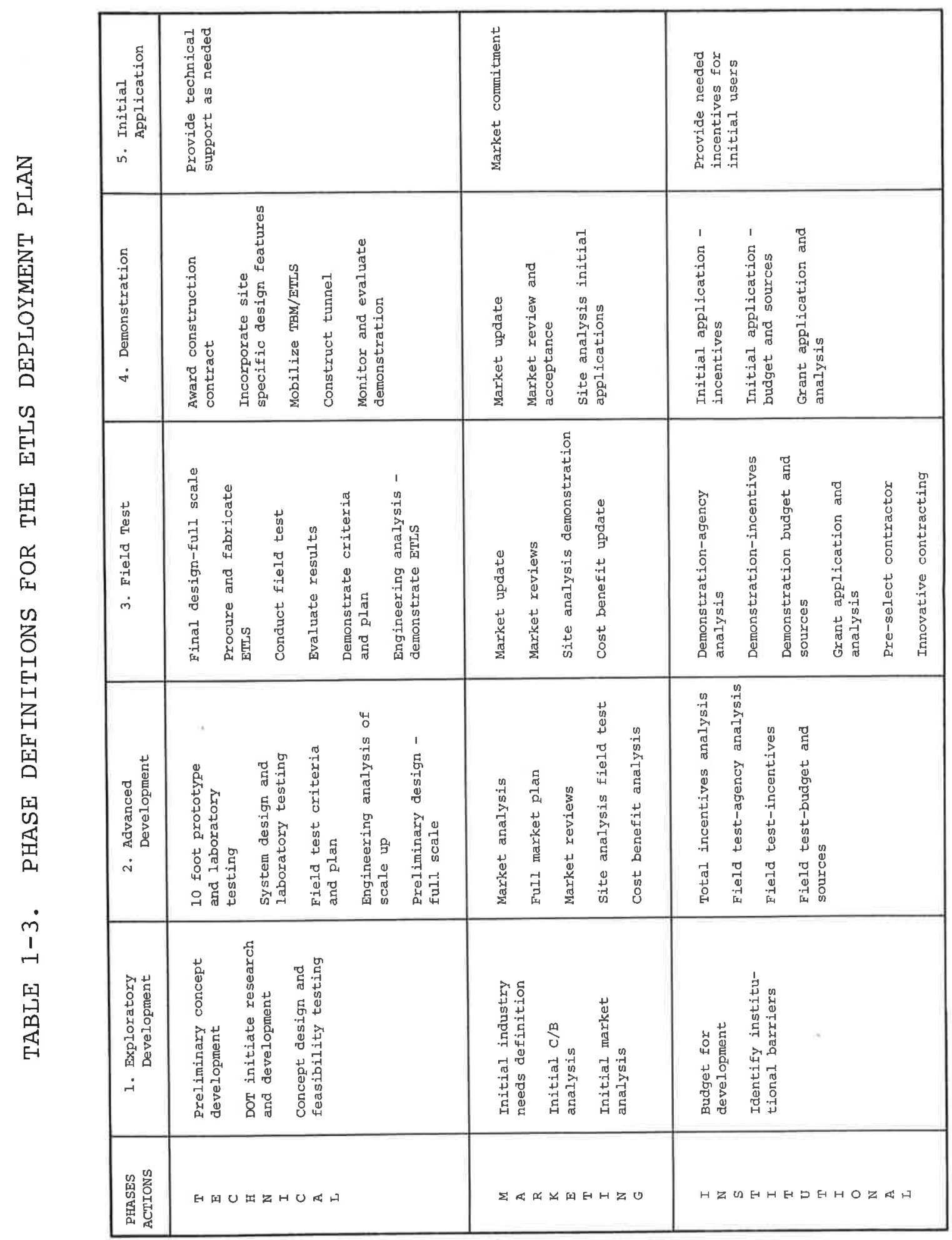


Finally, a "Peer Review" meeting was conducted in June, 1982, to provide a closure and final assessment of the program by industry representatives. The details of this meeting are discussed in Section 7.1.

\subsection{REPORT ORGANIZATION}

This report is organized into seven sections. The majority of the report is devoted to the Phase II laboratory program, which constituted the bulk of the program effort. Section 2 outlines the detailed objectives of the Phase II equipment development and test program. Section 3 discusses the overall test approach, including those tests identified as "critical tests" and conducted during Phase III. Section 4 discusses the test facility and all equipment in detail. Section 5 describes the test methods and results, while section 6 presents the overall test program conclusions, along with their impact on the overall design concept. Section 7 concludes with an analysis of the two major program reviews and, combining the reviewers recommendations with our test program conclusions, presents final recommendations regarding future directions. 


\section{PHASE II PROGRAM OBJECTIVES}

Eight major objectives were defined for the Phase II equipment development program. These objectives were as follows.

\subsection{DEVELOP A CONCRETE MIXING SYSTEM}

During Phase I a concrete mix design was formulated based upon very high early cement (VHEC). The mix design had the necessary characteristics of workability and early strength gain required to permit pumped placement and early exposure. Limited volumetric mixing of the material was done in conjunction with the Phase I distribution and slipforming tests (12). Volumetric mixing of the VHEC concrete is necessary (as opposed to batch mixing) because of the rapid-setting nature of the material. The material cannot be premixed at the surface and then transported to the heading, as can be done with portland cement concrete.

One of the Phase II objectives was to develop and demonstrate an overall volumetric mixing scheme which would be suitable for use in a tunnel and which would provide an acceptable and consistent concrete mix for the ETLS application.

\section{2 DEMONSTRATE CONSOLIDATION IN A FULL-ROUND FORM}

Another Phase II program objective was to demonstrate distribution and consolidation of the concrete inside a full-round form; and to evaluate the effects of placing pressure, number and location of concrete inlet ports, amount of vibration, and workability of the concrete on distribution and consolidation. Distribution and consolidation had been demonstrated during Phase 
I of the ETLS program but not in the full-round configuration. Full-round distribution and consolidation had to be demonstrated for the concept to be viable.

\subsection{DEMONSTRATE SELF-SUPPORT}

The third major objective of the Phase II development program was to demonstrate the ability of the placed liner to support itself upon leaving the form. Self-support clearly would be necessary for the process to work. In fact, in an actual tunnel the liner would have to mobilize enough strength to support some rock loads on leaving the form.

Self-support tests had also been conducted in Phase I; however, these were not in the full-round configuration. The ability of the liner to support itself in the full-round had to be confirmed. The effect of self-heating in a large form had to be determined, and the form length required at various advance rates needed to be established.

\subsection{EVALUATE ADVANCE RATE LIMITATIONS}

To evaluate rates of advance, and limitations imposed on advance rate by the workability and set time of the concrete mix, was another major objective. Workability, set time and advance rate were known to be interrelated. Their relationship had to be determired in order to establish the range of expected advance rates in conjunction with a tunnel boring machine.

\subsection{EVALUATE SLIPFORM DRAG}

The fifth major objective was to evaluate the drag forces on the slipform and to determine the effect on drag of changes 
in form length, concrete placing pressure, and form alignment within the tunnel.

\subsection{DEVELOP A BULKHEAD SEAL}

The sixth objective was to develop and demonstrate an effective method of sealing between the outer bulkhead surface and the tunnel wall. The effectiveness of various sealing techniques in maintaining hydrostatic as well as pumping pressures had to be determined

\subsection{EVALUATE QUALITY OF FINISHED LINER}

The seventh objective was to evaluate the characteristics of the finished concrete liner with regards to dimensional stability and distortion, shrinkage and sag, cracking, surface finish, long-term strength and uniformity of liner thickness. These characteristics were necessary for evaluating future slipform stiffness specifications, future tunnel support design considerations and to determine the need (if any) for patching or improving the surface quality.

\subsection{DEVELOP A PLACING LINE PURGING SYSTEM}

The last major objective was to develop and demonstrate a concrete placing line purging system. The rapid-setting nature of the ETLS concrete necessitated a means for quickly purging the placing line during planned shutdowns and unforeseen blockages. Because of the difficulties associated with gaining access to the bulkhead, it was expected that this system would have to be at least partially automated. 


\section{TEST APPROACH}

This section describes the test approach used to fulfill the previously stated objectives. The testing can be broken down into three major areas: laboratory tests, tunnel tests, and seal tests.

\subsection{LABORATORY TESTS}

The laboratory tests addressed technical issues and equipment development requirements which had to be resolved prior to conducting any full-round tunnel tests. The laboratory tests focused on three areas. These were concrete tests, prebatch tests, and slide valve and go-devil tests.

\subsubsection{Concrete Tests}

Several concrete mixes were formulated in the laboratory early in Phase II. These were done to verify the mix design developed in Phase I.

This was necessary because different raw materials were used in Phase II. Slight adjustments were required to the mix design to reproduce the Phase I results. Standard tests done in the laboratory included sieve analyses, slump tests, compressive strength tests, moisture content, air content, and unit weight measurements.

Long-term and durability tests were also performed to evaluate VHEC concrete as a lining material. Long-term tests included strength/time and shrinkage. Durability tests included resistance to sulfates and resistance to prolonged exposure to water. Some of these tests were conducted in Phase I. These results were augmented during Phase II. 
Tests were also conducted in the laboratory to evaluate buoyancy and drag forces. These tests provided information used in arriving at the final slipform design. Special laboratory test rigs were devised to carry out these tests.

During the course of the Phase II test program it was necessary to return to the concrete laboratory on a number of occasions when problems arose with the concrete mix. The tests conducted in the laboratory provided additional information about the sensitivity of the mix design to variations in temperature of raw materials, ambient temperature, contamination, retarder content, and water-cement ratio.

The initial mix verification tests, the long-term and durability tests, and the buoyancy and drag tests are described in detail in subsection 5.1.1. In the interest of clarity the remaining concrete tests are described in the sequence in which they occurred, in the sections of this report which deal with the tunnel tests.

\subsubsection{Prebatch Tests}

The idea of using prebatched aggregates in the concrete mix was conceived early in Phase II. It was expected that the use of prebatched aggregates would greatly simplify the logistics of transporting the raw materials and mixing them at the congested tunnel heading. Operations in the tight quarters of the ETLS laboratory test facilities would also be made easier. Different types of tests were conducted to develop a prebatch mixture which could be delivered accurately by feed auger and handled without segregating. These tests included handling tests, auger tests, moisture content tests and laboratory concrete mixing trials. The prebatch tests are described in subsection 5.1.2. 
The prebatch tests were expanded to include comparison tests of batch-plant-manufactured and laboratory-manufactured prebatch. This was done to identify possible sources of contamination. Comparison tests of batch-plant-manufactured and laboratorymanufactured prebatch were used to determine if the batching process was adding contamination to the prebatch. Sieve analyses and concrete mixing tests were used to find any differences. Prebatch was eventually manufactured using the auger-mixer. Prebatch contamination tests are described in subsection 5.4 .1 .

\subsubsection{Slide Valve and Go-Devil Tests}

Eaxly in Phase II, it was decided that the placing line purging equipment would have two key components. The two principal components were the slide valve and the remotely actuated godevil and winch. (Refer to subsection 4.3.1.5 for a more complete discussion of the placing and purging system).

The use of slide valves for concrete was common practice at the time. However, all standardly available valves were 4 in. I.D. or larger. A 3 in. I.D. valve was required because a 3 in. placing line was the largest that would fit in the annulus between the slipform and the tunnel wall. None of the slide valve manufacturers were interested in producing a special valve for this application. For this reason a special valve had to be made and tested.

Nothing similar to the remotely actuated go-devil and winch was available on the market. This equipment also had to be developed and tested.

Slide valve and go-devil tests are described in detail in subsection $5 \cdot 1 \cdot 3$. 


\subsection{TUNNEL TESTS}

The contract provided for three series of tunnel tests to be conducted in a specially designed test tunnel facility. This test facility is described in subsection 4.2 . The tests are referred to as the series I (preliminary) tests, series II (final) tests, and series III (critical) tests. Each test series was planned to cast one complete $22 \mathrm{ft}$ long liner. The plan for the tunnel testing is shown in Figure 3-1.

The preliminary tests were intended to demonstrate the basic concept. The main objectives were to demonstrate distribution and self-support. Anything else which could be learned would be extra.

Following the preliminary tests the contract provided for system modifications. These would include any alterations to the system required to correct for problems encountered during the preliminary tests. For obvious reasons the nature of these modifications was not defined.

The final tests were intended to test out the modifications and to prove distribution and/or self-support depending on the extent to which the preliminary tests were successful in accomplishing these objectives. Further, the tests were intended to provide information on form drag, steering and advance rate capability; and to gain additional experience with the system which would allow its operability and reliability to be assessed.

Finally, as a contingency, an additional 'critical' test series was provided for. These tests would be performed only if major problems remained to be addressed at the conclusion of the final tests. Alternately, critical tests would be conducted if a need for additional information was identified during conceptual design of a field test ETLS. 


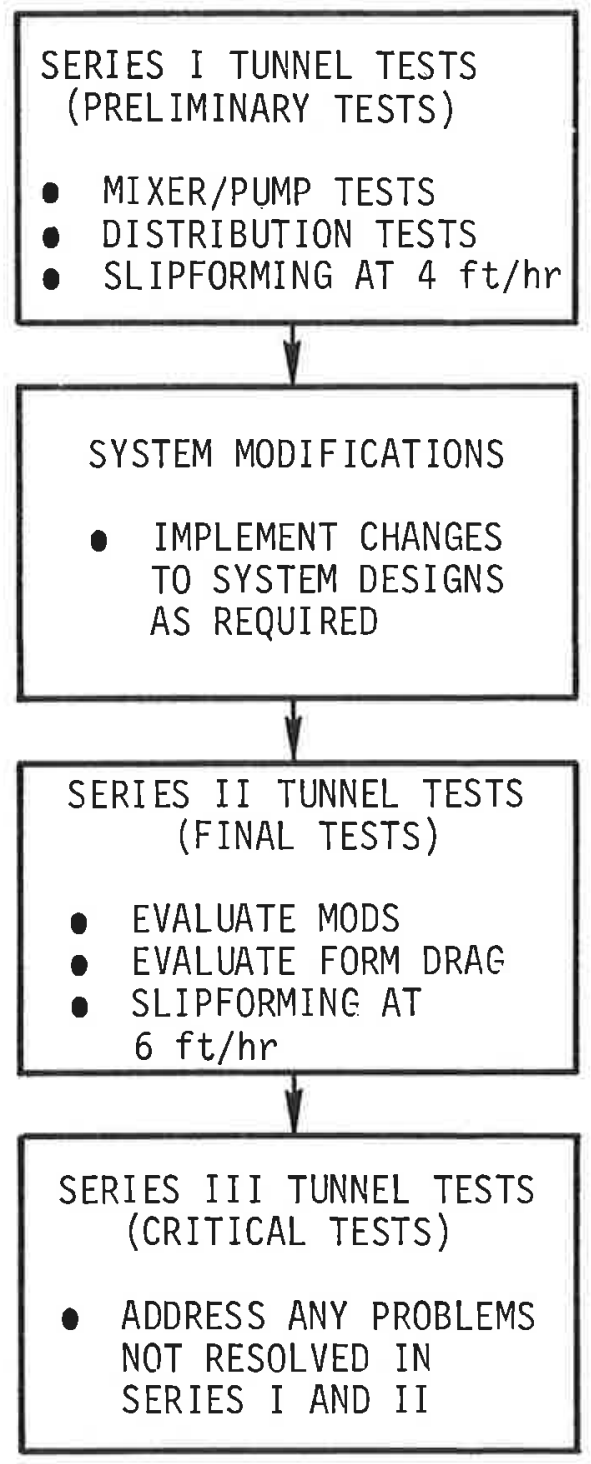

FIGURE 3-1. PLAN FOR TUNNEL TESTING 


\subsubsection{Series I (Preliminary) Tests}

The Series I tests included some initial mixer-pump tests. These were conducted to verify that the concrete was pumpable.

The mixer-pump tests were followed by a series of six tunnel tests conducted at an advance rate of $4 \mathrm{ft} / \mathrm{hr}\left(2.6 \mathrm{yd}^{3} / \mathrm{hr}\right)$. The tests were successful in demonstrating distribution and selfsupport. The first tests were done with portland cement concrete. Subsequent tests were done with VHEC concrete. Altogether a total of 20 ft of liner was cast during the series I tests. The Series I test results are described in detail in subsection 5.2.

The Series I tests identified several modifications which needed to be made. These included modifications to the slipform, the test tunnel and the bulkhead control system. These modifications are described in subsection 5.3.1.

\subsubsection{Series II (Final) Tests}

The Series II tests were intended to test out the modifications mentioned above. Additionally, it was planned to conduct the tests at a higher advance rate of $6 \mathrm{ft} / \mathrm{hr}\left(3.8 \mathrm{yd}^{3} / \mathrm{hr}\right)$.

Problems developed with the concrete early in the series II tests. Two initial test attempts failed due to concrete pumping problems caused by abnormally rapid slump loss of the concrete. This forced a return to the concrete laboratory where the cause of the problem was eventually identified as contamination of the prebatched raw-materials from portland cement residue remaining in the transit trucks used to mix and deliver the prebatch. 
For reasons which will be discussed later, no convenient method of eliminating the contamination of the truck mixed prebatch was found. A truck cleaning procedure was implemented which mitigated the effect of the contamination enough to proceed with the final tests.

Two more final tests were conducted. These tests were conducted at the $6 \mathrm{ft} / \mathrm{hr}$ rate and were successful in demonstrating the usefulness of the hardware modifications. The tests cast a total of approximately $16 \mathrm{ft}$ of liner. The concrete continued to exhibit abnormally rapid loss of slump during these last two final tests. The series II test results are described in subsection 5.3 .

\subsubsection{Series III (Critical) Tests}

Because the Series II test results were not entirely satisfactory, the decision was made to exercise the critical test option. Most of the critical test effort was directed towards determining the sensitivity of the VHEC concrete.

- How sensitive was the material to portland cement contamination, to changes in ambient temperature or temperatures of raw materials, to variations in water cement ratio?

- Was volumetric mixing accurate enough to produce a consistent material with the desired properties?

These questions had to be answered to decide if VHEC concrete could realistically be considered as a lining material. 
Considerable additional testing of the concrete was done during the series III tests, both in the laboratory and using the auger-mixer. To prevent the contamination from obscuring test results, a method was devised to produce prebatch which was guaranteed to be free of portland cement residue. This was accomplished by using equipment which had been used only for VHEC concrete. Once this was done, the concrete was found to be reasonably insensitive to changes in temperature or perturbations in the mixing process.

To complete the series III tests, two more tunnel tests were conducted using contaminant-free prebatch. These tests were conducted at the $7 \mathrm{ft} / \mathrm{hr}$ rate and were entirely successful. Approximately 12 ft of liner was cast and a substantial amount of additional data was collected. The results of the series III tests are described in subsection 5.4 .

\subsection{BULKHEAD SEAL TESTS}

The seal tests were performed to develop an effective sealing method between the outer bulkhead surface and the tunnel casing wall. Both laboratory bench top and full-scale seal tests were performed.

\subsubsection{Bench Top Seal Tests}

A test program was conducted which evaluated seals in a three step operation. Thirty-seven tests were conducted. The first series of tests investigated the ability of the seal to seal fully extended in the 3 in. slough zone against a smooth surface. The second series of tests investigated the seal's ability to seal under the normal wall configuration and to 
traverse a uniform slough zone of three inches. The third series of tests evaluated the ability to seal off odd shape slough zones with ramped and vertical slides. During the course of these tests, the seal design was modified to allow the concrete pressure to be raised to 45 psi.

\subsubsection{Full-Scale Seal Tests}

Full-scale prototype seals were manufactured and tested using a test rig built for the Department of Energy sponsored Continuous shaft Liner (CSL) program (15). Testing was performed over a simulated slough zone. The seal test results are described in detail in subsection 5.5 . 



\section{ETLS TEST FACILITY}

In order to fulfill the Phase II objectives listed in Section 2, a 10-ft diam ETLS test facility was designed and setup indoors at Foster-Miller's shops in Waltham, MA. The test facility was designed during the spring of 1980 and assembled during the winter of 1981. The test facility consisted of a 22 ft long, $10 \mathrm{ft}$ ID, steel tunnel mockup or test tunnel. The ETLS prototype was assembled inside the test tunnel. Also part of the test facility was a fully equipped concrete laboratory. The following subsections describe the main shop and concrete laboratory, the test tunnel, and the ETLS prototype.

\subsection{SHOP AND CONCRETE LABORATORY}

\subsubsection{Shop}

All Phase II testing of the ETLS was performed in the shop space of Foster-Miller's Building 2. The shop had approximately $5,000 \mathrm{ft}^{2}$ of high bay floor space. Access to the shop was provided by a combination loading dock and access ramp with an overhead door. The shop housed the test area, storage areas, tools and parts crib, and concrete laboratory. A floor plan of Building 2 shop is shown in Figure 4-1. 


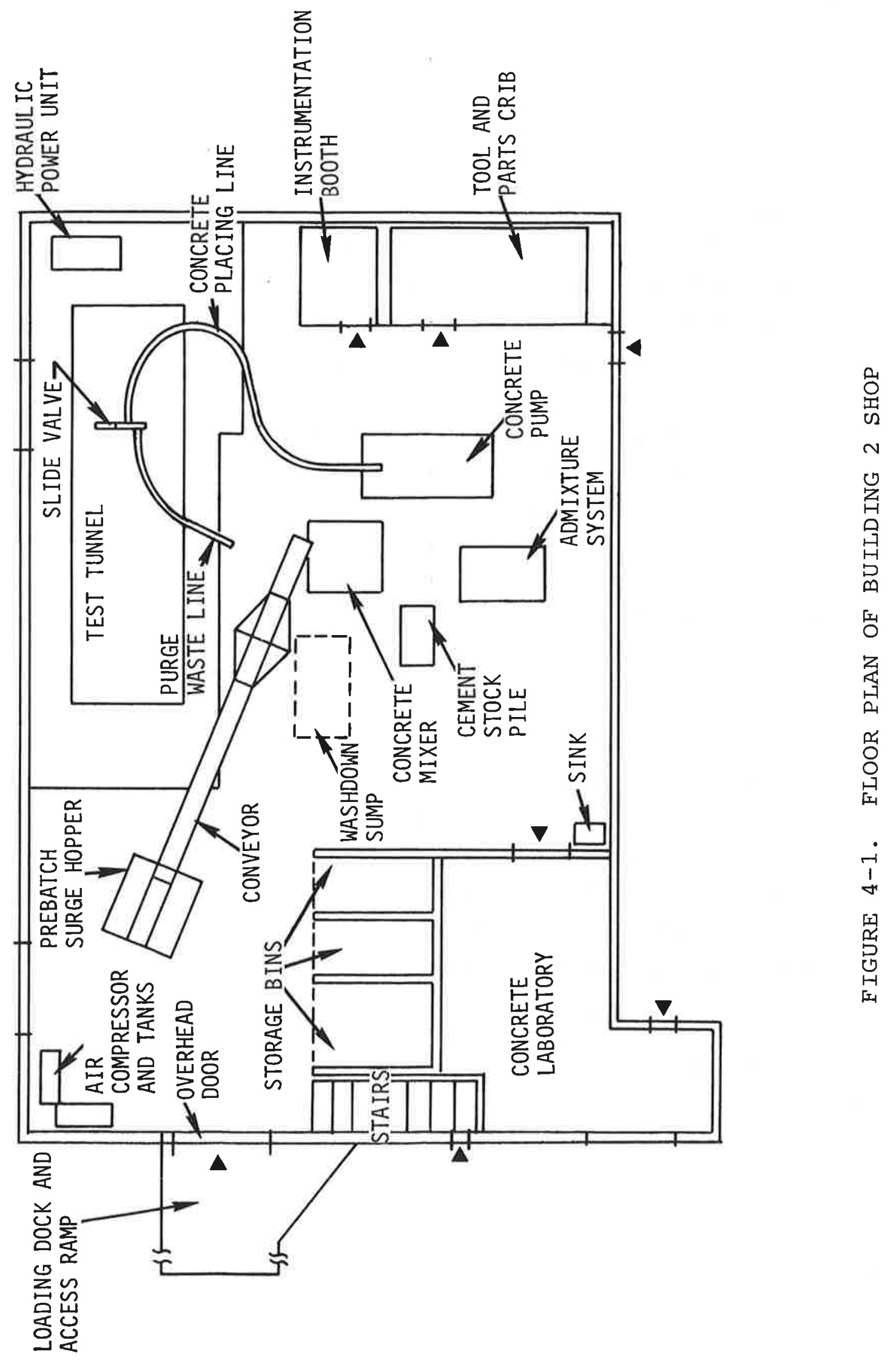


Support equipment included a crane, front end loader, fork lifts, hand and power tools, and welding equipment. Electrical power at 480, 208 and $110 \mathrm{~V}$ and compressed air at 100 psi were also available. The ETLS project also had access to a complete machine shop located in Foster-Miller's building 1.

The crane was a Drott model 3330 carry deck crane. The $8 \mathrm{ft} 1 \mathrm{in}$. standard height and propane conversion allowed it to be used inside the test facility. Lift capacity was 6 tons and an outrigger system was provided giving a constant 360 deg lifting capacity. The crane was equipped with pneumatic tires for use inside as well as outside. The crane was used for assembly of the test tunnel and ETLS, and for removal of the concrete liners.

The skid-steered front end loader used was a Clark model 520 Bobcat. It was equipped with a 4 -ft wide bucket and had a lifting capacity of $800 \mathrm{lb}$. It was also converted to propane operation so that it could be safely used indoors. The Bobcat was used primarily for loading the $3 / 4-i n$. stone into the concrete mixer and for cleanup operations.

\subsubsection{Concrete Laboratory Facility}

The concrete laboratory was located in the shop of FosterMiller's building 2, occupying approximately $450 \mathrm{ft}^{2}$ of floor space. The concrete laboratory was completely enclosed and had independent temperature and humidity control.

Major components of the laboratory included:

1. 250,000 lb electrically powered, hydraulic, concrete specimen tester

2. Temperature controlled, fog curing room 
3. Wash-down sump for trapping waste concrete

4. Microwave oven for drying aggregates to determine moisture content

5. Vibrating table for consolidating test specimens

6. Aggregate bin hatches for access to raw aggregate supplies

7. Work tables for general tasks

8. Water tub for water-curing specimens.

In addition to major components of the laboratory, there were a number of other pieces of laboratory test equipment. These included:

1. Length comparator for volume change measurements

2. Complete United States sieve set and shaker

3. Gillmore and Vicat needle time of setting apparatae

4. Immersion concrete vibrator

5. Tumble type, $3.5-\mathrm{ft}^{3}$ concrete mixer

6. Slump cones and tamping rods

7. Compressive strength cylinder molds $(6 \times 12$ in.)

8. Flexural strength molds $(6 \times 6 \times 12$ in. $)$

9. Bar molds $(2 \times 2 \times 10$ in. $)$

10. Air content measuring device

11. Unit weight containers. 


\subsection{TEST TUNNEL}

The test tunnel consisted of the test tunnel itself, the tunnel skid and the reaction structure. The test tunnel, tunnel skid and reaction structure are pictured in Figure 4-2.

\subsubsection{Test Tunnel}

The test tunnel consisted of a casing with an inside diameter of $122 \mathrm{in.}$ and a length of $22 \mathrm{ft}$. It simulated a hard rock tunnel and established the exterior surface of the concrete liner.

The tunnel casing was designed in two sections, each $11 \mathrm{ft}$ long, to facilitate fabrication, handling, shipment and installation. Both sections of the tunnel casing consisted of a base and two covers. The four covers were bolted to each other and to the two bases. The covers were unbolted and taken off to permit removal of the cast concrete liner.

\subsubsection{Tunnel Skid}

The entire test tunnel assembly was supported on a mat of railroad ties which distributed the load over the concrete floor of the test facility. The tunnel casing and reaction structure were supported by a skid which rested directly on the railroad ties. The skid was fabricated from four 12-in. wide flange structural steel beams. The four beams were joined together by lengths of 12-in. wide flange beams.

\subsubsection{Reaction Structure}

The reaction structure simulated the tunnel boring machine (TBM) at rest. The reaction structure consisted of a welded frame of structural steel beams which provided reaction load points for the four slipform hydraulic cylinders. The reaction 


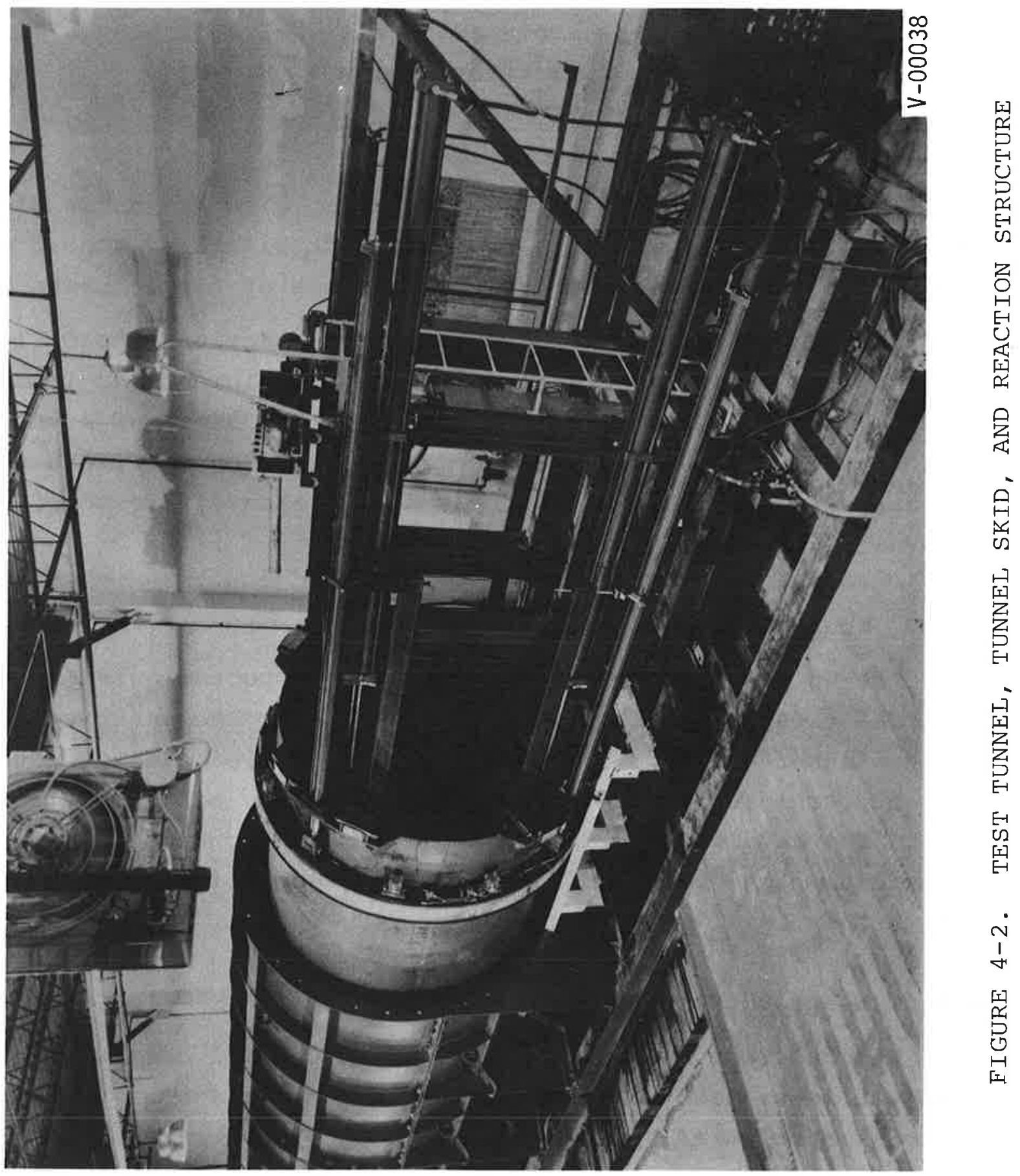


structure also supported the slide valve. The reaction structure was bolted to the two inner longitudinal beams of the skid at one of two mounting positions. The amount of existing cast concrete liner, the intended length of test and whether or not the slipform cylinder extensions were used, determined the position of the reaction structure prior to the start of a test.

\subsection{ETLS PROTOTYPE}

The ETLS prototype consisted of the concrete process, mechanical hardware, hydraulic power unit (HPU), and instrumentation and control subsystems.

\subsubsection{Concrete Process Subsystem}

The concrete process subsystem consisted of the materials handling equipment, auger-mixer, concrete pump, admixture metering equipment, and placing and purging equipment. The relative position of each of these items is shown in Figure 4-3.

4.3.1.1 Materials Handling Equipment - The mix design used was a blend of sand, 3/8-in. stone, 3/4-in. stone, fly ash, cement citric acid, Lomar-D and water. All these materials had to be handled properly to achieve the desired concrete mix.

Prebatch - At a batch plant, the 3/8-in. stone, fly ash and a portion of the mix water were batched and charged into a transit mixer. The transit mixer then delivered this material (prebatch) to the test facility. The prebatch was discharged from the transit truck into $1 \mathrm{yd}^{3}$ self-dumping hoppers. The dumpers were then transported by fork-lift into the test facility and emptied into a surge hopper. The surge hopper had a capacity of approximately $6 \mathrm{ya}^{3}$

The prebatch was raked through an opening in the bottom of the surge hopper onto a conveyor which transported it to one of the aggregate hoppers of the concrete mixer. 


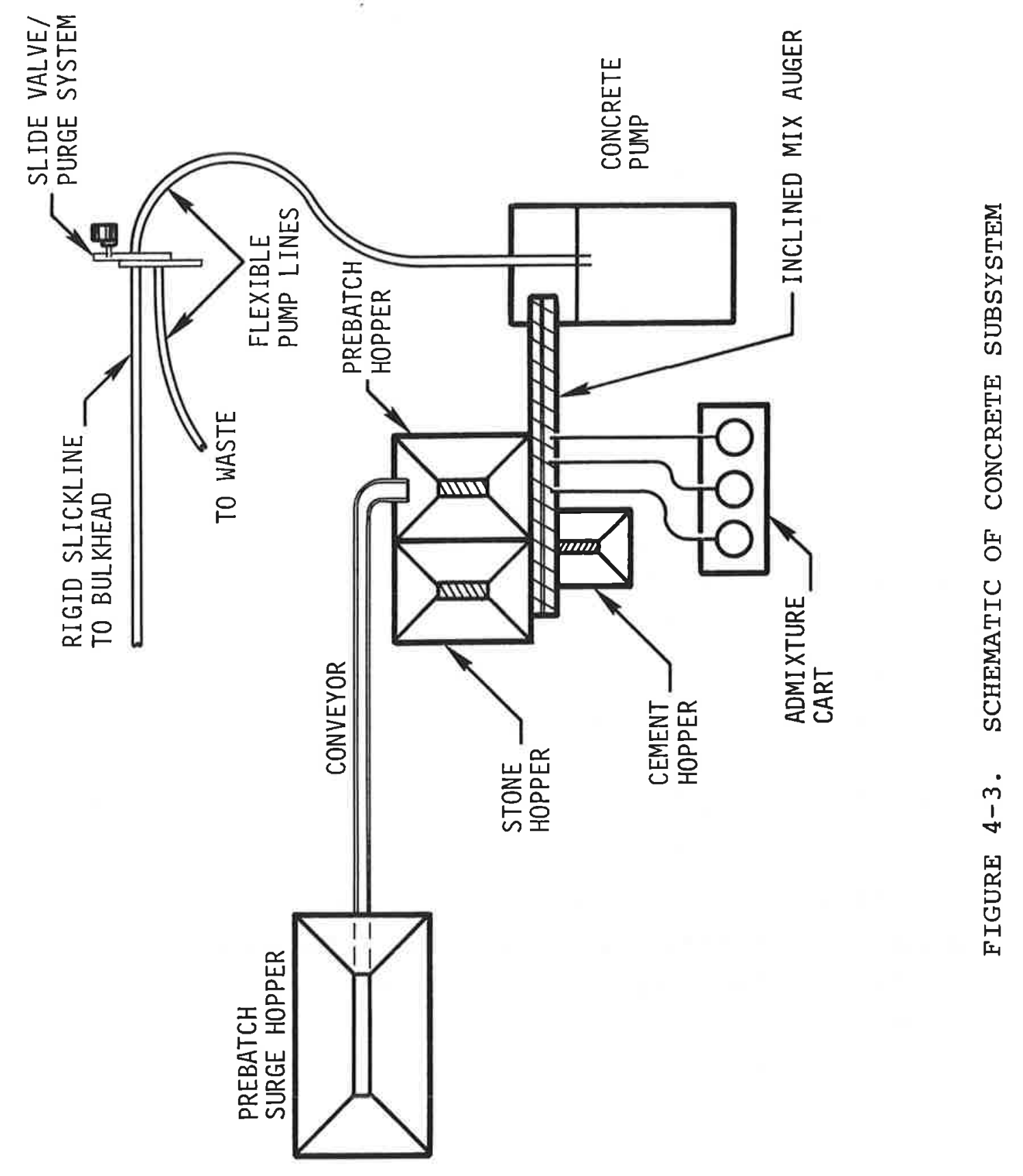


3/4-in. Stone - Approximately 15 tons of 3/4-in. stone were stored in an open bin outside of the test facility. To more closely control the temperature and moisture content of the 3/4-in. stone, a storage bin was fabricated inside the test facility. The 3/4-in. stone was transported from the outside storage to the inside storage bin with the Bobcat. Sufficient quantities were kept indoors to complete a whole tunnel test. The 3/4-in. stone was loaded into one of the aggregate hoppers of the concrete mixer using the Bobcat.

Cement - The bagged very high early cement (VHEC) was stored on pallets inside the test facility. The cement was manually loaded into the cement hopper of the concrete mixer.

4.3.1.2 Auger-Mixer - The proportioning and mixing of prebatch, 3/4-in. stone, cement, water and admixtures were accomplished using a model 8000 Reliable proportioning concrete mixer.

The mixer had three separate bins. The two aggregate bins each had a capacity of $1 / 2$ of a cubic yard and were equipped with a variable speed 6 in. diam auger. The cement bin had a capacity of approximately $1 / 4$ of a cubic yard and was equipped with a 5-1/4 in. diam variable speed auger. The concrete was mixed by an 8 in. diam, inclined, constant speed mixing auger.

A Parajust ${ }^{\circledR}$ frequency controller was added to the mixer to vary the speed of the cement, prebatch and stone augers together. Each of the augers was equipped with a Varidrive ${ }^{\circledR}$ unit which allowed for changing the speed of individual augers independently.

4.3.1.3 Concrete Pump - The concrete pump received the freshly mixed concrete from the discharge of the concrete mixer and delivered it to the annulus between the slipform and test tunnel. 
The system was capable of delivering approximately 2 to $10 \mathrm{yd}^{3}$ of concrete per hour over a range of slipforming pressures from 0 to $30 \mathrm{psi}$. (This equates to a pump discharge pressure of approximately 100 to 150 psi including placing line head losses.) The pump was capable of substantially higher delivery pressures and also of reverse operation to assist in clearing line blockages.

The concrete pump used was a challenge-Cook squeeze crete 250, peristaltic pump. The same pump was used during phase I of the program. Based on experience with the pump gained in Phase 1 , the pump was modified to provide more flexible operation and to ensure compatibility with the overall slipforming system. The modified pump is pictured in Figure 4-4. It consisted of the remix-hopper which received the concrete discharged from the concrete mixer and fed the pump inlet port, the pump unit itself, the arive motors, hydraulics, and control panel. The remixhopper, motor drives, hydraulics, and control panel were modified as described below.

Remix-Hopper - The size of the remix-hopper was reduced by installing false sides. This reduced the inventory of concrete contained in the remix-hopper and shortened the concrete residence time through the pump and placing line, allowing the concrete to enter the annulus at the highest possible slump, and assuring uniform filling of the concrete around the periphery at the bulkhead.

Modified mixing paddles were installed in the hopper. The new paddles were designed to wipe the hopper completely, eliminating dead spots where the concrete could collect and harden. This prevented lumps of partially set concrete from entering the pump. The modified remix-hopper is shown in Figure 4-5. 

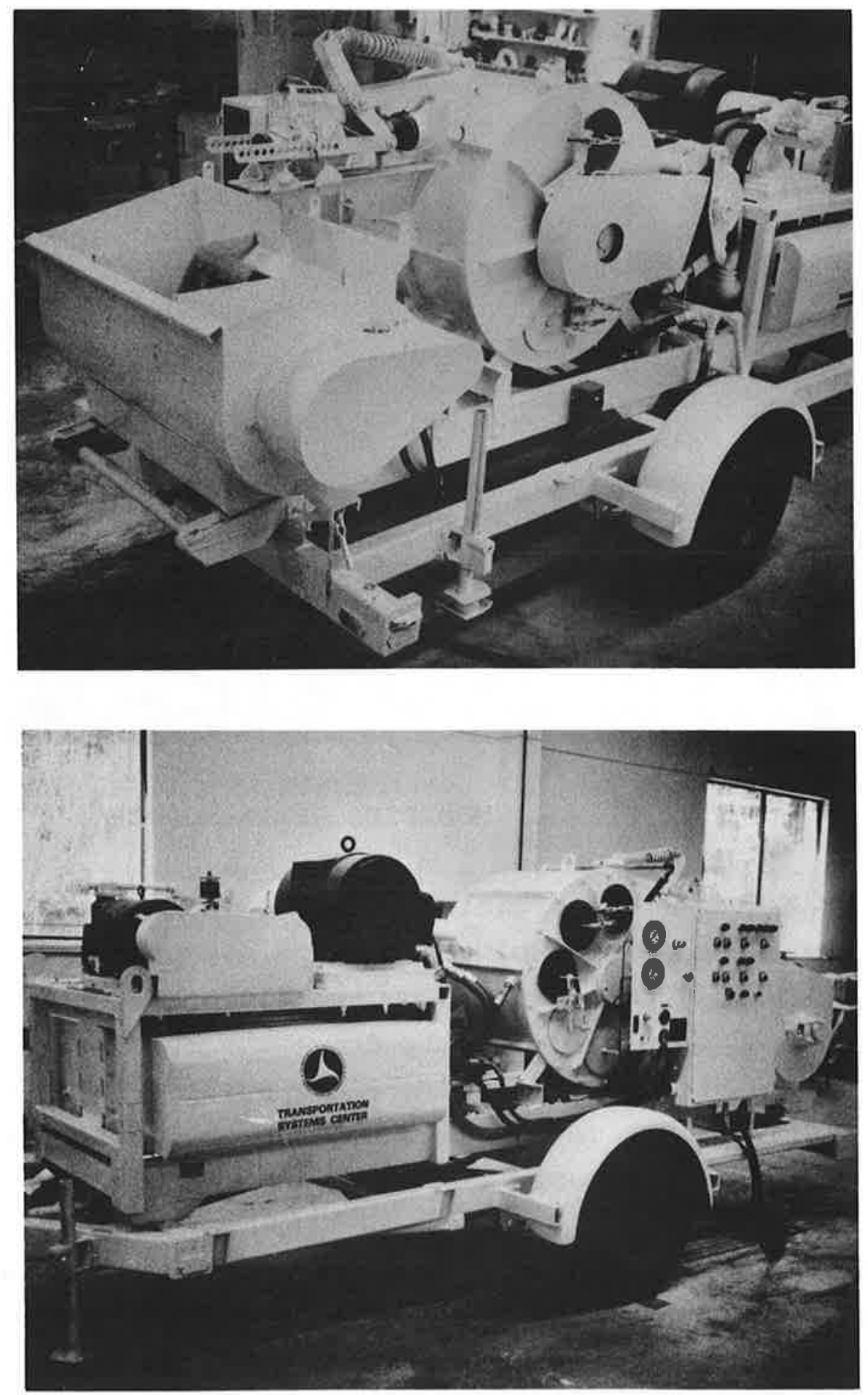

FIGURE 4-4. MODIFIED CHALLENGE-COOK SQUEEZE CRETE ${ }^{\circledR}$ CONCRETE PUMP 


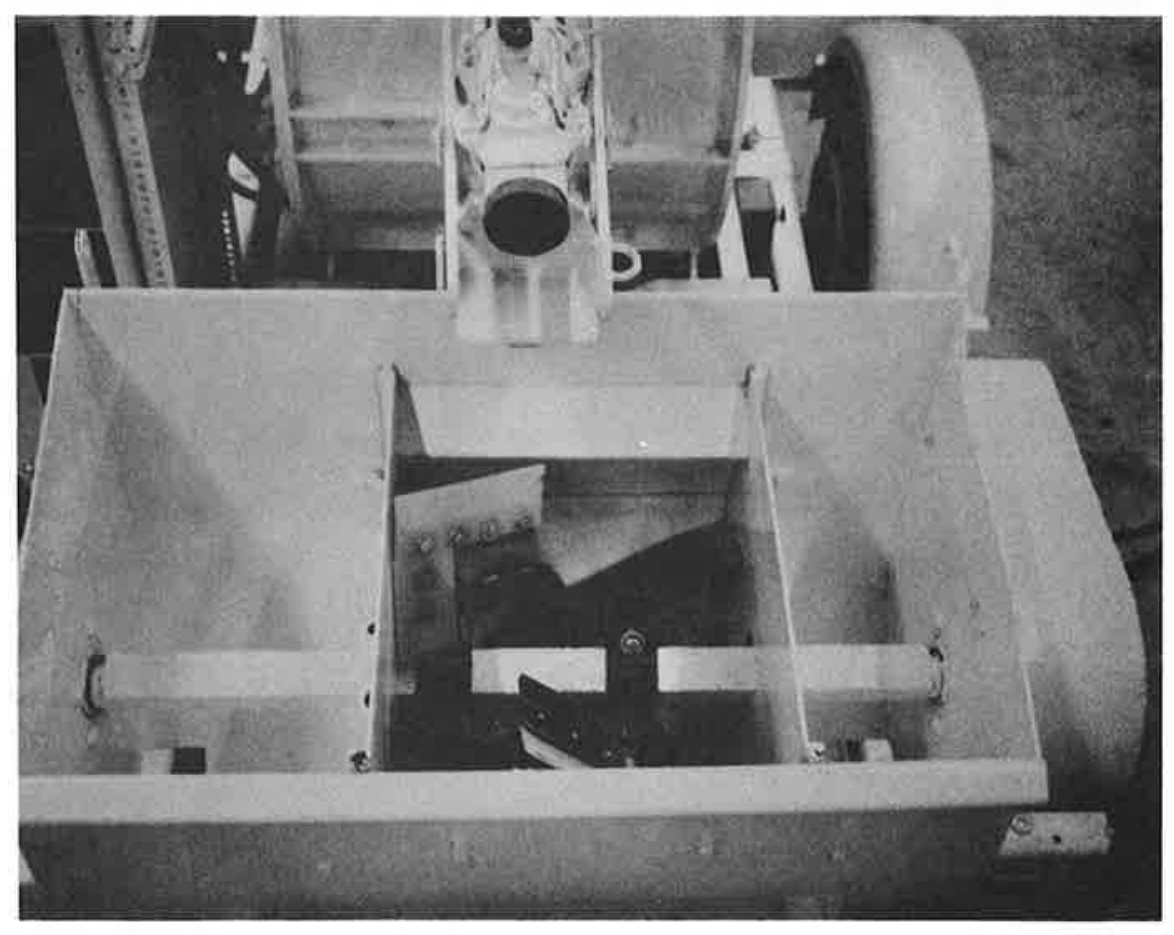

FIGURE 4-5. MODIFIED REMIX-HOPPER

Motor Drives - The orginial gasoline engine power unit, which drove the main hydraulic pump, the vacuum pump, and the other auxiliaries, was replaced by two $480 \mathrm{~V}$ three-phase electric motors. One $40 \mathrm{hp}$ motor directly drove the main hydraulic pump and another $7.5 \mathrm{hp}$ motor belt drove the auxiliaries. This reduced the noise level in the shop considerably and eliminated exhaust emissions problems.

Hydraulics - Modifications made to the pump hydraulic system are shown in Figure 4-6. The system was modified to permit continuously variable control of placing rate down to placing rates below $1 \mathrm{yd}^{3} / \mathrm{hr}$. The remix-hopper paddle speed could also be varied to prevent over-packing of the pump suction chamber. Solenoid operated direction control valves were added to permit all control actions to be performed from one local control panel. 


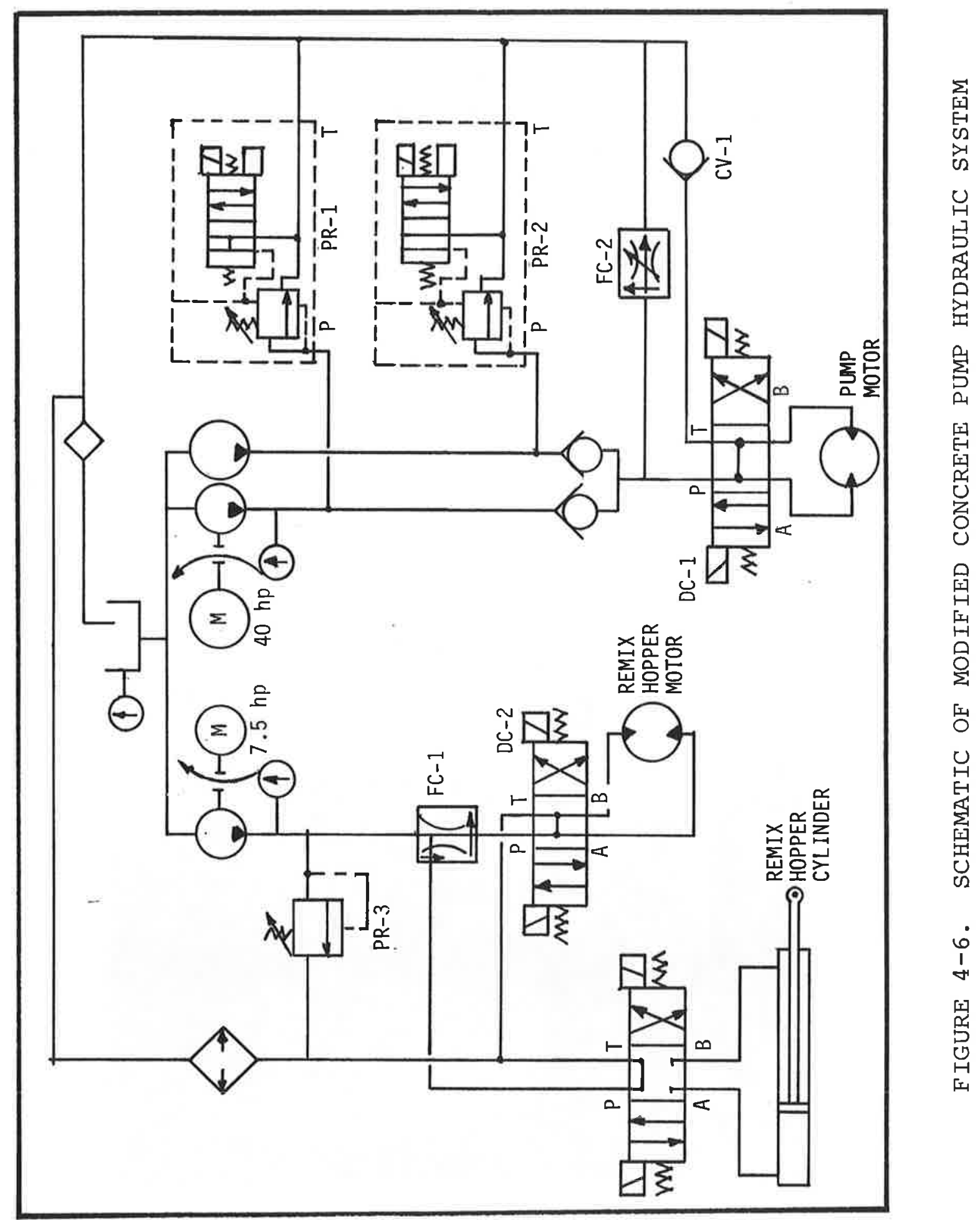


Control Panel - A new control panel was installed at the right rear quarter of the pump immediately adjacent to the remix-hopper. This permitted the pump operator to monitor pump performance and concrete quality and consistency. Placing rate was controlled from the pump control panel using valves PR-I, $\mathrm{PR}-2$, and $\mathrm{FC}-2$.

The new control panel is pictured in Figure 4-7. All electrical equipment was installed in watertight NEMA-4 box and sealtight conduit to allow the unit to be used in the field at a later date.

4.3.1.4 Admixture Metering Equipment - The admixture metering equipment consisted of three independent pumping subsystems. One subsystem pumped only water while the other two pumped

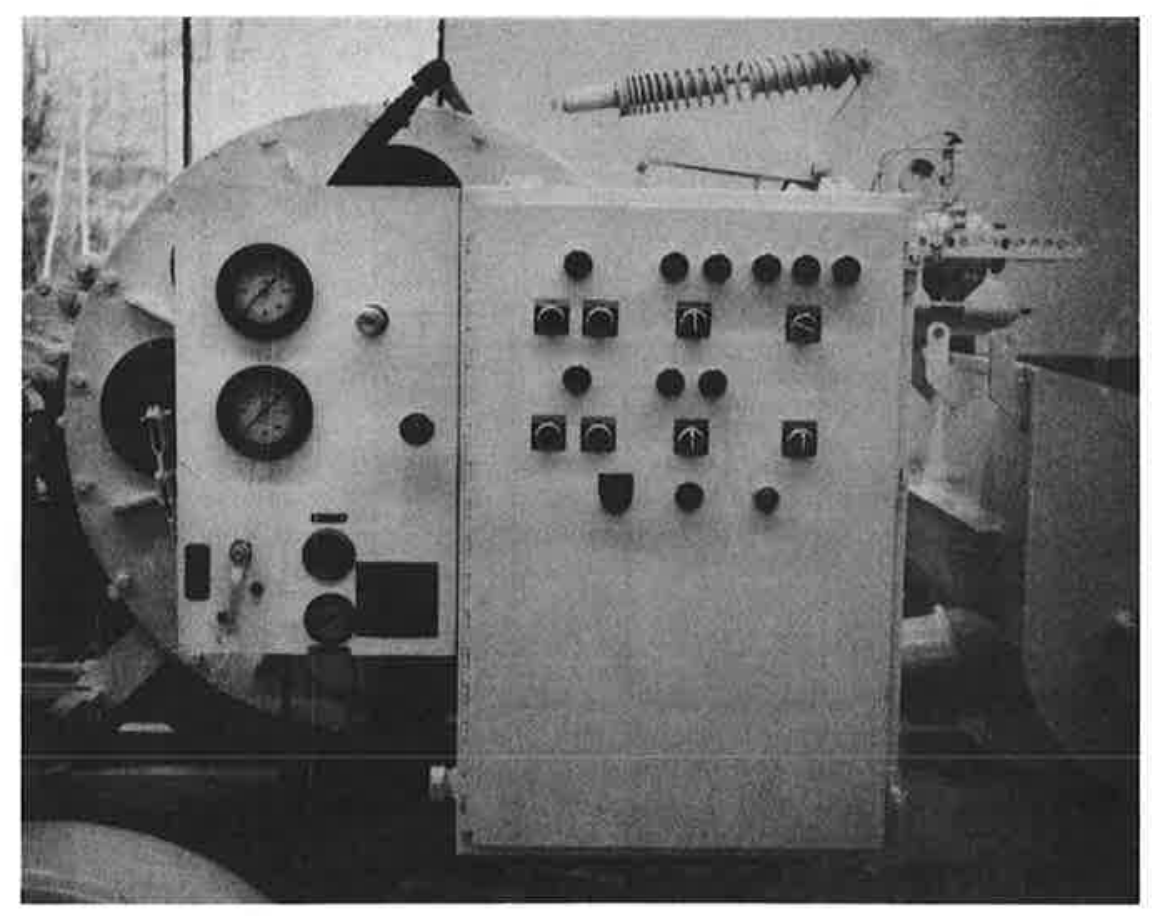

FIGURE 4-7. CONCRETE PUMP CONTROL PANEL 
solutions of the two admixtures, Lomar-D and citric acid, each mixed with water. Each subsystem consisted of a storage tank or tanks, metering pump, flowmeter and associated plumbing. The storage tanks for the admixtures were made of fiberglass and had a capacity of $55 \mathrm{gal}$ each. The two storage tanks for the water subsystem were made of steel and also had a capacity of 55 gal. The water tanks were insulated and one was equipped with a heating element. The outlets of the two tanks were plumbed through a mixing valve that was used to control the temperature of the mix water. Figure 4-8 is a flow diagram of the admixture system.

The metering pumps used were Masterflex variable speed peristaltic pumps. Flowmeters were installed in each pump discharge. The flowmeters were manufactured by Dwyer Instruments Company. The pumps and flowmeters were sized such that each had the required range, resolution and accuracy. The admixture solutions and water were added to the mix at a wet bar on the auger-mixer.

4.3.1.5 Placing and Purging Equipment - This subsection describes the placing and purging equipment which was used to conduct the series I, II, and III tunnel tests. As mentioned earlier, considerable development work was required to evolve the placing purging equipment into its final form. The developmental testing of this equipment is described in detail in subsection 5.1 .3 .

The placing and purging equipment consisted of the placing lines, slide valve, go-devils, and go-devil retrieval winch, and water supply. The placing and purging equipment is shown schematically in Figure 4-9. The slide valve and go-devil winch are pictured in Figure 4-10. The slide valve and go-devil winch were 


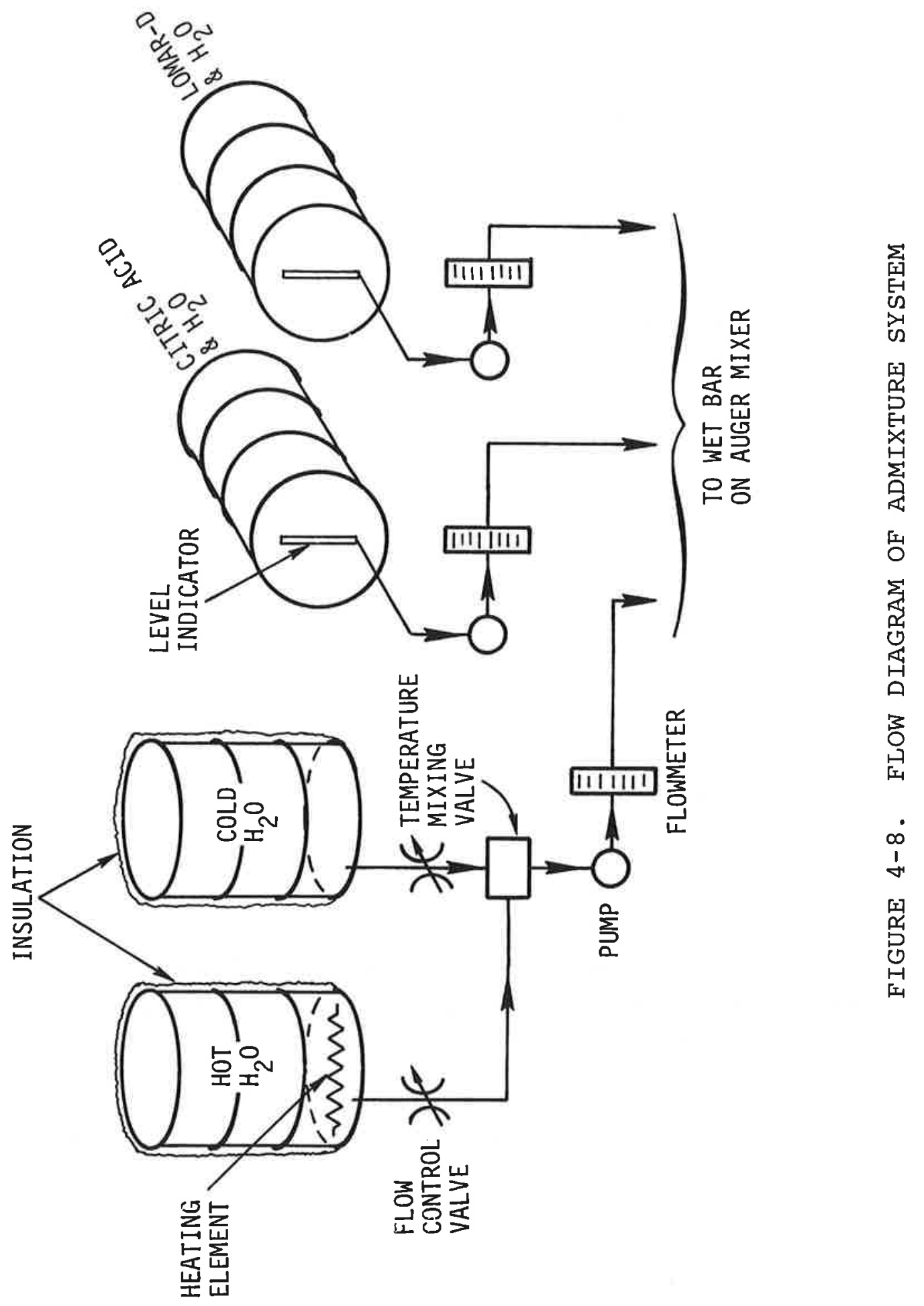



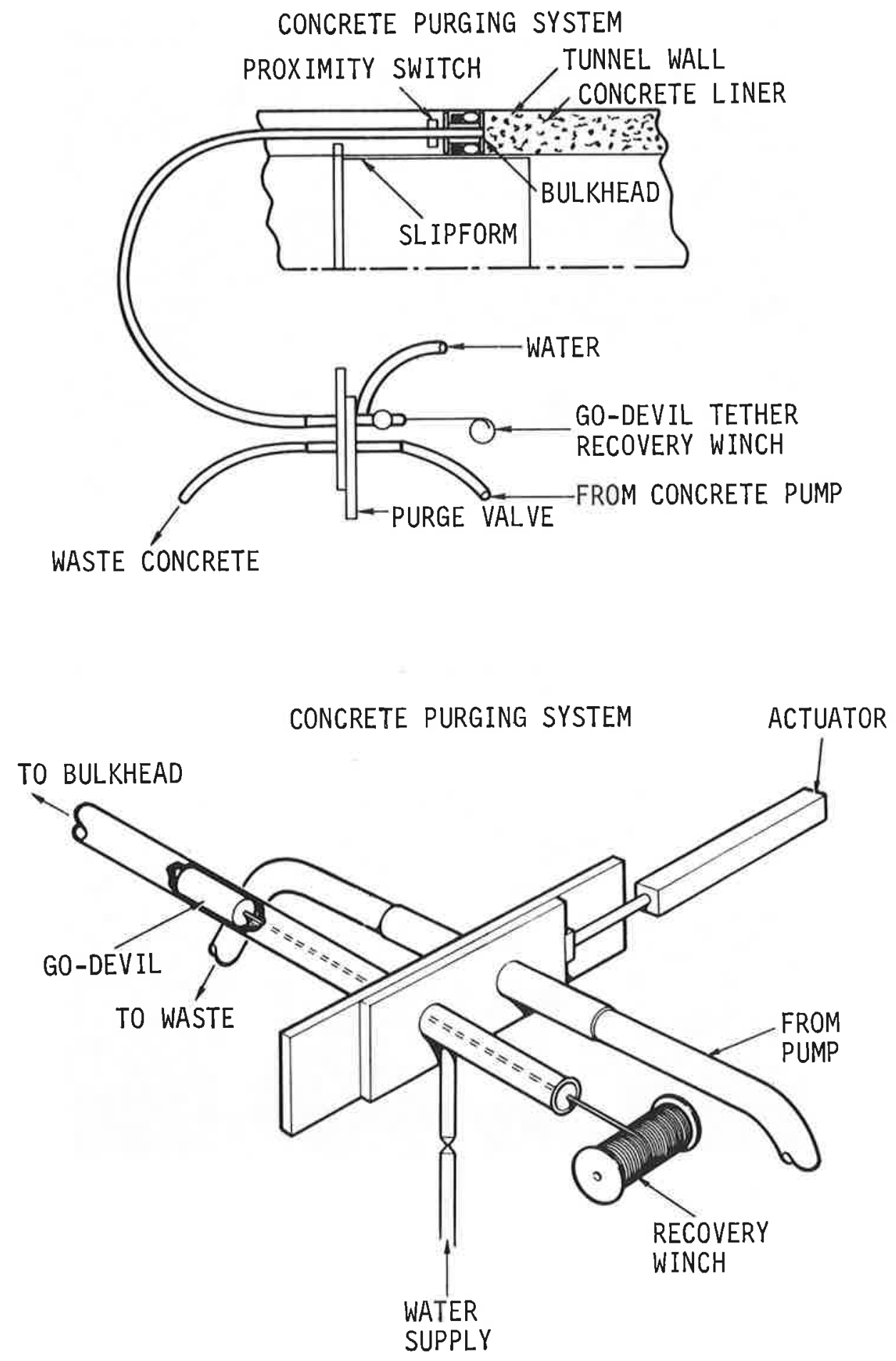

FIGURE 4-9. SCHEMATIC OF PLACING AND PURGING EQUIPMENT 

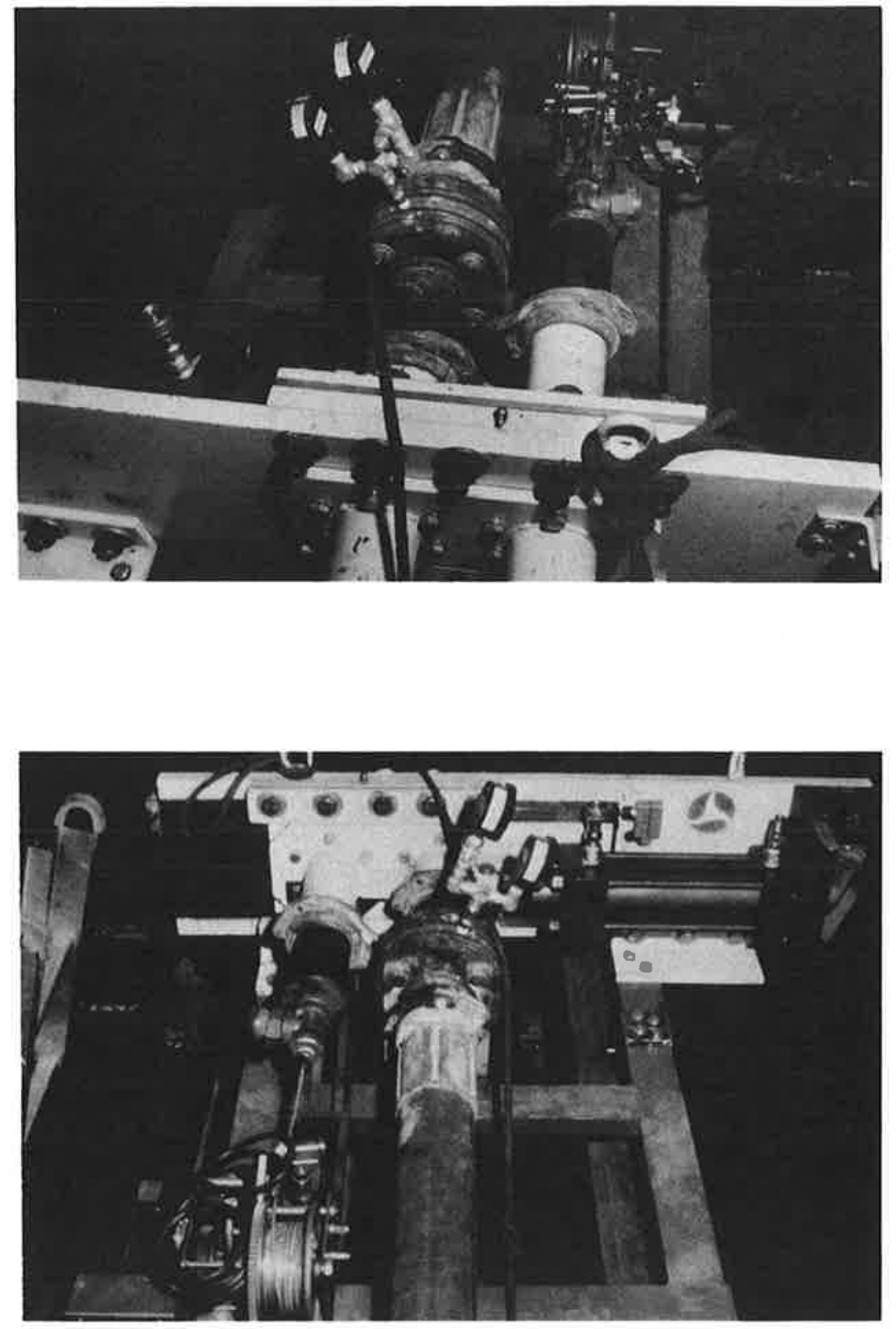

FIGURE 4-10. SLIDE VALVE AND GO-DEVIL WINCH 
both mounted on a carriage which rode on runners mounted on top of the reaction structure. This permitted the valve and winch to move along with the bulkhead as the lining was cast.

Operation - During normal operation, the concrete was pumped from the concrete pump, through approximately $60 \mathrm{ft}$ of flexible line (the exact length varied depending on which of the two possible positions the reaction structure was in), up to the slide valve. The slide valve was aligned so that the concrete flowed through the $20 \mathrm{ft}$ of steel slickline up to the bulkhead.

Red valve ${ }^{\circledR}$ pressure sensors were installed in the line at the pump discharge and at the slide valve. The sensor at the pump discharge was equipped with a local readout (bourdon tube pressure gauge). The one at the bulkhead was equipped with both a local readout and a 4 to $20 \mathrm{~mA}$ pressure transmitter which was connected to the computer (refer to subsection 4.3.4).

When a shutdown occurred the concrete pump was reversed to relieve the pressure in the lines. The pump was then shut off. The slide valve was repositioned so that the go-devil and winch assembly was aligned with the $20-\mathrm{ft}$ slickline leading to the bulkhead. At the same time the line leading from the pump aligned with the wasteline.

The line from the pump was then purged using a standard go-devil driven through by water pressure with the pump providing the motive force. The go-devil winch was then placed in the free-wheel mode and the supply valve was opened. At the same time, the bulkhead back-pressure setting was lowered. The go-devil was then driven forward by the water pressure, pushing the concrete ahead of it into the form. 
When the proximity switch indicated the go-devil had reached the bulkhead, the water supply was shut off, and the go-devil was held in place by the water trapped behind it in the slickline. After approximately $10 \mathrm{~min}$ the drain valve was opened and the go-devil winch was rewound.

An air valve was also mounted on the bulkhead to vent the space behind the go-devil and prevent concrete from being drawn up into the line as the go-devil was retrieved.

\subsubsection{Mechanical Hardware Subsystem}

The mechanical hardware subsystem consisted of the bulkhead, slipform and associated equipment. The slipform and bulkhead are pictured in Figure 4-1l.

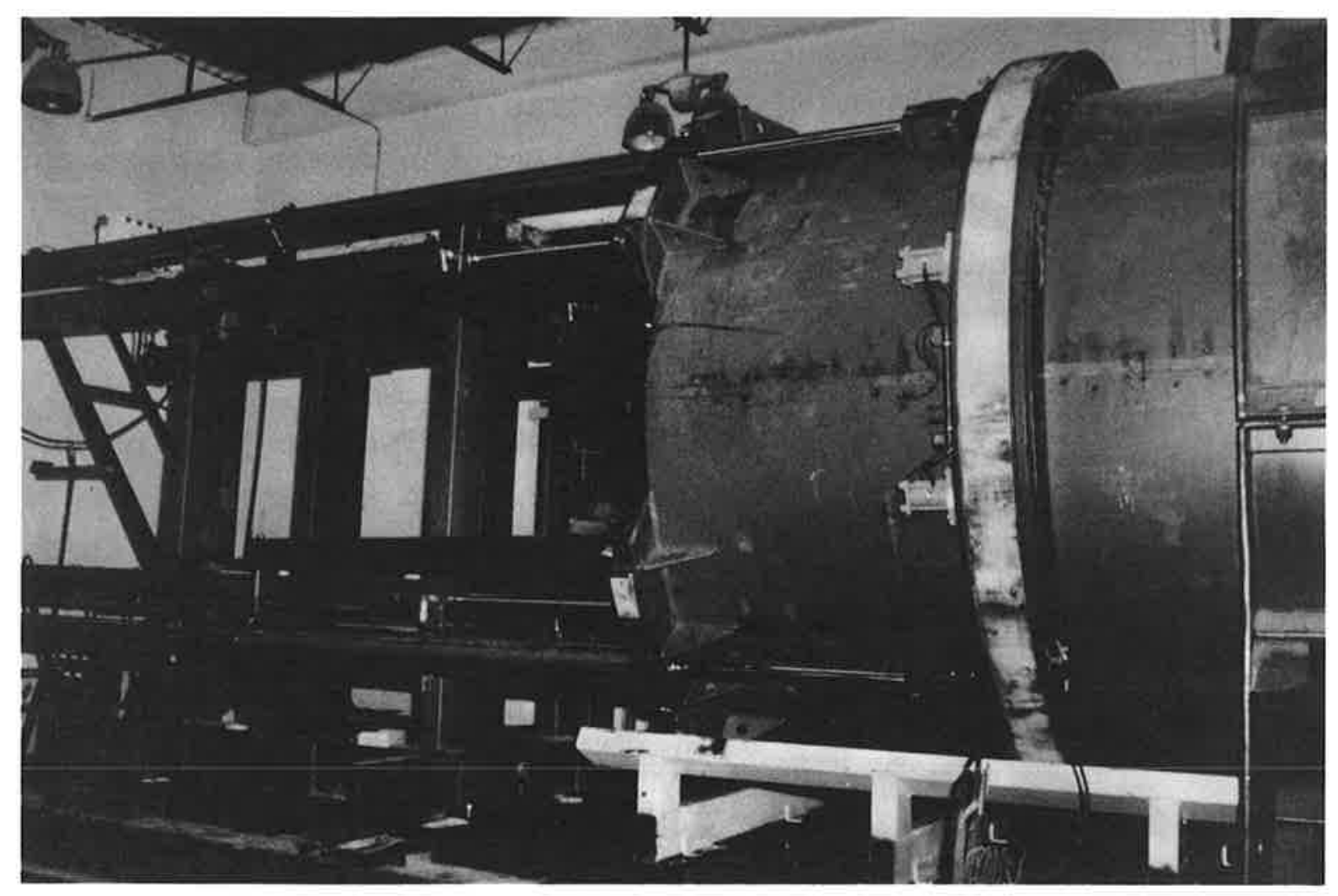

FIGURE 4-1I. SLIPFORM AND BULKHEAD 
4.3.2.1 Bulkhead - The bulkhead consisted of a cylindrical ring which was located between the outside of the slipform and the inside of the tunnel casing. The bulkhead was equipped with seals, vibrators and concrete inlet ports.

The bulkhead was fabricated from steel plate; it had an outer diameter of $121.5 \mathrm{in.}$ and an inner diameter of 108.25 in. When the bulkhead was centered, these dimensions resulted in radial clearances of 0.25 in. between the outside of the bulkhead and the inside of the tunnel casing and 0.125 in. between the inside of the bulkhead and the outside of the slipform. The bulkhead was 10.5 in. wide (longitudinally).

The inner and outer surfaces of the bulkhead were faced with pads made of an ultra high molecular weight polymer (UHMWP) to reduce the friction between the bulkhead and the slipform and tunnel casing. The pads were located at the leading edge of the bulkhead and were $6.5 \mathrm{in.}$ long. The trailing edge of the bulkhead had channels on the inside and outside to locate the seals. The channels were 2 in. wide.

The seals were made of rubber and consisted of an inflatable inner tube and a solid outer rubbing block. The seals were used to prevent the concrete paste from leaking out between the bulkhead and the tunnel casing and slipform. The tubes were glued to the bulkhead and to the rubbing block.

The bulkhead had two concrete inlet ports, one at the top and one at the bottom. They were fabricated by cutting holes in the end of the bulkhead and welding in a piece of slickline. A plate was provided to block off the bottom port. 
The bulkhead was equipped with eight pneumatic vibrators evenly spaced around its circumference. The vibrators' force was transmitted through a rod which was welded to the face of the bulkhead which was in direct contact with the fresh concrete. Each vibrator was plumbed to a separate solenoid so that the vibration pattern could be varied. The solenoids were controlled electrically by a timing circuit.

4.3.2.2 Slipform - The slipform consisted of a cylinder with an outside diameter of 108 in. It was fabricated from four shell sections hinged in pairs. Each section was made of 1 in. thick hot rolled steel sheet. When assembled to form a complete cylinder the faying surfaces between the sections were bolted together using tongue plates. Internal circumferential rings were provided at the hinge points and trailing edge. The leading edge was designed in four separate assemblies, welded and gusseted to the slipform. Each flange segement supported two pillow blocks, provided a mounting pad for a bulkhead cylinder and lugs for the rod-end of a slipform jack, and supported instrumentation for measuring cylinder extension. Auxiliary supports for the bulkhead cylinders were also mounted on the flanges. These auxiliary supports minimized flexure of the cantilevered bulkhead jacks.

The slipform was modified after testing as part of the system modifications task. Eight longitudinal cuts were made in the trailing end of the slipform. The purpose of the cuts was to reduce the stiffness of the trailing section of the slipform and thereby reduce the drag forces which resulted from a misalignment. Each cut was approximately $1 / 8$ in. wide and $3 \mathrm{ft}$ long. The tongue plates were removed from the trailing section of the slipform to further reduce its stiffness. 
Adjustable cross bracing was installed on the leading edge of end of the slipform to maintain the shape of the form under load in an effort to reduce form drag.

Slipform alignment within the tunnel was maintained by eight pillow blocks attached to the front slipform flange. These were positioned to maintain constant radial clearance between the slipform and the tunnel wall at the slipform leading edge. The slipform was aligned at the trailing end by the short overlap with set concrete. The pillow blocks were originally manually adjusted by jacking screws. Hydraulic actuators were added to the pillow blocks as part of the system modifications task. A hydraulic power supply was designed and fabricated to control the cylinders to permit steering of the slipform. This modification was made to improve control of the form.

\subsubsection{Hydraulic Power Unit (HPU) Subsystem}

The HPU subsystem consisted of four bulkhead cylinders, four slipform cylinders and an HPU.

4.3.3.1 Bulkhead Cylinders - The four bulkhead cylinders were identical. Each cylinder had a 4 in. bore, with a 3 in. rod and a stroke of $156 \mathrm{in.}$ The bodies of the double-acting cylinders were flange-mounted to the leading edge of the slipform and the rod ends were pin-mounted to the bulkhead. The cylinders were plumber to the HPU.

\subsubsection{Slipform Cylinders - The four slipform cylinders were} identical. Each cylinder had a 6 in. bore with a 3-1/2 in. rod and a stroke of $144 \mathrm{in.}$. The bodies of the double-acting cylinders were flange-mounted to the reaction structure and the rod ends were pin-mounted to the leading edge of the slipform. The cylinders were plumbed to the HPU. 
4.3.3.3 Hydraulic Power Unit - The bulkhead and slipform positions were controlled by an electrohydraulic control system consisting of two separate subsystems: the HPU and the central processing unit (CPU). The CPU, discussed in subsection 4.3.4 generated electrical command signals which, once received by the HPU, determined the rate at which the HPU pumped hydraulic fluid into the bulkhead and slipform cylinders. The main functions of the electrohydraulic system were as follows:

1. Maintain alignment between bulkhead, slipform and tunnel casing axes - to prevent jamming and to preserve uniform casing thickness - for any concrete pressure in the range of 0 to $30 \mathrm{psi}$ and any placing rate in the 2 to $12 \mathrm{ft} / \mathrm{hr}$ range

2. Move slipform at any desired speed from 0 to $24 \mathrm{ft} / \mathrm{hr}$ regardless of bulkhead position and speed

3. Maintain concrete pressure at specified level in the range of 5 to $30 \mathrm{psi}$

4. Provide backup protection to relieve presure in case of jamming and malfunction

5. Move both bulkhead and slipform, during maintenance mode, at speeds close to $60 \mathrm{ft} / \mathrm{hr}$.

The third function described above was accomplished manually by an operator and was not controlled by the CPU.

A schematic of the HPU hydraulics is shown in Figure 4-12. Two pumps, $\mathrm{P}-1$ and $\mathrm{P}-2$ provided the pressurized fluid required to move the bulkhead and the slipform respectively. Pump P-3 was an auxiliary pump, with a larger capacity than the other two, used primarily in the maintenance mode (function 5 above). P-3 was also used to provide back pressure at the rod end of bulkhead cylinders during liner placement tests. This back 


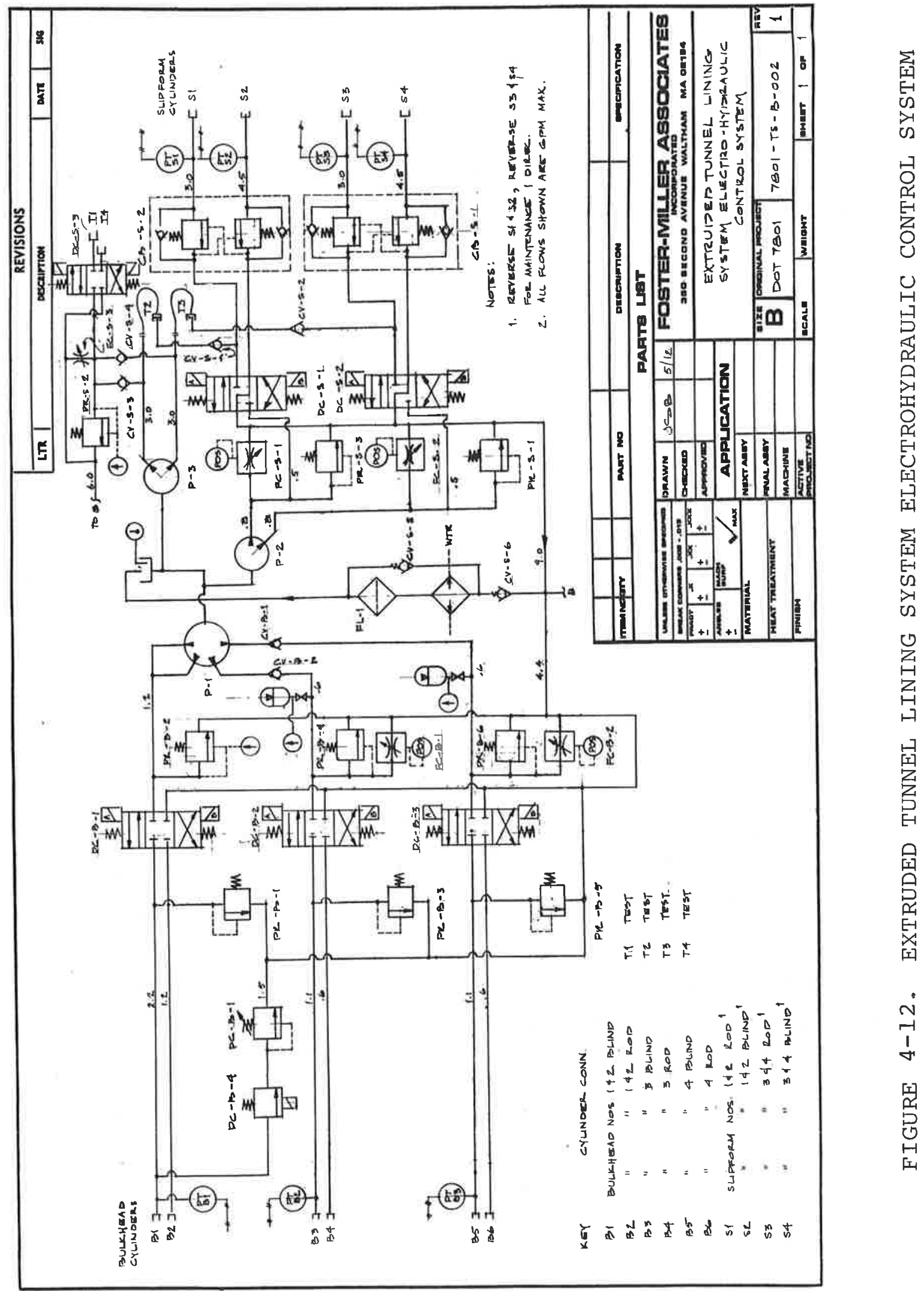


pressure prevented the bulkhead from jamming and eliminated the high peaks in the concrete pressure caused by excessive drag on the bulkhead.

The pressure relief valve $\mathrm{PC}-\mathrm{B}-1$, was adjusted manually and controlled the blind end pressure of the bulkhead cylinders which in turn determined the concrete pressure during tests. $\mathrm{DC}-\mathrm{B}-1,2$ and 3 were directional control valves which determined the direction of motion of the bulkhead in maintenance mode. During tests, these valves were always energized to port pressure to the blind ends, resisting the concrete pressure. PR-B-1, 2, $3,4,5$ and 6 were pressure reliefs whose function was to protect the test rig in case of jamming, excessive drags or component malfunction.

FC-B-1 and 2 were servo motor controlled pressure compensated valves bypassing a measured amount of oil to the sump. These valves were electrically coupled to the CPU which regulated their throughput in order to maintain alignment between the bottom bulkhead cylinder positions and one of the top cylinder positions. Since the bottom cylinders were controlled independently, at each instant in time three points on the rigid bulkhead were defined by the electrohydraulic system, enabling it to maintain the bulkhead in alignment with the tunnel axis.

During the initial phase of testing, the function described above was performed by a different set of servo valves (not pressure compensated). These leaked at high pressure and failed to respond fast enough to the alignment requirements of the system, hence they were replaced.

slipform alignment was accomplished in a manner somewhat similar to that used for the bulkhead, except that the servo valves used (FC-S-I and 2) were not pressure compensated. Also 
since the trailing end of the slipform was supported by the liner, and the misaligning forces were vertical in direction, the CPU controlled only the vertical alignment of the leading edge of the slipform. Thus FC-S-1 controlled the speed of the top slipform cylinders and FC-S-2 that of the bottom cylinders. DC-S-1 and 2 were directional control valves which determined the slipform's direction of travel. Two counter balance valves, CB-S-1 and 2, prevented the slipform from running out of control when the external forces on the slipform suddenly changed direction. The slipform force resultant could change direction because the balance between slipform drag and bulkhead pressure was dependent on form length. $\mathrm{PR}-\mathrm{S}-1$ and 3 were relief valves protecting the slipform system. DC-S-3 was used to control the slide valve, described in subsection 4.3.1.5. Cylinder pressures were transmitted by pressure transducers PTB-1, 2 and 3 and PTS-1, 2,3 and 4 to the CPU which displayed them on a CRT. Table 4-1 lists the specification of major HPU components discussed above.

\subsubsection{Instrument and Control Subsystem}

Instruments and control for the simulation rig included transducers, a controller, and necessary interfacing hardware. The controller and its attendant peripherals and interfacing electronics represented the CPU of the control and data acquisition system. The CPU monitored important test parameters, by means of the various transducers. Data was processed for immediate control actions and stored on tape for post-test analysis. Based on the data, control signals to the HPU maintained desired test conditions. Alarms signaled the CPU operator of any critical deviations from normal operation. The instrument and control subsystem is shown in Figure 4-13. 


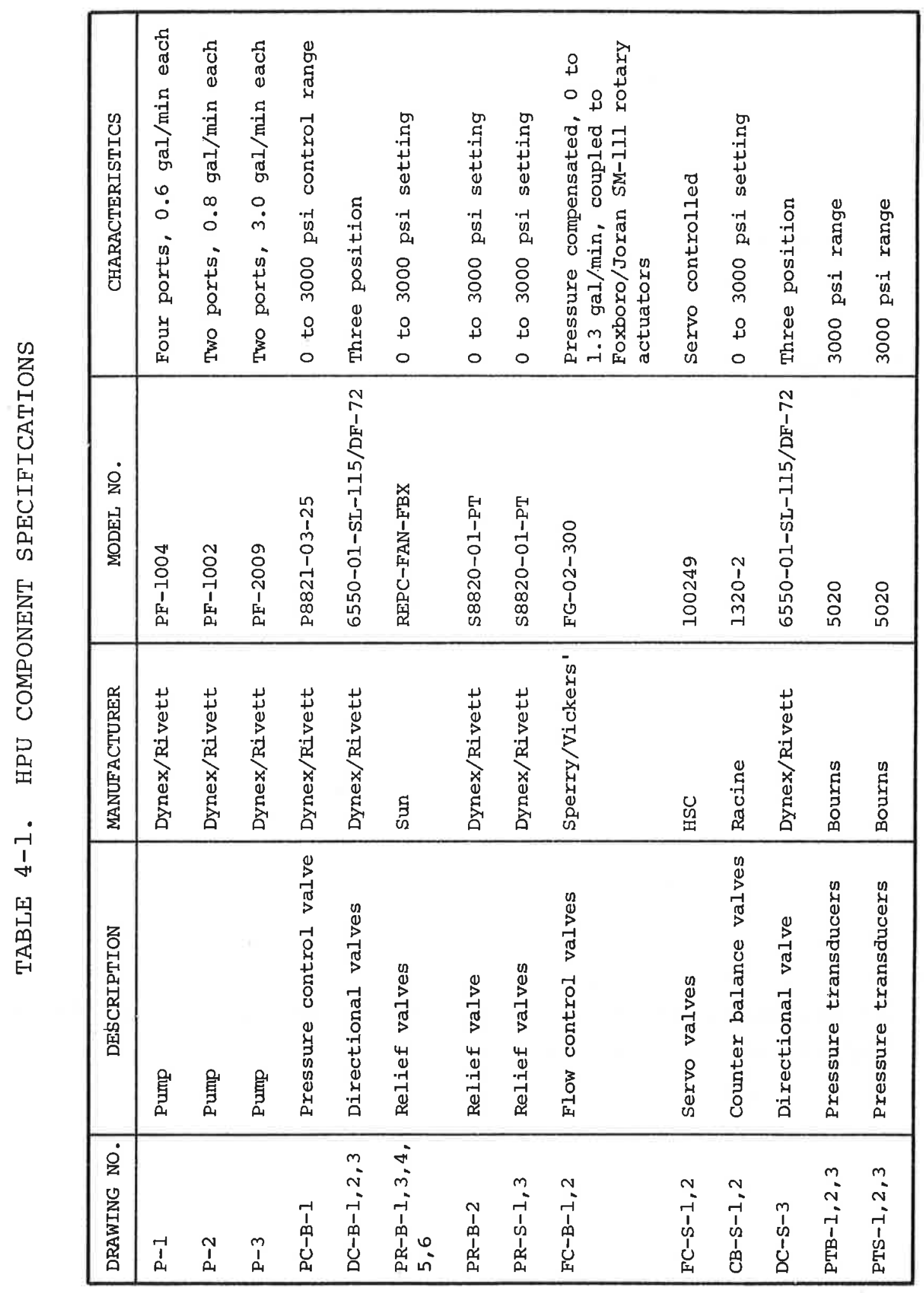




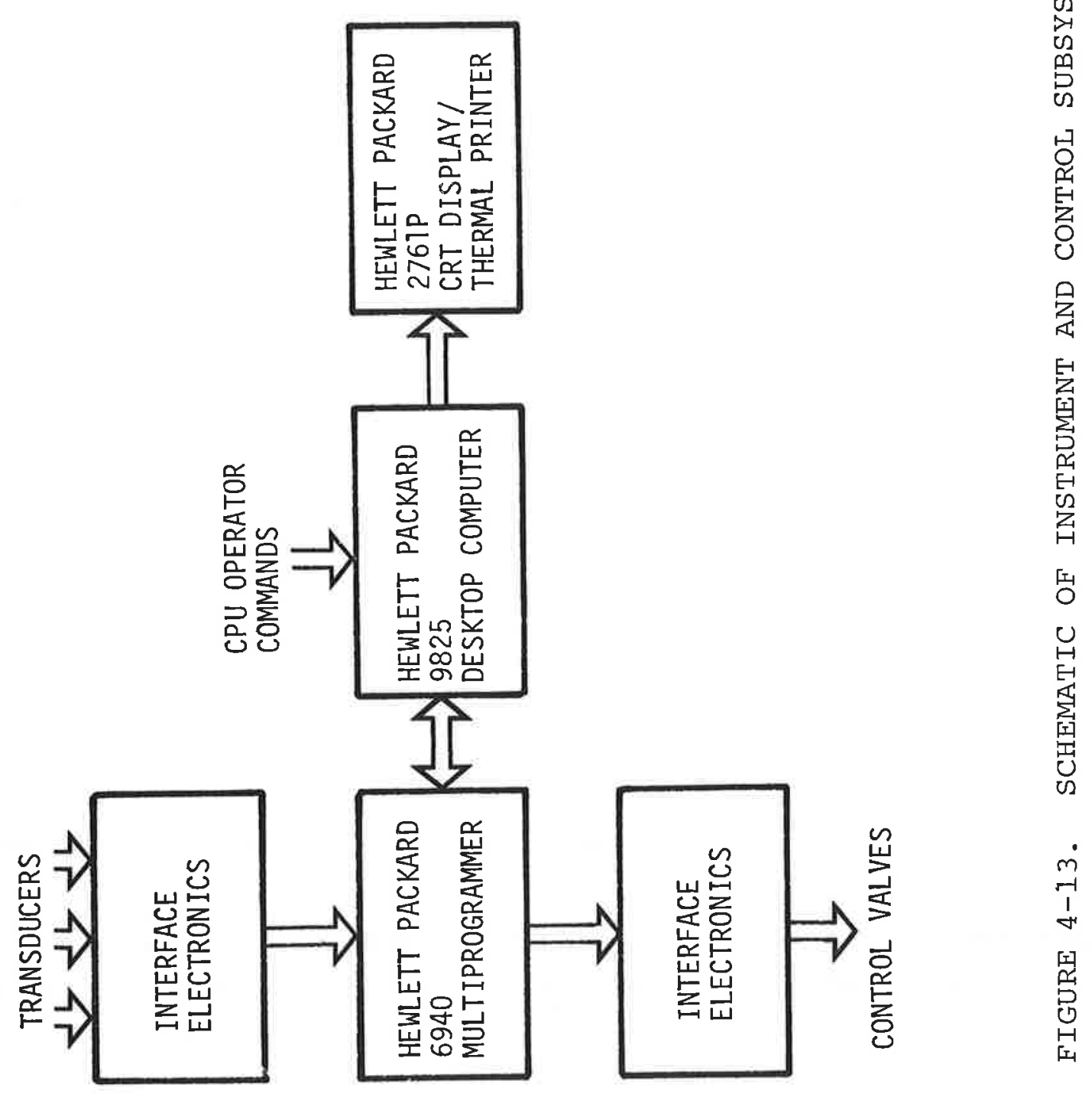


4.3.4.1 System Controller - The controller for the simulation was a Hewlett-Packard 9825 desktop computer. Programs for the HP 9825 were written in HPL, a language designed for HewlettPackard equipment. The main control program calculated and displayed test parameters, determined correct control signals, and sent them to the HPU. Operational changes were entered through the computer's keyboard. The computer could be queried for specialized information, such as concrete age or temperature at a particular location. A cassette tape drive in the computer stored the test program and all test data.

In addition to the test program, the HP 9825 was programmed to perform service routines. These included developmental programs such as editors and program listers, as well as analytical programs to tabulate and plot test results.

4.3.4.2 Periphals and Interface Hardware - The HP 9825 communicated with the simulation rig and the CPU operator through peripheral equipment. A Hewlett-Packard 6940 multiprogrammer managed input/output between the HP 9825 and the test hardware. A Hewlett-Packard $2761 \mathrm{P}$ CRT/thermal printer provided the system display and hardcopy needs. A Hewlett-Packard 9872 graphics plotter was used in data analysis.

The multiprogrammer handled all communication between the HP 9825 and the test system. It communicated with the HP 9825 via a 16 bit parallel interface. Scanner cords in the multiprogrammer monitored the various transducers. The grabs signals were converted to digital format, and transferred to the HP 9825 on request. Output commands were converted from digital signals to analog format, and sent to the appropriate control valves in the HPU. 
To interface the multiprogrammer with the transducers and control valves, signal conditioning electronics were required. The control valves were all current loop operated. Voltage to current converters using operational amplifiers performed the necessary conditioning. The interface electronics for the different transducers included excitation, resistance bridges, and current sensing resistors.

Operator display was provided by the HP 2761P. The CRT screen supplied information on slipform and bulkhead position, speed, and alignment. Current slipform commands were displayed. supplemental information included hydraulic cylinder pressures, and calculated drag forces.

In addition to real-time display, the HP 2761P was used to print hardcopy. Program listings and data tabulation were produced on the thermal printer.

Plots of test data were produced using the HP 9872 graphics plotter. The plotter used fiber tip pens to produce four color plots to assist test evaluation.

4.3.4.3 Transducers - Displacement, pressure, and temperature transducers monitored the test system and concrete during testing.

Celesco displacement transducers measured slipform and bulkhead position. Two transducers measured slipform location and alignment, relative to the reaction structure. Three transducers measured bulkhead location and alignment, relative to the slipform.

Bourns pressure transducers monitored hydraulic and concrete pressures. Seven transducers measured hydraulic cylinder pressure. One transducer measured concrete pressure at the slide valve. A Data Instruments pressure transducer measured concrete pressure at the bottom of the bulkhead. Omega thermistors 
monitored concrete temperature. Eleven thermistors were mounted in the crown of the slipform in the last $4 \mathrm{ft}$ of the trailing end. Temperature measurements were used to monitor concrete set, in order to avoid slipform lockup caused by thermal expansion. 


\section{TEST METHOD AND TEST RESULTS}

This section describes the test methods used to conduct the laboratory tests; Series I, II, and III tests; and seal tests. The results of the tests are discussed in depth. Results are presented in the order in which the tests were performed. The sequence of testing is shown in Figure 5-1. The approach taken in each test depends on the results of the previous test. Test conclusions are summarized at the end of each subsection.

\subsection{LABORATORY TESTING}

This subsection will describe the various test methods and results of work done in the concrete laboratory during Phase II. The laboratory testing consisted of:

1. Verifying the ETLS concrete mix design and assessing various fresh and hardened material properties

2. Developing prebatched aggregates, including batching, handling, and augering

3. Developing a slide valve and accompanying concrete line purging equipment.

\subsubsection{Concrete Mix Design and Material Properties}

Tests were conducted on the ETLS concrete first to verify and finalize the mix design and, second, to measure a number of fresh and hardened properties of the final mix. The fresh properties measured were slump loss with time, the buoyancy or 


\section{LABORATORY TESTING}

- MEAsuREMENT OF CONCRETE MATERIAL PROPERTIES

- PREBATCH FORMULATION AND TESTING

- Slide valve and purge system testing

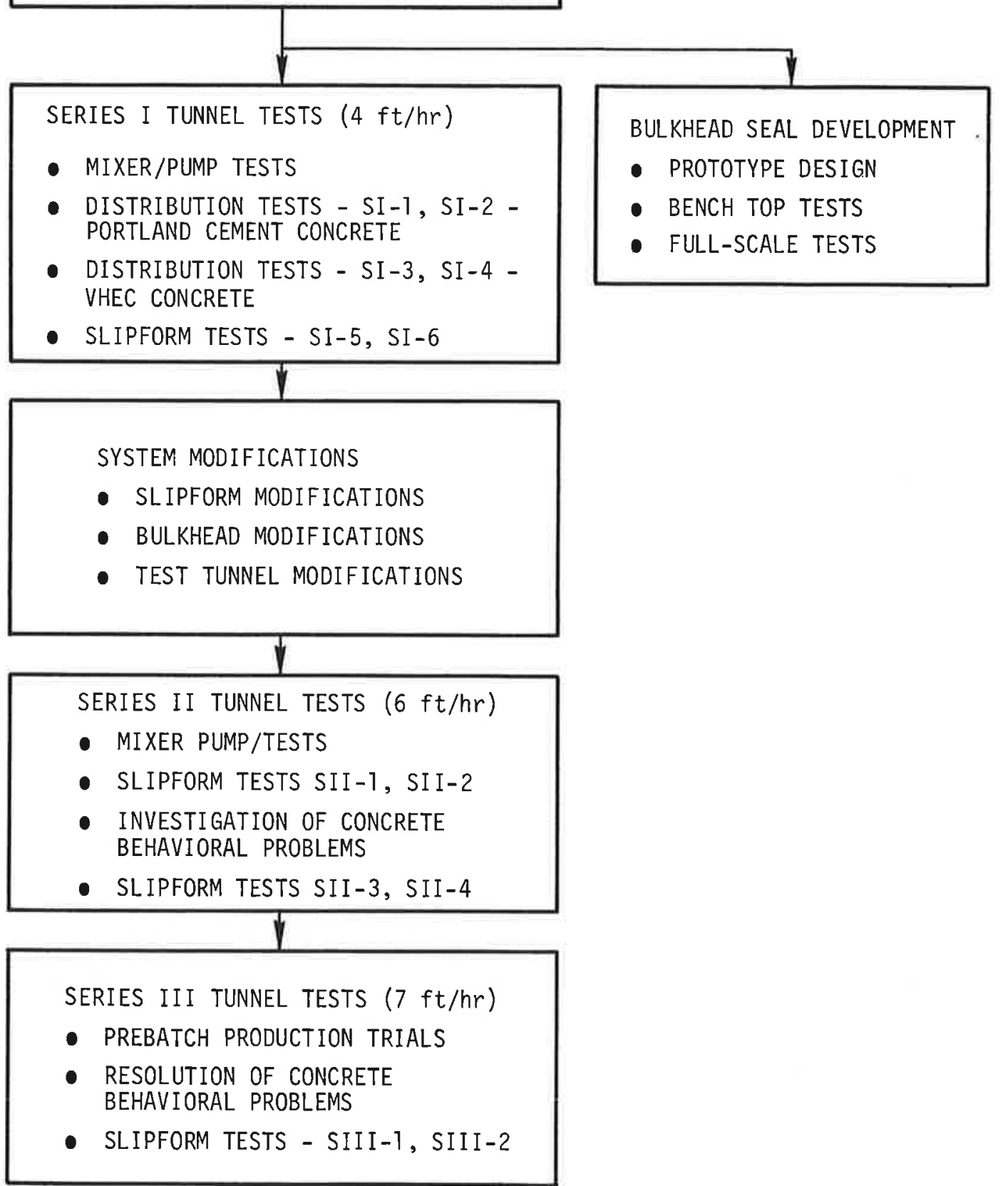

FIGURE 5-1. TEST PROGRAM SEQUENCE 
uplifting force of the fresh concrete, and the drag force developed between fresh concrete and a moving form surface. The hardened properties measured were strength development, shrinkage potential, and sulfate resistance.

5.1.1.1 Mix Design Verification - During Phase I of the ETLS program, a concrete mix design using very high early cement (VHEC) was developed and tested. The mix design met the specifications set out in Phase I and performed satisfactorily in the distribution and slipforming tests. Between the end of testing in Phase I (March 1979) and the beginning of Phase II (September 1979) a new run or burn of VHEC was manufactured to replenish dwindling stockpiles of the original VHEC. The new burn of VHEC was made with the same general formulation as the original run; however, the new VHEC had slightly different characteristics. In addition, a different source of fly ash was used for phase II. These changes required that mix design verification tests be performed with the new materials.

a. Materials - Two different aggregate types were used during Phase II both in the laboratory and for the tunnel lining tests. The first type, designated Type $A$, was the same aggregate used in Phase $I$. Type A included a coarse aggregate that was combined from two separate gradations of $3 / 4 \mathrm{in}$. and $3 / 8$ in. stone. The sand was a well-graded bank run deposit. The second aggregate source, Type B, came into use as a result of the prebatch tests (subsection 5.1.2). It consisted of the same, larger gradation of $3 / 4$ in. stone from Type A combined with a new smaller $3 / 8$ in. fraction and different sand. Both latter aggregates were of the crushed type.

It would have been preferable to use Type A aggregates for the entire test program; however, it was not possible to receive premixed or prebatched aggregates from source A on a regular basis. 
Therefore, laboratory testing was conducted on concretes containing both aggregate types. It was expected that minor changes to water content, aggregate quantity, and plasticizer content, would be required when changing aggregate type.

The VHEC used was manufactured in July 1979. It had a specific gravity of 3.0 and according to the manufacturer, U.S. Gypsum, it had a slightly different composition than the previous material.

Two sources of fly ash were used during the test program. One source, used in all laboratory tests, was received from Detroit Edison Company in bagged form. The second source of fly ash, available in bulk, was used in concrete mixes that were made from prebatch (subsection 5.1.2). Both sources of fly ash met the requirements of ASTM C618 Class F.

The same two admixtures used in Phase I were used for the Phase II test program. Lomar D superplasticizer was used to improve workability and citric acid provided retardation to prolong handling time.

b. Test methods - Concrete formulations were batched and mixed in a $3.5 \mathrm{ft}^{3}$ tumble mixer. Batch size was generally $1.75 \mathrm{ft}^{3}$. A standard charging procedure was used for all batches. Formulations were mixed for $3 \mathrm{~min}$ after addition of water and discharged into a sampling pan.

In order to evaluate the performance of concrete made with the new materials, 3 standard tests were used. These were the slump test (ASTM C143), air content test (ASTM C231), and compressive strength test (ASTM C109). All testing and sampling was started immediately after discharge. The slump test was performed immediately and repeated at $10,15,20,25$ and $30 \mathrm{~min}$ or until the concrete reached a slump of 1 in. The air content test was 
performed simultaneously. Three, 6-in. diam, 12-in. compressive strength cylinders were cast. These specimens were stored under burlap until test times of $1 \mathrm{hr}, 1-1 / 2 \mathrm{hr}$ and $2 \mathrm{hr}$. Cylinders were stripped just prior to testing. When possible, specimens were capped. Compression testing was performed using an electrically driven hydraulic testing machine.

c. Results of testing - Initially, 12 mix design verification tests were conducted. Tests were performed with Type A aggregates. The results indicated that the new VHEC required much less retardation than the previous cement; less plasticizer was required to prolong workability; and early strength development was more advanced. In addition, the air content of the $\mathrm{mix}$ (non-air entrained) was much lower and more in line with expected values. Results of these preliminary tests are shown in Table 5-1.

Since it was expected that the tunnel lining tests would be conducted using concrete made from prebatched aggregates (Type B aggregates), another series of $\mathrm{mix}$ tests were performed to finalize the mix design. Results of this second series of tests showed that the mix required only minor changes to aggregate quantity (due to specific gravity differences) and a change in total coarse aggregate gradation (more of the coarser fraction). Results of the second series are shown in Table 5-2. The final mix design is shown in Table 5-3.

5.1.1.2 Long-Term Testing - In addition to slump behavior and early strength gain, three long-term concrete properties were assessed. These tests were:

1. Long-term compressive strength development

2. Shrinkage potential

3. Sulfate resistance. 


\begin{tabular}{|c|c|c|c|c|c|c|c|c|c|c|c|c|c|}
\hline \multirow{3}{*}{ 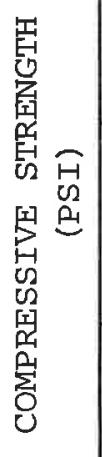 } & $\begin{array}{l}\text { 出 } \\
\text { v }\end{array}$ & 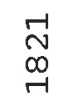 & $\begin{array}{l}\check{-} \\
\stackrel{0}{0} \\
\stackrel{-}{r}\end{array}$ & $\underset{\stackrel{\sim}{N}}{\stackrel{\sim}{\sim}}$ & $\begin{array}{l}\overrightarrow{-} \\
\infty \\
o \\
-1\end{array}$ & $\begin{array}{l}N \\
\sigma \\
\infty \\
\cdots\end{array}$ & 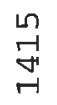 & $\underset{\sim}{\sim}$ & $\begin{array}{l}\underset{r}{H} \\
\underset{N}{N}\end{array}$ & $\begin{array}{l}\stackrel{\sim}{~} \\
\stackrel{\sim}{\sim}\end{array}$ & $\begin{array}{l}N \\
\sigma \\
10 \\
r\end{array}$ & $\begin{array}{l}\text { Ln } \\
\stackrel{\text { On }}{\sharp} \\
\text { N }\end{array}$ & $\begin{array}{l}\text { Ln } \\
\text { O } \\
\text { N }\end{array}$ \\
\hline & 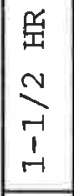 & ને & 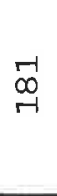 & $\stackrel{\circ}{\circ}$ & 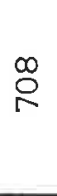 & 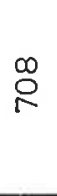 & $\stackrel{-1}{r}$ & $\begin{array}{l}\overrightarrow{-1} \\
0 \\
0 \\
\end{array}$ & $\begin{array}{l}0 \\
\text { م } \\
0 \\
\text { r }\end{array}$ & $\underset{\infty}{\stackrel{\infty}{\infty}}$ & $\stackrel{H}{\stackrel{H}{m}}$ & $\underset{r}{n}$ & $\begin{array}{l}0 \\
0 \\
0 \\
6 \\
-1\end{array}$ \\
\hline & $\begin{array}{l}\text { 缹 } \\
r-1\end{array}$ & 1 & $\stackrel{N}{N}$ & $\stackrel{ }{\sim}$ & $\stackrel{m}{\sim}$ & 유 & $\stackrel{\operatorname{Ln}}{m}$ & $\stackrel{N}{m}$ & $\stackrel{N}{m}$ & $\begin{array}{l}M \\
\stackrel{\infty}{N}\end{array}$ & $\stackrel{\vec{N}}{N}$ & $\begin{array}{l}\infty \\
\stackrel{0}{+} \\
\stackrel{+}{1}\end{array}$ & $\vec{m}$ \\
\hline \multirow{5}{*}{ 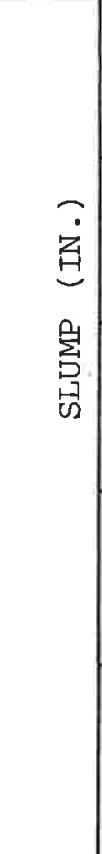 } & 임: & $\begin{array}{l}\vec{H} \\
\overrightarrow{1} \\
1 \\
\infty\end{array}$ & 1 & 1 & $N$ & 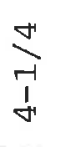 & $\nabla$ & 1 & 1 & $N$ & $r$ & 1 & 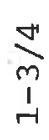 \\
\hline & $\stackrel{\sim}{\sim} \cdot \stackrel{G}{*}$ & $\underset{\substack{1 \\
1 \\
\infty}}{\stackrel{1}{1}}$ & $\underset{\substack{N \\
⿱ 亠}}{N}$ & 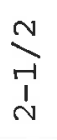 & 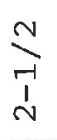 & $\frac{5}{5}$ & in & 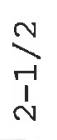 & 1 & 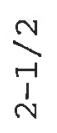 & $r$ & $N$ & $\frac{\sim}{\stackrel{N}{\Lambda}}$ \\
\hline & 옴. & $a$ & 1 & $\begin{array}{l}\frac{\nabla}{m} \\
\grave{m} \\
\grave{n}\end{array}$ & $\begin{array}{l}\stackrel{N}{~} \\
\stackrel{1}{m} \\
\stackrel{m}{n}\end{array}$ & $\begin{array}{l}\frac{1}{m} \\
! \\
b\end{array}$ & $\varphi$ & $m$ & $N$ & $\begin{array}{l}\frac{\nabla}{1} \\
\text { mे } \\
\grave{1} \\
\sim\end{array}$ & $\frac{\vec{m}}{\frac{1}{1}}$ & $\begin{array}{l}\vec{J} \\
\text { I- } \\
\stackrel{1}{N}\end{array}$ & $\begin{array}{l}\vec{J} \\
\overrightarrow{1} \\
\dot{m}\end{array}$ \\
\hline & $\mid \begin{array}{l}n \\
\rightarrow \\
\rightarrow\end{array}$ & 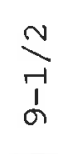 & $\begin{array}{l}\underset{J}{J} \\
\vec{I} \\
\vec{J}\end{array}$ & $\begin{array}{l}\vec{J} \\
\stackrel{-1}{1} \\
\text { m }\end{array}$ & $\nabla$ & $\begin{array}{l}\vec{\nabla} \\
\grave{m} \\
b\end{array}$ & $\begin{array}{l}\vec{J} \\
\overrightarrow{1} \\
\infty\end{array}$ & $\begin{array}{l}\stackrel{N}{ન} \\
\stackrel{1}{1} \\
\dot{m}\end{array}$ & $\begin{array}{l}\underset{N}{~} \\
m \\
1 \\
\sim\end{array}$ & $\begin{array}{l}N \\
\text { ને } \\
1 \\
m\end{array}$ & $\sigma$ & $\begin{array}{l}N \\
\stackrel{N}{~} \\
\stackrel{1}{\sim}\end{array}$ & 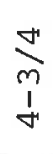 \\
\hline & $\begin{array}{l}\text { 庳 } \\
\text { 帠 } \\
\text { 总 }\end{array}$ & 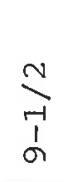 & $\begin{array}{l}\frac{ \pm}{2} \\
\frac{1}{1}\end{array}$ & $\underset{\frac{1}{1}}{\frac{1}{n}}$ & $\infty$ & $\begin{array}{l}\frac{\nabla}{m} \\
1 \\
1\end{array}$ & $\begin{array}{l}\vec{J} \\
m \\
1 \\
\infty\end{array}$ & \begin{tabular}{l}
\multirow{2}{*}{} \\
$\frac{1}{6}$
\end{tabular} & 6 & $\begin{array}{l}\vec{r} \\
1 \\
b\end{array}$ & $\sigma$ & సે & $\sigma$ \\
\hline \multicolumn{2}{|c|}{ 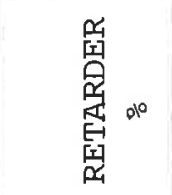 } & $\stackrel{\stackrel{N}{N}}{\dot{0}}$ & 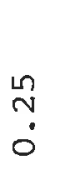 & $\begin{array}{l}\stackrel{\operatorname{Ln}}{N} \\
\dot{0}\end{array}$ & $\begin{array}{l}\stackrel{\overbrace{}}{~} \\
\dot{0}\end{array}$ & $\begin{array}{l}\text { n } \\
\text { r. } \\
0\end{array}$ & $\begin{array}{l}n \\
\stackrel{n}{r} \\
0\end{array}$ & $\begin{array}{l}\stackrel{n}{r} \\
\stackrel{0}{0}\end{array}$ & $\begin{array}{l}\stackrel{n}{N} \\
\stackrel{1}{r} \\
\dot{0}\end{array}$ & $\begin{array}{l}\stackrel{\operatorname{Ln}}{N} \\
\stackrel{\leftrightarrow}{\circ} \\
\dot{0}\end{array}$ & $\begin{array}{l}\text { 움. } \\
\dot{0}\end{array}$ & $\stackrel{\circ}{\stackrel{\leftrightarrow}{\circ}}$ & $\begin{array}{l}\infty \\
\stackrel{0}{0} \\
\dot{0}\end{array}$ \\
\hline \multicolumn{2}{|c|}{ 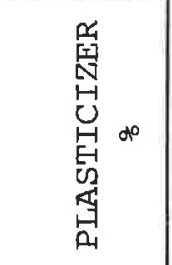 } & $\begin{array}{l}8 \\
\dot{\sim}\end{array}$ & $\begin{array}{l}8 \\
8 \\
\text { ¿ }\end{array}$ & $\begin{array}{l}\text { 오 } \\
\text {-ं }\end{array}$ & $\begin{array}{l}\text { 운 } \\
\text { - }\end{array}$ & $\begin{array}{l}\stackrel{n}{R} \\
\\
r-1\end{array}$ & 올 & $\begin{array}{l}O \\
\text { \&' } \\
\text {-i }\end{array}$ & $\begin{array}{l}\text { Oे } \\
\text { - }\end{array}$ & $\begin{array}{l}\text { 으 } \\
\text {-i }\end{array}$ & $\begin{array}{l}8 \\
0 \\
-i\end{array}$ & $\begin{array}{l}0 \\
\qquad \\
\dot{-1}\end{array}$ & $\begin{array}{l}\text { In } \\
0 \\
-1\end{array}$ \\
\hline$\stackrel{X}{\mid}$ & $\dot{z}$ & $r-1$ & $v$ & $m$ & $\nabla$ & in & 6 & $r$ & $\infty$ & $a$ & 음 & $\underset{-1}{-1}$ & $\begin{array}{l}N \\
+1\end{array}$ \\
\hline
\end{tabular}


0

\begin{tabular}{|c|c|c|c|c|c|c|c|c|}
\hline \multirow{3}{*}{ 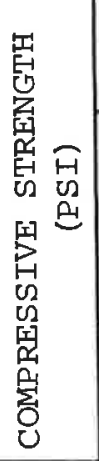 } & $\begin{array}{l}\text { 䍃 } \\
\sim\end{array}$ & $\begin{array}{l}\stackrel{\mathscr{N}}{\sim} \\
\underset{\sim}{N}\end{array}$ & 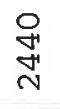 & $\underset{\stackrel{L}{\sim}}{\stackrel{\sim}{\sim}}$ & $\begin{array}{l}\stackrel{n}{\circ} \\
\stackrel{\sim}{\sim}\end{array}$ & $\begin{array}{l}m \\
\stackrel{6}{ } \\
\stackrel{1}{H}\end{array}$ & $\begin{array}{l}\stackrel{H}{\mathrm{~m}} \\
\stackrel{\mathrm{o}}{ }\end{array}$ & $\begin{array}{l}\underset{N}{N} \\
\sim \\
\sim\end{array}$ \\
\hline & 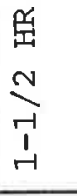 & 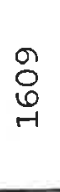 & $\begin{array}{l}\text { ㅇ } \\
\text { ज̆ } \\
\stackrel{+}{+}\end{array}$ & $\begin{array}{l}0 \\
\stackrel{1}{0} \\
\stackrel{D}{N}\end{array}$ & $\begin{array}{l}N \\
\text { N } \\
\text { In } \\
\sim\end{array}$ & $\begin{array}{l}\infty \\
0 \\
0\end{array}$ & $\begin{array}{l}\text { g} \\
\stackrel{p}{m} \\
\stackrel{r}{r}\end{array}$ & 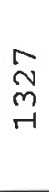 \\
\hline & $\begin{array}{l}\text { 䍃 } \\
r\end{array}$ & $\stackrel{-}{m}$ & $\stackrel{\infty}{r}$ & $\stackrel{\varphi}{m}$ & $\stackrel{\infty}{\sim}$ & $r$ & $\stackrel{m}{\sim}$ & $\stackrel{r-1}{\sim}$ \\
\hline \multirow{5}{*}{$\begin{array}{l}\text { 总 } \\
\text { 点 } \\
\text { 昜 }\end{array}$} & 일.द्ध్ & $N$ & 1 & $\begin{array}{l}\overrightarrow{1} \\
\stackrel{1}{1} \\
\stackrel{1}{N}\end{array}$ & 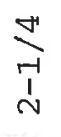 & $N$ & $\underset{\substack{m \\
⿱ \\
r}}{\stackrel{\nabla}{m}}$ & $\underset{-1}{N}$ \\
\hline & 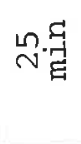 & $\underset{\substack{N \\
\stackrel{1}{N}}}{\stackrel{1}{\prime}}$ & $\underset{\substack{1 \\
1}}{\stackrel{1}{1}}$ & $\frac{\vec{H}}{\stackrel{1}{1}}$ & $\begin{array}{l}\vec{m} \\
\grave{1} \\
\sim\end{array}$ & $m$ & $\underset{\substack{N \\
\sim}}{\stackrel{1}{v}}$ & 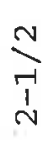 \\
\hline & 올્ધ & $\nabla^{\prime}$ & $\underset{\substack{\sim \\
\sim}}{\stackrel{N}{N}}$ & 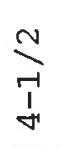 & $\begin{array}{l}\stackrel{+}{m} \\
\stackrel{m}{m} \\
\dot{m}\end{array}$ & $\begin{array}{l}\frac{\nabla}{m} \\
\mathfrak{m} \\
m\end{array}$ & $\frac{v}{\stackrel{v}{1}}$ & $\frac{N}{-1}$ \\
\hline & ㄴ. & $\underset{\substack{N \\
\frac{1}{1}}}{\stackrel{1}{1}}$ & $\frac{N}{\grave{1}}$ & $\frac{N}{1}$ & 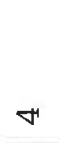 & เก & $\underset{m}{\stackrel{+}{m}}$ & 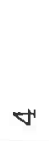 \\
\hline & 㞓 & 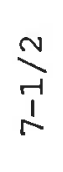 & $r$ & \begin{tabular}{l}
$\frac{\pi}{2}$ \\
\multicolumn{1}{c}{} \\
0
\end{tabular} & $\infty$ & $\underset{m}{\frac{\pi}{1}}$ & $\infty$ & 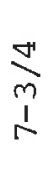 \\
\hline \multicolumn{2}{|c|}{ 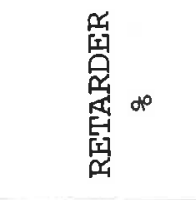 } & $\begin{array}{l}\circ \\
\stackrel{-}{-} \\
0\end{array}$ & $\begin{array}{l}\circ \\
\stackrel{+}{0} \\
\dot{0}\end{array}$ & $\begin{array}{l}0 \\
\text { r. } \\
\dot{0}\end{array}$ & $\begin{array}{l}\stackrel{0}{r} \\
\dot{0}\end{array}$ & $\begin{array}{l}\stackrel{0}{+} \\
\stackrel{\circ}{\circ}\end{array}$ & $\begin{array}{l}\stackrel{\circ}{\mathrm{H}} \\
\stackrel{0}{0}\end{array}$ & $\begin{array}{l}\stackrel{0}{?} \\
\text { ㅇ }\end{array}$ \\
\hline \multicolumn{2}{|c|}{ 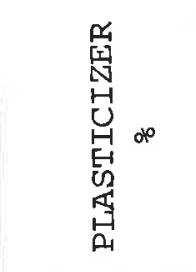 } & $\begin{array}{l}\stackrel{n}{r} \\
\end{array}$ & $\stackrel{\text { an }}{r}$ & -i & $\begin{array}{l}P \\
\dot{r}\end{array}$ & $\begin{array}{l}8 \\
\ddot{1} \\
\dot{r}\end{array}$ & $\begin{array}{l}\circ \\
0 \\
-1\end{array}$ & $\begin{array}{l}8 \\
8 \\
\text {-1 }\end{array}$ \\
\hline \multicolumn{2}{|c|}{ 常 } & $\stackrel{m}{r}$ & $\underset{\sim}{H}$ & $\stackrel{\text { Ln }}{r}$ & $\stackrel{\bullet}{r}$ & I & $\stackrel{\infty}{+}$ & $\stackrel{\Omega}{\sim}$ \\
\hline
\end{tabular}


TABLE 5-3. FINAL MIX DESIGN

\begin{tabular}{|l|c|c|c|c|c|c|}
\hline \multicolumn{7}{|c|}{ BATCH QUANTITIES, LB/YD } \\
\hline WATER & CEMENT & FLY ASH & GRAVEL & SAND & $\begin{array}{c}\text { CITRIC } \\
\text { ACID }\end{array}$ & $\begin{array}{c}\text { LOMAR D } \\
\text { LIQUID }\end{array}$ \\
\hline $274 *$ & 611 & 94 & $1625 * *$ & $1325 * *$ & 0.61 & 11.3 \\
\hline \\
*Water content changes of $1 \%$ to $2 \%$ were required due to variations in \\
aggregates \\
* Saturated surface dry condition, Type B aggregates
\end{tabular}

All specimens were made using the final mix design except that Type A aggregates were used. Mixes were batched in the laboratory in the same manner as described in subsection 5.1.1.1 except that the sand, $3 / 8 \mathrm{in}$. stone, and fly ash were premixed before being charged into the mixer. Unit weight and air content was checked on random batches. After casting, specimens were covered with burlap until stripped for storage.

a. Compressive Strength Development - Compressive strength specimens were 6 in. diam 12 in. long cylinders. Testing times of 1,7 , and 28 days were used. Specimens were stored in a fog room in accordance with ASTM C511 until test time. specimens were tested following ASTM C109.

Results of the testing are shown in Table 5-4. The longterm strengths are somewhat lower than those values found in Phase I. This may be due to three major factors. First, the formulation of the latest VHEC was changed slightly to increase early strength. This change may have been accomplished at the expense of ultimate strength. Second, concretes made with a portion 
TABLE 5-4. IONG-TERM COMPRESSIVE STRENGTH DEVELOPMENT

\begin{tabular}{|l|c|c|}
\hline \multicolumn{3}{|c|}{ STRENGTH (PSI) } \\
\hline 1 day & 7 days & 28 days \\
\hline 3880 & 4100 & 4200 \\
\hline
\end{tabular}

of the aggregate mixed in a prebatch form with fly ash may produce lower strengths. This may be due to the formation of a coating of fly ash and water on the surfaces of the particles which will reduce the cement paste-aggregate bond. Finally, the fly ash used for these mixes may not show much reactivity until after 28 days. Specimens cast from random mixes during Phase II have produced more than 6000 psi at 90 days.

Strength development with time is shown in Figure 5-2. The average values of numerous batches at ages $1,1-1 / 2,2 \mathrm{hr}$ have been combined with the results of long-term testing to produce the graph shown.

b. Shrinkage Potential - The shrinkage potential of VHEC concrete was assessed by measuring the length change of $2 \times 2 \times$ 10 in. bar specimens. The procedure outlined in ASTM C 157 was followed except that concrete was used instead of mortar. The amount of shrinkage through 100 days was minimal. This confirms findings supplied by the manufacturer, U.S. Gypsum (1). A plot of shrinkage with time is shown in Figure 5-3.

c. Sulfate Resistance - Test results of sulfate resistance of VHEC concrete from Phase I clearly showed very little susceptibility to sulfate attack. After 3 years of observation no reaction and no degradation was evident. 


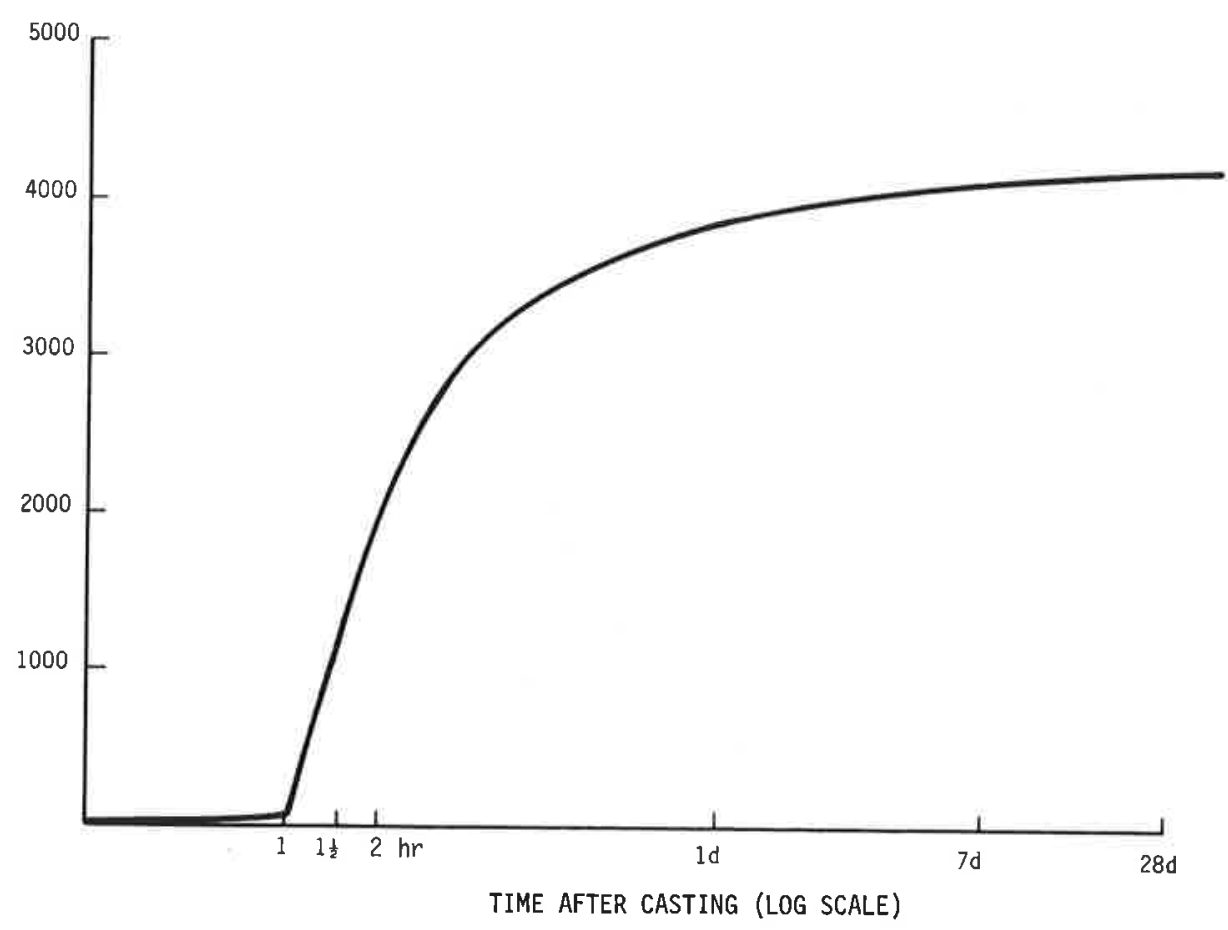

FIGURE 5-2. STRENGTH DEVELOPMENT WITH TIME OF VHEC CONCRETE

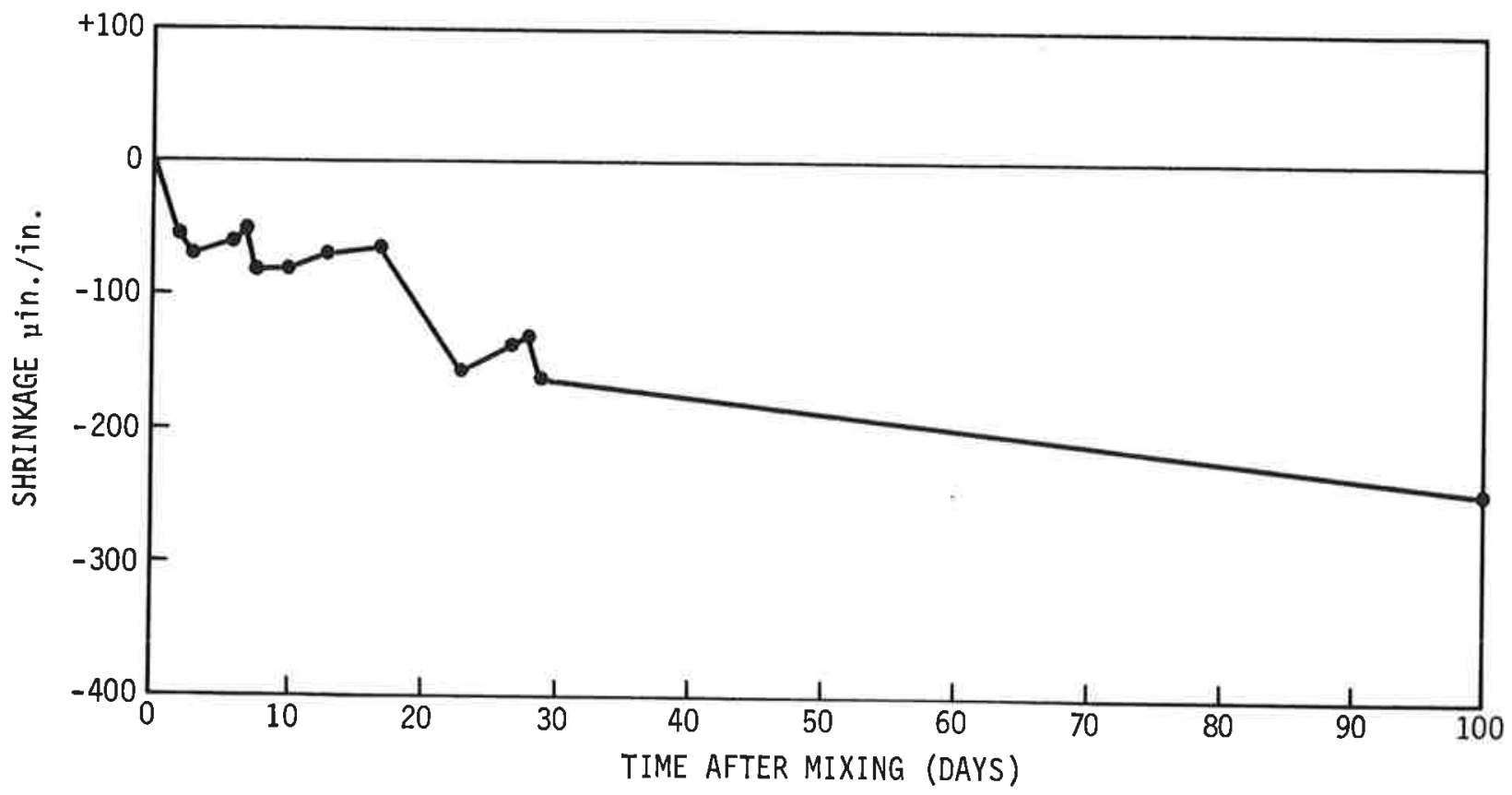

FIGURE 5-3. SHRINKAGE POTENTIAL OF VHEC CONCRETE 
Another set of specimens was cast using the new VHEC formulation to verify these findings. The expansion of concrete specimens continuously submerged in a 10 percent solution of sodium sulfate was monitored. Control specimens were placed in tap water. After initial measurements were made, the specimens were placed in their respective solutions and withdrawn for measurement weekly.

The expansion is shown in Figure 5-4. The results to date confirm the earlier testing. Very little reaction has occurred. VHEC has excellent sulfate resistance.

5.1.1.3 Buoyancy Tests - In addition to the standard material tests previously reported, a laboratory test was performed to assess the buoyancy or uplift provided by fresh concrete. Determination of the uplift for varying degrees of concrete plasticity was used first to resolve the force balance in the tunnel test facility so that drag could be more accurately determined and second, to account for the direct effect of uplift on form steering.

a. Test Method - In order to determine uplift, a simple test was devised using a standard slump cone. The slump cone was placed on a baseplate and filled with fresh concrete and rodded in the usual manner. At the completion of rodding and striking, a plate of known weight was placed on top of the cone and a bucket of sand placed on top of the plate, as shown in Figure 5-5. Sand was then gradually removed from the bucket until the slump cone lifted away from the baseplate. The weight of sand, bucket, plate and cone is equal to the uplift force.

b. Results - Tests were conducted using slumps ranging from 8-3/4 in. to $1 \mathrm{in.}$ The results are shown in Table 5-5. The theoretical uplift of concrete, if considered a true fluid, is defined as $0.15 \gamma$ for the slump cone shape, where $\gamma$ is the 


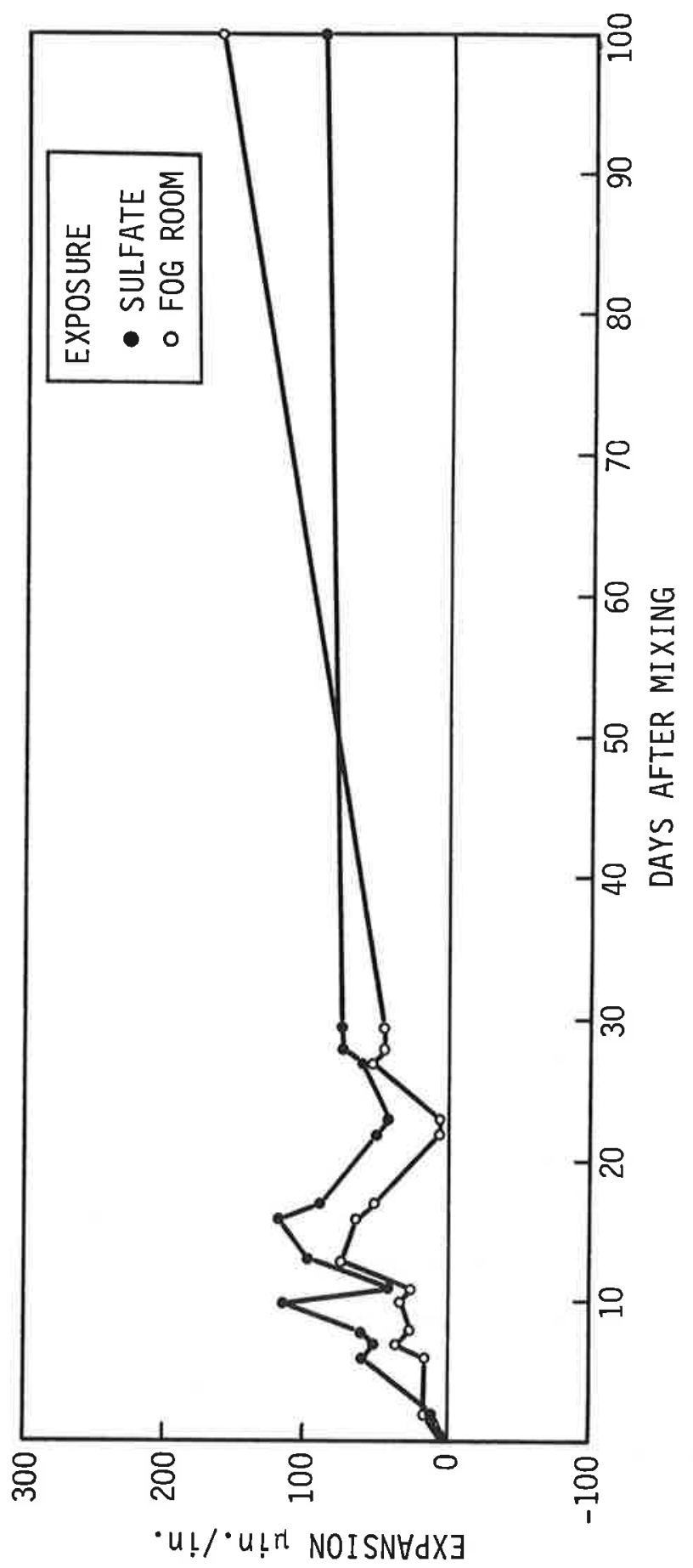

晸 


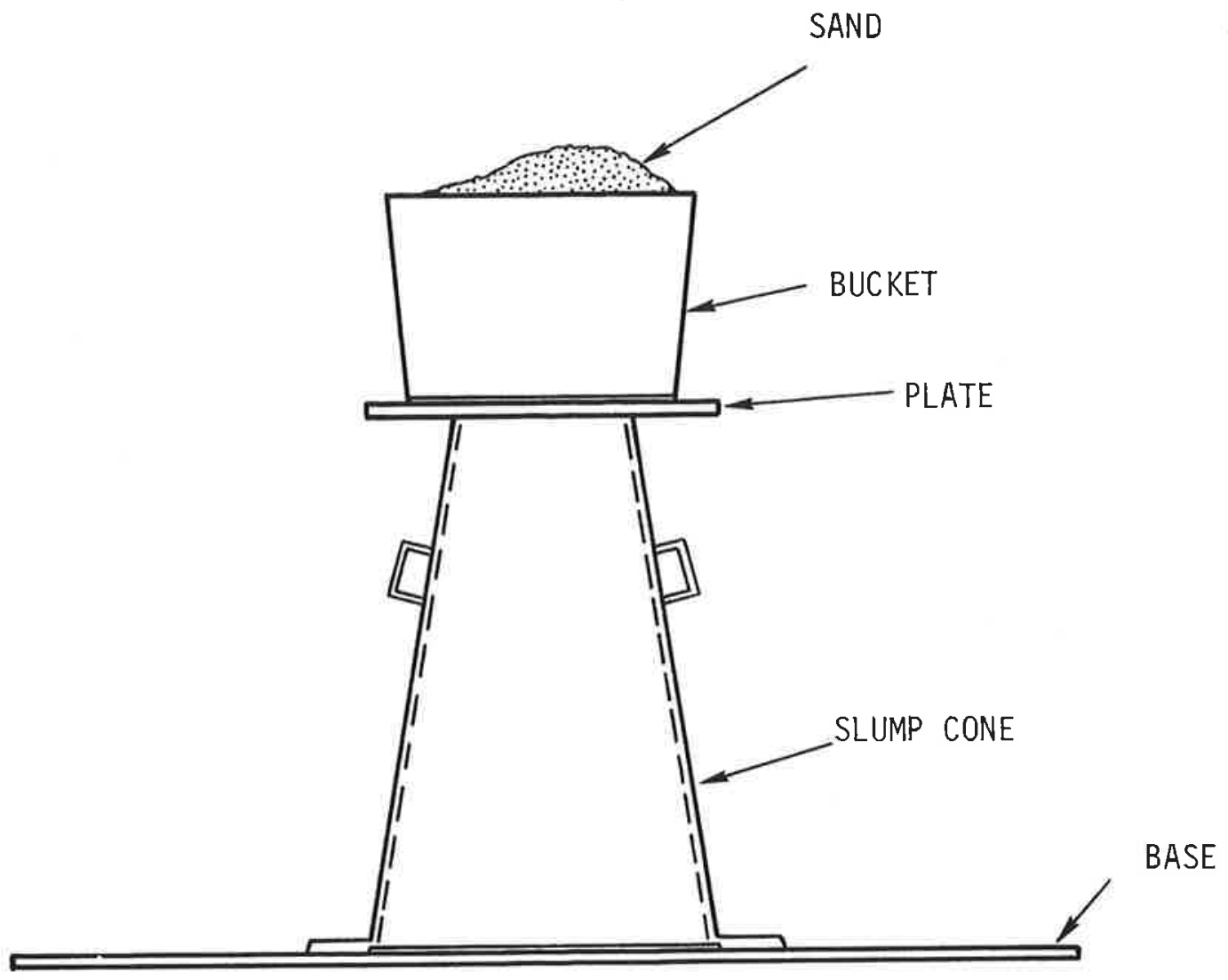

FIGURE 5-5. BUOYANCY TEST RIG

\section{TABLE 5-5. RESULT OF UPLIFT TEST FOR CONCRETE OF} VARYING SLUMP

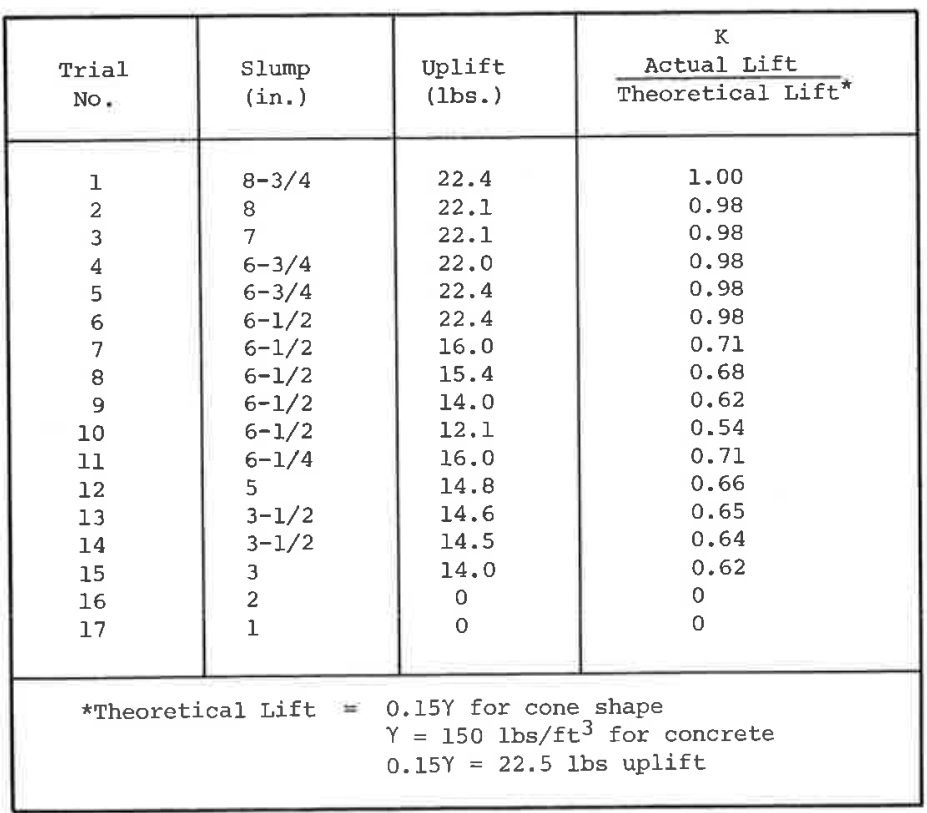


specific gravity of fluid. This equates to $22.5 \mathrm{lb}$. Results indicated the concrete exhibited a fluid behavior until the slump reached approximately 6-1/2 in. At this point, the uplift dropped to about 65 to 70 percent of the theoretical value and appeared to be constant until about a 3 -in. slump. At 2 in. slump, the uplift dropped to 0 .

c. Conclusions - The results indicate that the uplift force provided by concrete has three phases. First, with high slump concrete, the concrete is like a fluid; second, for moderate slump ranges, the uplift is about 60 to 70 percent of maximum; and finally, low slump concrete offers no uplifting force.

5.1.1.4 Drag Tests - Laboratory tests were performed to assess the drag force of steel sliding over semi-solid concrete in a slipforming motion. The test was conducted to help estimate the drag force that would occur in the tunnel test facility slipforming operation. Two tests using different concrete consistencies were used. The first test used 1 in. slump concrete and the second, zero slump concrete.

a. Test Method - A simple apparatus was constructed for the tests. It basically consisted of a 6-in. diameter compression cylinder mold and a hydraulic cylinder arranged in a boot-strap configuration as shown in Figure 5-6. A sample of concrete was placed and consolidated in the cylinder mold on top of a lower disc plate placed above a spacer block. An upper disc plate was then placed on top of the sample. The top frame was attached and a small hydraulic cylinder was placed between the cross beam of the frame and the upper disc plate. As fluid was pumped to the hydraulic cylinder, the rod extended. The hydraulic cylinder base reacted against the cross beam which transferred the load to the cylinder mold through the threaded rods. As the rod extended, 
(1) MOLD CYLINDER $\phi=6 \mathrm{in.,} L=12 \mathrm{in}$.

(2) DISC $\phi 5-7 / 8$ in. $t=1 / 4$ in.

(3) HYDRAULIC CYLINDER (AREA 0.9940 in.) $^{2}$ )

(4) CROSS BEAM (SLOTTED ANGLE)

(5) THREADED ROD

(6) SPACER BLOCK

\author{
(n)
}

$3-7 / 4$

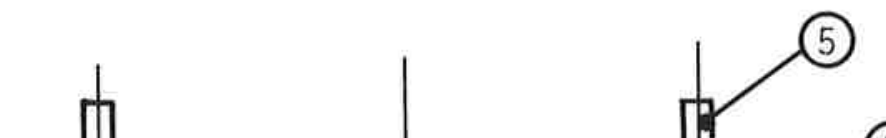

(4)

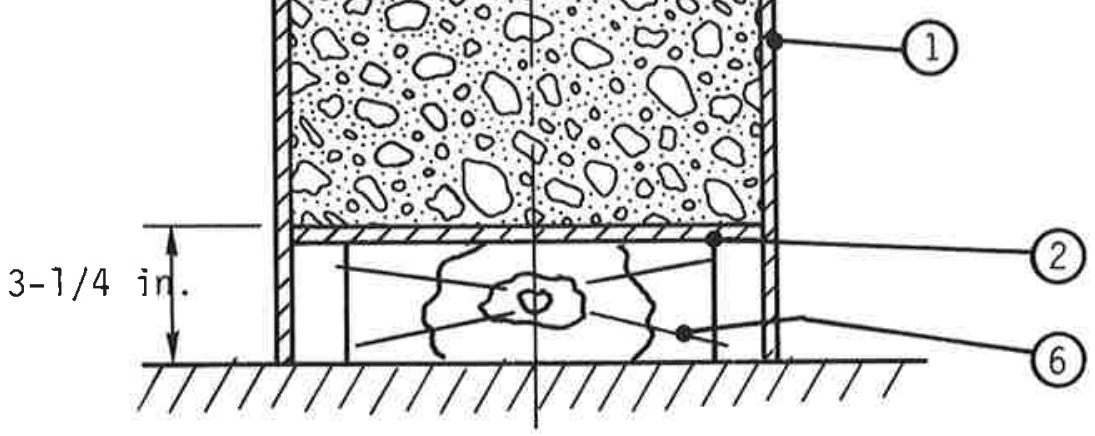

FIGURE 5-6. DRAG TEST APPARATUS

the concrete remained stationary and the mold moved up vertically over the sides of the concrete specimen. The amount of load required to move the cylinder mold over the concrete, accounting for the dead weight of the apparatus, is the drag force.

b. Results of Testing - Results of the first test using concrete with a 1-in. slump showed that about $80 \mathrm{lb}$ was required to move the mold. After subtracting dead weight the net drag was about $57 \mathrm{lb}$. The area of contact between concrete and cylinder mold was $119 \mathrm{in.}{ }^{2}$. Therefore, the drag was about $0.5 \mathrm{lb} / \mathrm{in} .{ }^{2}$.

For the second test, zero slump concrete was used. The net drag was about $72 \mathrm{lb}$ for this sample. This was equivalent to about $0.6 \mathrm{lb} / \mathrm{in} .^{2}$. 
c. Conclusions - For concrete that has lost most of its slump, the drag force encountered in slipforming will be about $0.5 \mathrm{lb}$ for each square inch of form in contact with that concrete. When the concrete has no slump at all the drag increases to $0.6 \mathrm{lb} / \mathrm{in} .{ }^{2}$ of form contact. For a $10 \mathrm{ft}$ diam system with $8 \mathrm{ft}$ of form length imbedded in this type of concrete, the drag will be about 22,000 lb.

\subsubsection{Prebatch Tests}

5.1.2.1 Purpose - The ETLS concrete mix is made up of cement, fly ash, two sizes of gravel, sand, water and admixtures. For batch plant produced concrete, this number of different ingredients would not cause any problems. Since VHEC concrete cannot be made in batches due to its rapidly changing behavior, a continuous mixing system must be employed. Using the tunnel test facility auger-mixer, with five different systems for handing raw materials, would have been very cumbersome. For a tunnel lining application, it would be impractical, both due to space limitations and the requirement to transport all of the materials separately.

In order to reduce the materials handling problems, a scheme was devised to deliver the aggregates in a "prebatched" form. The prebatch would contain all of the inert ingredients $13 / 4 \mathrm{in}$. stone, $3 / 8 \mathrm{in}$. stone, sand and $f l y$ ash), and a portion of the $\mathrm{mix}$ water. This would form a mixture with sufficient cohesiveness to allow both handling without segregation and metering with the auger-mixer system. The use of prebatch would also greatly simplify the in-tunnel mixing equipment. Only cement, admixtures, and the remaining mix water need be added at the heading. 


\subsubsection{Preliminary Tests}

a. Method - A test was made to determine the feasibility of discharging prebatched aggregates from a transit mixer. The aggregates used for Phase I testing (Type A) were used for this test. Approximately $3 \mathrm{yd}^{3}$ of material containing $3 / 4 \mathrm{in}$. stone, $3 / 8$ in. stone, sand, fly ash, and 70 percent of the mix water were charged into the mixer. Bagged fly ash from Foster-Miller's supply was added to the truck by hand at the plant. The prebatch was mixed for about $15 \mathrm{~min}$ before discharge. Several different rates of discharge were used. Samples of the material were taken at various intervals for laboratory sieve analysis.

b. Results - The results of the test varied. At the start, loading fly ash into the mixer by hand was very messy and difficult. During the discharge, the larger stone particles became separated from the main flow of the mix. Most particles larger than $3 / 8$ in. could not be retained within the matrix of the smaller particles. The material discharged more consistently at higher drum speed, but the final analysis proved unsatisfactory. Samples were taken, dried, and sieved at our concrete laboratory. Table 5-6 shows the results of the testing along with the anticipated water-content and particle size distribution. It was apparent from both the visual inspection during the test and the test results that prebatching a mixture with the $3 / 4 \mathrm{in}$. stone was not feasible using a common inclined transit truck mixer.

c. Conclusions - Transit trucks were the only readily available means to have prebatch mixed and delivered in the quantities required for Phase II testing. Therefore, it was concluded at this point in the program that no further trials should be attempted with the large stone. Although this meant the total simplicity of handling one composite aggregate was forfeited, it 
TABLE 5-6. RESULTS OF SEIVE ANALYSES PERFORMED ON SAMPLES OF PREBATCH TAKEN FROM TRANSIT MIXER DISCHARGE

\begin{tabular}{|c|c|c|c|c|c|c|c|c|c|c|}
\hline \multirow{3}{*}{$\begin{array}{l}\text { Sieve } \\
\text { Size }\end{array}$} & \multicolumn{10}{|c|}{ Percent Passing } \\
\hline & \multirow{2}{*}{$\begin{array}{l}\text { Design(Source } \\
\text { A Aggregates) }\end{array}$} & \multicolumn{9}{|c|}{ Sample Number } \\
\hline & & 1 & 2 & 3 & 4 & 5 & 6 & 7 & 8 & 9 \\
\hline $1 "$ & 100 & 97.6 & 100 & 100 & 100 & 100 & 100 & 100 & 100 & 100 \\
\hline $3 / 4 "$ & 96.87 & - & - & - & - & - & - & 98.58 & 100 & 99.1 \\
\hline $1 / 2^{\prime \prime}$ & 77.18 & 46.54 & 63.45 & 78.87 & 86.74 & 81.86 & 85.48 & 79.81 & 81.68 & 84.04 \\
\hline $3 / 8 "$ & 67.97 & 31.24 & 51.73 & 66.48 & 78.26 & 71.58 & 74.09 & 68.73 & 66.73 & 40.24 \\
\hline \#4 & 49.23 & 22.84 & 37.01 & 49.07 & 59.89 & 53.73 & 54.65 & 51.58 & 46.15 & 13.56 \\
\hline$\# 8$ & 40.36 & 20.37 & 30.25 & 40.21 & 47.50 & 43.75 & 44.52 & 41.83 & 36.94 & 10.37 \\
\hline$\# 16$ & 32.27 & 17.38 & 24.94 & 32.65 & 38.15 & 35.43 & 36.19 & 34.02 & 30.10 & 9.15 \\
\hline$\# 30$ & 21.25 & 12.32 & 17.53 & 22.86 & 26.41 & 24.75 & 25.43 & 24.03 & 21.54 & 7.26 \\
\hline$\# 50$ & 13.56 & 8.06 & 11.52 & 14.87 & 17.28 & 16.18 & 16.71 & 15.76 & 14.39 & 4.78 \\
\hline$\# 100$ & 6.65 & 4.13 & 5.21 & 7.19 & 9.13 & 6.91 & 7.70 & 7.69 & 7.10 & 2.12 \\
\hline$\# 200$ & 4.11 & 1.13 & 1.90 & 2.42 & 2.93 & 2.13 & 2.58 & 2.93 & 2.67 & 0.54 \\
\hline Pan & 0 & 0 & 0 & 0 & 0 & 0 & 0 & 0 & 0 & \\
\hline F.M. & 4.95 & 6.42 & 5.58 & 4.88 & 4.37 & 4.66 & 4.55 & 4.78 & 4.95 & 6.49 \\
\hline
\end{tabular}

\begin{tabular}{|c|c|c|c|c|c|c|c|c|c|c|}
\hline \multirow{2}{*}{$\begin{array}{l}\text { Parameter } \\
\text { Measured }\end{array}$} & \multirow{2}{*}{$\begin{array}{l}\text { Design(Source } \\
\text { A Aggregates) }\end{array}$} & \multicolumn{9}{|c|}{ Sample Number } \\
\hline & & 1 & 2 & 3 & 4 & 5 & 6 & 7 & 8 & 9 \\
\hline $\begin{array}{l}\text { Moisture } \\
\text { content, } \\
\text { (percent) }\end{array}$ & 6.67 & 4.42 & 5.25 & 7.72 & 8.01 & 7.73 & 7.80 & 7.45 & 6.40 & 3.15 \\
\hline $\begin{array}{l}\text { Percent } \\
\text { mix } \\
\text { water }\end{array}$ & 70 & 46.38 & 55.09 & 81.01 & 84.05 & 81.11 & 81.84 & 78.17 & 67.15 & 33.05 \\
\hline
\end{tabular}

would have little impact on the tunnel testing. Since the augermixer was equipped with two aggregate bins, the 3/4-in. stone could be placed in one and prebatch in the other.

In addition, it was obvious that prebatching would be less difficult if a supply of good quality aggregates could be found at a plant that also had fly ash in bulk and a large fleet of transic trucks. Adding fly ash to the truck from a hopper was highly desirable and the availability of a large number of trucks would limit delays to the testing program during peak construction periods.

5.1.2.3 Aggregate Selection - Based on the conclusions from the preliminary testing, subsection 5.1.2.2, a survey was made to 
locate a concrete or aggregate supplier with good quality aggregate and bulk fly ash. The survey was limited to operations within a $25 \mathrm{mi}$ radius of the Waltham, MA tunnel test facility.

Although a number of locations had promising materials, no one supplier had good aggregates, fly ash, and transit truck operations. A majority of suppliers dealt exclusively in crushed stone which would have further complicated the mix design.

A local concrete firm (Source B) had the best operation and proved most cooperative. The aggregate shape was only fair. The 3/8-in. stone was angular to sub-angular and the sand was manufactured and not natural; however, fly ash was available in bulk and Source $B$ promised to provide the best delivery service. In addition, they operated year round.

Since the 3/4-in. stone was to be handled separately, it could be procured from any local source. The original supplier (Source A) had the best of a generally poor selection. All testing was done with this supply of $3 / 4-i n$. stone.

5.1.2.4 Finalization of Prebatch Formulation - Once the selection of aggregates was complete, a series of prebatch tests was conducted. Tests were performed to optimize the prebatch consistency to ensure a uniform dispersion of materials and minimize segregation during handling. Since the aggregate proportions were fixed to meet the overall concrete requirements, no changes in fly ash content or sand/stone ratio could be made. Only water content could be varied.

All tests were conducted at the batch plant facility of the chosen material supplier. Three trucks, each charged with $6 \mathrm{yd}^{3}$ of prebatch, were used. Each batch had a different moisture content as follows: 
1. Truck No. 1 - 60 percent mix water

2. Truck No. 2 - 50 percent mix water

3. Truck No. 3 - 30 percent mix water.

The trucks were thoroughly cleaned before charging. A minimum of 60 drum revolutions was used for each test. The trucks were discharged at a uniform rate and samples were taken for subsequent sieve analysis and moisture content tests.

The results were very good. The first mix, with 60 percent water, was homogeneous and consistent throughout the test. The second mix, with 50 percent mix water, exhibited similar properties. The third mix, with 30 percent mix water, segregated during discharge. The larger stone particles could not be contained within the mix. Results of the sieve analyses and moisture content test are provided in Tables 5-7, 5-8, and 5-9.

Results of these tests indicated that prebatched aggregates up to $3 / 8$ in. maximum size could be successfully mixed and discharged with a moisture content of about 6.5 to 8 percent (50 to 60 percent of the total $\mathrm{mix}$ water). Prebatch with water contents below 5.5 percent segregated while being discharged from the transit truck.

The results also indicated that it was somewhat difficult to control the final moisture content of the prebatch. This was caused by variations in moisture content of the raw aggregates and inaccuracy of the batch plant water metering equipment at low water amounts. Ordering the slightly dry material and adding water upon delivery worked the best.

5.1.2.5 Auger-Mixer Metering Tests - The auger mixer was tested to determine whether it could accurately meter the prebatch formulation which displayed the best handling characteristics. Two 


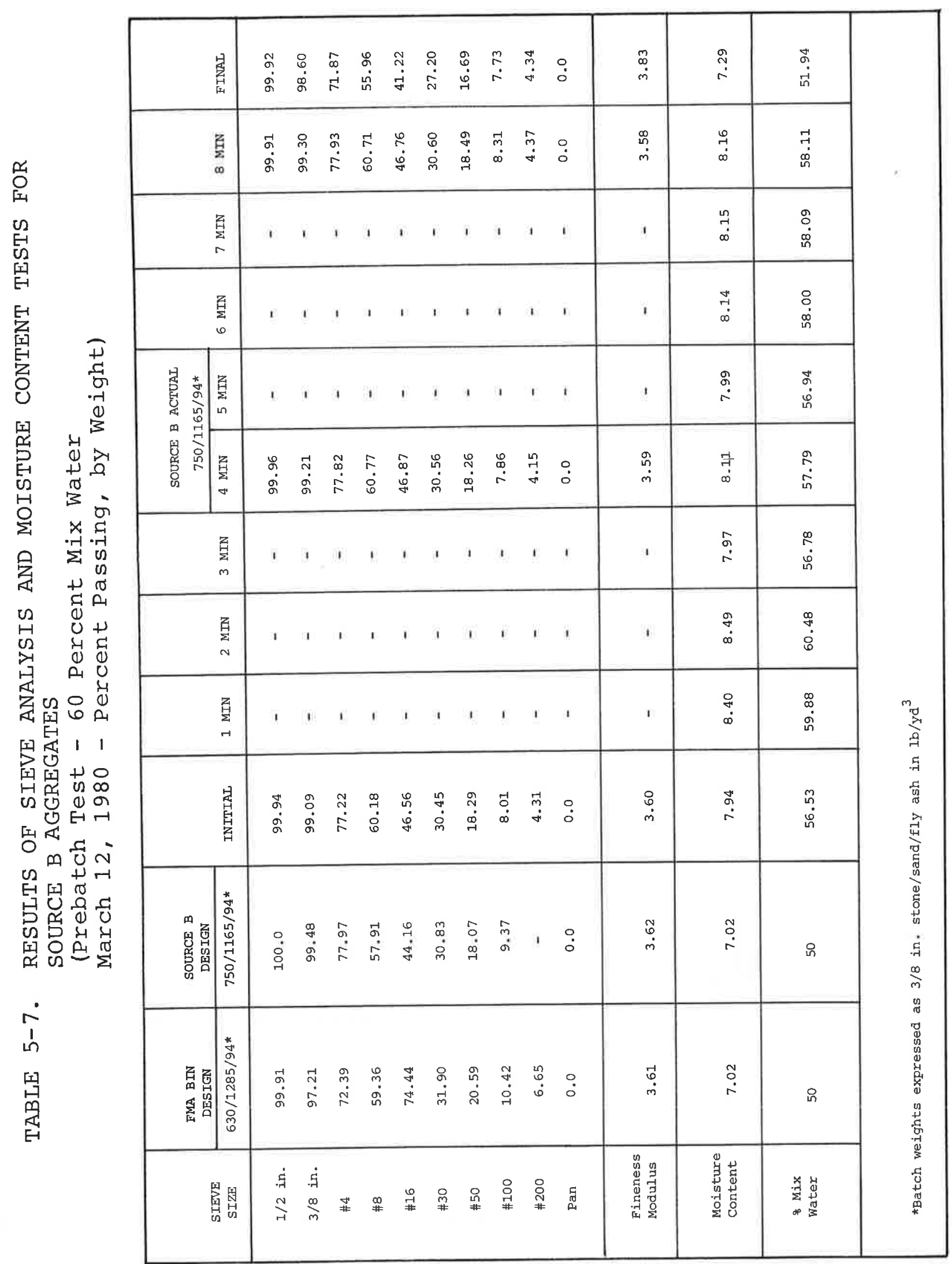




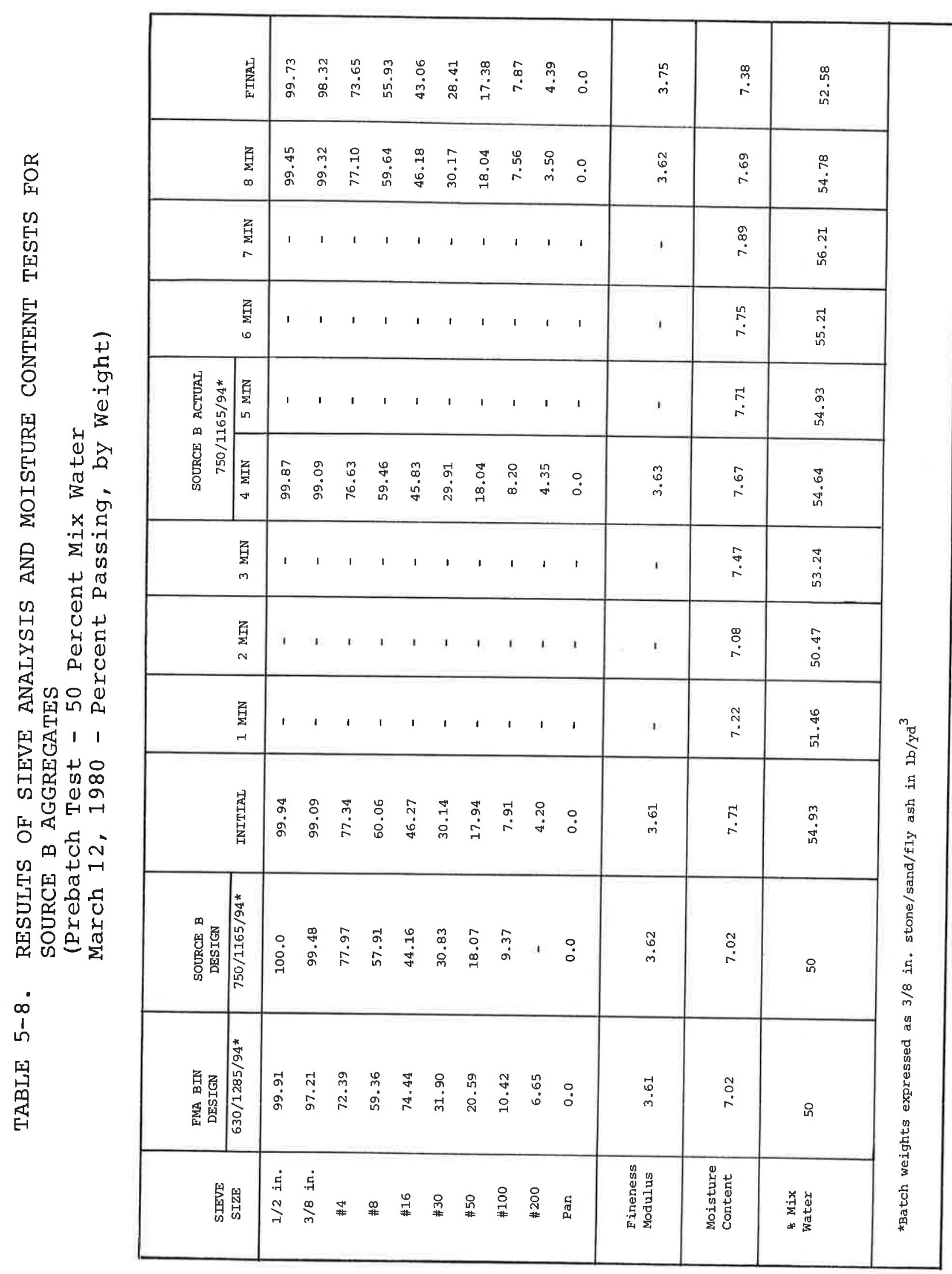


TABLE 5-9. RESULTS OF SIEVE ANALYSIS AND MOISTURE CONTENT TESTS FOR SOURCE B AGGREGATES

(Prebatch Test - 30 Percent Mix Water

March 12, 1980 - Percent Passing, by Weight)

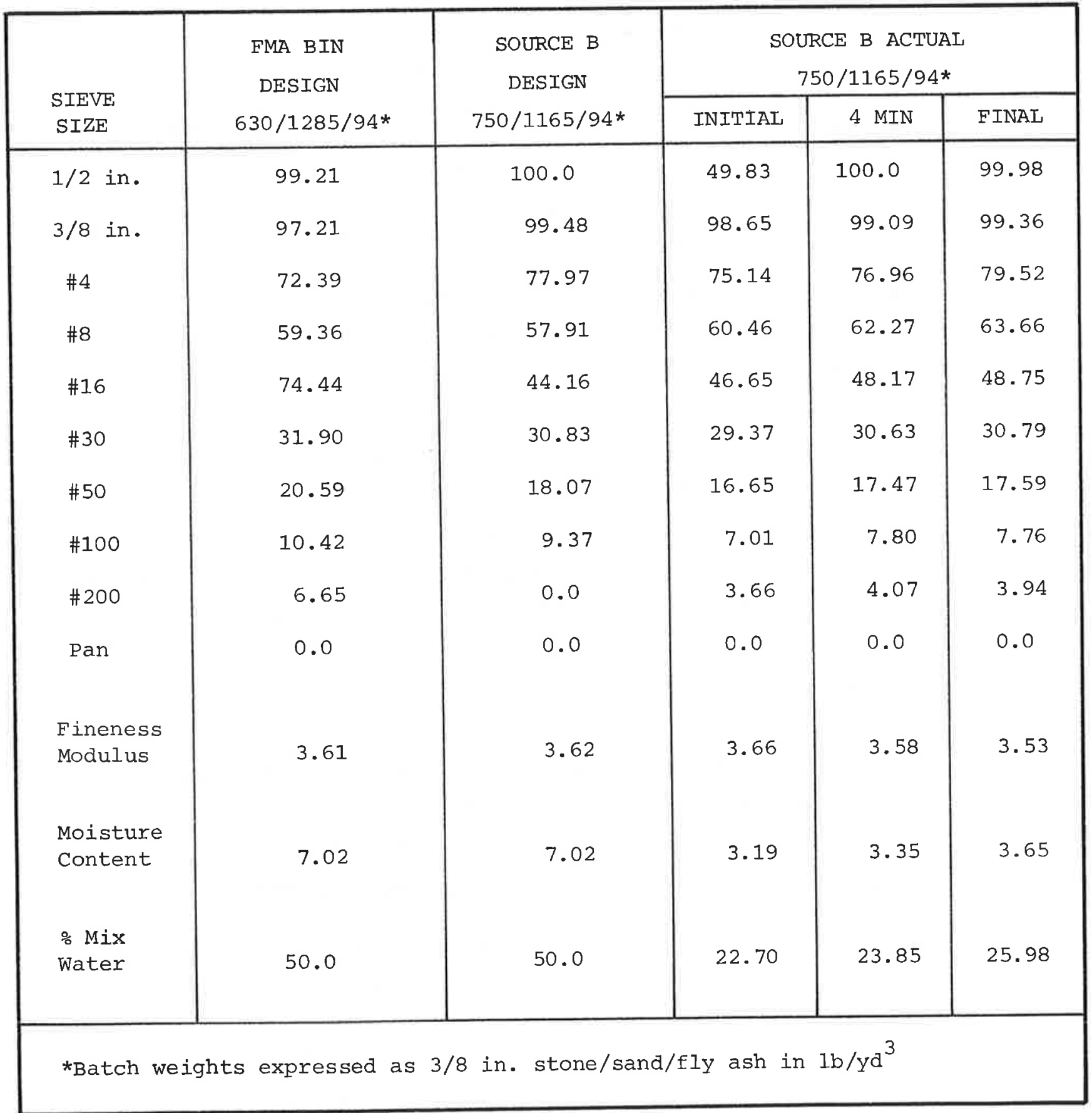


prebatches were tested. One batch had a moisture content of about 7 percent and the second about 8 percent.

Upon arrival of the trucks, the material was visually inspected and sampled for moisture content. The material was discharged onto plastic sheeting and transferred to the augermixer hopper. Tests were run at various material output.

Results showed that the auger mixer could deliver prebatch at rates from $26 \mathrm{lb} / \mathrm{min}$ to $295 \mathrm{lb} / \mathrm{min}$ with an accuracy of about 2 percent. Vibration was required to maintain even flow of material in the hopper.

Auger metering tests performed over the entire course of the program generally indicated no problems in metering prebatch until the moisture content of the prebatch exceeded about 8 percent. At this level of moisture, the prebatch acted very cohesively preventing free flow in the holding hopper. A variability of 2 percent in output was seen throughout the program and seemed to be related to variations in auger speed more than to material properties. This was evidenced by the fact that the 3/4-in. stone output was also subject to approximately the same variability.

\subsubsection{Contamination of Prebatch - As described earlier,} prebatch contains 3/8-in. stone, sand, fly ash and water. Although the fly ash in prebatch will exhibit some pozzolanic activity in the presence of hydrating cement, it is non-reactive to the raw materials in the prebatch. Therefore, no reaction should take place in the prebatch while it is stored awaiting use.

If prebatch is contaminated with portland cement residue, two major problems are created. First, the prebatch will react with the cement and stiffen with age and become difficult to handle. Second, and much more serious, the contamination will affect the properties of the VHEC concrete. VHEC concrete containing portland 
cement residue behaves very erratically. Water demand is increased; flash setting occurs; and strength gain is retarded.

It is very important, therefore, to specify that the transit trucks should be thoroughly rinsed after transporting concrete and before mixing prebatch. It is decidedly preferable that one transit truck should be dedicated only to prebatch mixing and delivery. For the Phase II testing program, this was impossible.

Prebatch contamination created a number of problems during the testing program. The problem and eventual solution is discussed in subsections 5.3 .3 and 5.4 .

\subsubsection{Slide Valve and Purge Systems Tests}

5.1.3.1 Slide Valve Development - As described in subsection 3.1 .3 , the slide valve was used to divert the flow of concrete from the placing line connected to the bulkhead to a waste line. This permitted rapid purging of the main concrete line during shutdowns. The section of placing line from the slide valve to the bulkhead was purged separately by a method to be described in the next subsection, 5.1.3.2.

The slide valve, shown in Figure 4-9, was developed at Foster-Miller since there was no commercially available device to perform its unique, yet simple function. A well-known concrete construction accessories supplier, construction Forms of Cedarburg, WI was asked to bid on the construction of a slide valve; however, the production cost for one slide valve was prohibitive. Only one slide valve design was developed. Parts were fabricated by local vendors and assembly was done at the Foster-Miller waltham shop facility.

a. Testing - After assembly and check-out, the slide valve was cycled dry to check pump line configuration in both alignments, identified as the pump and purge positions. 
Tests using concrete were conducted. Concrete hose lines were connected to the slide valve and a small amount of concrete was pumped through the valve in the pump position. The pump was stopped, the slide valve switched to the purge alignment, and pumping was resumed. Only a small amount of leakage occurred. No other problems were evident. About 3000 lb was required to activate the valve from one position to the other.

Higher concrete pump line pressure was then induced by capping off the end of the concrete hose. The valve was switched to the purge position. At concrete line pressures of about 20 psi only a small amount of water leakage was noticed. When the pressure was increased to about 50 psi, leakage increased slightly; however, even at about 100 psi line pressure, no major leaks were observed. Pressure was then relieved and the slide valve actuated repeatedly. Actuator force varied between 3000 to $50001 \mathrm{~b}$.

The valve was tested a second time and actuated 8 times without incident. On the ninth trial, the slide plate became jammed. After disassembly it was observed that both slide plates were badly gouged from the scraping action of trapped aggregate particles. The surfaces were repaired by welding, ground smooth, and the slide valve reassembled.

b. Conclusions - The slide valve worked very well. Very little leakage was observed, even at increased line pressure. The sliding surfaces of the valve should have been hardened to avoid gouging by the aggregates.

5.1.3.2 Purge System Development - When the slide valve is placed in the purge position, the hose line from the pump is diverted from the line leading to the bulkhead to a waste line to permit purging. The section of line from the slide valve to the bulkhead cannot be removed from its position for cleaning for two reasons. 
First, its connection at the bulkhead is not always accessible and second, pressure must be maintained in the line so as not to allow concrete behind the bulkhead to leak out. A remote purging system was developed to clean this line while maintaining the bulkhead pressure.

a. Go-Devil Development - The purge system operation consisted of pushing a go-devil down the pumpline pushing the concrete ahead of it into the bulkhead. The go-devil was advanced by water pressure which both cleaned the line behind the go-devil and held it in place when it reached the face of the bulkhead.

b. Laboratory Testing - Six basic go-devil configurations, shown in Figure 5-7, were tested in the laboratory. All had cables attached and were designed to be retrieved by a winch.

The concrete pump and slide valve were used for the tests. Twenty feet of placing line was attached to the slide valve pump port and layed out straight or in a 180 deg vertical curve. The far end of the placing line was left open for some tests and fitted with a backpressure device in others. The test set-up, in the curved configuration, is shown in Figure 5-8.

This configuration provided a more difficult test than the straight run and was performed to determine whether the slide valve/go-devil system could be placed on the floor, $10 \mathrm{ft}$ below the bulkhead concrete port, and facing in the opposite direction.

To start a test, concrete was pumped into the placing lines. The slide valve was then moved to the purge position aligning the 20-ft placing line with the go-devil as shown in Figure 5-8. The various configurations were tested by placing the go-devils in the line and advancing it through the concrete hose under water pressure until it reached the end of the hose. The water pressure was then released and the winch, positioned behind the slide valve and in line with the hose, was activated to recover the go-devil. 
A

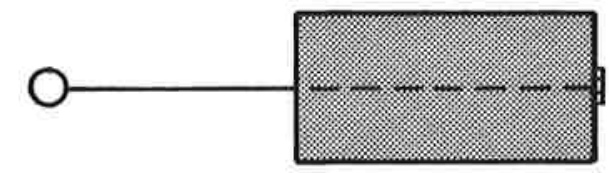

CLOSED-CELL FOAM

B

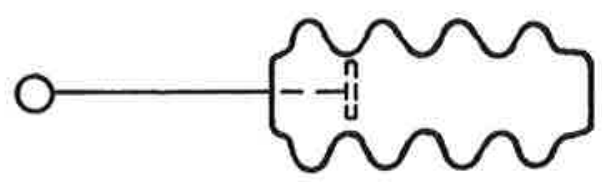

HARD RUBBER

C

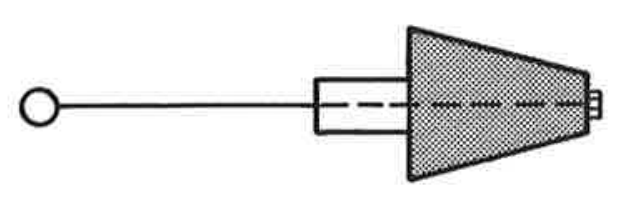

CLOSED-CELL FOAM

D

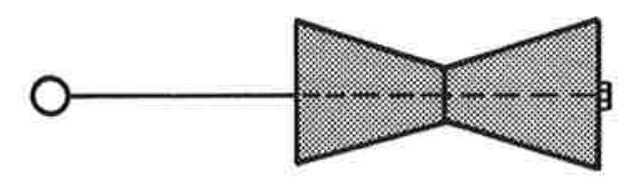

CLOSED-CELL FOAM

E

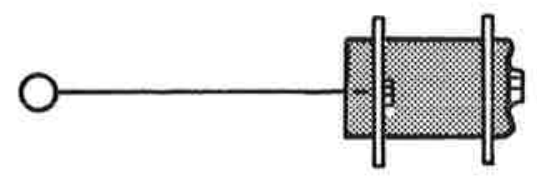

FIGURE 5-7. GO-DEVIL CONFIGURATIONS 

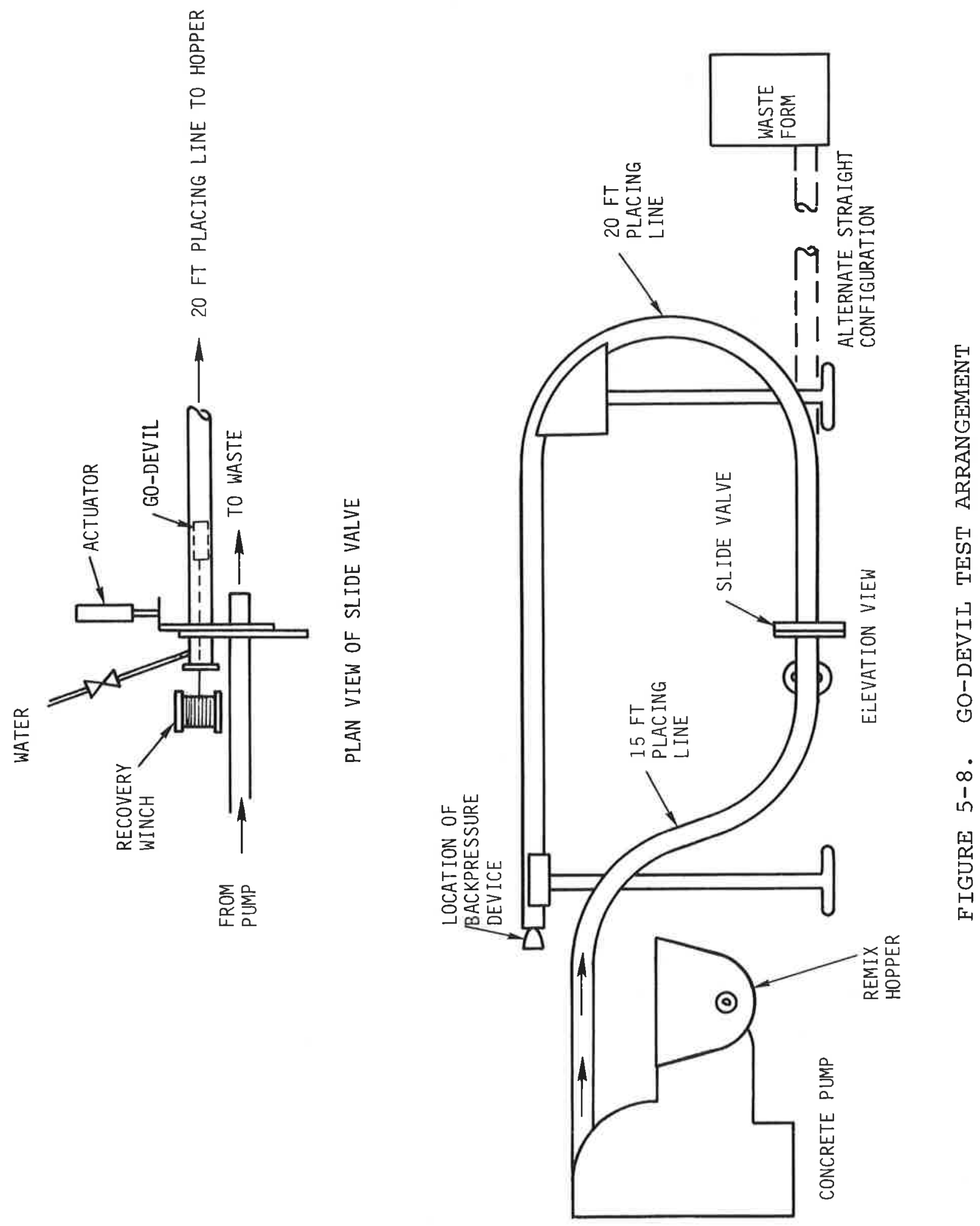
c. Results of Testing - The first tests were performed using the straight hose configuration and Designs $A$ and $B$. No backpressure was applied. Both go-devils allowed a large amount of water to leak by them into the concrete. Design B was very difficult to retrieve. These designs were discarded.

Design $C$ was tested in the straight configuration with a small amount of backpressure induced by a spring loaded device. The go-devil traveled about $2 \mathrm{ft}$ into the line and stalled. Water pressure was about $20 \mathrm{psi}$. When the backpressure device was removed, the go-devil continued but it allowed a lot of water to leak by. Recovery was easy.

Design D was a variation of Design $C$ and was outfitted with a different head shape. In the straight configuration, with no backpressure, it worked very well, using 5 psi water pressure. No water leakage occurred and recovery required only about 5 lb force. In a second test, in the 180 deg configuration, a large volume of water blew by the go-devil; however, it did reach the end of the hose. Retrieval was very easy. A third test in the 180 deg configuration and with the backpressure device applied, was a complete failure. The go-devil would not move at all and water leaked rapidly.

Go-devil configuration $\mathrm{E}$ was outfitted with two rubber washers in an attempt to eliminate water blow-by that the other designs allowed. Go-devil E worked very well in the straight test requiring about 15 to 20 psi water pressure and performed fairly well in the 180 deg configuration using about 30 to 40 psi water pressure. Go-devil retrieval in the 180 deg configuration worked well in some tests but not in others. In one straight test the hose was connected to a waste form to provide some backpressure since the spring loaded device did not work well. The go-devil traveled down the hose easily; however, it could only be retrieved a few feet. Continued pulling by the winch sucked the 
hose line flat. The go-devil could only be retrieved after a hose connection was broken and air was allowed into the hose. d. Conclusions - It was clear at this point in the testing that configuration $\mathrm{E}$ worked the best. Some minor modifications were made after the laboratory testing, but the basic design remained the same. It was also apparent that the system would not work repeatedly if a 180 deg curve was used. Finally, no go-devil return was possible if the space behind the go-devil was not vented when pulling back the go-devil. Some form of air valve was required for this purpose.

5.1.3.3 Purge System Air Valve Development - In a closed system the go-devil could not return unless air was vented into the void that was formed as the go-devil was retrieved.

Tests were conducted using the slide valve purge system and a number of vent configurations.

Results indicated that a hole with a simple ball valve arrangement was not adequate since paste from the pumped concrete would clog the inlet and harden in place. A positive air pressure was required to blow out the paste plug to allow air into the pump line.

\subsubsection{Final Slide Valve/Purge Configuration - Due to the} problems encountered in retrieving the go-devil from a curved section of pump hoseline, the slide valve and accompanying purge system was placed on the reaction structure, 20 ft behind and in direct line with the bulkhead concrete port. The slide valve was mounted on rails to permit it to follow the motion of the bulkhead relative to the reaction structure. The slide valve was connected to the bulkhead with a 20-ft steel slickline. This reduced the frictional resistance encountered by the go-devil 
during purging. This location of the slide valve/purge system was much less desirable than floor mounting since access for maintenance and repair was difficult.

\subsection{SERIES I TUNNEI TESTS}

The first tests using the ETLS laboratory tunnel test facility were conducted in March and April of 1981. As stated earlier, the intent of the initial tests was to demonstrate distribution of the concrete in the full round configuration and to demonstrate that the liner was capable of supporting itself when exposed at an age of approximately 1 to $1-1 / 2 \mathrm{hr}$. A sequence of tests arranged in increasing complexity leading up to an actual slipforming test. In this way, the test crew was able to become familiarized with the equipment and test procedures one step at a time. The first tests conducted were tests of the pump and auger-mixer. Some difficulties were encountered with the concrete during these tests necessitating a brief return to the concrete laboratory. These tests were then followed by distribution tests and then by slipform tests. The following subsections describe in detail the test method and test results used for the auger-mixer, distribution and slipforming tests.

\subsubsection{Mixer Pump Tests}

During these tests, VHEC concrete was produced at a $2.6 \mathrm{yd}^{3} / \mathrm{hr}$ (4 ft/hr) using the auger-mixer and admixture cart. The concrete produced was pumped through a short length of placing line to the waste containers. Test duration was approximately two hours.

\subsubsection{Test Objectives - The test objectives were:}

1. To verify proper performance of admixture equipment and auger-mixer 
2. To develop operating experience with mixing and pumping VHEC concrete.

3. To demonstrate the effectiveness of the prebatch handling, moisture and temperature control strategy.

5.2.1.2 Test Procedure - Prior to performing the mixer-pump tests, the auger-mixer and admixture equipment were calibrated. The equipment was adjusted to produce the design mix (Table 5-3) at the $2.6 \mathrm{yd} / \mathrm{hr}$ rate. The actual outputs and measured accuracies of the various augers and metering pumps are given in Table 5-10.

Figure 5-9 shows the equipment layout for the mixer pump tests. Nine people were required to conduct each test. Prior to the test, the temperature and moisture content of the prebatch and 3/4-in. stone were measured. The required auger speeds and mix water temperature were then calculated.

TABLE 5-10. MEASURED ACCURACIES OF METERING PUMPS AND AUGER-MIXER METERING AUGERS

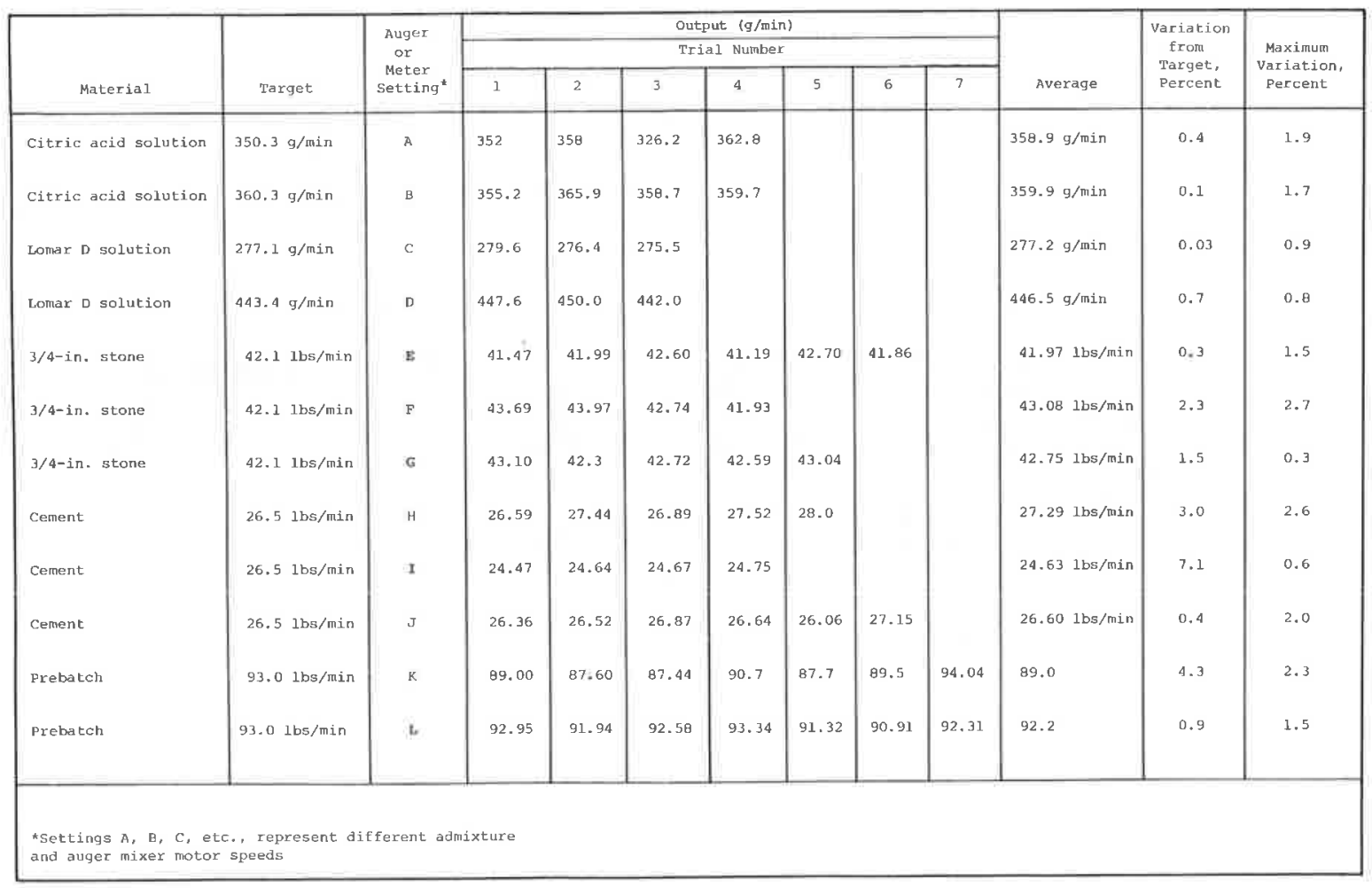




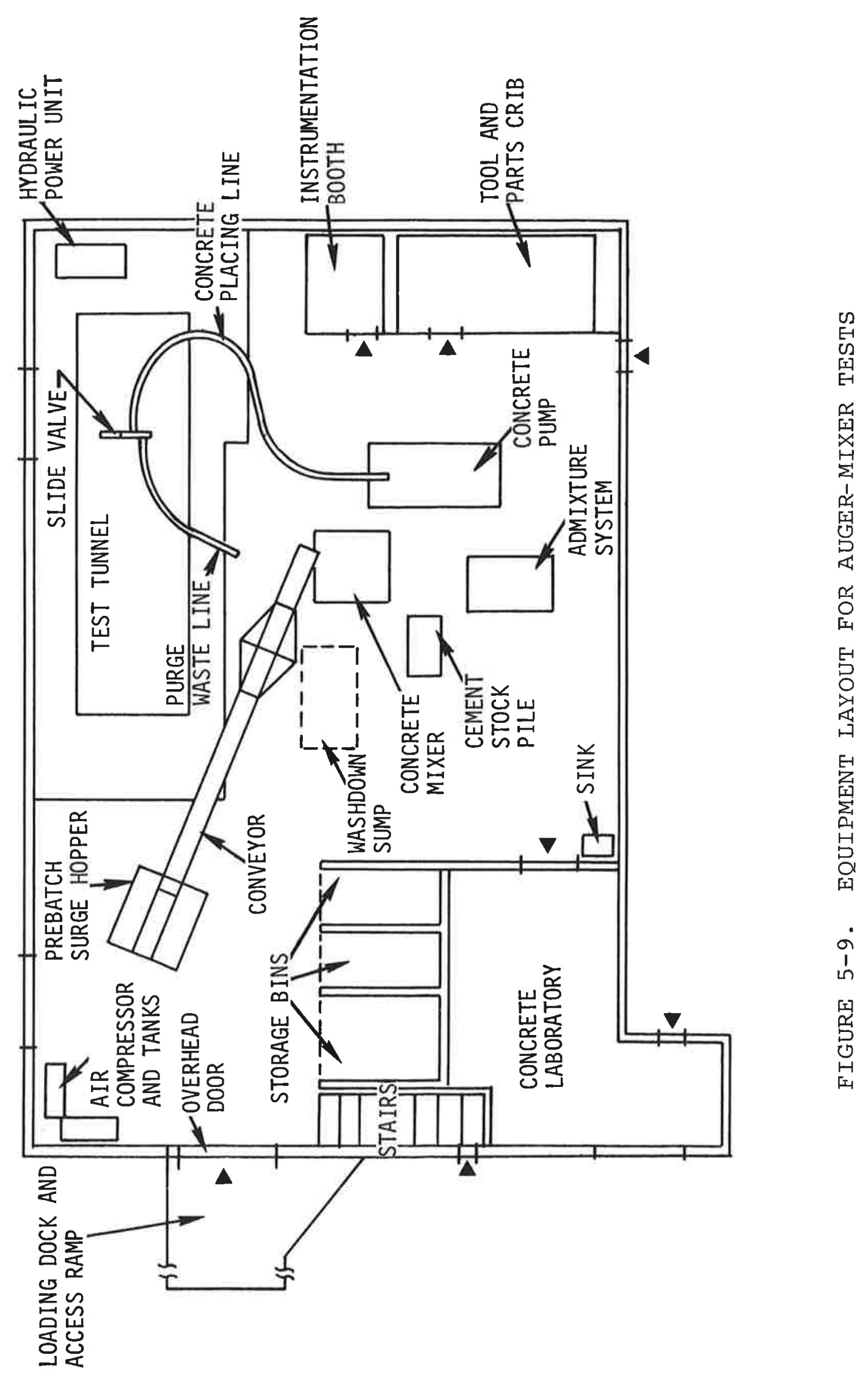


At 20 minute intervals during the test, a sample of concrete was taken directly from the mixer output to test for slump and to cast strength specimens. A slump test was conducted immediately after sampling and repeated $15 \mathrm{~min}$ later. Compressive strength specimens were tested one hour after casting. Admixture flow rates and pump discharge pressure were monitored continuously. Mix temperature was measured at $15 \mathrm{~min}$ intervals.

5.2.1.3 Test Results - During the first two mixer-pump tests the concrete exhibited rapid slump loss and delayed strength gain. Several placing line blockages were experienced during the tests. on the day following each test, batch mixes were made in the laboratory using the same materials to attempt to reproduce these results. The laboratory mixes showed normal slump loss and normal strength gain. Auger-mixer and admixture equipment calibrations were rechecked after each test and found to be correct.

At this point it was suggested that the prebatch was contaminated with portland cement from the transit mixers and that this cement hyarated overnight thus permitting acceptable mixes to be made in the laboratory with prebatch the following day.

A third test was performed with prebatch which had been allowed to stand covered in the hopper overnight. This test was successful. No blockages occurred during the test. At this point the decision was made to proceed to the distribution tests.

\subsubsection{Distribution Tests}

Distribution tests were conducted at the $2.6 \mathrm{yd}^{3} / \mathrm{hr}$ rate using both portland Type I and VHEC concretes. The $2.6 \mathrm{yd}^{3} / \mathrm{hr}$ (4 ft/hr) rate was selected as being on the low end of the 2 to $12 \mathrm{ft} / \mathrm{hr}$ design advance rate range. 
A low advance rate was selected because it is a more severe test of the distribution properties of the fresh concrete. This is due to the time elapsed while the concrete is in transit through the placing line. At low advance rates the concrete enters the form at a lower slump than at high advance rates.

5.2.2.1 Distribution Test objectives - The primary objectives of the distribution tests were to:

1. Demonstrate that concrete would distribute itself around the annulus under pressure

2. Evaluate the effects on distribution of workability, placing pressure, vibration, and port location

3. Demonstrate venting of the starting cavity and bulkhead advancement control from startup to pressure control mode

4. Determine whether the workability "window" for distribution was large enough to accommodate the variation in workability imposed by the concrete mixing system

5. Demonstrate control of concrete pressure inside the annulus.

In addition to the primary objectives, the following secondary objectives were to be fulfilled if possible:

1. Evaluate the effectiveness of purge when purging into a closed form, and effects on concrete consolidation

2. Evaluate quality of the cold joints that will occur in the liner between placements.

5.2.2.2 Distribution Tests with Portland Type I - It was decided to conduct the first distribution test (test no. SI-1) using portland Type I having a 6 to 7 in. slump. The 6 to 7 in. slump 
would be representative of the VHEC slump (initial slump $8 \pm 1$ in.) at the time it enters the form. In this way it could be determined whether or not concrete could completely fill the annulus from a single point of entry at the top of the bulkhead, without the additional problems introduced by the rapid-setting material.

a. Test Procedure - Test SI-1. Before the start of the test the bulkhead was positioned $8 \mathrm{in}$. from the end cover on the test tunnel. After slicking the concrete placing lines with grout, concrete production was started. Concrete was pumped into the 8-in. annulus. During this operation the bulkhead was held stationary. After the annulus was filled, a sharp increase in pumping pressure was observed at both concrete pumpline pressure sensors. This indicated that the starting void was filled. At this time control of the bulkhead was switched to the pressure control mode.

The bulkhead vibrators were actuated for 5 sec per $60 \mathrm{sec}$ period. This was started $8 \mathrm{~min}$ into the test. Vibration time was increased to $10 \mathrm{sec}$ per $60 \mathrm{sec}$ for the last $12 \mathrm{~min}$ of the test.

Variation in pumping pressures was observed from two red valves; one valve was located on the floor $25 \mathrm{ft}$ from the pump outlet and the other located just upstream of the slide valve on top of the reaction structure. The concrete pressure was observed to vary from 20 to 40 psi at the slide valve. The test proceeded smoothly for the first $49 \mathrm{~min}$. Concrete pumpline pressures were normal and at no time did the pressure at the slide valve exceed 40 psi.

After 50 minutes, the concrete pump was stopped to correct a 3-in. misalignment of the bulkhead. Pumping was resumed 2 minutes later with no further complications for the rest of the pumping sequence. 
Concrete pumping was stopped after another 3 minutes and a purge sequence was initiated. The purge operation did not work very well. The problems encountered appeared to be a combination of a lack of both worker communication and practice. The purge operation of the slick line was successful only after the bulkhead was backed away from the concrete. During the purge the go-devil seals inverted resulting in a considerable water flow into the fresh concrete.

Approximately $5 \mathrm{hr}$ after test completion, the slipform was to expose the young concrete. Concrete compressive strength, as measured by cylinder tests, was only 70 psi; however, the concrete in the form appeared to have developed higher strength. While moving the slipform, a "stick-slip" condition developed. Slipform drag of approximately 45,000 lb was measured. The stickslip condition began to induce cracking in the liner, therefore, movement of the form was stopped. The next day, slipping was continued. The stick-slip condition did not occur. Drag was measured at about $20,000 \mathrm{lb}$. The exposed section of concrete liner is shown in Figure 5-10. A void approximately $1 \mathrm{ft}^{2}$ in area was observed in the top of the liner. This was probably due to an 8-min delay in starting the bulkhead vibration at the beginning of the test.

b. Conclusions of Portland Type I Distribution Test - Test SI-1 demonstrated that concrete of slump 7 in. could be distributed completely around $8 \times 7$ in. by $9 \mathrm{ft}$ ID annulus from a single $3-i n$. entry port at the crown. It demonstrated that venting of the starting volume and consolidation of the concrete could be achieved using 20 to $40 \mathrm{psi}$ pumping pressure. The test demonstrated that the bulkhead control system could maintain bulkhead alignment and control the backpressure within the desired limits. 


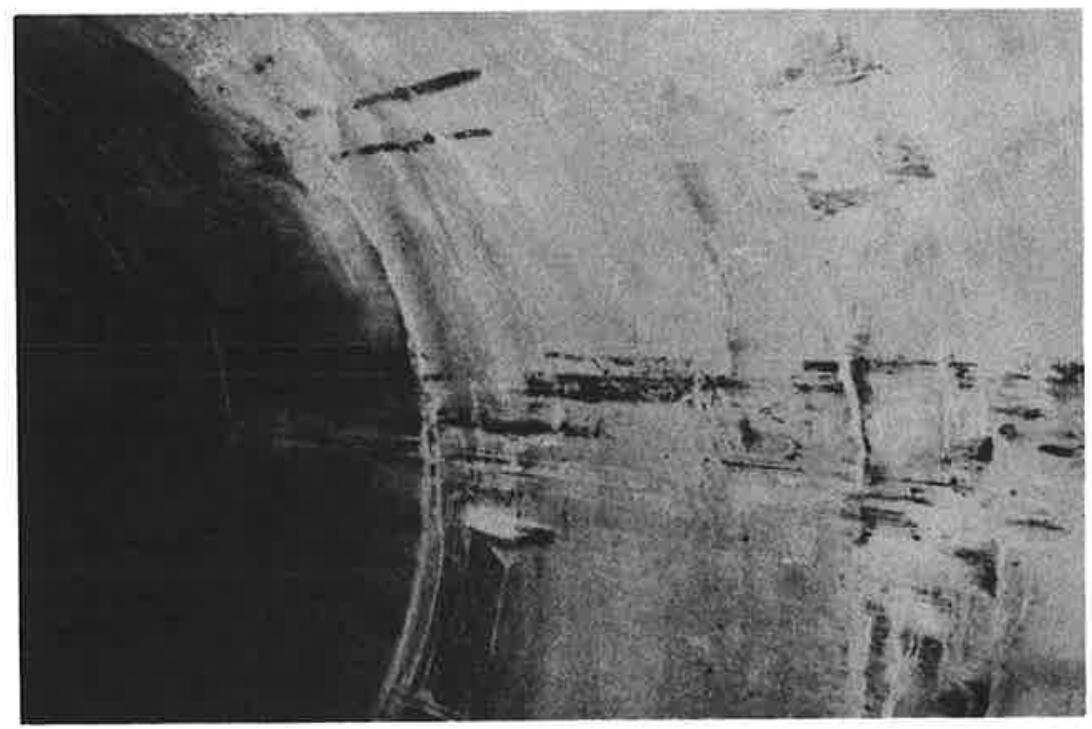

FIGURE 5-10. LINER CAST DURING TEST SI-1

Based on the stick-slip experienced when moving the slipform during test SI-1, it was concluded that excessive hose compliance existed in the hydraulic system. To combat this problem, needle valves were installed on the blind ends of slipform cylinders immediately adjacent to the outlets from the cylinders. These were to act as snubbers.

Also based on test SI-1, it was concluded that additional experience with the purging system was needed before conducting any tests with rapid-setting material. To satisfy this requirement, another test was conducted using portland Type I concrete (test No. SI-2). During test SI-2 an additional 13 in. of concrete was placed in the test tunnel. During the test, three consecutive purges were performed. All three purges were successful. Very little water blow-by was experienced and the go-devil retrieval winch worked perfectly. It was determined 
that the backpressure setting on the bulkhead had to be lowered to around 20 psi concrete pressure before performing the purge, otherwise the 80 psi water pressure was not sufficient to overcome the backpressure plus the losses in the placing line

5.2.2.3 Distribution Tests with VHEC Concrete

a. Test SI-3 - This test was the first distribution test (SI-3) with VHEC concrete. Immediately after the start of pumping the concrete pressure became very high. It was subsequently discovered that the port in the bulkhead was partially blocked with set concrete from test SI-2. The blockage was located at the downstream end of the bulkhead penetration. Based on the blockage, the purging procedure was modified for subsequent tests.

It was postulated that when the go-devil was withdrawn following the purge, the backpressure applied by the bulkhead forced concrete to back up into the placing line. The solution to this was to leave the go-devil at the end of the line for 5 to 10 min following the test until the concrete reached initial set. The go-devil was held in place by closing the water drain valve so that the volume of water in the placing line behind the go-devil was trapped. The water was then drained out and the go-devil retrieved after about $5 \mathrm{~min}$, to prevent it from sticking to the concrete.

b. Test SI-4 - The blockage was removed and another VHEC distribution test was conducted (test SI-4).

Testing began with the grout making operation. Concrete production followed and concrete pumping was started. Vibration was started 7 min later and was applied for 10 sec per $60 \mathrm{sec}$ period at $40 \mathrm{psi}$ air pressure. No variation in 
vibration duration or frequency (air pressure) was made. Concrete was pumped continuously without problem. Normal slumptime results were recorded, however, the strength specimens hardened very rapidly.

The slipform and bulkhead were set in motion 24 minutes into the test. The slipform advance rate was adjusted so that the fresh concrete would be exposed $90 \mathrm{~min}$ after it was placed.

The test ran smoothly for the first $60 \mathrm{~min}$ with no report of excess slipform drag. At about 65 min into the test, an upward deflection of the tunnel skid beams was observed. The deflection was approximately 2 in. and was increasing. At this time the slipform drag was in excess of 100,000 1bf. One minute later, the slipform jammed. Sixty-eight minutes into the test, concrete placement was stopped. Simultaneously, the bulkhead became jammed at the bottom. The load on the slipform was relaxed eliminating the skid end deflection. Normal purge was initiated and successfully completed.

Attempts made to move the slipform backwards proved futile. No slipform movement could be made in either direction. Approximately $1 \mathrm{hr}$ after the slipform jam, another attempt was made to push the form back using both the bulkhead and slipform cylinders. No movement occurred. It was postulated that the effects of both mechanical expansion due to heat of hydration and chemical expansion of the concrete might have caused the jam. A decision was made to wait until the following day for volume changes to occur before attempting another movement.

The following day no movement of either the bulkhead or the slipform could be obtained. A combination of unbolting the tunnel casing and unbolting the slipform tongue plates freed the bulkhead. The slipform was freed by disassembly from inside. 
A total of $60 \mathrm{in.}$ of concrete was placed inside the test tunnel. After withdrawing the slipform, the concrete was found to be completely consolidated and free from voids. Two small stone inclusions were found at the starting edge (these same stone inclusions were also found in almost every subsequent test). Each stone inclusion was approximately $1 \mathrm{ft}^{2}$ in area. The liner placed during test SI-4 is pictured in Figure 5-11.

5.2.2.4 Conclusions of Distribution Tests with VHEC Concrete The distribution tests with VHEC concrete were successful in demonstrating the primary objectives. It was shown that concrete having a slump of 7 to 8 in. could be distributed around the closed annulus from a single placing port at the top. It was demonstrated that an acceptable liner, free of voids, could be obtained using a backpressure of $30 \pm 10 \mathrm{psi}$ and intermittent vibration. It

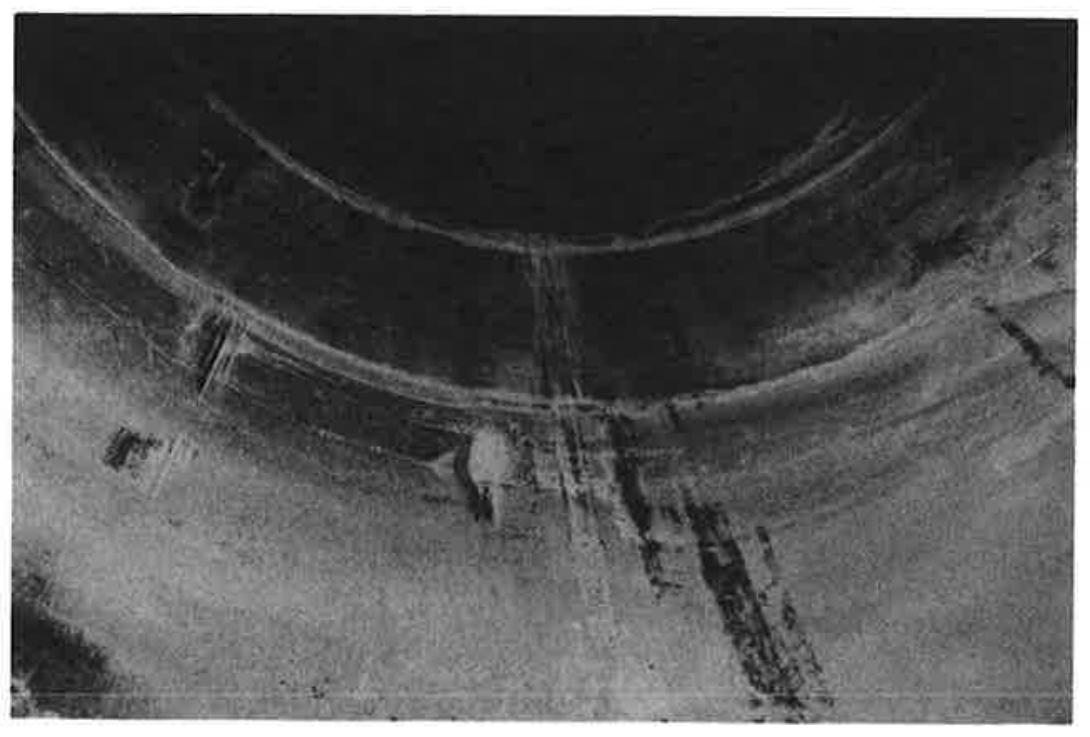

FIGURE 5-11. LINER CAST DURING TEST SI-4 
was also shown that the variation in concrete workability occurring during normal operation of the auger-mixer and admixture equipment could be accommodated in obtaining distribution. Figure 5-12 shows the variation in slump time history observed during tests SI- 3 and SI-4.

The distribution tests also demonstrated that the bulkhead control system was marginally capable of maintaining alignment within \pm 3 in. and backpressure within \pm 10 psi. Some difficulties were experienced in accomplishing these objectives. The problems with bulkhead control system are discussed in subsection 5.2 .4 .

The secondary objective of evaluating purge system performance was partially fulfilled. Five out of a total of 6 purge attempts were successful. Some problems with water blow-by and concrete intrusion back into the end of the pipe were experienced,

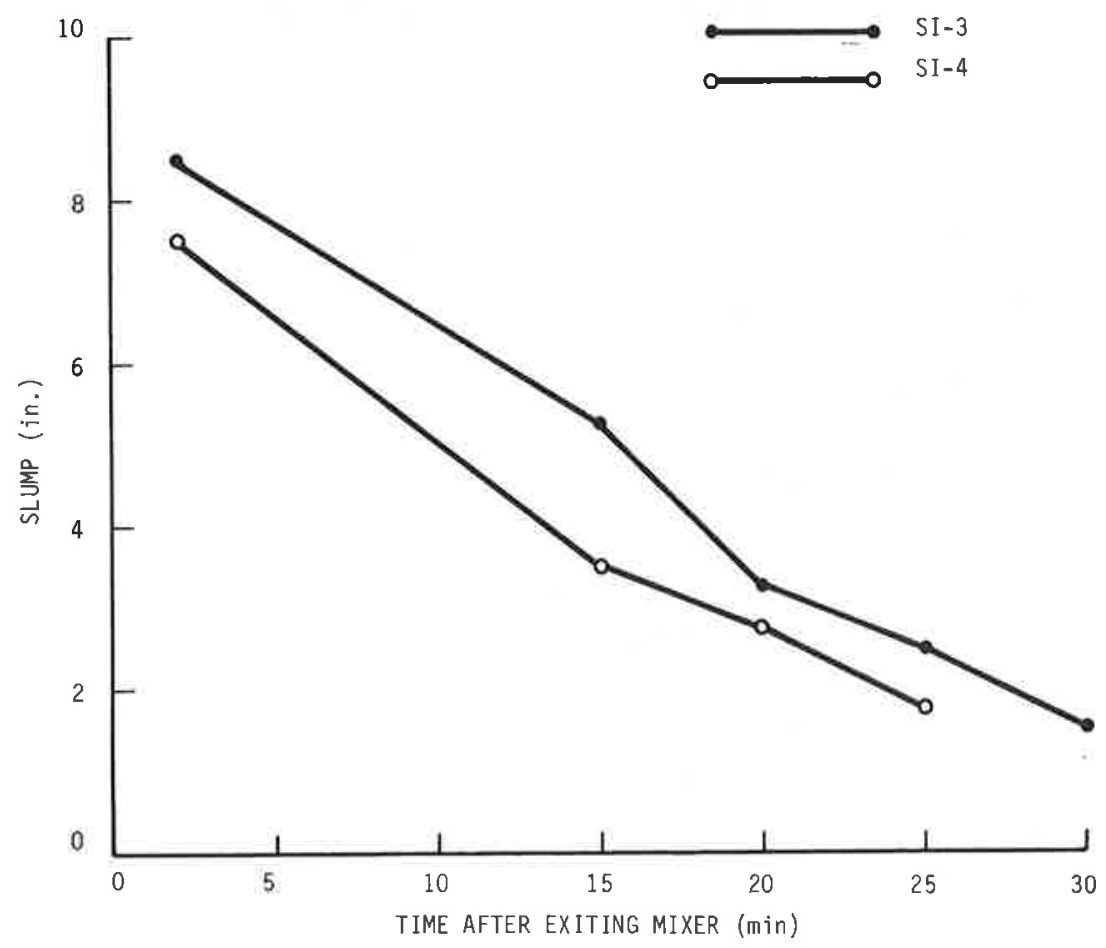

FIGURE 5-12. VARIATION IN SLUMP TIME HISTORY FOR TESTS SI-3 AND SI-4 
however, these were correctable. The long-term serviceability of the purge system could not be assessed based on the relatively few purges performed.

The quality of the cold joint was not assessed until the completion of the series I tests. This was done at the time of liner demolition (refer to subsection 5.2.4).

The results of test SI-4 raised serious questions about the ability to perform an actual slipforming test. Although test SI-4 was intended primarily as a distribution test, the test did incorporate some slipforming. As mentioned previously in the test description, only a few feet of slipforming was achieved before the drag exceeded the capacity of slipform hydraulic system. Prior to test SI-4, very little was understood about the relationship of slipform drag to the many independent variables. It was postulated that any of the following independent variables might significantly affect slipform drag and cause a jam similar to that which was observed:

1. Form stiffness

2. Form concentricity (from station to station along the form)

3. Form alignment

4. Thermal expansion (of forms and concrete)

5. Chemical expansion (of concrete)

6. Concrete pressure.

Before discussing the results of the series 2 slipform tests, it is useful to digress briefly to a discussion of these variables and their postulated effects on slipform drag. 
5.2.2.5 Analysis of System Force Balance - For the sake of simplicity, the slipform was considered as having three distinct regions along its length. These three regions are shown in Figure 5-13. Different arag relationships were expected to apply in each region. In region I the concrete was expected to behave as Bingham fluid, hence, the drag would be dependent on advance rate. The magnitude of this drag was expected to be very small because of the lubrication provided by the paste present at the form surface.

The concrete in region II was assumed to be in a plastic state. In other words, the slump was near zero but initial set had not yet occurred. In this region the drag was expected to be affected by pressure. The drag in this region was expected to have at least a component which could be represented by ary friction and was therefore expected to be dependent on normal force.

In region III, the concrete was assumed to have gained minimal compressive strength (10 to 100 psi). In this region, the drag would be primarily dependent on interference between the form and the concrete. This interference could be the result of form geometry and alignment or it could be due to thermal or chemical expansion of the concrete. Form stiffness was expected to play an important role in controlling drag in this region.

Obviously, three such distinct regions did not exist. However, it was felt that the three region model would adequately represent the continuum of concrete properties which did exist, from the 6 to 7 in. slump entering the form to the 500 to $1000 \mathrm{psi}$ strength leaving the form.

The drag in region III was expected to dominate the total slipform drag. Region II could not be neglected, however, because of the positive pressure drag loop which could occur in this region. Figure 5-14 illustrates this loop. It can be seen from the figure, that the total pressure applied by the bulkhead 


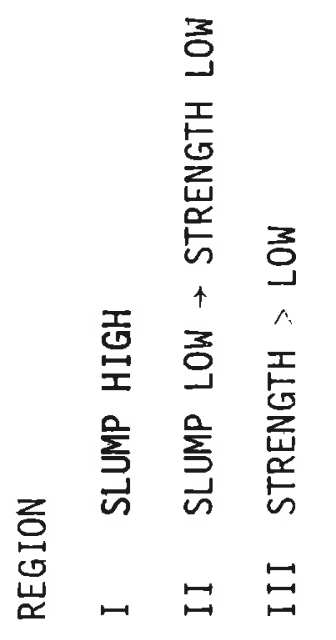

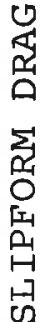

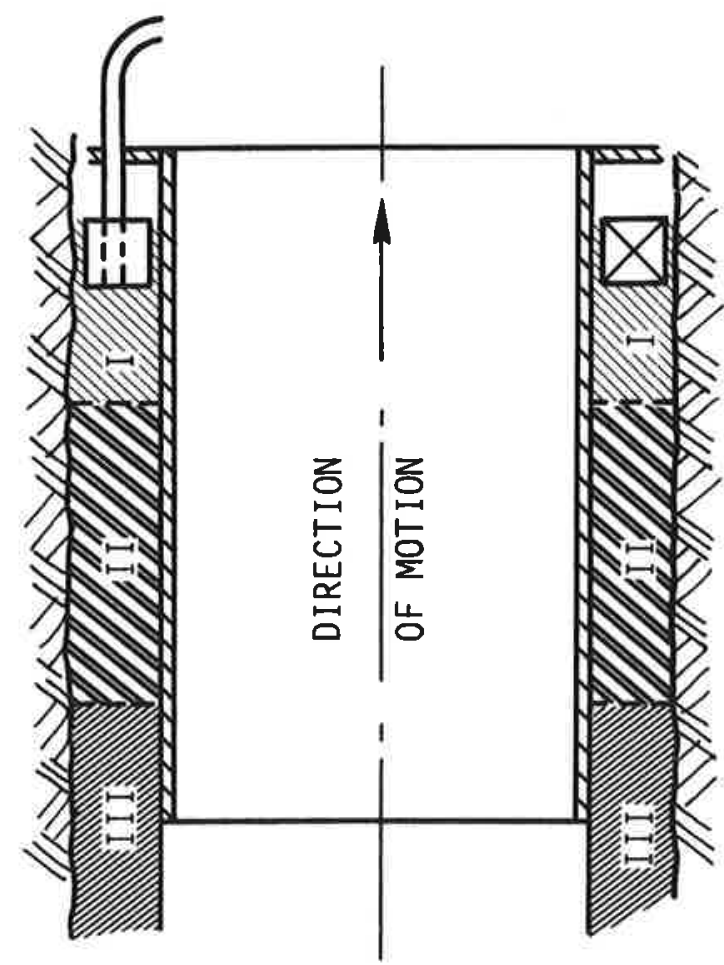

떵

星

m.

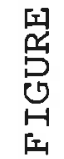




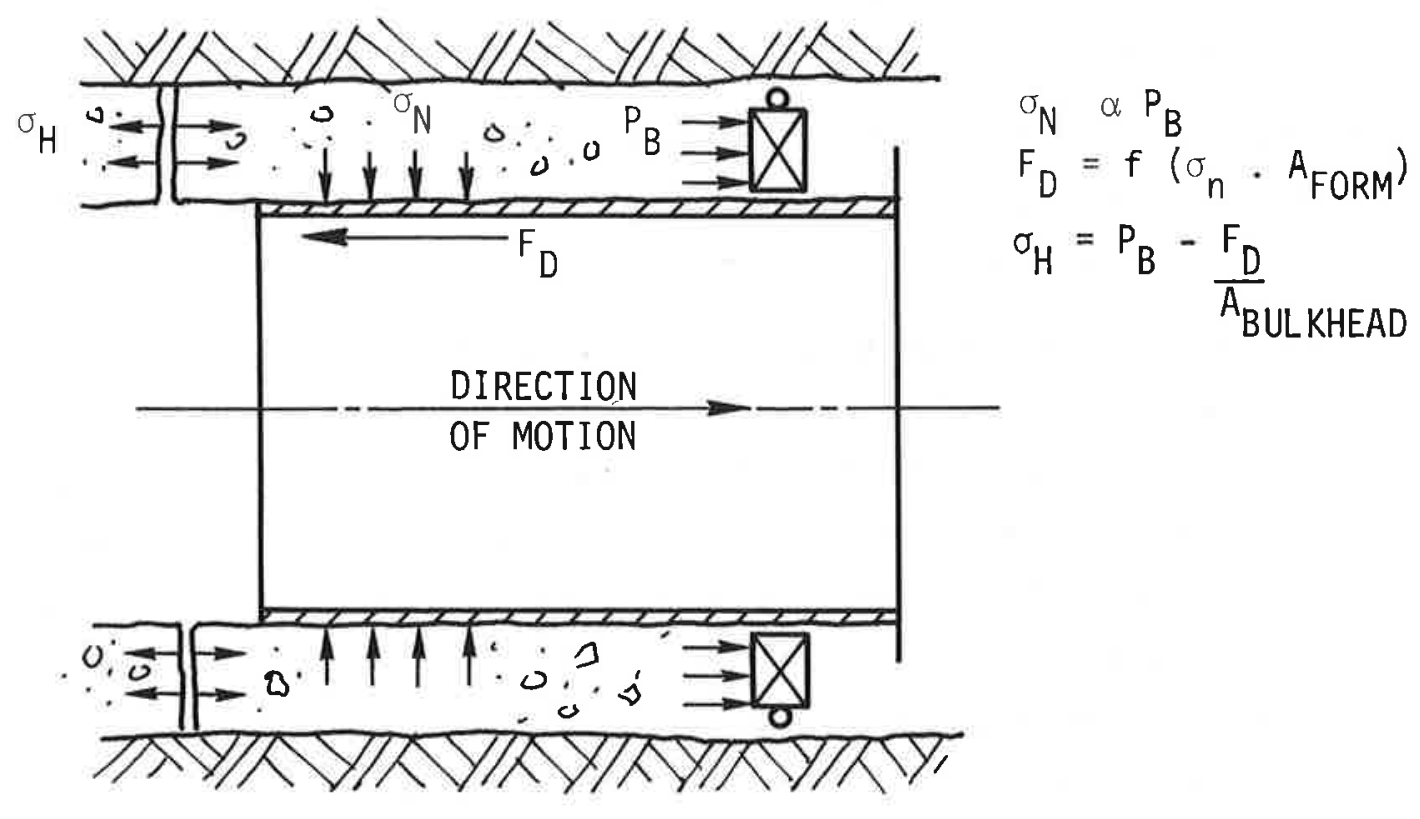

FIGURE 5-14. SLIPFORM PRESSURE-DRAG LOOP

must be equal to or greater than the total form drag in order to prevent tension cracks from forming at the trailing edge of the slipform (the shear bond formation at the outer wall was neglected). If the drag in region II was significant, and largely dependent on normal force, then a condition would exist where increasing the pressure to control cracking would also increase the drag. This could require the use of unacceptably high pressures to prevent cracking.

Based on the results of test SI-4, it appeared probable that the drag which caused lock-up was due to region III. This was deduced primarily from the fact that the slipform drag did not appear to rise at all linearly with the length of the placed concrete, up to the point at which lock-up occurred. Rather, it appeared to rise abruptly over a period of only $10 \mathrm{~min}$. prior to 
lock-up. Such a condition could only be due to region III. Within region III, several different jamming modes were postulated. These are shown in Figure 5-15.

It was considered to be unlikely that the observed lock-up was due to shape jamming, again because the form drag was initially quite low and then rose rapidly.

Jamming on the bulkhead or jamming in the tunnel could not be ruled out based on the available information. Jamming on the bulkhead seemed highly probakle since the bulkhead and slipform were observed to jam at approximately the same time. Thermal expansion of the forms and the concrete was considered to be the most likely cause at the time that the lock-up occurred. No temperature instrumentation was installed during test SI-4; however, the interior of the form was perceptibly hot to the touch. The following day, however, when the form still could not be moved, it seemed improbable that the lock-up was solely due to thermal expansion. When the form was finally removed, some keying of the form to the concrete was found to exist. This keying occurred at the tongue-plate bolt holes. Total shear area of the keys was calculated to be about $30 \mathrm{in.}$, which was not sufficient to cause the lock-up to persist after the concrete had cooled. It was concluded that further testing was necessary to establish the cause of the lock-up.

\subsubsection{Slipform Tests}

5.2.3.1 Slipform Test objectives - the primary objectives of the Series I slipform tests were to:

1. Demonstrate self-support of the full round liner when exposed at an age of 1 to $1-1 / 2 \mathrm{hr}$

2. Demonstrate controlled movement of the slipform and evaluate the significant factors influencing form drag 

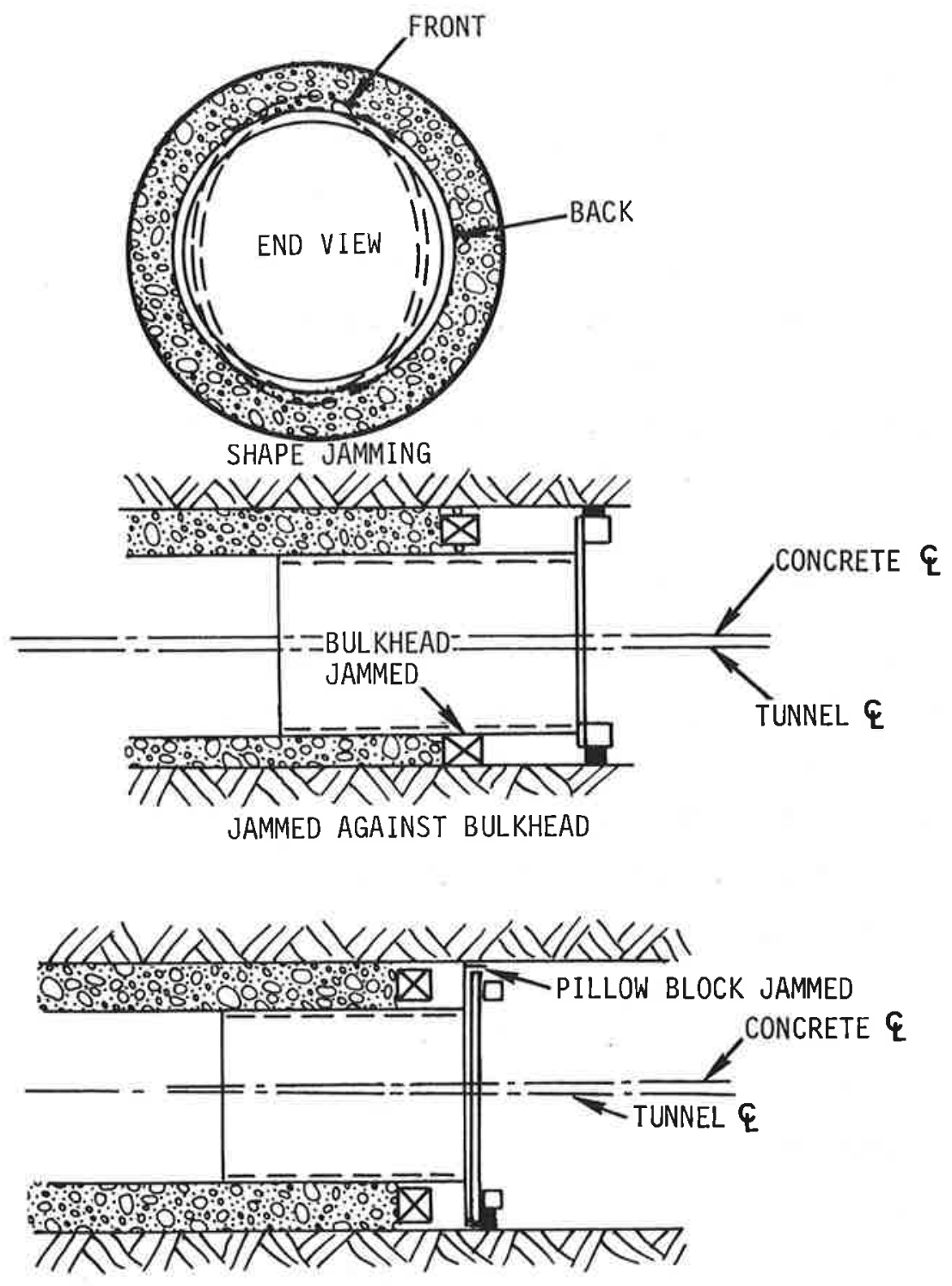

JAMMED AGAINST TUNNEL WALL

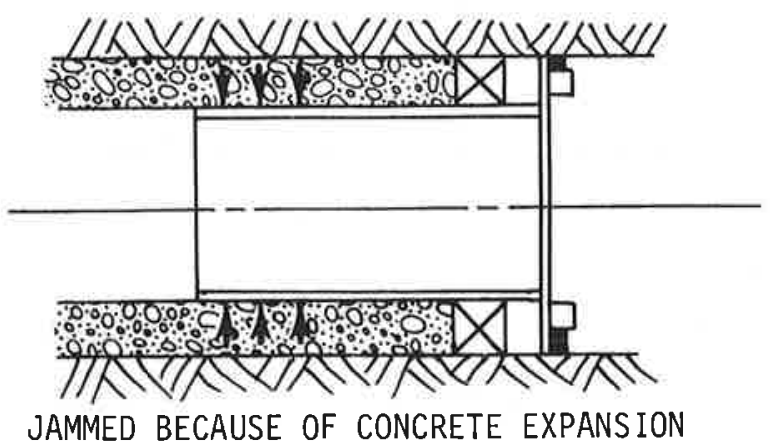

FIGURE 5-15. SLIPFORM JAMMING MODES 
3. Demonstrate that a backpressure of $30 \pm 10 \mathrm{psi}$ is adequate to balance form drag and prevent the formation of cracks at the trailing edge.

All Series I slipforming tests were conducted at the $2.6 \mathrm{yd}^{3} / \mathrm{hr}$. To permit the relationship between form alignment and form drag to be investigated, cross-hairs were constructed at each end of the slipform and at each end of the test tunnel. These were sighted using an engineer's level.

\subsubsection{Description of Tests}

a. Test SI-5. Test SI-5 was conducted at an advance rate of $4 \mathrm{ft} / \mathrm{hr}$. Due to constraints imposed by the position of the tunnel casing seam relative to the bulkhead, an initial 15-in. gap between the old concrete and the bulkhead was required. Therefore, the first $22 \mathrm{~min}$ of the test elapsed with the bulkhead fixed in place. At this point in the test, the bulkhead was allowed to move under pressure control. The slipform was set in motion $24 \mathrm{~min}$ into the test and was programmed to advance so as to expose concrete approximately $60 \mathrm{~min}$ after initial placement.

Both pumping/distribution and slipforming were performed simultaneously. Slipform drag averaged 28,000 lb throughout the slipping sequence. During the test, slipform alignment, shape, and attitude were carefully monitored. Corrections to slipform alignment were made by adjusting the pillow blocks.

Vibration was started $5 \mathrm{~min}$ into the test with $10 \mathrm{sec}$ of vibration per $60 \mathrm{sec}$ period. No variation in vibration duration or frequency was made. Concrete was pumped continuously for 64 min without difficulty.

The first concrete exposed was about $65 \mathrm{~min}$ old. By increasing the slipform rate, concrete at the end of the sequence was 
exposed at about $55 \mathrm{~min}$ of age. Upon inspection, all exposed concrete was warm and of adequate strength except for a small amount of overly retarded grout (used to slicken the pumplines) which was located in the invert. Total length of the liner cast was 51 in.

Some surface cracking and honeycombing was seen upon exposure. The honeycombing may have been the result of filling the 15-in. gap at a $4 \mathrm{ft} / \mathrm{hr}$ advance rate. The surface cracking appeared to be tension cracks. It is possible that localized drag forces may have exceeded the average pressure exerted by the bulkhead.

The purge sequence for both the slickline and flexible lines was normal except that a small blockage formed in one flexible line and required line disassembly.

b. Test SI-6. The initial gap between the bulkhead and the previously cast liner was set at about $10 \mathrm{in.} \mathrm{Concrete}$ was pumped continuously for $78 \mathrm{~min}$ under a nominal backpressure of 35 to 45 psi. Vibration was started 2 min into the test. Vibration was applied for $10 \mathrm{sec}$ in a $30 \mathrm{sec}$ period. The slipform advance rate was adjusted to expose concrete at an age of $60 \mathrm{~min}$.

During the test, continuous visual observation of the slipform shape and alignment was performed using an engineer's level. Corrections to alignment were made with the pillow blocks until the leading edge of the form exited the end of the test tunnel. Beyond this point, alignment corrections were made by applying a force couple with the slipform jacks. Form shape was maintained using a come-along attached to the x-axis of the slipform.

At the time the concrete was initially exposed, about $60 \mathrm{~min}$ after the start, the slipform advanced in a stick-slip mode. The amplitude of the stick-slip was small. The exposed crown of the 
newly cast lining was poorly consolidated as evidenced by a void about 12-in. long, $\times$ 4-in. wide $\times 3$-in. deep. Aggregate, which had segregated from the mix and surrounded the void, became dislodged and fell onto the invert as the slipform advanced. Slipforming was not stopped. Beyond this single crown void the concrete was well-consolidated without irregularity. As more of the lining became exposed, it was observed that part of the bulkhead outer seal had become dislodged from its seating and was cast in the concrete. A strip of seal about 12-in. long could be seen in the concrete just ahead of the crown void.

Drag forces during the sequence were low and no misalignment or irregular form shape was observed. The stick-slip condition continued for the first 12 in. of concrete exposed.

Slipforming advance rate was gradually increased until the concrete was exposed at $43 \mathrm{~min}$ of age. At this point, it was evident, due to the observed soft condition of the exposed concrete, that the slipform was beginning to outrun the concrete strength development. The slipform was stopped until the concrete was $55 \mathrm{~min}$ old. Slipforming was resumed at that time and continued until the bulkhead was exposed. The slipform trailing edge was moved onto the bulkhead exposing the bulkhead concrete interface. Figure 5-16 shows the liner case during tests SI-5 and SI-6.

5.2.3.3 Conclusions of Series I Slipform Tests - The Series I slipform tests were successful in demonstrating self-support of the concrete at early ages. Concrete was exposed as early as 45 min after mixing and was able to support itself without any sagging or sloughing from the crown of the test tunnel. 

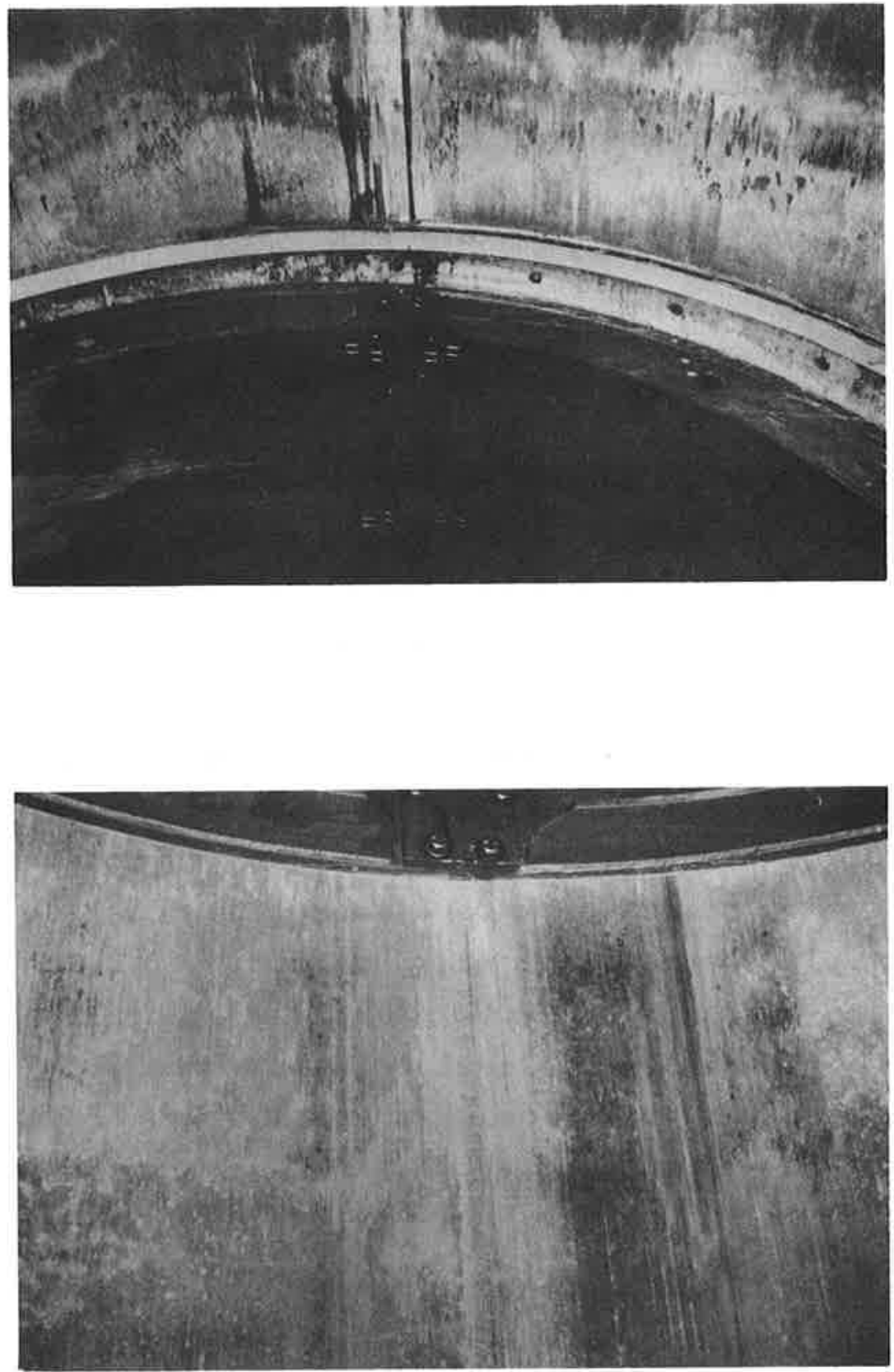

FIGURE 5-16. LINER CAST DURING TESTS SI-5 AND SI-6 
The tests also demonstrated that a backpressure of 30 to 40 psi was adequate, in most cases, to prevent cracking. Some tension cracking was observed in the invert during test SI-6. This cracking correlated with visual observation of form alignment. At the time the cracking occurred, the form was observed to be oriented with the tail down, causing a higher drag at the bottom.

The tests also revealed some additional information concerning the relationships affecting form drag. The information was not entirely conclusive since a second lock-up did not occur.

With respect to alignment, a sudden increase in drag was observed to occur each time that an alignment change was made using the pillow blocks. The drag forces, however, never approached those which were observed during test SI-3.

There was evidence to suggest that a drag dependence on temperature did exist. This could not be supported with actual data since no temperature instrumentation was installed on the form during the series I tests. The conclusion was based primarily on visual observation of the surface of the concrete. Figure 5-17 shows a close-up of the surface of the liner cast during test SI-6. Multiple longitudinal markings can be seen on the surface. These markings were actually in areas where localized interference had caused a thin layer of steel to be scraped from the form surface. These markings were observed to be uniformly distributed around the circumference of the greater portion of the liner cast during test SI-6.

These markings did not occur, however, in the portion of the liner which was exposed at an age of 45 to $50 \mathrm{~min}$. The appearance of the concrete when exposed at 55 min was noticeably different than at $45 \mathrm{~min}$. At $55 \mathrm{~min}$, the concrete was hot to the 


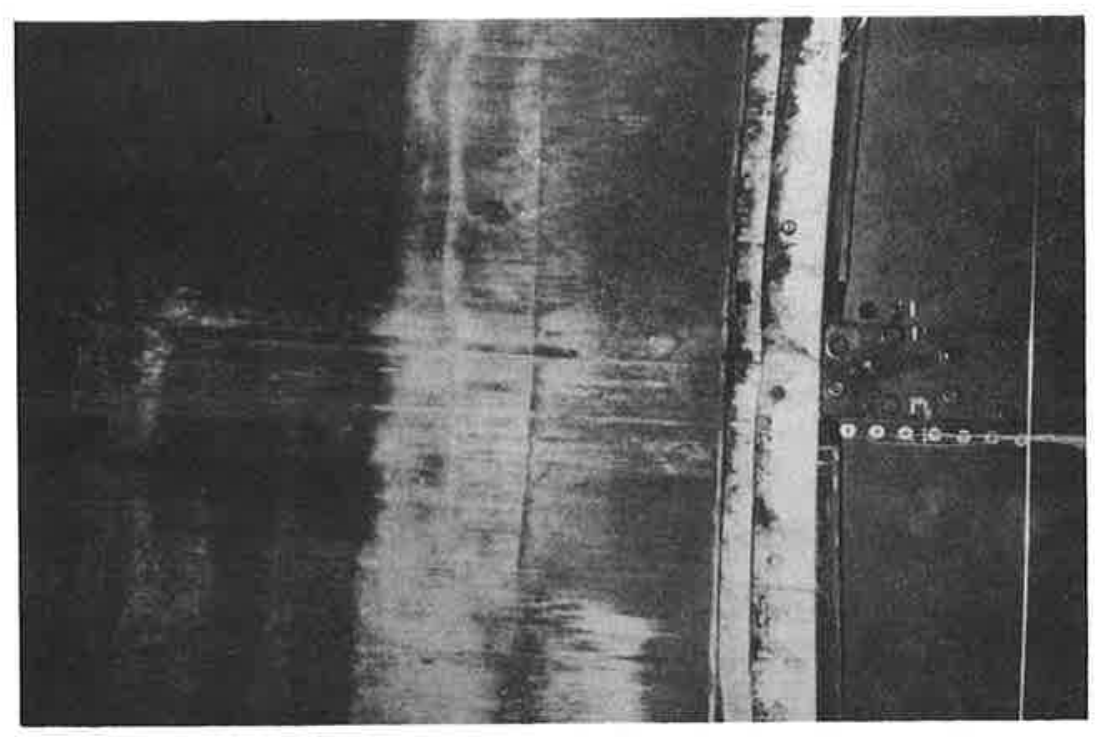

\section{FIGURE 5-17. CLOSE-UP OF LINER CAST DURING TEST SI-6}

touch, the surface appeared to be dry, and the concrete was whitish in color. At $45 \mathrm{~min}$, the concrete was warm, the surface was slightly damp and the color was perceptibly darker. All of this suggested that if the concrete was exposed before it had a chance to become hot, the high drag forces would not occur.

\subsubsection{Conclusions of the Series I Test Program}

The Series I test program demonstrated both the distribution of the concrete within the closed form, and the self-support of the liner upon leaving the form. The series I test program identified several problem areas in need of further investigation. The major problems identified were:

1. Contamination of prebatched aggregates

2. Performance of the bulkhead pressure and alignment control system 
3. High slipform drag due to alignment problems and/or thermal expansion.

5.2.4.1 Contamination of Prebatched Aggregates - portland cement contamination of the prebatched aggregates was found to be a problem during the initial auger-mixer tests. The contamination caused rapid slump loss and delayed strength gain. The problem appeared to be alleviated by allowing the aggregates to stand overnight which allowed any cement residue to hydrate and become less reactive.

Portland cement contamination was assumed to be introduced in the transit mixers used to transport the prebatched aggregates to the Foster-Miller test facility. This source of contamination was not expected to be a problem in the field because the cars used to transport the prebatch to the heading would be used on only one job and would, therefore, not have the opportunity to become contaminated with portland cement. The contamination might, however, pose a problem to the remainder of the test program. Identification of the actual contaminant and devising some means to eliminate it was, therefore, considered to be desirable.

5.2.4.2 Performance of Bulkhead Control system - Although the bulkhead control system functioned well enough for the Series I tests to be completed, its operation in controlling backpressure and alignment required improvement. The servo valves used to control alignment did not have a large enough pressure range to overcome circumferential variations in bulkhead drag and maintain alignment. Frequent manual adjustments were required to pressure and flow controls in order to maintain alignment and backpressure control within the desired limits. The problem was aggravated by the fact that the test tunnel was manufactured with an ID 1-in. below specifications. This caused the bulkhead to hang up as it passed by each rib in the test tunnel. 
Modifications were required to improve the performance of the bulkhead control system. These modifications are described in subsection 5.3 .1 .

5.2.4.3 High Slipform Drag due to Alignment Problems and/or Thermal Expansion - Based on the results of the Series I tests, major modifications were required to the slipform. The 1-in. thick slipform with fixed pillow blocks appeared to cause high drag forces and was difficult to steer.

During tests SI-5 and SI-6 the drag forces were reduced somewhat by keeping the inserted length of the form as short as possible and staying ahead of the temperature rise. This approach would not be viable in a real tunnel. At higher advance rates, more form insertion would be required. Upon leaving the form, the liner would have to support rock loads in addition to its own weight. For this reason, the liner would have to remain in the form for a longer period and the temperature rise would occur while the liner was still within the form. Based on test results, the tail of the form would have to be made more flexible, so that it could accommodate the thermal expansion but continue to support the concrete.

Flexibility also was considered to be desirable to facilitate steering of the form. This is illustrated in Figure 5-15. It can be seen from the figure that if the form is stiff in bending and the tail of the form is inserted in set concrete, then the form is constrained to follow the centerline of the set concrete. If this centerline diverges from the actual tunnel centerline, then the form will become jammed between the concrete and the tunnel wall, after travelling a few form lengths from the position shown. The stiffer the form, the higher the forces required at the pillow blocks to steer it, and the higher the 
drag forces generated in region III (as defined in Figure 5-13). This was consistent with the series I test results.

It was also apparent that the pillow block design used during Phase I was not adequate. The design of the pillow blocks needed to be modified so that they would apply a constant force but could move in and out with respect to the form centerline to permit them to pass over discontinuities in the tunnel wall. In other words, the pillow blocks needed to behave as though they were spring mounted. The force applied by the pillow blocks also needed to be variable to permit steering.

It was also decided that some sort of temperature instrumentation should be installed near the trailing edge of the slipform. This would permit the drag versus temperature relationship to be investigated in detail. The modifications made to the slipform are described in subsection 5.3.1.

5.2.4.4 Liner Cold Joint - when the liner was demolished, it was found that very little bonding existed at the cold joint. It was concluded that for the ETLS concept to be attractive, a simple and straightforward means of installing a water-stop across the cold joint would have to be devised. 


\subsection{SERIES II TUNNEL TESTS}

During the summer of 1981, the extruded tunnel lining system was modified. The modifications were designed based on the Series I test results. A second program of tests (Series II tests) was defined to test out the modifications. These tests were carried out during the Fall of 1981. The ETLS modifications and the results of the series II tests are described in the following sections.

\subsubsection{Modifications to the ETLS}

Modifications were made to the slipform, the bulkhead control system and the test tunnel.

5.3.1.1 Slipform Modifications - Three different modifications were made to the slipform. These modifications are shown in Figure 5-18.

Small enerpac ${ }^{\circledR}$ hydraulic cylinders were installed on the pillow blocks. These were connected to air accumulators. A schematic of the accumulator hydraulic system is shown in Figure 5-19. Each pair of pillow blocks was connected to a separate accumulator. Separate pressure controls were provided for each accumulator. This system would permit steering of the form using the pillow blocks. The accumulators would provide the spring loading that was determined to be required from the Series I test results.

Tie rods were installed on both the horizontal and vertical axes at the front of the form. These were to insure that the form did not deform to an oval shape under the loads applied by the pillow blocks.

The tongue plates were removed from the trailing 3 ft of the horizontal joints between the upper and lower halves of the 


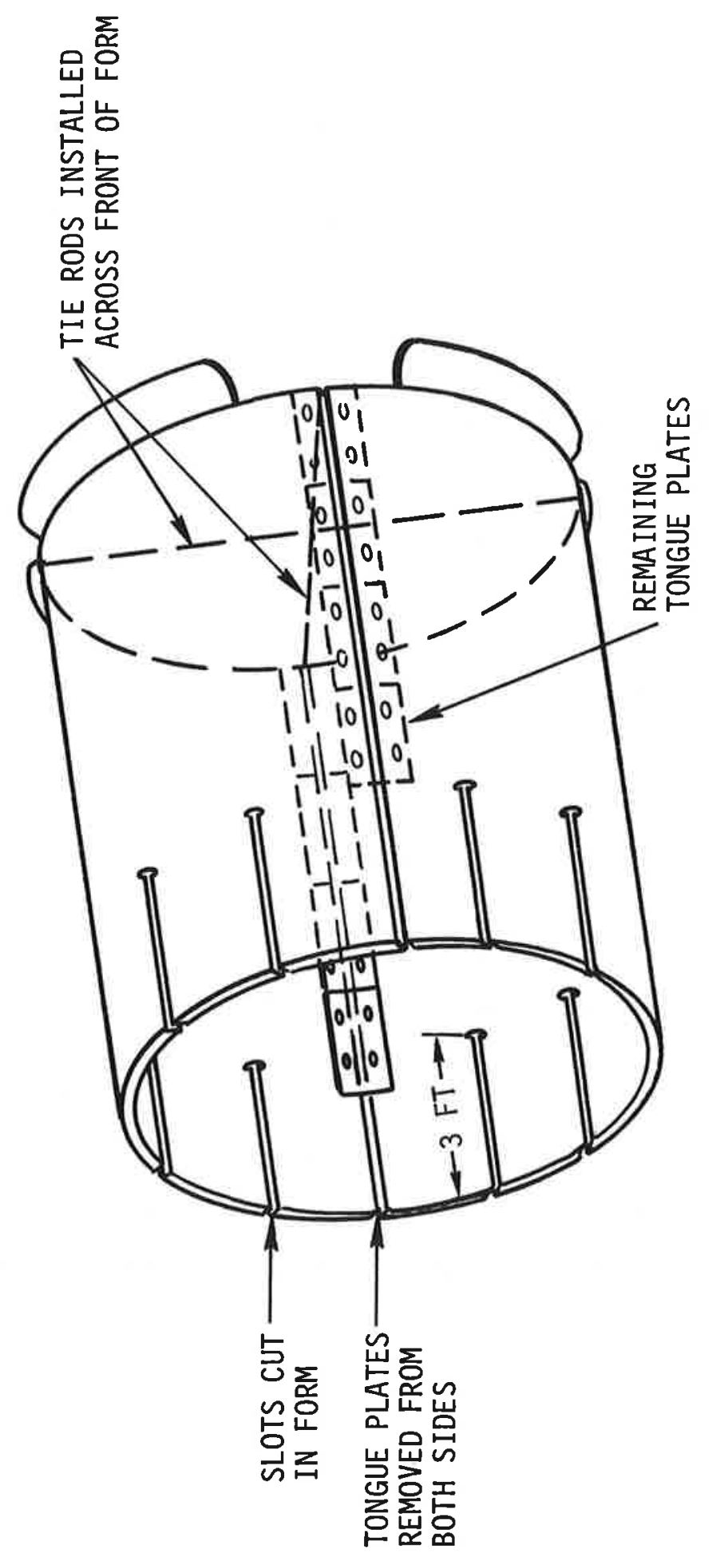

OD 


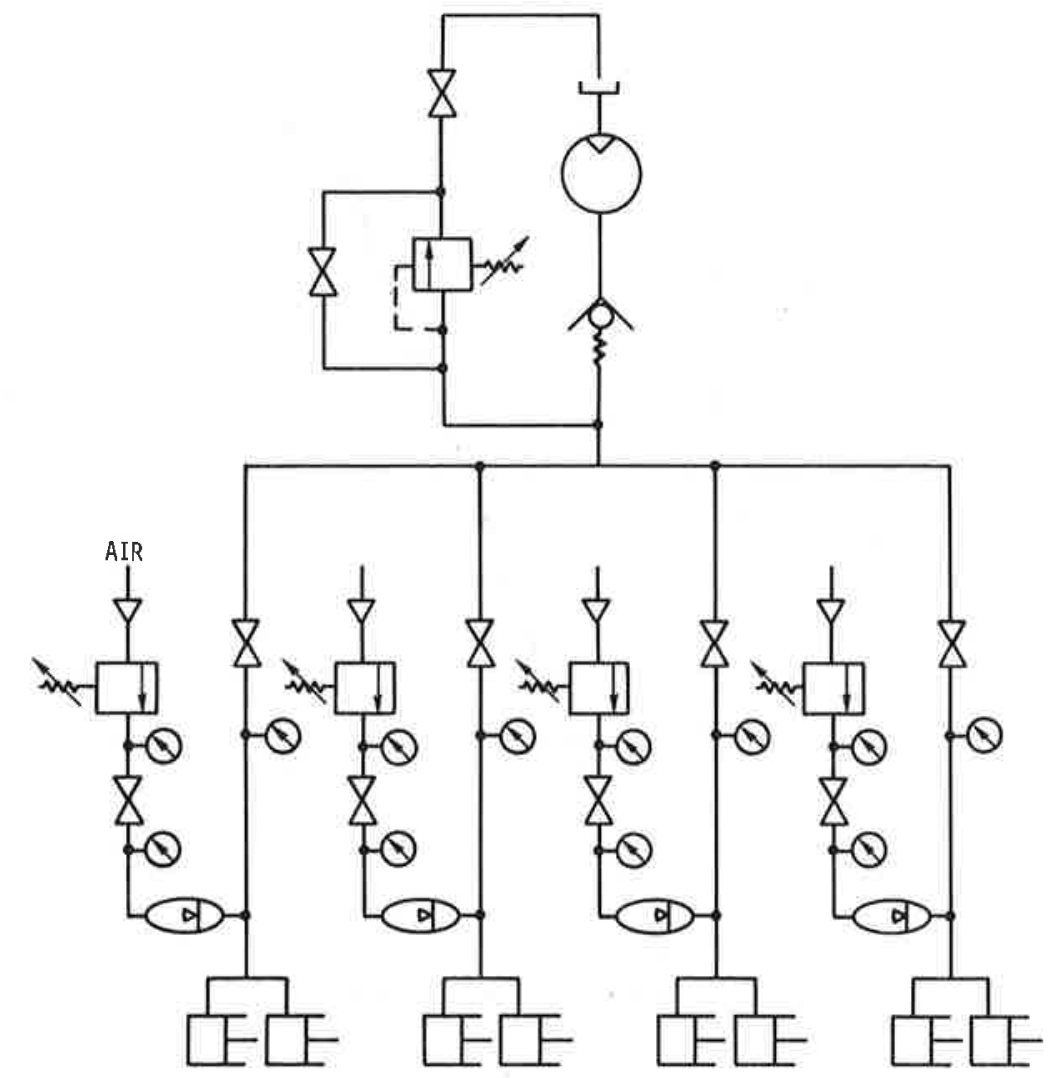

FIGURE 5-19. HYDRAULIC SYSTEM FOR SLIPFORM PILLOW BLOCKS

slipform. Eight equally spaced longitudinal cuts were made in the tail of the form. The cuts extended in a distance of 3 ft from the end of the form. The combination of the cuts together with removal of the tongue plates resulted in 12 flexible leaves created in the rear of the form. The calculated force-deflection characteristic of the leaves is shown in Figure 5-20. These leaves would provide the flexibility determined to be required during the Series I tests.

This manner of introducing flexibility was felt to be less than ideal because of the tendency of the rear of the form to become oval under bending loads. This would cause the leaves to separate from the concrete at the inside of a curve. However, this method was the only one that could be readily implemented on the existing slipform. 


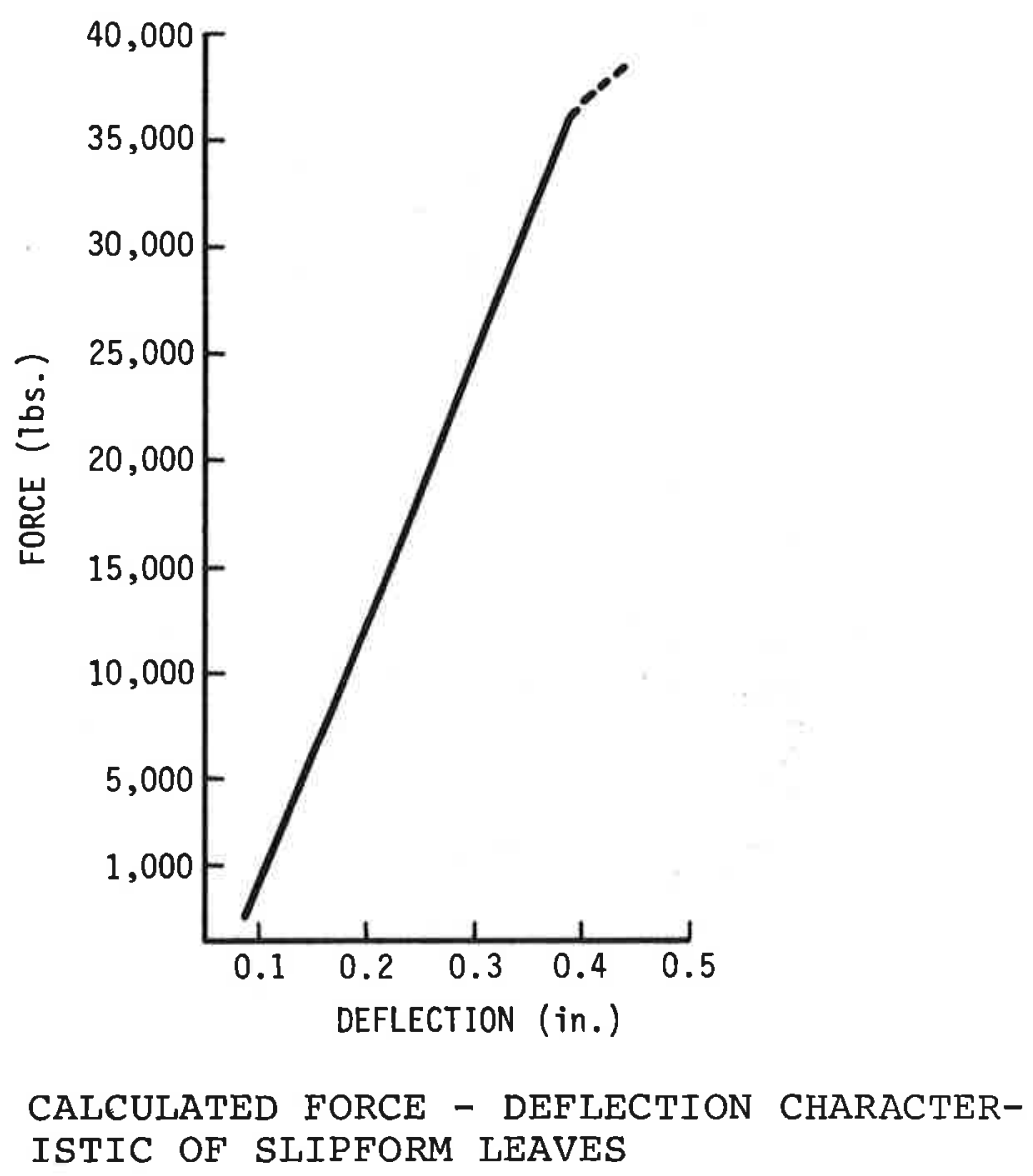

A row of holes was drilled in the crown of the slipform. The hole spacing is shown in Figure 5-21. Ten thermistors having a 30 to $120^{\circ} \mathrm{F}$ temperature range were installed in the holes. The hole spacing was designed to permit three different thermistor arrangements to be used, depending on advance rate (see Figure 5-21). The thermistors were connected to the HP-9825 via the multiprogrammer. The thermistor outputs were stored on magnetic tape at 2 min intervals.

5.3.1.2 Bulkhead Modifications - Modifications to the bulkhead hydraulic system involved installation of servo actuators on the valves FC-B-1 and FC-B-2 (see Figure 4-12). These servo actuators were of the torque motor type. Since these valves 


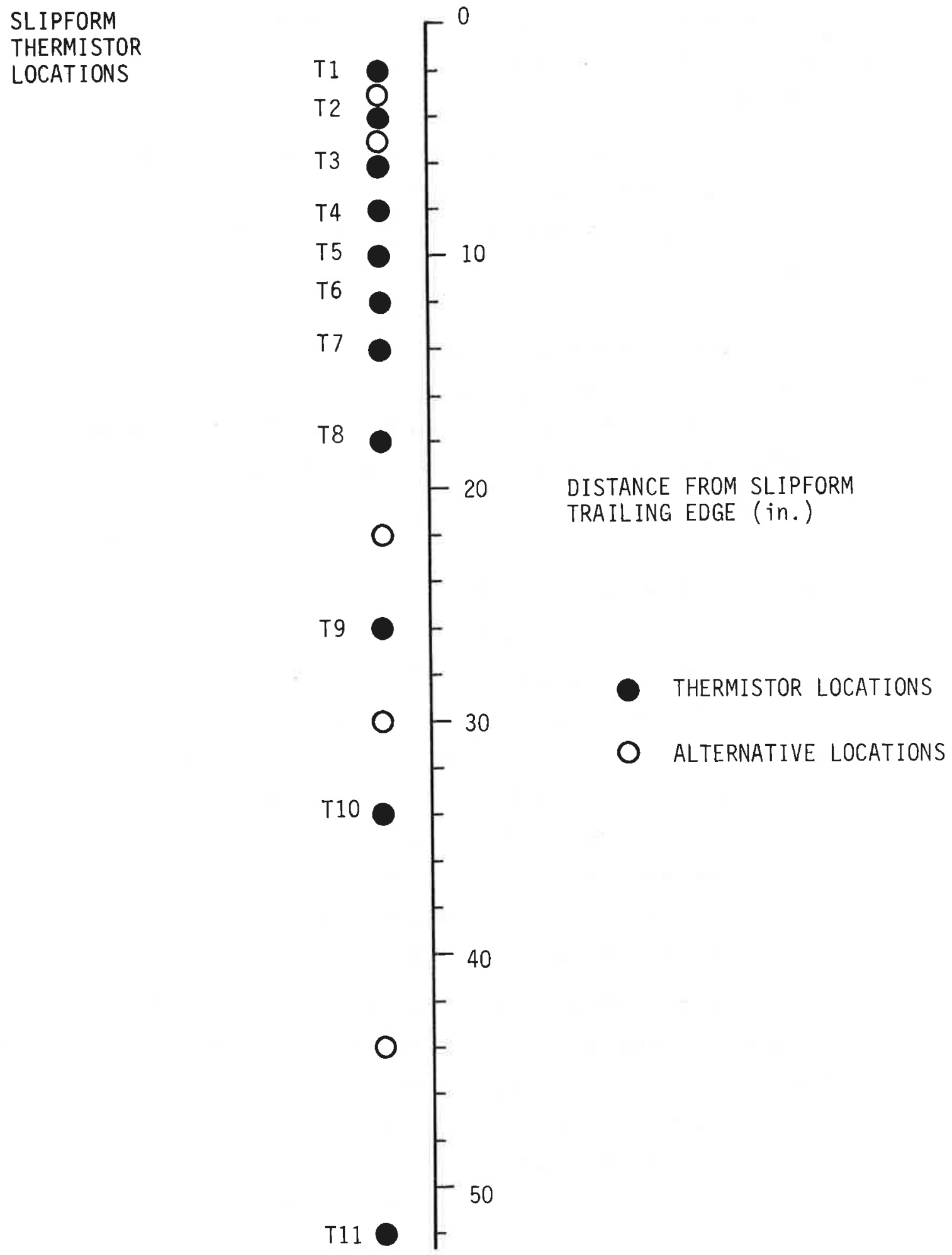

FIGURE 5-21. SLIPFORM THERMISTOR HOIE SPACING 
were pressure compensated they provided guaranteed flow control of cylinders B-3 and B-4. The original servo valves were removed from the system.

The torque motor operators had a much slower response than the original servo valves. Stability calculations indicated that rapid response was not necessary for proper alignment control.

5.3.1.3 Test Tunnel Modifications - Shims having a thickness of $1 / 2$ in. were installed along the full length of the horizontal joint in both sides of the test tunnel. This was expected to help correct the problem of bulkhead jamming observed during the series I tests.

\section{3 .2 Slipform Tests at $6 \mathrm{ft} / \mathrm{hr}$}

A second series of slipforming tests was planned to test out the modifications described in subsection 5.3.1. These tests were carried out at a higher advance rate. The higher advance rate required a longer length of form to be used and was a more severe test of the modifications designed to control form drag. The new advance rate also provided additional information on the auger-mixer. The variability in outputs of the individual augers and the consequent variation in mix performance were assessed at the new rate.

A new shipment of VHEC was obtained for the tests. Augermixer and admix equipment were recalibrated for the new advance rate. Before conducting an actual tunnel test at the $6 \mathrm{ft} / \mathrm{hr}$ $\left(3.8 \mathrm{yd}^{3} / \mathrm{hr}\right)$ rate, auger-mixer tests were carried out to verify that concrete could be produced at the new rate, with the required workability and rate of strength gain. 
5.3.2.1 Auger-Mixer Tests - The auger-mixer tests were conducted during hot summer weather. The concrete produced in the first two tests showed rapid slump loss and accelerated strength gain. In an attempt to implement a quick solution to the rapid slump loss problem, the retarder content was increased. Additional augermixer tests were subsequently conducted. Citric acid (retarder) content was increased first to 125 percent of design, then to 150 percent, and finally to 200 percent in an effort to obtain the desired slump history at ambient temperatures between 80 and $85^{\circ} \mathrm{F}$. Concrete formulated with 200 percent of the design retarder content exhibited more acceptable slump loss behavior but also showed increased sensitivity to water content. This produced a wide variation in initial slump from small changes in total water content.

5.3.2.2 Tunnel Tests SII-1 and SII-2 - Using the modified mix design, a $6 \mathrm{ft} / \mathrm{hr}$ tunnel test (test SII-1) was attempted. This test was plagued by a succession of problems with the concrete. The concrete had low initial slump (6 to 7 in.) and rapid slump loss. It was difficult to pump and a number of placing line blockages occurred. During the test, only 7 in. of concrete liner was placed in the test tunnel.

Following test SII-1 the pump roller clearances were adjusted and the pump was checked for proper operation. Another test (test SII-2) was attempted. Retarder content was increased to 225 percent for the test. Once again the concrete was difficult to pump. Line pressures were consistantly high. Several blockages occurred and the test was aborted after placing only 8 in. of concrete inside the test tunnel.

5.3.2.3 Conclusion of Initial $6 \mathrm{ft} / \mathrm{hr}$ Slipform Tests - At this point it was apparent that adding massive amounts of retarder to combat slump loss was not a good solution and only served to complicate the situation. Major problems existed with the concrete that were not presented during the spring tests. A number of possible causes were postulated. These included: 
1. Temperature: High raw material temperatures due to summer ambient conditions had caused higher mix temperatures than in the spring $\left(78\right.$ to $80^{\circ} \mathrm{F}$ as opposed to 68 to $\left.70^{\circ} \mathrm{F}\right)$. In this temperature range it may not be possible to produce a rapid-setting concrete with predictable and consistent behavior.

2. Cement: A different shipment of cement was being used than in the spring tests. Although from the same original burn, its storage history may have been different. It may have been exposed to moisture.

3. Auger-mixer: It was possible that the auger-mixer operated differently at the new rate. Perhaps the augers went off calibration during the test, or the dynamics of the mixing process was different.

4. Prebatch: Prebatch contamination was suspected during the Series I tests. A method had been devised to deal with this problem, but perhaps the levels of contamination were higher or for some reason the mix had become more sensitive.

A program of laboratory tests was conceived, to be followedup by a series of auger-mixer tests. The tests were specifically designed to determine the cause of the problems with the mix. The laboratory and auger-mixer tests are described below.

\subsubsection{Laboratory Testing of Concrete}

Thirty-nine laboratory batches were made during october to November 1981. The purpose of the laboratory tests was to determine the cause of the rapid slump loss of the concrete. Tests were conducted to study the change in behavior with the following variables: 
1. Cement age

2. Prebatch type

3. Water-cement ratio

4. Mix temperature.

5.3.3.1 Concrete Behavioral Requirements - In order to measure the relative behavior of various concrete batches, mixes were tested for slump loss and strength gain. A set of guidelines were used for determining acceptable mixes.

Mixes were expected to meet the following minimum slump values at the times indicated in Table 5-11.

\section{TABLE 5-11. MINIMUM SLUMP VALUES AT THE TIMES INDICATED}

\begin{tabular}{|c|c|}
\hline $\begin{array}{c}\text { AGE } \\
(\min )\end{array}$ & $\begin{array}{c}\text { SIUMP } \\
\text { (in.) }\end{array}$ \\
\hline Initial slump & 7 \\
10 & $5-1 / 2$ \\
15 & 4 \\
20 & 3 \\
25 & 2 \\
30 & $1 / 2$ \\
\hline
\end{tabular}


In addition to slump requirements, the concrete had to gain strength at the following rates to ensure structural integrity upon extrusion.

Time After Mixing
$($ hr)

1

$1-1 / 2$

2
Minimum Compressive Strength (psi)

10

800

1500

Mixes that did not exhibit these slump and strength characteristics were not considered acceptable for use.

\subsubsection{Test Results}

a. Influence of Cement Age - Tests were conducted to determine whether the cement received in March 1981 was the cause of the fast-setting problem. A fresh supply of the same lot of cement was received in mid-october. Test results indicated that there was no discernible difference between the new and old cement. Acceptable results were obtained with both cements using the original mix design.

b. Influence of Prebatch Type - Tests were conducted with prebatch made in the laboratory and prebatch received by transit truck. Prebatch made in the laboratory was mixed in the tumble mixer. Two truck-delivered prebatches were used. Initially, prebatch was delivered by trucks that were rinsed with water once before loading. In later testing, trucks were cleaned more thoroughly before loading. 
In the first tests (using prebatch from trucks only rinsed once), all of the mixes exhibited either low initial slump or rapid slump loss. Prebatch age varied from 3 hr to 7 days. All tests were conducted at 100 percent design citric acid with water-cement ratios between 0.40 and 0.52 . None of the concretes met the minimum slump guideline, and only one mix met the strength guideline.

In contrast, concrete mixed from laboratory-made prebatch repeatedly met both slump and strength specifications. No unusual behavior was observed for these mixes.

The results indicated that truck-delivered prebatch was contaminated. Tests were conducted using laboratory-mixed prebatch purposely contaminated with 1 percent portland cement. The mixes showed no abnormal behavior when the prebatch was used immediately; however, concretes made with the same prebatch both $1 \mathrm{hr}$ and $27 \mathrm{hr}$ later exhibited very fast setting behavior. It was concluded that portland cement contamination was most likely the cause of the concrete problems.

In order to reduce the likelihood of contamination in subsequent truck-delivered prebatches, a thorough truck cleaning process was initiated. Trucks were rinsed out and charged with sand and stone. The mixture was tumbled for 15 minutes and discharged. This was followed by a second rinsing. All concrete made with prebatch delivered by these specially-cleaned trucks exhibited normal slump and strength behavior.

c. Influence of Water-Cement Ratio - Generally, increases in water-cement ratio increased workability for noncontaminated mixes. Slight changes in water-cement ratio were required to increase initial slump when aggregate gradation changed or a different fly ash was used. For large increases in watercement ratio, workability was increased; however, early 
strength was reduced. In addition, some prebatches, which were delivered by trucks that were only partially cleaned, made acceptable concretes when water-cement ratio was increased.

d. Influence of Mix Temperature - Concrete batches were made at temperatures from 68 to $80^{\circ} \mathrm{F}$. Mixes made with noncontaminated prebatch showed little variation in properties due to temperature for the range examined.

5.3.3.3 Conclusions from the Laboratory Testing - As long as the prebatch was free from portland cement residue or other contaminants, acceptable concrete could be made in the laboratory. These mixes were made with the original admixture quantities with only slight changes in water-cement ratio to accommodate changes in aggregate size and fly ash type.

Transit trucks, when properly cleaned, delivered prebatch that produced concrete identical to that made with laboratorymixed prebatch.

Cement age had no effect on the concrete properties. Small variations in water-cement ratio were made to adjust initial slump without affecting strength. Variation in mix temperature from 68 to $80^{\circ} \mathrm{F}$ had little influence on mix properties.

\section{3 .4 Auger-Mixer Tests}

Tests were then conducted using the auger-mixer in an attempt to duplicate these results. The auger-mixer was calibrated to produce $3.8 \mathrm{yd}^{3}$ of concrete per hour using the mix design finalized in the laboratory test program. Ten auger-mixed concrete samples were taken from tests conducted during the latter part of November 1981 . 
The results of the first auger test trial indicated that more than 100 percent of the design citric acid was required to control slump loss even though the transit mixers had been cleaned using the new procedure. Subsequent tests, using 150 percent design citric acid, produced variable results. Some mixes exhibited satisfactory slump behavior with low early strength while others showed the reverse. Mix temperature varied from 68 to $71^{\circ} \mathrm{F}$.

\subsubsection{Conclusions from Auger-Mixer Testing}

The following conclusions were reached based on the limited auger-mixer testing:

1. Auger-mixed concrete did not exhibit the same properties as laboratory-mixed concrete.

2. The auger-mixed concrete did not visually appear as well-mixed as companion laboratory batches.

3. The auger-mixed concrete seemed to be more sensitive to prebatch contamination than the laboratory batches.

4. The unusual combination of satisfactory workability and very low strength gain at low water-cement ratio, observed during some of the tests, would require further investigation.

5. Pumping difficulties may have been caused by aggregates which did not meet the mix specifications.

6. 150 percent of the design citric acid was, in most cases, adequate to obtain the desired workability: however, rate of strength gain was unpredictable. 


\section{3 .6 Slipform Tests at $6 \mathrm{ft} / \mathrm{hr}$}

Because no reasonable alternative existed to prebatch delivered by transit mixers, the decision was made to proceed with the $6 \mathrm{ft} / \mathrm{hr}$ slipform tests despite the somewhat questionable results of the auger-mixer tests just described.

In an effort to provide additional confidence that an acceptable mix could be obtained for each test, it was decided that a laboratory $\operatorname{mix}$ and an auger-mixer trial mix would be produced prior to and on the same day as each tunnel test. This was to insure that the particular prebatch delivered produced an acceptable mix on the day of the test. This was necessary since the erratic mix behavior caused by the prebatch appeared to depend on the prebatch age.

5.3.6.1 Test SII-3. The laboratory mix produced prior to the test showed both acceptable slump history and acceptable strength gain. The auger-mixer mix showed slightly rapid slump loss and acceptable strength gain. The decision was made to proceed with the test with 150 percent retarder.

The test was started at midday. After 12 min of operation, the pressure at the upper red valve pressure sensor quickly rose to over $40 \mathrm{psi}$ which was higher than the desired pressure of 30 \pm 5 psi. Control actions were taken which caused the bulkhead to advance approximately $3 \mathrm{ft}$ in about $3 \mathrm{~min}$. The bulkhead was then stopped and backed up a few inches and held in that position until the new void was filled.

The vibrators were turned on after $14 \mathrm{~min}$ of testing and the vibrator duration was increased from 12 to $17 \mathrm{sec} 18 \mathrm{~min}$ later. After $42 \mathrm{~min}$ of testing the slipform advance was started and the first concrete was exposed at an age of $1 \mathrm{hr} 17 \mathrm{~min}$. After $1 \mathrm{hr}$ 
26 min of testing, the slipform jammed. Although several attempts were made to advance the slipform, it took an additional $1 \mathrm{hr}$ $37 \mathrm{~min}$ to unjam the slipform. The method that succeeded was removal of one row of the tongue plates on the slipform.

Concrete pumping was stopped after the form could not be quickly unjammed and the vibrators were shut off. The first attempt at purging the slickline was conducted 14 min after jamming with bulkhead pressure on ( $245 \mathrm{psi})$. When that attempt failed, a second attempt was made 10 minutes later with the bulkhead pressure reduced to zero. When the second purge attempt failed, the slickline was removed and manually cleaned.

During the first third of the test the pressure at the upper red valve ranged from 5 to $35 \mathrm{psi}$. During the remainder of the test the pressure was between 35 and 65 psi. No blockages occurred during the test.

In general, the concrete was difficult to pump and its workability was barely acceptable despite the pretest augermixer trial. After extrusion, the concrete liner appeared to be of good quality. A total of 59 in. of liner was cast during the test.

5.3.6.2 Test SII-4. In an effort to improve workability the mix temperature was lowered to $65^{\circ} \mathrm{F}$. The laboratory mix showed slightly slower than normal slump loss and normal strength gain. The auger-mixer trial mix also showed slightly slow slump loss but slow strength gain. The decision was made to proceed with the test with 150 percent retarder. 
The test was started and proceeded without incident for $1 \mathrm{hr}$ and $13 \mathrm{~min}$ of operation. At this point, it was noticed that the electric motors on the auger-mixer had become abnormally warm. The cement auger motor was $240^{\circ} \mathrm{F}$, the $3 / 4$ in. stone auger motor was $275^{\circ} \mathrm{F}$, and the prebatch auger motor was $245^{\circ} \mathrm{F}$. No measurement was made of the main mix auger motor. A fan was used to cool the $3 / 4$ in. stone auger motor since it was the hottest.

After 1 hr $30 \mathrm{~min}$ of testing, the concrete pump developed a blockage. At this point the mixer output was diverted to waste. Five minutes later the bulkhead vibrators were shut off. Since the supply of prebatch was almost exhausted, it was decided to stop the test. The concrete mixer was stopped and citric acid was added to the concrete inventory in the pump hopper. The pumping lines were taken down and cleaned. The blockage in the pump was removed.

The first attempt at purging the slickline was made $8 \mathrm{~min}$ after pumping was stopped. The go-devil went approximately $1 \mathrm{ft}$ and stopped. The go-devil was pulled back and the bulkhead vibrators were turned back on again and cycled for $4 \mathrm{~min}$ and then shut off. Seven minutes after the first attempt, the purge was tried a second time. Again, the go-devil only went about 1 ft. The first two attempts at purging the slickline were done with concrete pressure on the bulkhead. The bulkhead pressure was then relieved and the purge was attempted a third time. This attempt was also unsuccessful. While the bulkhead pressure was being relieved for the third purge attempt, a crack appeared in the top of the liner at the trailing edge of the slipform. When the bulkhead pressure was reapplied the crack closed. The slickline was removed and cleaned manually. 
During test SII-4, the concrete pressure varied between 20 to $40 \mathrm{psi}$. Despite the lower back pressure, the concrete was harder to pump than in test SII-3. The rate of strength gain was unacceptable. During the test, attempts were made to improve strength gain by increasing the mix temperature. This adjustment did not have much effect.

The liner could not be exposed until an age of 1 hr $35 \mathrm{~min}$. A total of 93 in. of liner was cast. After extrusion, the liner appeared to be of good quality. Some slight honeycombing was evident on the exterior when the covers were removed from the test tunnel. Form drag remained low throughout the test.

\subsubsection{Conclusions of Slipform Tests at $6 \mathrm{ft} / \mathrm{hr}$ - The most} obvious conclusion of the series II slipform tests was that serious problems still existed with the concrete. The source of these problems could not be identified based on the data collected from the series II auger-mixer tests and slipform tests. It was certain that no further tunnel tests could be done until the source of the concrete problems was identified and the problems corrected.

The Series II slipform tests also raised doubts about the performance of the purging system. The problems with the purge system were later identified as being due to a space heater which was mounted on the ceiling near the slickline leading to the bulkhead. The space heater blew hot air in the direction of the slickline. The heater caused the concrete in the line to set more quickly. The heater had not been in operation during the series I tests. 
The tests also provided additional information about the source of the high form drag. It was hypothesized that the form lock-up which occurred during test SII-3 was due to the irregular age profile in the 3 ft of concrete which were placed after the bulkhead run-away. Since this section was placed from the bottom up, as if in an open form, the concrete at the top was approximately the same age over the $3 \mathrm{ft}$ length. By the time the concrete at back of this section had gained enough strength to be exposed, all of the concrete in the section had begun to heat-up rapidly. Since the form could not be advanced faster than $15 \mathrm{ft} / \mathrm{hr}$, it was not possible to pull the form clear of this region before the lock-up occurred.

The situation was made worse by the fact that the concrete at the back of the section gained strength more slowly than at the front. The concrete at the front was accelerated by the selfheating effect of the large mass. The concrete at the back edge was retarded by the influence of the boundary with the concrete from the last test.

Figure 5-22 shows the temperature distribution along the form at the time that the first liner was exposed. It can be seen that concrete $40 \mathrm{in}$. forward from the end of the form was hotter than the concrete at the end of the form. Since the cuts made in the end of the form extended forward for a distance of 36 in., they were not adequate to prevent the lock-up.

In contrast, during test SII-4 the concrete gained strength much more slowly. The temperature rise was much less rapid; and, by watching the thermistor data, it was possible to time the advance so that the temperature increase occurred over the flexible section of the slipform. The drag remained low throughout test SII-4. 


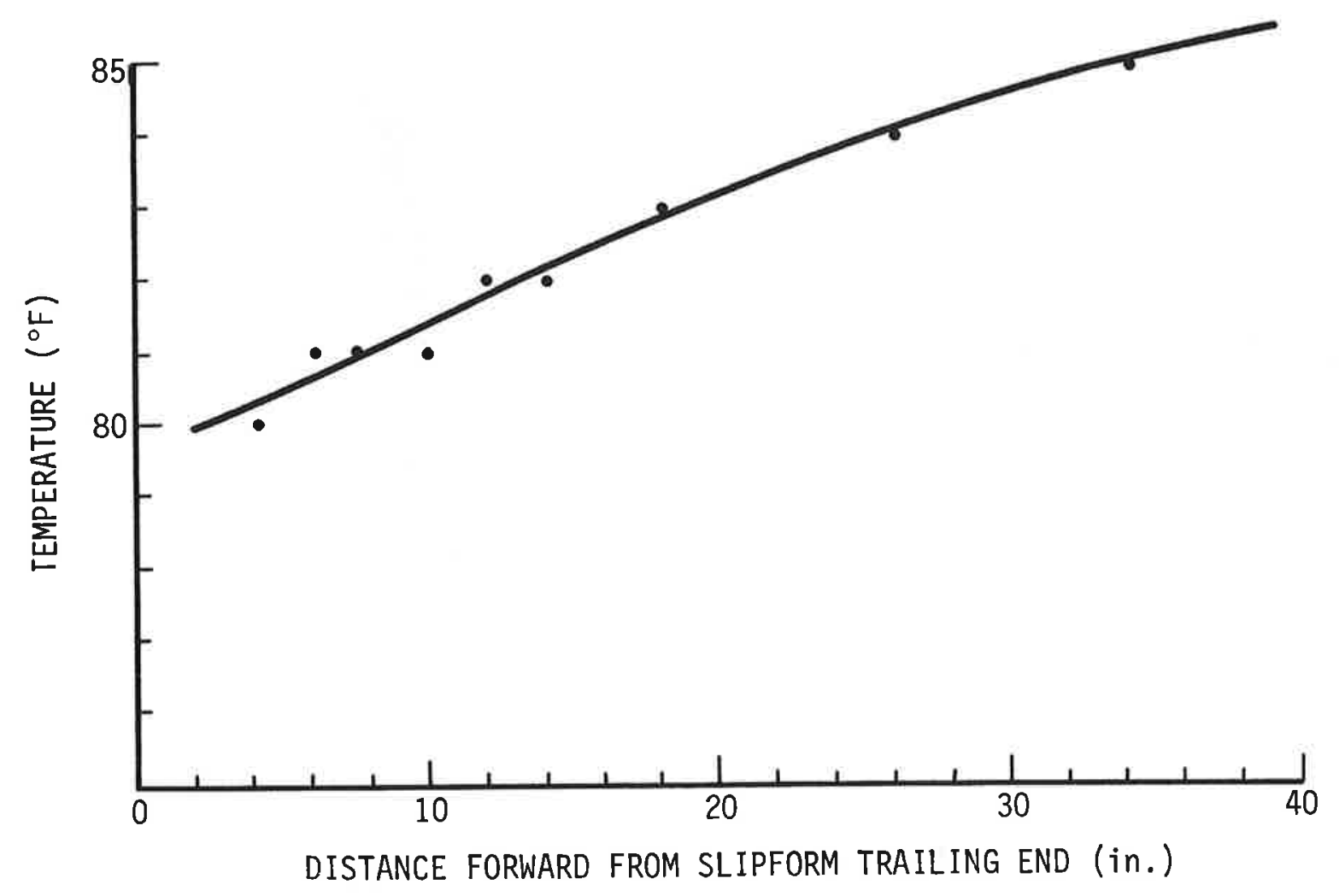

FIGURE 5-22. CONCRETE TEMPERATURE DISTRIBUTION AT TIME OF FIRST EXPOSURE (TEST SII-3)

Thermistor data collected during tests SII-3 and SII-4 were used to confirm the hypothesis that form drag was largely dependent on temperature. Figure 5-23 shows plots of temperature versus drag for tests SII-3 and SII-4. It can be seen from the figure that a marked dependence on temperature does exist.

Test SII-4 also confirmed the hypothesis that cracks would occur in the concrete or the trailing edge of the form if the bulkhead pressure was allowed to drop too low while the form was moving. Cracks formed at the crown (where the concrete is youngest) when the pressure was reduced to perform the purge. The pressure at which this occurred could not be measured since the red valve pressure sensor was normally isolated 


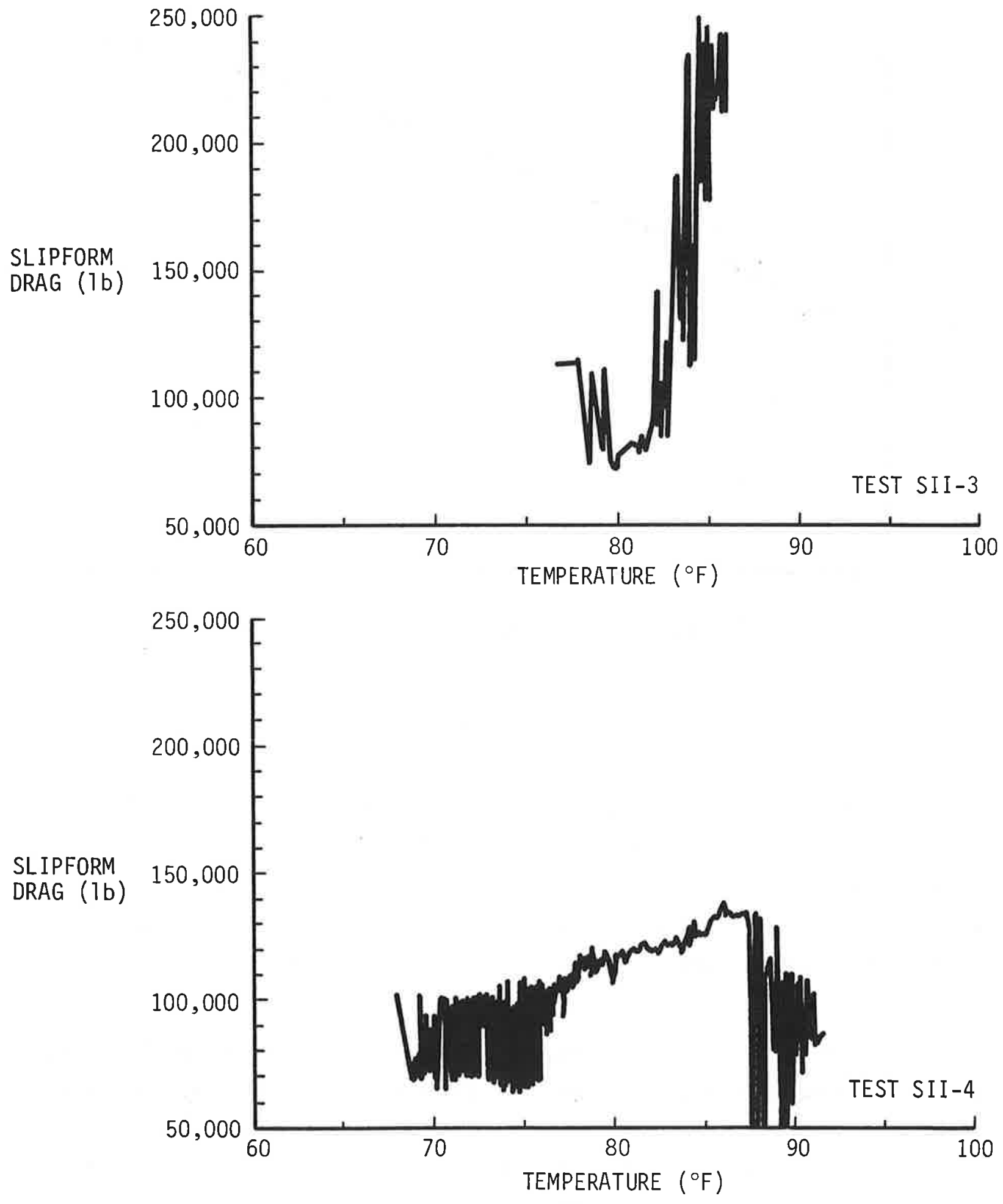

FIGURE 5-23. DRAG-TEMPERATURE RELATIONSHIP FOR TESTS SII-3 AND SII-4 
whenever a purge was performed. It was decided that, in the future, the form should be stopped before purging.

\subsection{SERIES III TUNNEL TESTS - CRITICAL TESTS}

The critical test program was divided into three test areas:

1. Prebatch production trials

2. Auger-mixer concrete trials

3. Critical tunnel tests I and II

A major conclusion drawn from the final test series (subsection 5.3) was that the concrete continued to exhibit erratic behavior. Problems with both slump loss and strength gain continued. Conclusions reported from the laboratory concrete testing performed during October and November 1981 (subsection 5.3.1.2) indicated that VHEC concrete would perform predictably if no portland cement residue was present in the prebatch. Therefore, for the final test series, steps were taken to clean the trucks as well as possible before handling prebatch. Because there was no absolute method of insuring that the trucks would be clean each and every time the prebatch was delivered, erratic concrete behavior was not impossible. Since transit trucks were by far the most practical method to make prebatch, it seemed that there was little alternative but to minimize the contamination and design the mix accordingly.

From the results of the final tunnel test series, it was clear that this solution was not satisfactory. The only way to conduct a meaningful tunnel test was to make certain the prebatch was contaminant-free. The options available to do 
this were to procure a transit truck or try to make prebatch in the Foster-Miller shop using the auger-mixer. Since the former was cost-prohibitive, the latter was attempted.

\subsubsection{Prebatch Production Trials}

Preparations were made for a test run to determine whether the auger-mixer could make prebatch. The prebatch constituents, 3/8-in. stone, sand and fly ash, were stockpiled. The augermixer and the fly ash metering cart were calibrated to supply the raw materials in the correct proportions. The material feed rates were adjusted to produce as much prebatch as possible. Make-up water was added directly from the admixture cart at appropriate temperature to produce shop temperature prebatch with about a 6 to 7 percent moisture content.

The first few cubic feet of prebatch produced was discarded due to mix irregularities associated with start-up. Beyond this point and until the end of the production run, the prebatch was very uniform in gradation. Some minor variation in moisture content occurred which was directly caused by variations in the stone and sand water contents. Since all of the equipment that was used to produce prebatch was dedicated to making VHEC concrete, there was no possibility of any portland cement being in the prebatch.

Making prebatch in the shop with the auger-mixer had its drawbacks. It proved to be a dirty, labor intensive operation. Raw aggregates had to be handled in many small loads due to the limited hopper size on the mixer. It created dust problems associated with handling $f l y$ ash in bags. Finally, it was a long, slow process. Including preparation, it took approximately $16 \mathrm{hr}$ to produce what a transit truck and batch plant could do in $15 \mathrm{~min}$. 
From the results of the trial run it seemed certain that prebatch would be made in the shop for the remainder of the test program. This allowed the use of the original aggregate types (Source A). These aggregates had been used for Phase I with success and were investigated in the early laboratory studies of Phase II (subsection 5.1). The Source A aggregates were natural and not of the crushed variety supplied in the transit mixed prebatch. It was expected that this aggregate shape change might alleviate some of the concrete workability problems.

\subsubsection{Auger-Mixer Trials}

With a new, contaminant-free prebatch, trials were run to finalize the auger-produced concrete mix design. The trails were used to determine the bounds of behavior for different mix and ambient temperatures. This was very important since during the period of the critical tunnel tests (late spring 1982), the ambient temperature in the tunnel test facility could vary between 60 and $80^{\circ} \mathrm{F}$, depending on the daily weather.

A total of 33 auger-mixer tests were performed from February to June 1982 .

\subsubsection{Preliminary Testing}

a. Mixer Calibration - Although contamination of the prebatch was eliminated, it was not certain whether the mixing action of the auger-mixer was contributing to the erratic concrete behavior previously reported.

The auger-mixer was calibrated for each of the raw constituents, 3/4-in. stone, prebatch, and cement. Both 3/4-in. stone and prebatch metering proved to be accurate within about 
2 percent of target values. The cement metering variability was somewhat higher until a standard bag loading and bin stirring procedure was used. Vibration of the cement bin was attempted; however, this gave erratic results.

In addition to performing the normal calibration procedure of capturing the raw materials at the ends of the feed augers, a total output test was done. This test was performed by weighing the total output of the auger-mixer with all feed augers on and no additional water added. Material was collected at the end of the main lift auger boot and weighed. Results of these tests indicated the normal variation was about 2 percent which coincided with the individual augering variation.

Raw material calibrations were performed when either the prebatch or stone moisture content changed significantly. The cement calibration was performed more often since it had the greatest impact on the mix behavior.

b. Concrete Tests - Initially, eight auger-mixed concrete tests were done. Mixes were made at the $2.6 \mathrm{yd}^{3} / \mathrm{hr}$ ( $4 \mathrm{ft} / \mathrm{hr}$ ) rate. Tests were performed to determine whether there was a shift in material properties between mixes made in the laboratory and by auger-mixer. This included testing a hypothesis that less Lomar D superplasticizer was required in auger-mixed concrete since the intense mixing action made the plasticizer more effective. In addition, two ambient temperature ranges were used. Mix temperature was held constant. Results indicated the following:

1. Decreasing Lomar $\mathrm{D}$ content increased water demand. slump history was not affected, but strength gain was slower. 
2. A citric acid content of 100 percent of laboratory design value produced satisfactory results only when ambient temperature was about $62^{\circ} \mathrm{F}$.

3. With an ambient temperature near $70^{\circ} \mathrm{F}, 125$ percent of design citric acid was required.

No erratic or highly unusual properties were observed. The auger-mixer was capable of making acceptable concrete, although there definitely seemed to be a shift in properties from the laboratory mixes.

5.4.2.2 Mix Design Finalization at $2.6 \mathrm{yd}^{3} / \mathrm{hr}(4 \mathrm{ft} / \mathrm{hr}$ ) - A larger series of tests were performed to further investigate auger-mixed concrete behavior. Seventeen tests at the $2.6 \mathrm{yd}^{3} / \mathrm{hr}$ rate were conducted with citric acid contents of 100 to 125 percent of design, 60 to $70^{\circ} \mathrm{F}$ ambient temperature and constant plasticizer content. Concrete mix temperature was varied between 67 and $72^{\circ} \mathrm{F}$. During the testing two additional production runs of prebatch were required which forced numerous recalibration trials.

Results indicated that the mix properties followed a definite pattern relating ambient temperature directly to citric acid content, and to a lesser degree, to the mix temperature.

Specifically, if the ambient temperature was about $60^{\circ} \mathrm{F}$, 100 percent design citric acid worked very well. For this ambient temperature/citric acid combination, increasing the mix temperature caused slightly more rapid slump loss and cooler mix temperature prolonged it. Strength gain was not affected. With the ambient temperature near $70^{\circ} \mathrm{F}, 114$ percent design citric acid produced the best mix. For a fixed citric acid content, cooler ambient temperature further retarded the mix. Combinations of 
125 percent of design citric acid and $\operatorname{cool}\left(60^{\circ} \mathrm{F}\right)$ ambient temperature produced mixes with slow slump loss and slow strength gain.

In conclusion, it appeared that the mix design could be controlled properly by adjusting the citric acid content to match the ambient temperature condition. Low ambient temperatures required lower citric acid content and higher temperatures required higher citric acid content. Since 114 percent design citric acid was required for normal room temperatures $\left(70\right.$ to $\left.72^{\circ} \mathrm{F}\right)$, it seemed likely that there was a definite, although small, shift in concrete properties due directly to the mixing method.

5.4.2.3 Mixing Tests at $4.5 \mathrm{yd}^{3} / \mathrm{hr}(7 \mathrm{ft} / \mathrm{hr})$ - Testing was performed to verify mix performance at the $4.5 \mathrm{yd}^{3} / \mathrm{hr}$ rate in preparation for the critical tunnel tests.

Another production run of prebatch was made and the augermixer was calibrated for the new, faster rate. No major problems were encountered except that the prebatch became difficult to auger satisfactorily at this rate if its moisture content exceeded about 8 percent. In addition, it appeared that if the prebatch was made at a moisture content much above 6.5 percent, the free water would percolate to the bottom of the storage bin if it was stored for long periods.

Eight mixer tests were performed in this final series. Since the critical tunnel tests were planned for mid-June, the emphasis in this series was placed on dealing with warm ambient conditions. It was previously concluded that increasing citric acid content could counteract higher ambient temperatures (in a limited range).

Testing was conducted to determine the level of citric acid content required for ambient temperatures between 75 and $80^{\circ} \mathrm{F}$ using $75^{\circ} \mathrm{F}$ concrete. The increased concrete temperature 
was used since it was felt that if warm conditions continued for an extended period, cooling the mix below this value might not be possible due to the large amount of the total mix water retained by the prebatch.

The results showed that up to 175 percent design citric acid would be required if the ambient temperature was $80^{\circ} \mathrm{F}$. A citric acid content of 150 percent design was required for $75^{\circ} \mathrm{F}$ conditions.

Although the results seemed to indicate that the concrete was fully controllable up to $80^{\circ} \mathrm{F}$, this was not quite correct. It appeared that as citric acid content was increased to these levels, initial slump was increased at constant water content. Since any increase in slump beyond 9 in. caused segregation of the mix, the water content had to be reduced. Reducing the water content, however, created problems. From the early laboratory studies it was found that VHEC concretes formulated with a water/cement ratio much below 0.40 will not repeatediy exhibit the required slump history. To counteract the effect of the high citric acid contents on initial slump, the superplasticizer content of one mix was reduced to 75 percent of design. This seemed to work satisfactorily.

5.4.2.4 Conclusions from Auger-Mixed Concrete Trials - The following conclusions were drawn concerning the auger-mixed concrete:

1. The auger-mixer had only a small effect on the mix design requiring a citric acid content increase to 114 percent of the standard laboratory formulation for normal $70^{\circ} \mathrm{F}$ conditions.

2. The superplasticizer is equally effective in both the laboratory mixer and the auger-mixer. 
3. Changes in ambient temperature can be counteracted by changing citric acid content in a limited range.

4. Mix temperature has a secondary effect on mix properties in the range tested.

5. Slump history and strength gain are directly related: Prolonged workability results in slower strength gain.

6. Concrete quality was the same for both 2.6 and $4.5 \mathrm{yd}^{3} / \mathrm{hr}$ rates.

\subsubsection{Critical Tunnel Tests SIII-1 and SIII-2}

The last tunnel lining tests that were conducted during Phase II were the critical tests, identified as SIII-1 and SIII-2. These tests were performed to evaluate the slipforming process without the complications encountered in the earlier testing that was caused by poor concrete behavior.

5.4.3.1 Test SIII-1 - The plan for the test was to place approximately $2 \mathrm{ft}$ of liner at a nominal rate of $7 \mathrm{ft} / \mathrm{hr}\left(4.5 \mathrm{yd}^{3} / \mathrm{hr}\right)$. The purpose of the test was to evaluate pumping pressures at the faster placing rate and to confirm that the concrete would behave as expected. At the start of the test, the slipform trailing edge was placed $3 \mathrm{ft}$ beyond the end plate. This allowed the slipform to be moved slowly during the pumping sequence without exposing the plastic concrete. The bulkhead was placed in a position $7 \mathrm{in}$. forward of the end plate.

The ambient temperature in the shop was $72^{\circ} \mathrm{F}$ when the test was started. As was usual for all of the tunnel tests, a grout mixture was made and pumped to slick the concrete placing 
lines. After this was completed, concrete production began and concrete with 114 percent design citric was pumped through the lines to the slide val.ve and on into a waste form. This slightly different procedure was implemented since it was common at test start-up to encounter some form of pumping difficulty. In this manner, if a problem occurred, no concrete would have entered the form. This allowed a restart without dealing with the setting concrete from the first try. Once the concrete successfully negotiated the system, the slide valve was switched to the pump position and concrete proceeded to the form through the slickline.

No problems were evident throughout the test. The bulkhead vibrators were cycled on for $12 \mathrm{sec}$ every minute. The pumping continued for $22 \mathrm{~min}$ and stopped. All concrete lines were purged. The purge system was operated after the bulkhead pressure was released and the slipform momentarily stopped. The slipform was restarted, and the concrete was exposed at an age of $65 \mathrm{~min}$. The computed advance rate was $6.4 \mathrm{ft} / \mathrm{hr}$.

The quality of the concrete liner was very good except for some minor honeycombs that were evident at the invert in the first few inches of concrete placement. The form was stopped approximately 6 in. before the end of the concrete.

5.4.3.2 Test SIII-2 - In preparation for this test, the slipform rod extensions were removed to permit the longest possible concrete placement. The trailing edge of the slipform was placed 12 in. into the previous casting from SIII-1. 
The test was started about noon. Ambient temperature was about $75^{\circ} \mathrm{F}$. After normal grout making and pumping procedures were complete, concrete making was started. The procedure of pumping to waste before the test, described before, was used. Problems were encountered starting up as a number of line blockages occurred. A complete cleanout and restart were required. After resolving the start-up problem, concrete was pumped continuously for $78 \mathrm{~min}$. Concrete with 114 percent citric acid was used throughout the test. Vibration for $12 \mathrm{sec}$ per 1 min period was used.

Pumping pressure during the test was moderate except that on occasion it reached $70 \mathrm{psi}$, as measured at the slide valve. The concrete pump struggled anytime the pressure exceeded $50 \mathrm{psi}$. Concrete was exposed at an age of $70 \mathrm{~min}$. The first few feet of lining was slipformed while the pumping operation continued. The concrete was observed carefully as it was being exposed. It was generally of good quality with the usual minor honeycombing apparent at the invert at the start of the placement. As exposure continued, a tension crack was observed at the crown. There was no firm explanation as to its origin; however, further along during the test another crack occurred. The appearance of the second crack coincided with an action taken to reduce the bulkhead back pressure to alleviate the back pressure on the concrete pump. The reduction in back pressure created a force imbalance which resulted in a net tensile strain in the newly exposed concrete. Since the concrete at young age had very little tensile resistance, a crack formed.

The remainder of the test continued without incident. After $100 \mathrm{in.}$ of concrete was placed, the pumping was stopped and the flexible pumplines were cleaned out manually. The slipform was then stopped and the normal slickline purge cycle was conducted. 
After purging was successfully completed, the slipform was restarted. No tension cracking occurred.

Slipforming continued until all but about $4 \mathrm{in.} \mathrm{of} \mathrm{liner}$ was exposed. Aside from the two cracks previously described, the liner was well-consolidated and had good strength at exposure. The computed advance rate for this test was $6.4 \mathrm{ft} / \mathrm{hr}$.

Drag during the test remained low and averaged about 22,000 1b. The thermistors worked very well in identifying the region of rapid strength gain.

5.4.3.3 Conclusions from Critical Tests SIII-1 and SIII-2 - For the most part, critical tests SIII-1 and SIII-2 were very successful. The following conclusions were reached from the results of these tests:

1. Form drag was very low averaging only 22,000 lb.

2. The concrete mix behavior was predictable and no longer caused any problems.

3. The particular concrete pump used for these tests was barely adequate to maintain the pressures required at this advance rate $(7 \mathrm{ft} / \mathrm{hr})$.

4. A force balance must be maintained that results in a net compression in the concrete emerging from the slipform. 


\subsection{EXTRUDED TUNNEL LINING SYSTEM SEAL DEVELOPMENT PROGRAM}

\subsubsection{Background}

The objective of the seal development program was to design and demonstrate an effective outer bulkhead seal for the Extruded Tunnel Lining system. The seal is located at the leading edge of the bulkhead. Its purpose is to maintain pressurized conditions inside the slipform by preventing pressurized concrete from flowing out between the moving bulkhead and the machine bored rock wall (Figure 5-24).

The difficulties in obtaining an effective seal for this annular space are primarily due to the surface irregularities of the bored tunnel and the limited available space. Variations in the radial, circumferential and axial dimensions of the sealing zone occur as a result of:

1. The helical bore cutter pattern

2. Gauge cutter wear

3. Abrupt shift in centerline

4. Distortion of tunnel cross section

5. Sloughing of rock areas, especially in the tunnel crown

6. Tunnel wall damage due to TBM grippers

7. Horizontal. sloughs due to bedding and vertical sloughs due to thruster crushing or guide scraping.

In order to prevent concrete from leaking out ahead of the slipform, the seal must be flexible enough to conform to the various surface contours encountered yet it must also be rigid enough to resist the considerable force exerted on it by the concrete under pressure. 


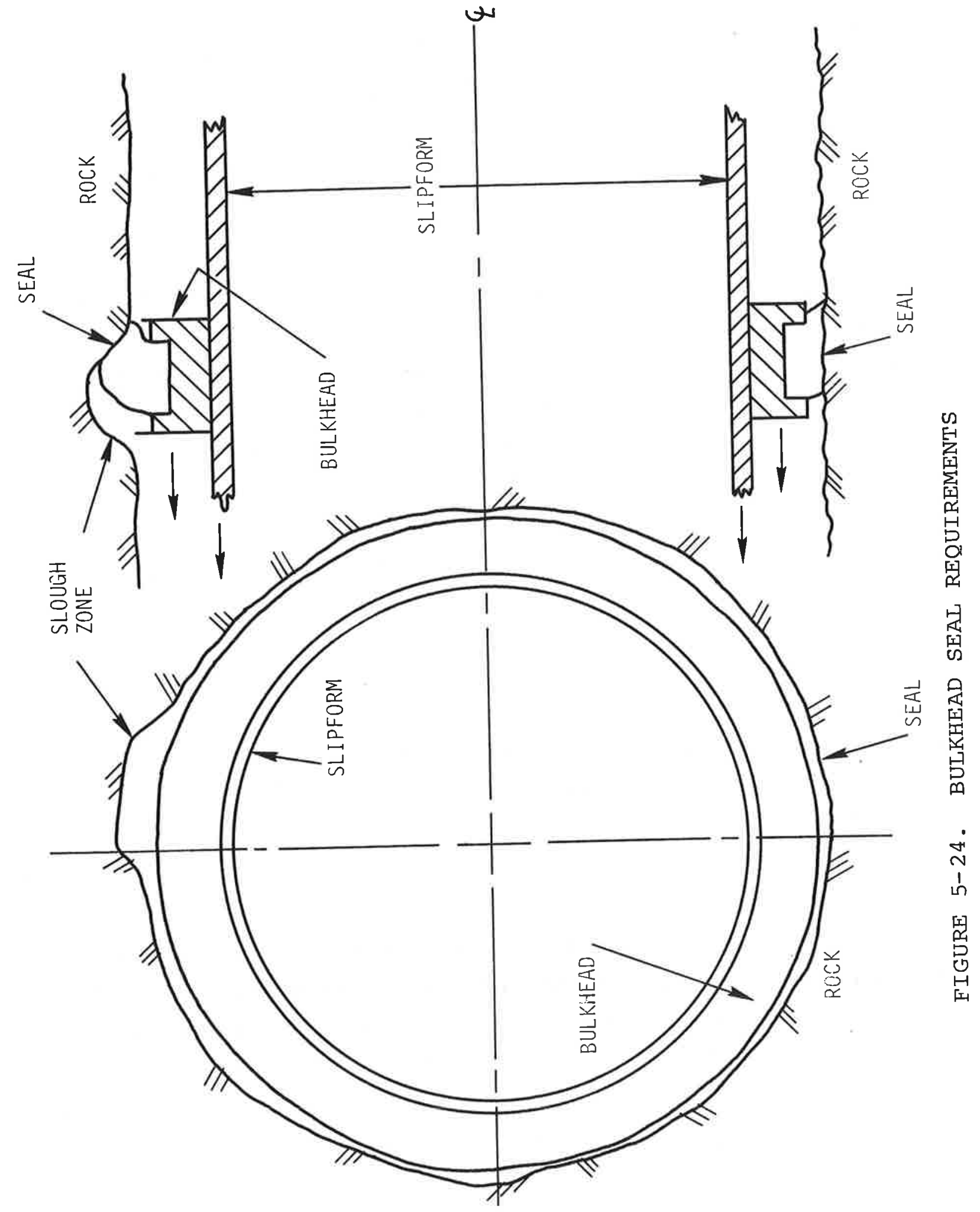


Another seal characteristic is imposed by the abrasive nature of its operating environment. As the slipform progresses along the tunnel, the seal is dragged along the rough tunnel wall and is subject to sliding wear. An abrasion resistant material must therefore be selected to insure seal integrity over a reasonable operating life.

Finally, the seal must be designed so that it can readily be integrated into the operation of the ETLS. Since the bulkhead may be retracted, on occasion, to compensate for concrete leakage, the seal must be capable of withstanding this reverse motion without jeopardizing its normal performance. Certain dimensional constraints characteristic of the system are also implied due to space limitations.

Specifications have been established for the parameters which impact the performance of the outer bulkhead seal of the ETLS. These specifications were used to evaluate the suitability of various conceptual and existing seal designs. The evaluation resulted in the selection of an appropriate design which was built and tested in a laboratory simulation test rig. The test rig was constructed so that the proposed seal design could be evaluated and optimized under the conditions defined by the specifications. A summary of the operating conditions and the performance specifications defined for the seal design are listed in Table 5-12.

In addition to seal performance criteria, the impact of seal design on overall system cost was considered. A simple design was obviously preferred in order to reduce the costs of fabrication, installation, maintenance and replacement.

The optimized seal candidate, based on the laboratory tests, was then studied for integration into an existing full scale bulkhead. 

TABLE 5-12. OUTER BULKHEAD SEAL PERFORMANCE
SPECIFICATIONS

\begin{tabular}{|c|c|}
\hline Design Condition & Performance Specification \\
\hline Surface Roughness of Tunnel Wall & $\begin{array}{l}3 / 4 \text { in. deep (maximum) } \\
3 / 4 \text { in. pitch (maximum) helical pattern }\end{array}$ \\
\hline Reduction in Tunnel Diameter & $\begin{array}{l}3 / 4 \text { in. reduction in diameter due to gauge } \\
\text { cutter wear }\end{array}$ \\
\hline Abrupt Shift in Centerline & $\begin{array}{l}1 \text { in. maximum shift due to weak/strong contact } \\
\text { in rock formation or due to steering correction }\end{array}$ \\
\hline Distortion of Tunnel Cross Section & $\begin{array}{l}1 / 4 \text { in. (maximum) increase in horizontal diameter } \\
\text { over vertical diameter due to horizontal curve in } \\
\text { tunnel }\end{array}$ \\
\hline Sloughs in Tunnel Crown & $\begin{array}{l}\text { Small blocks less than } 12 \mathrm{in.} \text { in dimension may } \\
\text { occasionally fall out ahead of the ETLS system }\end{array}$ \\
\hline Tunnel Wa1l Damage Due to TBM Grippers & $\begin{array}{l}3 \text { in. deep (radially outward) } \\
24 \text { in. wide (axial direction of tunnel) } \\
36 \text { in. high (circumferentially) }\end{array}$ \\
\hline Concrete Pressure on Seal & $\begin{array}{l}0 \text { to } 40 \text { psi } \\
20 \text { psi variation from invert to crown due to } \\
\text { gravity }\end{array}$ \\
\hline Seal Life Expectancy & $\begin{array}{l}500 \mathrm{ft} \text { of advance/seal in highly abrasive rock } \\
2000 \mathrm{ft} \text { of advance/seal in less abrasive rock }\end{array}$ \\
\hline Space Constraints on seal & $\begin{array}{l}3 \text { in. radial thickness of uninterrupted hoop } \\
12 \text { in. of axial width (excluding any shield ahead } \\
\text { of the bulkhead) }\end{array}$ \\
\hline Direction of Motion & $\begin{array}{l}\text { Forward only while placing concrete } \\
\text { slight reversal ( } 1 \text { to } 2 \mathrm{in.} \mathrm{maximum)} \mathrm{following} \\
\text { discontinuation of pumping to compensate for con- } \\
\text { crete leakage }\end{array}$ \\
\hline
\end{tabular}


A seal arrangement was engineered, fabricated and retrofitted onto this existing bulkhead. A series of actual concrete lining tests was performed, including use of simulated slough zones, in order to evaluate the viability of the seal design. The seal arrangement successfully met the requirements of the performance specification.

\section{5 .2 Seal Concepts}

Various conceptual seal designs were generated in house. In addition, several commercially available seals were studied. These seal arrangements can be divided into three generic categories:

1. Lip

2. Inflatable

3. Rolling.

After careful study and in consultation with various commercial seal manufacturers, the inflatable and rolling seals were eliminated from further consideration. The rolling type seals were eliminated primarily due to their physical complexity, problems with space constraints, and excessive maintenance requirements. The inflatable seals were eliminated due to their vulnerability to puncture and excessive seal drag due to high inflation pressures.

As mentioned earlier, a test rig was designed and various types of lip seals were evaluated. The test program evaluated these seals in a three-step scheme. The first series of tests investigated the ability of the seal to seal (fully extended in a 3 -in. radial slough zone) against a smooth surface. The 
second series of experiments examined the ability of the seal to seal under the normal wall configuration and then to transition into a uniform, 3-in. slough zone. The final series of tests investigated the ability of the seal to seal off odd shaped slough zones with both ramped and abrupt sides. During these tests, the seal design was modified as required. The final sealing design pressure was set at 45 psi.

The final seal configuration based on the laboratory studies is a series of 3 and 6-in. overlapping polyurethane lips, approximately $8 \mathrm{in.}$. in length. The seal is comprised of 5 lips which are fixed at a common base (see Figure 5-25). The seal is a combination of variable durometers, thicknesses and lengths. The layer which interfaces with the concrete is $1 / 4$ in. thick 60 durometer polyurethane. This layer is followed by three layers of $1 / 8$ in. thick 60 durometer polyurethane of increasing lengths. The top most layer is a $1 / 4$ in. thick 80 durometer and is the shortest of the 5 layers. The seal leafs are attached to the bulkhead on a 45 deg angle relative to the direction of travel and are combined with the unidirectional stiffener. Cuts in each leaf are arranged so that an overlapping shingle arrangement is formed.

\subsubsection{Prototype Seal Design.}

The seal arrangement developed from the laboratory test phase was then studied for application and adaptation to a full size prototype bulkhead. An existing $12 \mathrm{in.} \mathrm{wide} \mathrm{bulkhead} \mathrm{of} \mathrm{similar}$ design to the ETLS bulkhead was also being tested for the Department of Energy (DOE) on another program (The Continuous shaft Lining (CSL) System) (15). A decision was made to adapt the seal design to the shaft liners bulkhead; however, the results of the 


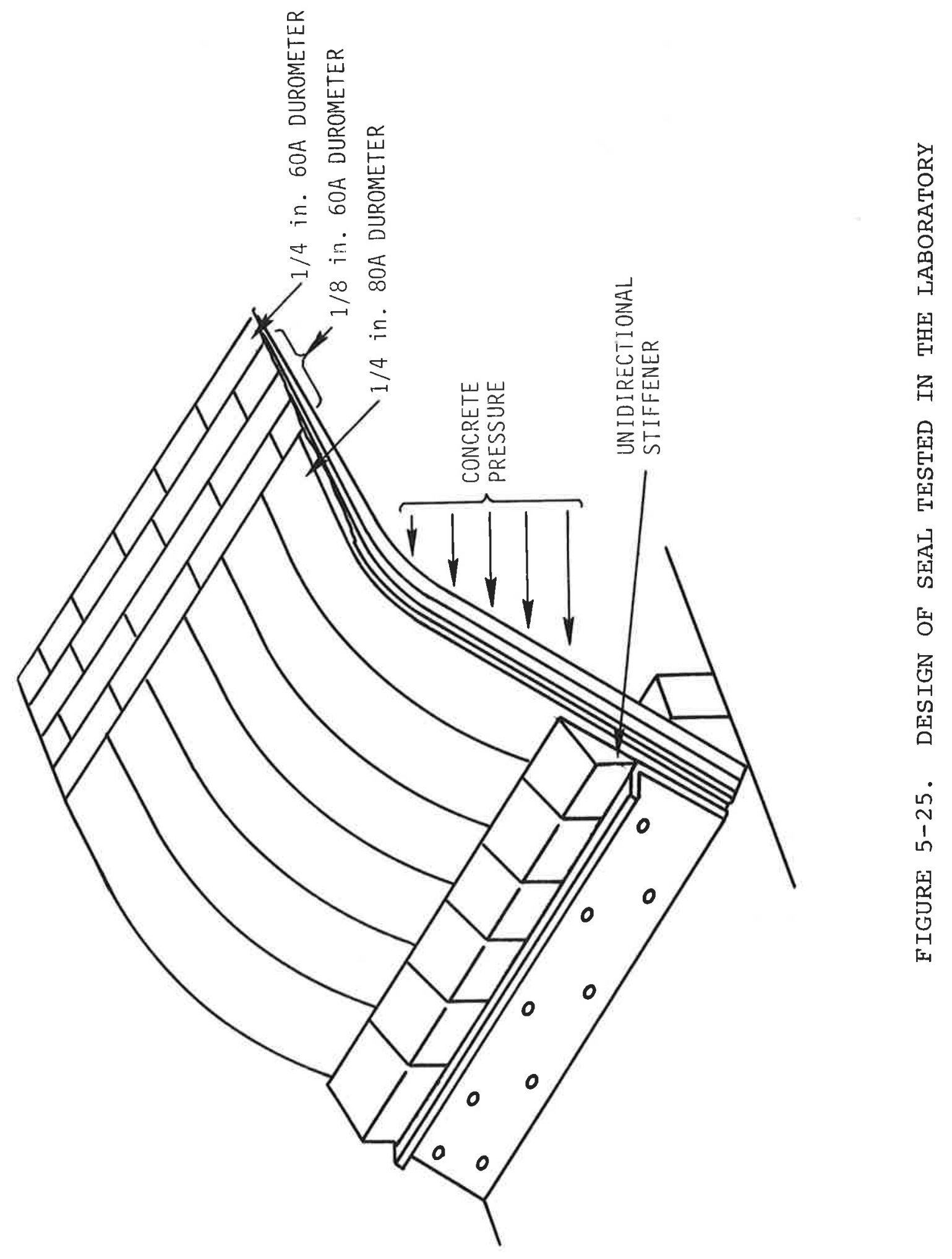


tests would have the same implications to both programs. The transition of the laboratory design to protytype design is shown in Figure 5-26. The prototype design utilizes the same 5 leaf, overlapping shingle arrangement. The unidirectional hinge has been improved. The 45 deg mounting bracket is an adaptation required to attach the seal to an existing bulkhead. A different mounting bracket, one which is integral to the bulkhead itself, would most certainly be preferred. This detail is factored into the conceptual design of the ETLS bulkhead.

The seals are manufactured in $12 \mathrm{in.} \mathrm{widths}$ and the different layers are arranged for lateral overlap as well as vertical overlap. A typical seal segment completely assembled is shown in Figure 5-27a. The photograph clearly depicts the ability of the seal to accommodate variations in radial overbreak. Twenty of these seal segments were mounted on the shaft liners bulkhead and tested three times through various shaft wall conditions and concrete pressures. A special slough zone panel was fabricated for the shaft liner test shaft. This panel allowed the forming of any shaped 3-1/2 in. deep slough zone.

\section{5 .4 Test Results}

The photograph in Figure 5-27b depicts the results of an initial slough zone test using the CSL test facility. What the photograph depicts is the concrete surface after the form has been removed. The seal demonstrated its ability to pass over and seal against corrugated sheet metal (water panning) and a triangular shaped $3 \mathrm{in}$. deep slough zone. During this particular test, the seal also demonstrated its ability to flex back against a smooth shaft wall which was only $1 / 2$ in. radially away from the edge of the bulkhead. 


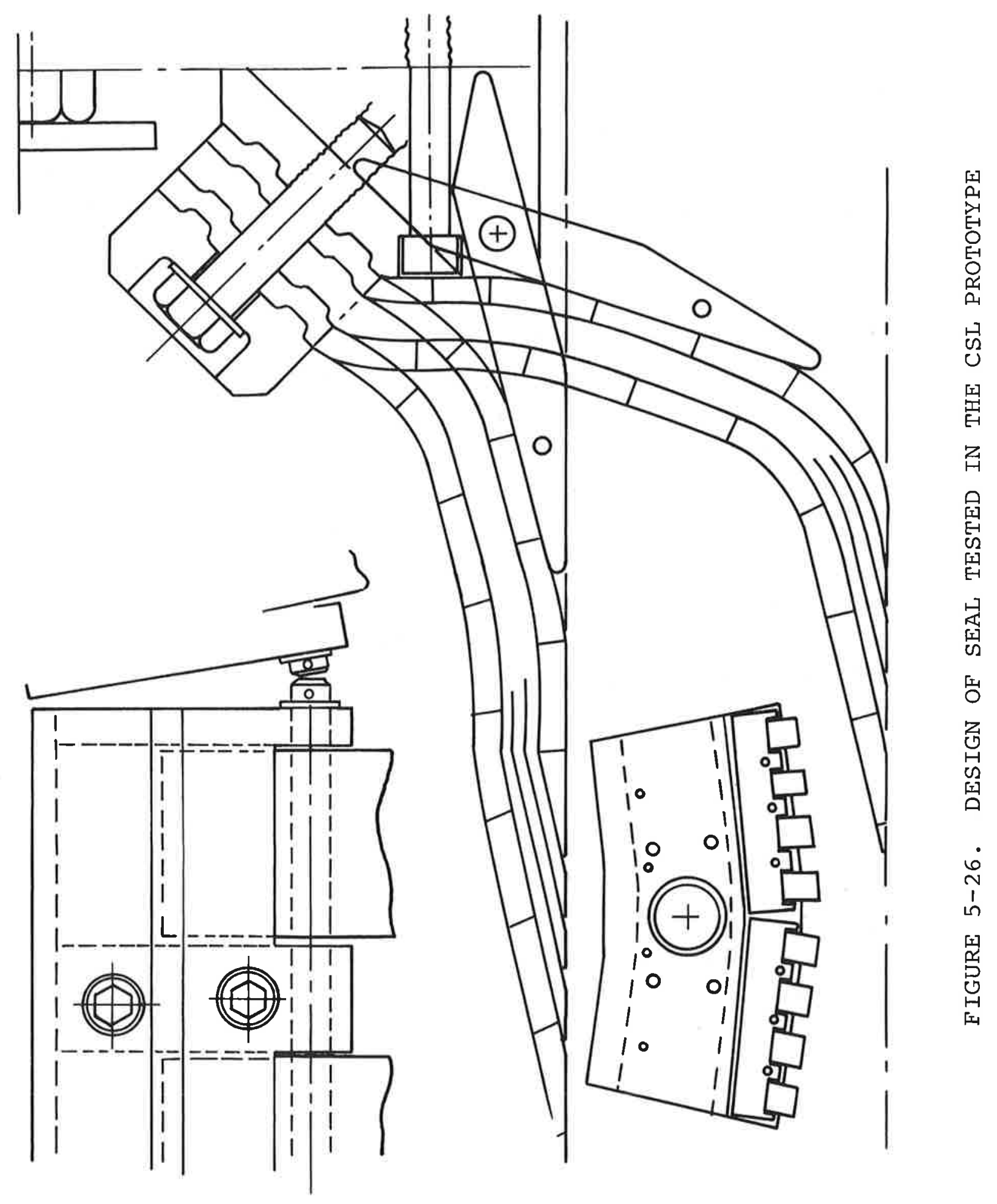




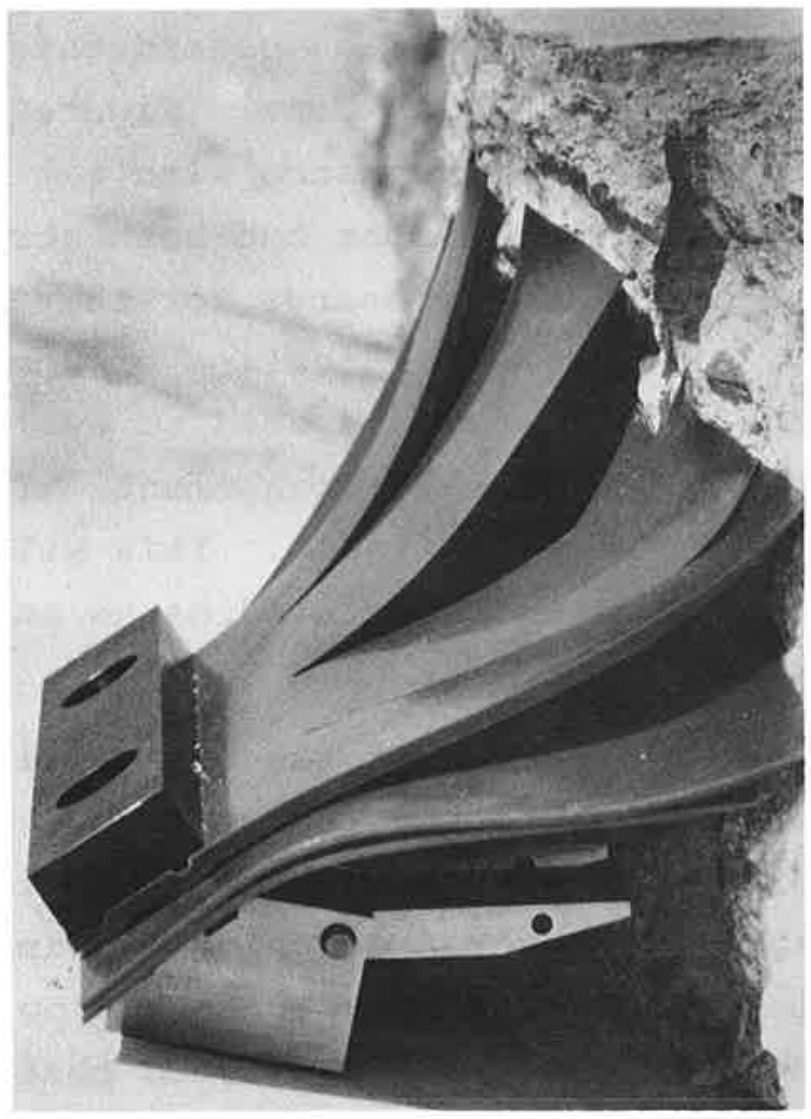

a) PROTOTYPE SEAL DESIGN

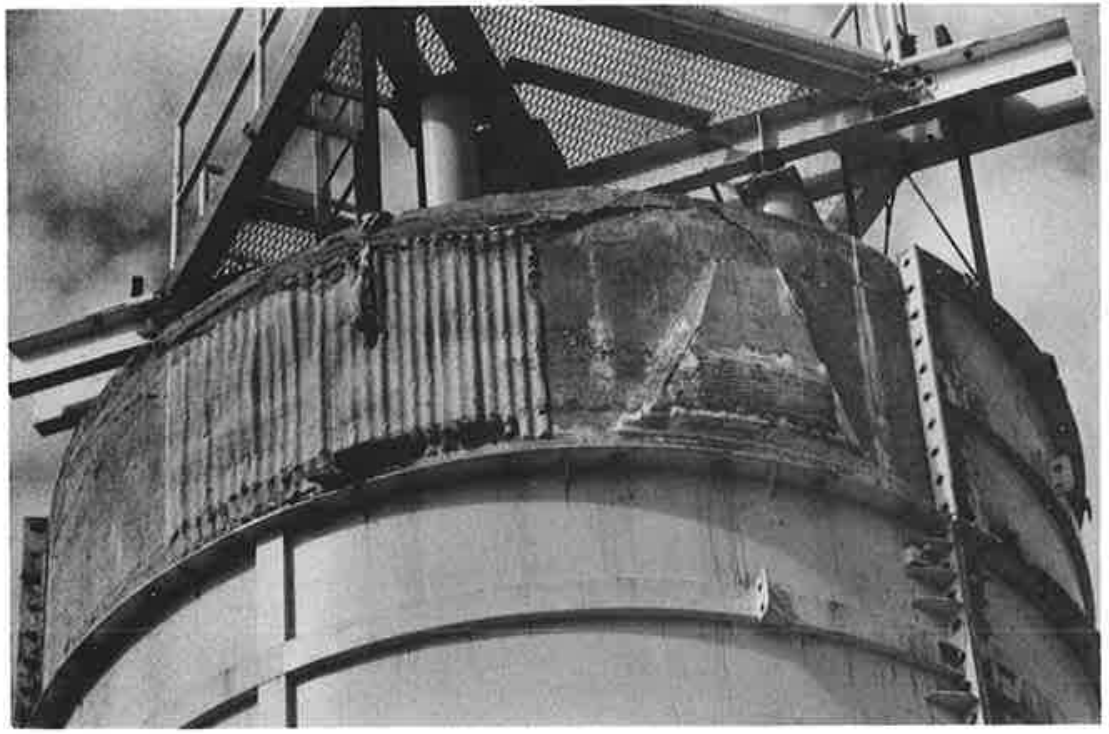

b) INITIAL SLOUGH ZONE TEST

FIGURE 5-27. FULL-SCALE SEAL TESTING 
In a second test, the seal was passed through a deeper (4 in. radial) and larger slough zone. Figure 5-28 depicts the results of the seal's performance with the larger slough zone. This particular slough zone had both abrupt and gradual transitions. The operating pressures for these seal tests ranged from 10 to $30 \mathrm{psi}$ without any indication of concrete blow-by. Also, during this test a 4 leaf seal was used to evaluate its performance compared to the 5 leaf arrangement. The 4 leaf seal performed as well as the 5 leaf seal. This will be factored into any further seal development studies as an economic consideration only.

Another important feature of the seal is its ability to be intentionally left, set into the last pour of concrete, and then pulled free. This obviously should be accomplished without damage to the seal. On several occasions during the shaft liner tests, the seal's resilience to this type of action was demonstrated. However, it should be noted that the polyurethane material, while highly stretchable and wear resistant, is susceptible to tearing. Once a tear is initiated, its propagation is very likely. Additionally, the seal did demonstrate its ability to be moved in two directions without significant problems. 


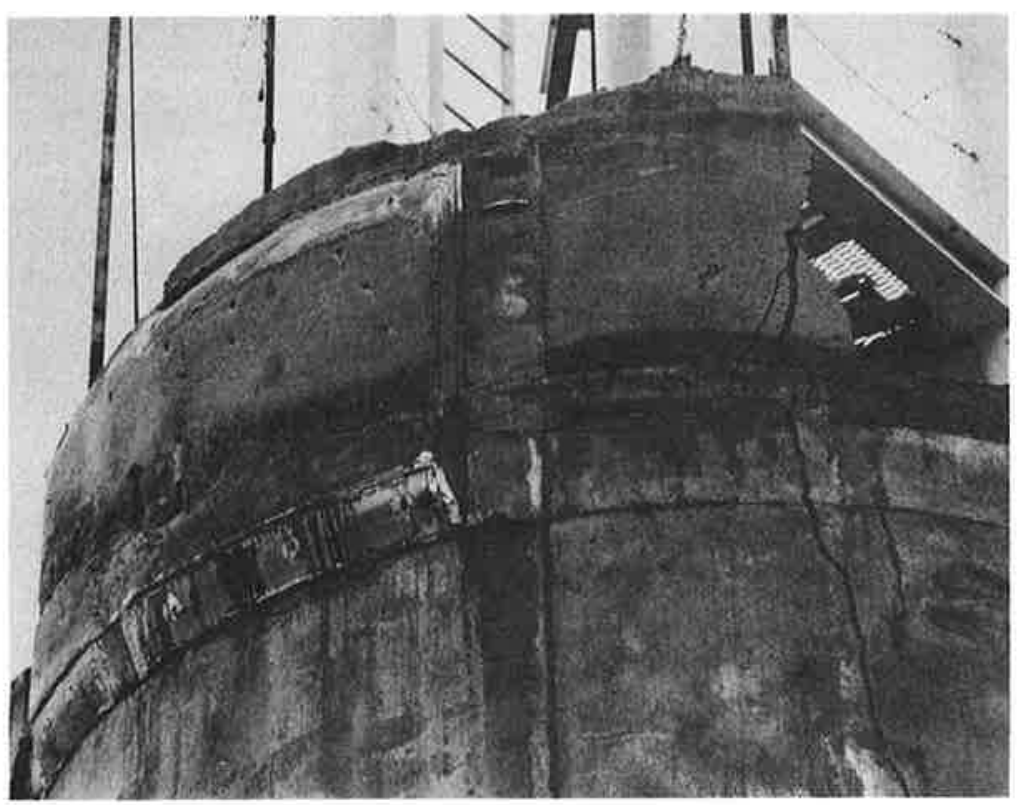

FIGURE 5-28. RESULTS OF TESTING USING THE 4-LEAF SEAI ARRANGEMENT ON THE DEEPER AND LARGER SLOUGH ZONE 

6. CONCLUSIONS OF TEST PROGRAM AND IMPACT ON ETLS DESIGN

In all, 12 tests of the 10 ft diameter ETLS prototype were carried out during Phase II of the program. The results of these tests are summarized in Table 6-1.

The tests were successful in proving the feasibility of the ETLS concept. The essential properties of distribution and self-support were demonstrated in the full-round. Operating experience with the system was acquired based on which conclusions were reached about its ultimate application and serviceability.

These conclusions are discussed in the following subsections. The conclusions are grouped into three subject areas: conclusions on the concrete, conclusions on mechanical hardware and conclusions on the process.

\subsection{CONCLUSIONS ON THE CONCRETE}

It was concluded that the original mix design arrived at during Phase I was acceptable (8) . Minor adjustments were required to correct for changes in aggregate supplies. An adjustment to the retarder content (to 112 percent of the original design) was found to be required to correct for the differences in the mixing process when using the auger-mixer.

Generally, the entire volumetric mixing concept, including prebatch was found to be workable with some constraints.

Attempts to combine the $3 / 4$ in. aggregate into the prebatch were not successful. The logistics of in-tunnel materials handling and mixing would be simplified if this could be done. It is believed that the segregation was caused by the use of inclined 


\begin{tabular}{|c|c|c|c|c|c|c|c|c|c|c|c|c|}
\hline 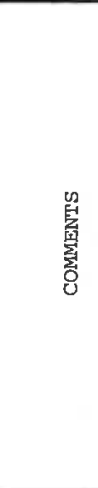 & 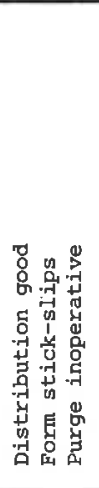 & 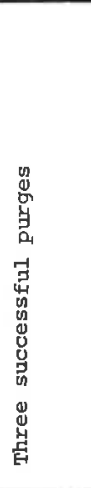 & 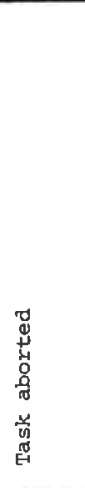 & 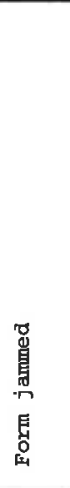 & 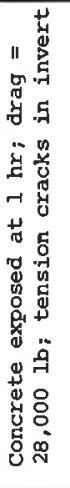 & 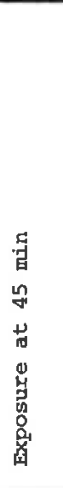 & 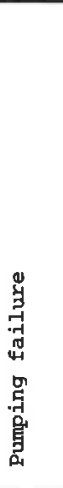 & 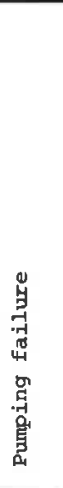 & 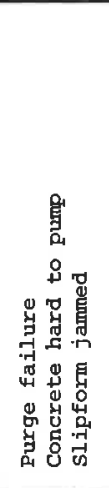 & 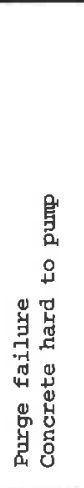 & 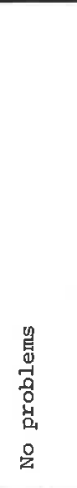 & 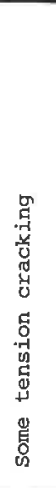 \\
\hline 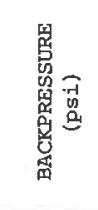 & $\begin{array}{l}q \\
i \\
i \\
p\end{array}$ & ' & 1 & 1 & 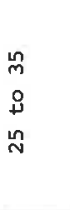 & $\begin{array}{l}q \\
o \\
i \\
m\end{array}$ & ' & ' & $\begin{array}{l}\stackrel{2}{ } \\
\stackrel{8}{ } \\
0 \\
0\end{array}$ & 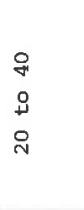 & $\begin{array}{l}\stackrel{i}{1} \\
\vdots \\
i\end{array}$ & $\begin{array}{l}0 \\
i n \\
8 \\
i \\
i\end{array}$ \\
\hline 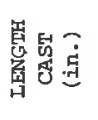 & そ & $\stackrel{9}{\rightarrow}$ & 1 & : & in & 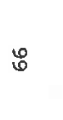 & $r$ & . & g & $\tilde{n}$ & $\stackrel{\mathscr{N}}{\sim}$ & $\stackrel{ }{\circ}$ \\
\hline 罯睡 & + & $\sigma$ & $\sigma$ & $\sigma$ & $\nabla$ & $\sigma$ & 0 & 0 & 6 & 0 & r & r \\
\hline 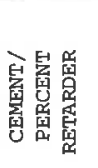 & 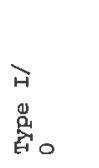 & 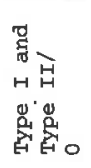 & 獣总 & 鮟遌 & 摠总 & 预苨 & 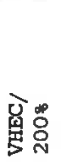 & 预总 & 兽哭 & 害总 & 䀡哭 & 当。 \\
\hline 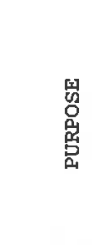 & 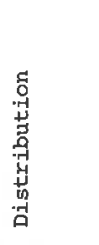 & 总 & 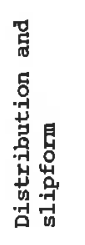 & 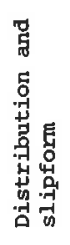 & 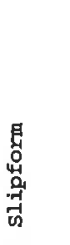 & 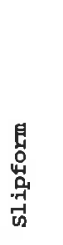 & 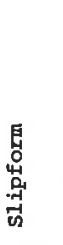 & 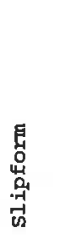 & 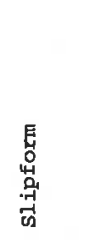 & 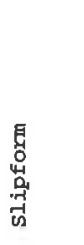 & 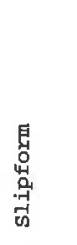 & 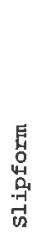 \\
\hline 㫐罟 & 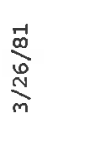 & 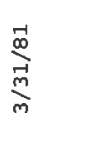 & $\frac{\vec{D}}{\stackrel{D}{N}}$ & $\sum_{a}^{+\infty}$ & 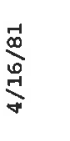 & & 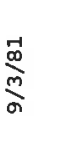 & $\overbrace{\sigma}^{\vec{m}}$ & $\begin{array}{l}\stackrel{\infty}{0} \\
\stackrel{0}{0} \\
\stackrel{7}{7}\end{array}$ & 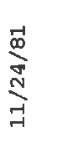 & $\overbrace{0}^{\infty}$ & 兽 \\
\hline 舅宗 & $\vec{t}$ & $\begin{array}{l}\tilde{y} \\
\dot{y} \\
\omega\end{array}$ & 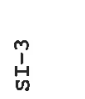 & 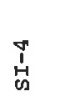 & 虽 & 足 & 营 & 苔 & 站 & 莣 & 吉 & 苫 \\
\hline
\end{tabular}


transit mixers. Horizontal transit mixers might yield better results; however, this was not tested. It was also found that prebatch contamination from portland cement caused major problems in the testing, but this type of contamination is not expected to be present in a field application.

Volumetric mixing was found to be adequate provided that careful calibrations of the metering augers were performed at each new rate. Prebatch was found to auger repeatedly at 5 to 6 percent moisture content. All of the material augers augered with an accuracy of \pm 2 to 3 percent, which was acceptable.

Continuous variability in advance rate from 2 to $12 \mathrm{ft} / \mathrm{hr}$, as might be required if connected to a TBM, would be difficult to achieve with the present auger-mixer. First, the auger drives were not capable of operating accurately and repeatedly over a 6 fold range. Second, the auger characteristics were not linear, nor were they the same for each material over the range.

These problems could possibly be overcome with a different drive system and more sophisticated controls. This would require additional development work. Alternatively, if the ETLS could be made independent of the TBM (self-propelled), then two discrete advance rates could be used (fast and slow) to keep the ETLS close behind the TBM. If for some reason the ETLS were to lag behind, because of operational problems, temporary supports could be used between the TBM and the ETLS. In this way the progress of the TBM would not have to be delayed.

Another conclusion reached about the concrete was that special provisions would be required in the tunnel to deal with the rapid-setting material. Provisions must be made for rapid clean-out of the pump, mixer, and placing lines. Provisions must also be made to handle waste material so that it does not spill on and set-up on other equipment. This would complicate the overall logistics of the tunneling operation, but not seriously. 
Finally, the concrete was determined to be slightly more sensitive to changes in water cement ratio and changes in $\mathrm{mix}$ temperature (i.e., changes in temperature and moisture content of raw materials) than conventional portland cement concrete. The auger-mixer operator and quality assurance personnel will have to be better trained to recognize problems with the mix than they would if conventional cast-in-place portland cement concrete was used.

\subsection{CONCLUSIONS ON THE PROCESS}

The process of horizontally slipforming a concrete liner was clearly proven to be feasible. The process was determined to be sensitive to variations in certain parameters. These were the following:

The process was found to be dependent on the ability to control pressure within the form. It is critical that this pressure not be allowed to fall below 20 psi while slipforming is in progress. Otherwise, cracks will develop in the liner as it leaves the form.

Some reliable means of providing the operator with feedback on the pressure in the form will be essential in a field application. The red valve pressure sensors were not adequate for this purpose because of the uncertainty introduced by the pressure drop in the placing line between the sensor and the bulkhead. Diaphragm sensors were installed directly on the bulkhead in the Continuous shaft Liner Program (15). These worked reasonably well, although concrete setting up on the face of the sensor sometimes caused them to read incorrectly. These problems could probably be corrected in a second generation device. Alternatively, a system such as the one described in subsection 6.3 might be used. 
The operation of the bulkhead seal is critical to the ability to maintain pressure inside the form. The seal which was developed and tested is adequate to contain the concrete pressure within the limits set by the Phase I ETLS specifications (8) (3-1/2 in. slough and $40 \mathrm{psi}$ concrete pressure). However, should the seal pass over a deeper slough, the pressure would drop and the liner would be spoiled. Deeper sloughs will require patching ahead of the ETLS. This will require access to the rock surface the full way round, for inspection and patching. This would require some design modifications to certain types of TBMs.

In addition to pressure feedback, the ETLS operator will require feedback on the rate of strength gain of the concrete inside the form. It is clear from the test results that the rate of strength gain will vary during continuous operation due to variability in the mixing process. It will be important to insure that the concrete temperature rise occurs over the flexible region of the form. It will also be important to provide a factor of safety on the strength of the liner as it leaves the form to be sure it can support the rock loads.

To fulfill these objectives while at the same time keeping the form as short as possible (for steering and form drag), it will be necessary to know accurately the strength of the concrete relative to its position along the form. It is very probable that thermistors installed on the crown of the form will provide the required feedback. However, a more complete understanding of the relationship between temperature and strength will be required. The temperature-strength relationship and the self-heating effect will be different in a rock tunnel from those of the test tunnel, because of the differences in heat capacity and heat transfer coefficient. Drag forces on the form due to thermal expansion will also be different since in the laboratory some expansion was also experienced by the test tunnel. Control of the ETLS 
advance should not be difficult once the operator becomes experienced with the system.

\subsection{CONCLUSIONS ON MHE MTCHANICAL HARDWARE}

The most important thing to keep in mind when designing an underground ETLS will be to keep it simple. In the process of addressing additional design requirements for underground, the ETLS must not be allowed to evolve into a more complicated system. Rather, the ETLS must be made less complicated and easier to operate than the prototype. This will maximize the chances for success in the field. This is consistent with the recommendations of the IPA review (13).

It is important to note that the design of the ETLS prototype was complicated by the need to design for operational contigencies. Because the process was not fully understood allowances had to be made in the design of the hardware, hydraulics, and controls for several different modes of operation. For example, because the balance between bulkhead pressure and form drag was not known, it could not be determined whether the ETLS would have to be pulled forward or be held back by the slipform actuators. Now that the tests are complete, a number of ways to simplify the system have been identified.

\subsubsection{Eliminate Independent Bulkhead}

The independent bulkhead should be eliminated. The independent bulkhead introduces considerable additional complexity. The control system which is required to maintain back pressure and bulkhead alignment is complicated and will be prone to malfunction in a tunnel. The bulkhead hydraulic cylinders are large and difficult to align. In addition, it is difficult to access any equipment mounted on the bulkhead for maintenance. This 
includes the seals, pressure transducers, vibrators, and possibly the slide valve.

The two functions performed by the bulkhead are varying form length, for starting and stopping or changing advance rate, and controlling back pressure. If the bulkhead is eliminated alternate methods will be needed to perform these functions.

Varying the form length could be done with the slipform as shown in Figure 6-1. The flexible form design could incorporate a means for bringing sections of the form in or out of contact with the concrete for starting and stopping or changing advance rate. There would also be the added benefit that sections not in contact with the concrete would serve as a safety shield in the event of liner collapse. The design of such a form is discussed further in section 6. 5 .

Control of back pressure could be done from the concrete pump as shown in Figure 6-2. For the ETLS prototype the pump was flow controlled (i.e., the lining rate was set from the pump). The bulkhead was controlled to maintain the desired back pressure within the form. For an ETLS with no independent bulkhead, the advance rate would be set by the form actuators. A piston concrete pump would be used in conjunction with a set of bladders behind the bulkhead. The operator would then control the pump based on the pressure in the bladders. When the pressure in the bladders fell below a predetermined value the pump would be started. Above a certain value the pump would be shut-off.

With a system such as the one just described the bulkhead hydraulics are eliminated completely. The seal, the vibrators, and the connection for the concrete placing line can all be moved to the front of the form where they can be reached easily. The placing line can be made shorter, reducing the chance of a blockage. This system is discussed further in section 6,5. 


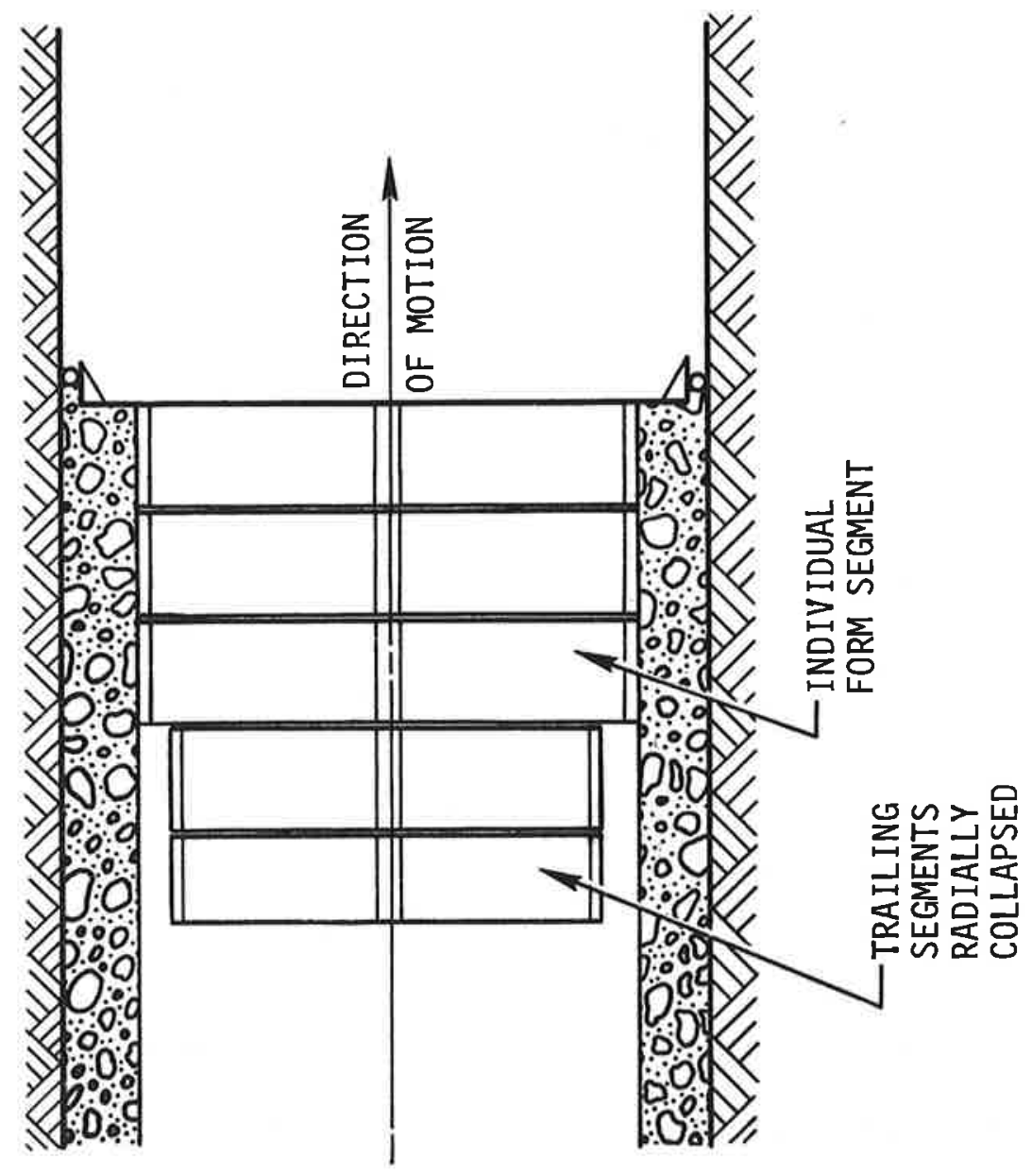

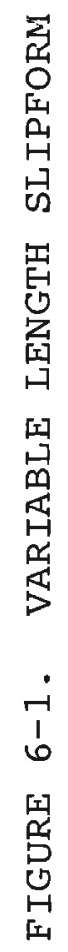




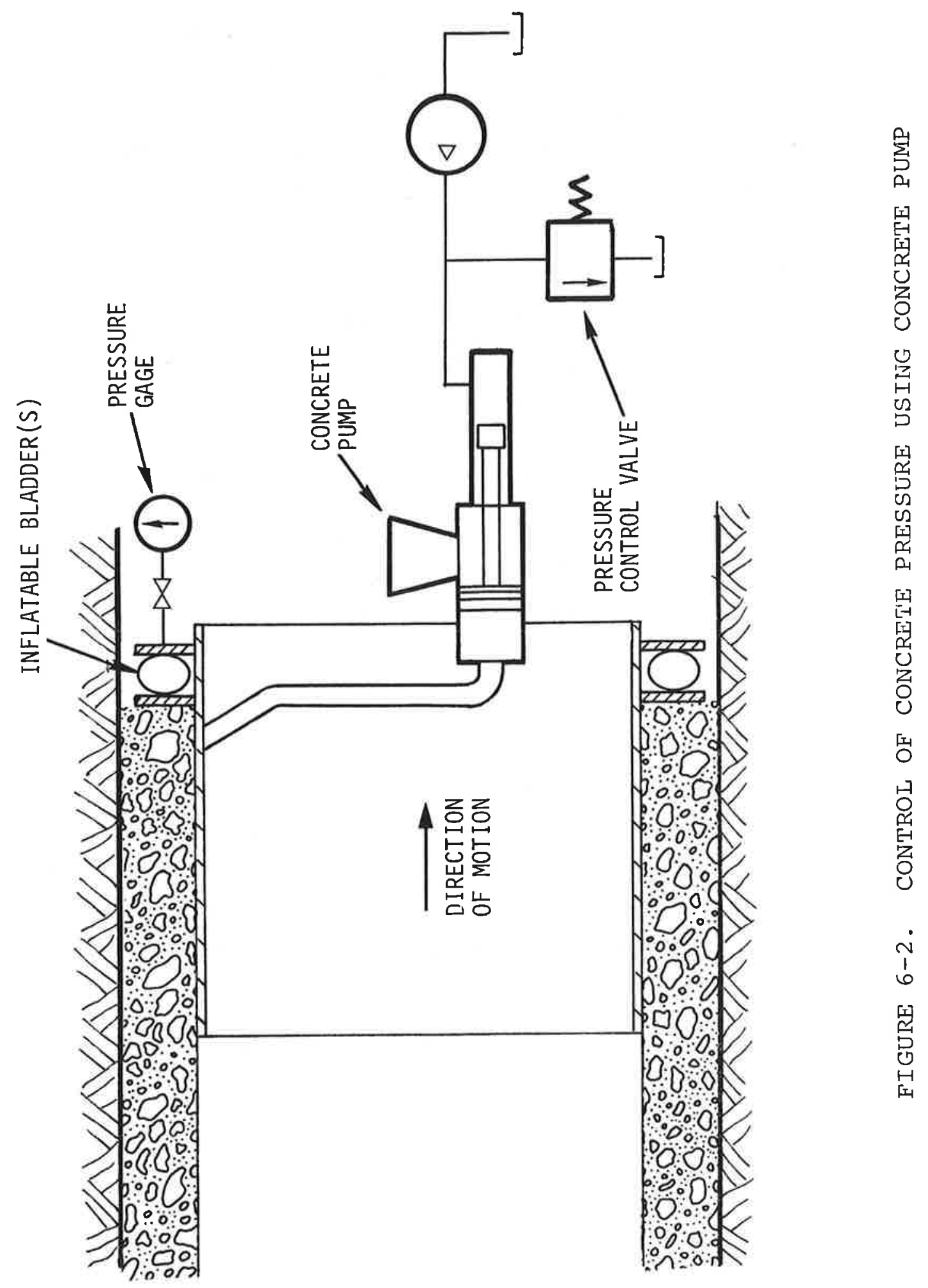




\subsubsection{Eliminate Purge System}

Once the bulkhead is eliminated the purge system could also be eliminated. When a shutdown occurs, the placing line could be disconnected from the front of the form and cleaned in the standard manner. Eliminating the purge system would reduce the overall complexity of the ETLS considerably.

\subsubsection{Design of Slipform}

The results of the ETLS laboratory test program showed that the slipform must be designed to have varying stiffness. It must be stiff at the front to react the hydrostatic load of the fluid concrete. It must be flexible at the tail to permit steering and minimize the form drag due to thermal expansion.

In addition, the slipform design must incorporate a means of rapidly stripping the forms from the concrete in the event of a jam-up. This is especially important if the bulkhead is eliminated, as the forms will have to be stripped after each shutdown. It is recommended that a set of small hydraulic cylinders be incorporated on the form for this purpose.

The use of a form which is not full-round would also reduce stiffness and facilitate steering. A form of this type would work nicely in a transit tunnel where the liner and the invert could be slipformed in separate passes. This would also reduce the cost of materials since there is no need to use VHEC in the invert.

The design of the slipform is discussed further in subsection 6.5 . 


\subsubsection{Joints in the Liner}

Before the ETLS can be taken underground a method must be devised for sealing of cold joints in the liner. In addition, some provision must be made for installing expansion joints in the liner. Eliminating the independent bulkhead may help considerably. With a fixed bulkhead, it should be possible to devise a method of removing the bulkhead from the front of the form to install an expansion joint or water stop. The expansion joint or water stop could then be formed directly into the liner. Otherwise it will be necessary to grout the cold joints and saw cut the liner to install expansion joints. This would not be desirable.

\subsection{CONCEPTUAL DESIGN OF AN UNDERGROUND ETLS}

With the above conclusions in mind, some preliminary design studies were prepared for the design of the first underground ETLS.

The design studies which were prepared focused primarily on the design of a second generation slipform with integral bulkhead. Some work was also done on the design of a materials hanciling system which could be integrated with the TBM trailing gear.

Finally, some very preliminary design concepts were prepared for an ETLS integrated with other tunneling machines lother than hard rock TBM's) for different types of ground conditions. These included a fully shielded TBM for incompetent rock, and two soft ground machines; a shield with a mechanical excavator and a rotary mechanical shield. 


\subsection{SLIPFORM DESIGN STUDY}

Three different flexible slipform designs were prepared. Each design incorporated a fixed bulkhead at the front of the form. The three designs are presented in Figures 6-3, 6-4 and $6-5$.

All three designs are for a full-round slipform. As mentioned earlier a slipform which is not full-round would be desirable and integrate nicely with typical transit tunnel cross sections. However, since the major application area of the ETLS was clearly other than transit (refer to Table 1-1), it was decided to study ways of providing the required flexibility in a full-round form. Two longitudinally segmented form designs and one circumferentially segmented form design were developed.

\subsubsection{Circumferentially segmented slipform}

The circumferentially segmented slipform design is shown in Figure 6-3. The form consists of a rigid forward section 6 ft in length. The forward section carries the bulkhead-seal assembly, the attachment for the placing line, and the hydraulically operated pillow-blocks. The section is stiff to react to the load of the fluid concrete.

The remainder of the form is made up of 24 steel leaves running lengthwise similar to the leaves which were cut in the prototype slipform during the system modifications task described. in section 5.3.1 Strips of hard rubber or polymer material are installed between the leaves to provide a seal and prevent concrete from leaking out between the leaves. A 6 in. tee section is welded lengthwise to the back of each leaf. The tee sections would be bent to provide a slight inward camber towards the tail of the form. 


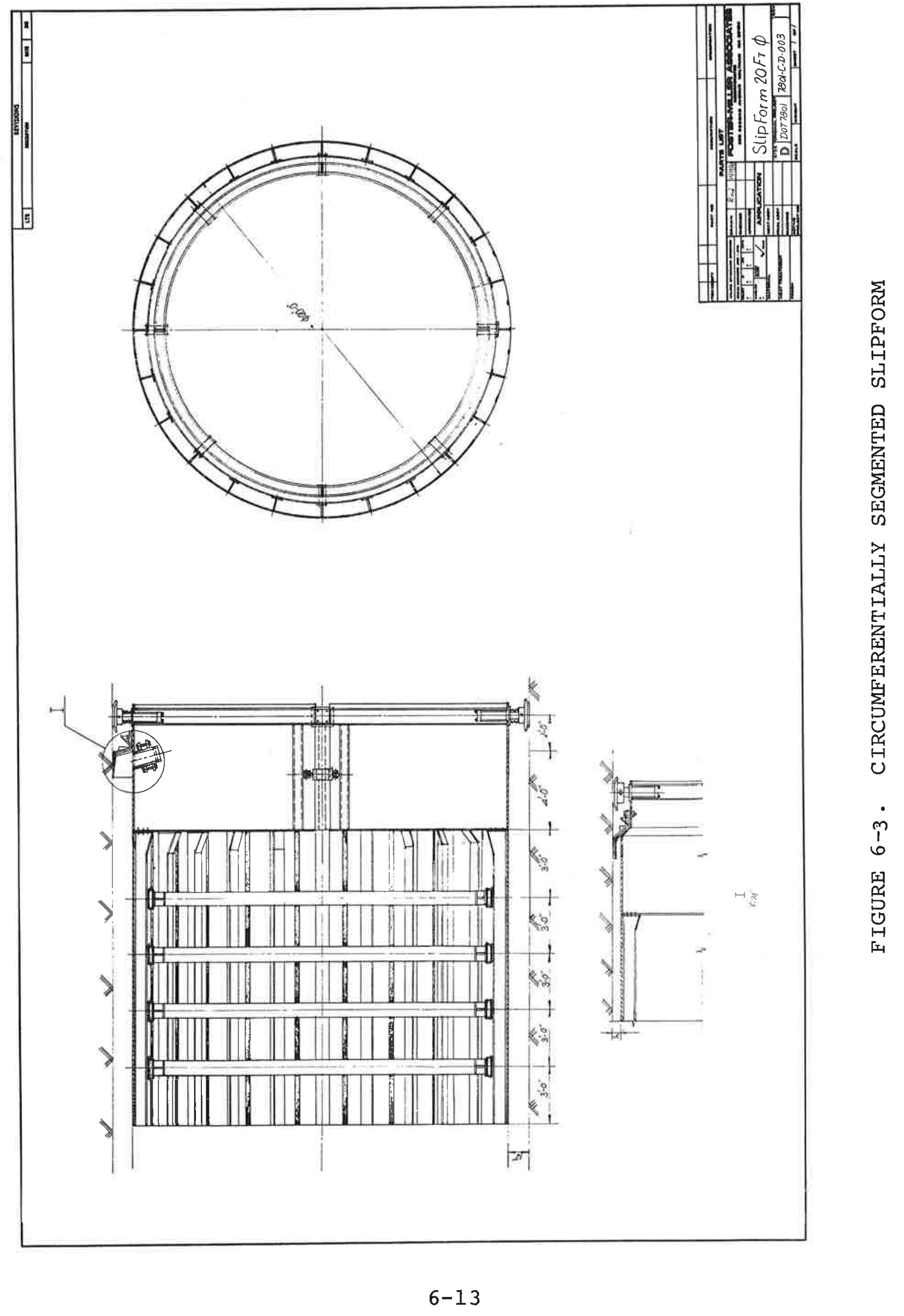


Four doughnut shaped bladders are installed so that they rest against the back of the tee sections as shown in the figure. Each of the bladders is contained by a circular box-beam on the inside. By controlling the air pressure supply to the bladders, the form can be forced out against the concrete. This would effectively allow the form length to be varied depending on the advance rate.

This design has several undesirable aspects. It is complicated to fabricate and to assemble in the tunnel. It does not provide a positive mechanism to collapse the forms inward in the event they become stuck to the concrete. It will also become oval at the rear as it goes around a curve or starts into a grade.

\section{5 .2 Longitudinally Segmented Slipform}

The longitudinally segmented slipform design is shown in Figure 6-4. This form also incorporates the stiff forward section. The tail is made-up of 3 circular segments with seals in between. Each segment has a single longitudinal slot along one side. A hydraulic cylinder is installed so that it bridges the slot. Tee section 'fingers' are provided across the seals between the segments. The fingers are welded to one segment and slide in or out of the next. These locate the segments laterally with respect to one another.

This form would negotiate curves by stretching the seals between the segments on the outside of the curve. The seals must have sufficient strength to transmit the form drag into the forward section of the form. Preliminary design calculations indicate this is not a problem.

The hydraulic cylinders in each section would be used to bring the section in or out of contact with the concrete, or for stripping the forms following a shutdown. 


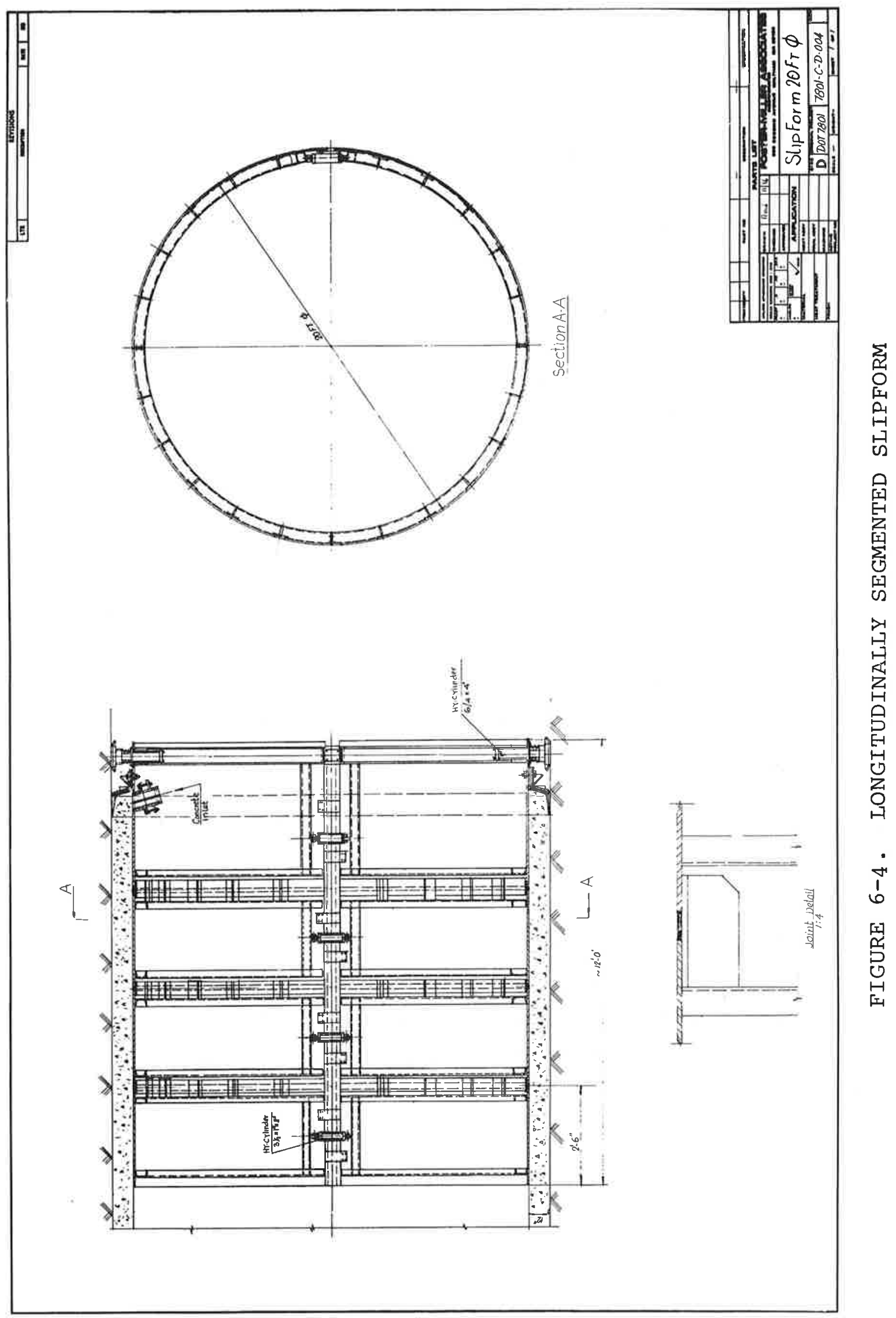


A second longitudinally segmented form design was also studied. This is shown in Figure 6-5. The design in Figure 6-5 incorporates hydraulic cylinders bridging between the sections. These would permit the form shape in a curve to be actively controlled. Design calculations showed that the cylinders would not be effective once the concrete gained minimal strength.

It is also worth mentioning that all three form designs have the placing port in the form. The vibrators would also be mounted on the form. This simplifies removing the seal and also provides for easier access to the placing line penetration. Based on the consistently good consolidation obtained during the Phase II tests, this change should not cause any problems.

It is intended that the purging system be eliminated entirely. The placing line from the pump up to the penetration would be disconnected for cleaning. The design of the penetration incorporates a tapered sleeve which is slotted along one side. When the placing line is removed the sleeve can be withdrawn. The concrete plug is easily removed from the tapered sleeve by inserting a pry-bar in the slot and expanding the sleeve. This design was used on the Continuous shaft Liner Program (15) with good results.

\section{5 .3 Conclusions of Slipform Design Study}

The slipform design study concluded that the longitudinally segmented form design shown in Figure 6-4 best embodies the conclusions of the Phase II test program with regard to slipform design. It offers the necessary flexibility. It provides for control of form length and stripping of the forms following a shutdown. It incorporates a fixed, easily accessible bulkhead. 


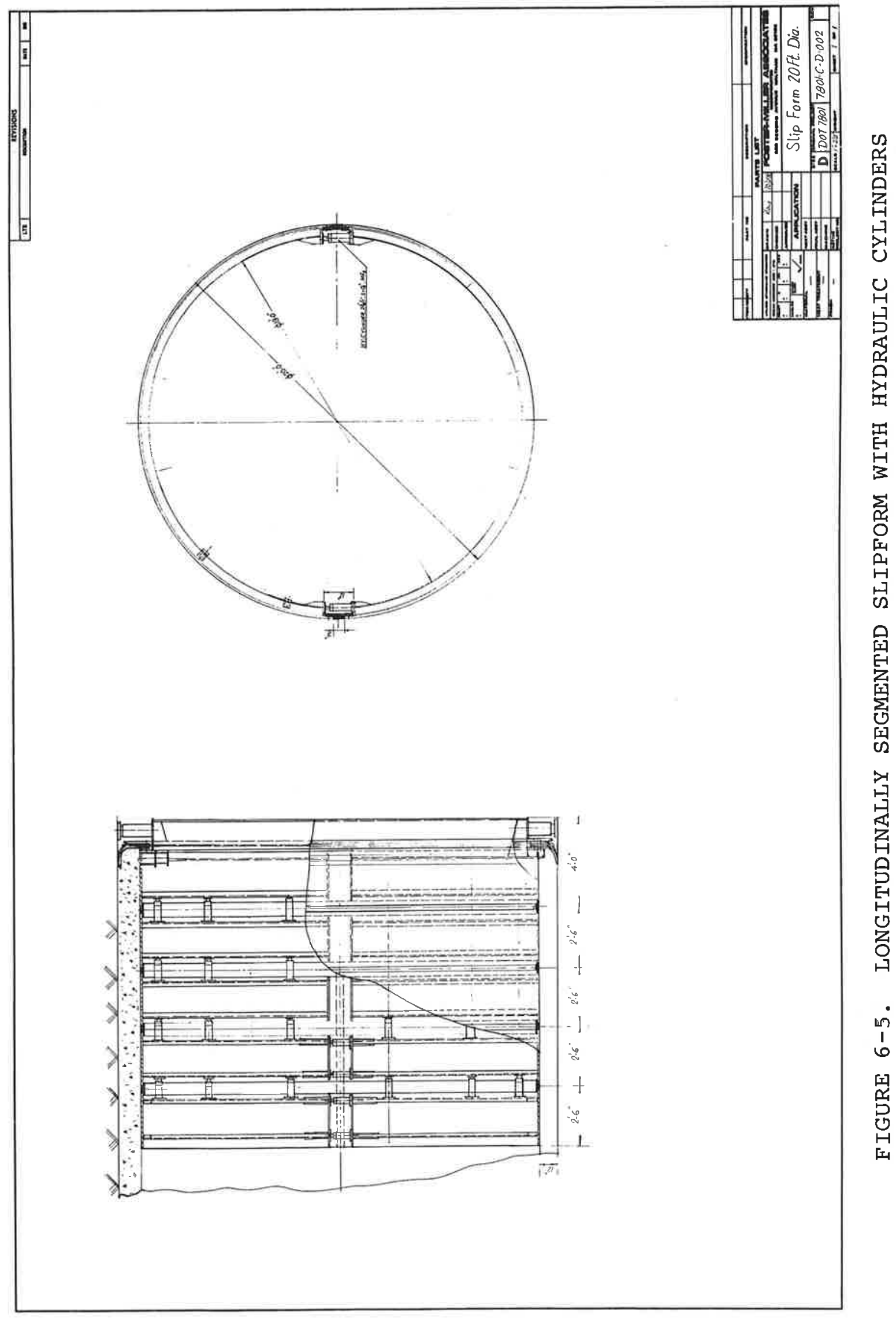


It should also be reasonably straightforward to fabricate. It is recommended that a similar form design be used in any contemplated field test of the ETLS.

\subsection{INTEGRATION OF ETLS WITH TBM}

Figure 6-6 shows the ETLS integrated with a hard rock TBM. The ETLS is located directly behind, and reacts off of the TBM back frame.

\subsubsection{Rock Conditions}

A design such as the one shown could be used in rock having an RQD of 40-50. Specially designed rock bolts could be used if required to stabilize the rock between the cutter head and the lining operation. The heads of the rock bolts would have to be designed so that they do not project more than a few inches from the rock surface, so that the seal can pass over them.

\subsubsection{ETLS Materials Handling}

Figure 6-6 shows the ETLS material handling system integrated with the TBM muck train. Raw materials are delivered to the heading in two bulk components: prebatched aggregates and cement. The cement is then charged into the auger-mixer using a pneumatic system or a button conveyor. The prebatched aggregates would be discharged from horizontal agitator cars onto a conveyor and charged into the auger-mixer. Based on the relative volume of the lining to excavation it is calculated that a prebatch car would be required for every 6-7 muck cars. A cement car would be required for every 12-24 muck cars.

\subsubsection{Rail Laying Operations}

Care will have to be taken in the design of the ETLS materials handling system to insure that it does not interfere 


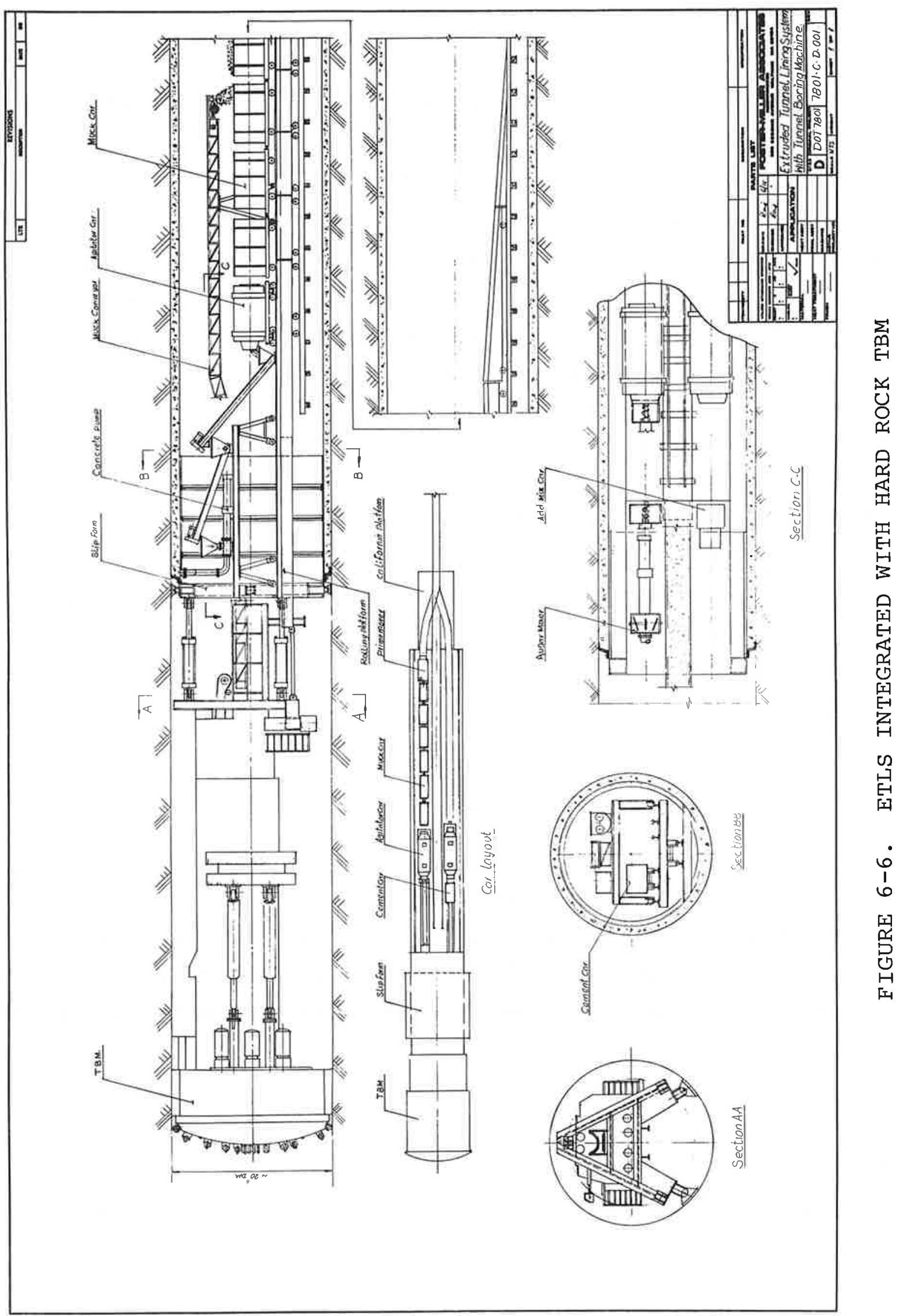


with rail laying operations which normally take place just ahead of the muck train. A monorail would have to be fitted to the underside of the muck conveyor to bring the rails forward, since the rail car can no longer be at the front of the train.

In a large diameter tunnel it may be possible to use an arrangement similar to the one shown in Figure 6-6. The rails would be layed in the space between the tracks of the rolling platform. In smaller tunnels the ETLS raw materials would have to be conveyed forward past the rail laying operation. Alternatively, the concrete could be mixed at the front of the muck train and pumped forward.

\subsection{INTEGRATION OF ETLS WITH OTHER TUNNELING MACHINES}

To conclude the conceptual design activities, the adaptability of the ETLS to other types of tunneling operations was essential. It is important to note that the discussion provided in this section is very preliminary and represents the initial thoughts of the authors as to the suitability of the ETLS for ground conditions other than hard rock.

\section{7 .1 ETLS with Shielded TBM}

Figure 6-7 is a cross section of the ETLS integrated with a fully shielded TBM. A three piece shield would be required to accomodate the relative movement of the ETLS and TBM. The gripper section would react to the cutter head loads and the ETLS loads. The gripper section could be thrust forward off the ETLS during regrip.

This type of machine has two major disadvantages. It is difficult to obtain access to the rock surface for inspection and patching ahead of the ETLS. The machine may also be prone to jam if any rock rotates downward into the telescoping joint. 


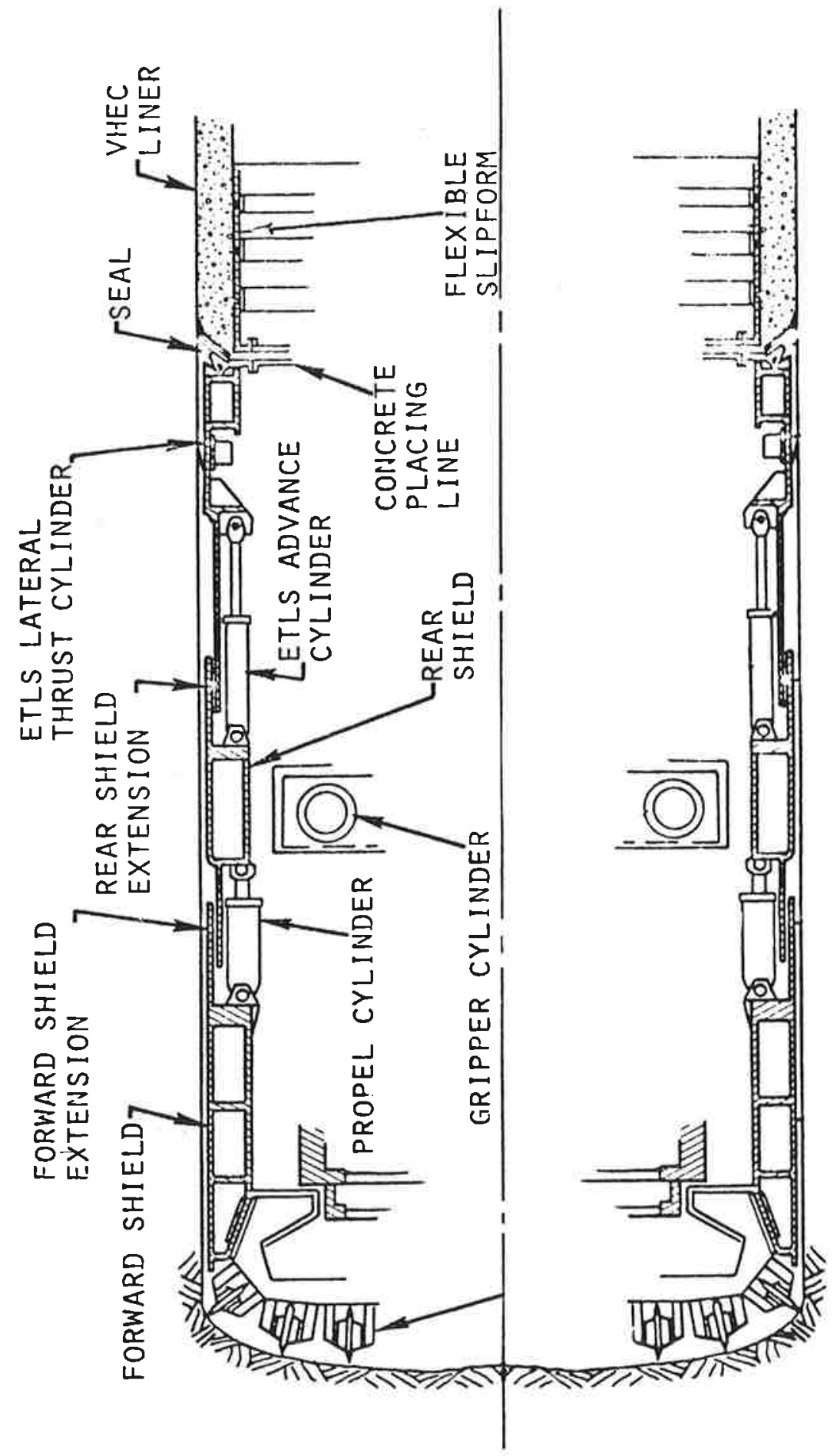

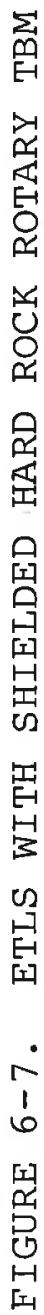


The more recent TBM designs for incompetent rock have tended away from this type of fully shielded design. Designs which incorporate finger shields around the top 90-120 are currently favored. Temporary supports (steel ribs and lagging) are installed, working from underneath the shield, as close to the cutter head as possible.

It is expected that the ETLS could be readily integrated with this type of design. Depending on the rock conditions the grippers could be moved as far forward as possible and the ETLS located immediately behind the grippers. The shield would be extended slightly to reach back to the ETLS. Roof bolts could be installed through the gaps in the shield if required. Alternatively the ETLS could be placed directly behind the cutter head, ahead of the grippers. The grippers would then react off the set concrete. The latter design would make it more difficult to patch the rock or clean-up the invert ahead of the ETLS.

It is the opinion of the authors that an ETLS could be developed which would adapt to a TBM for tunneling in incompetent rock.

\subsubsection{ETLS with Two Piece Shield with Mechanical Excavator}

Figure 6-8 is a cross section of the ETLS integrated with a two piece shield with mechanical excavator. To advance the tunnel the blade shield forward section is thrust forward reacting off the concrete and the skin friction of the shield rear section. The shield rear section is then advanced by the pressure of the concrete pumped into the ETLS. At the same time the excavation is advanced.

Clearly for a system such as this to work, the time elapsed while the shield forward section is advanced should be short 


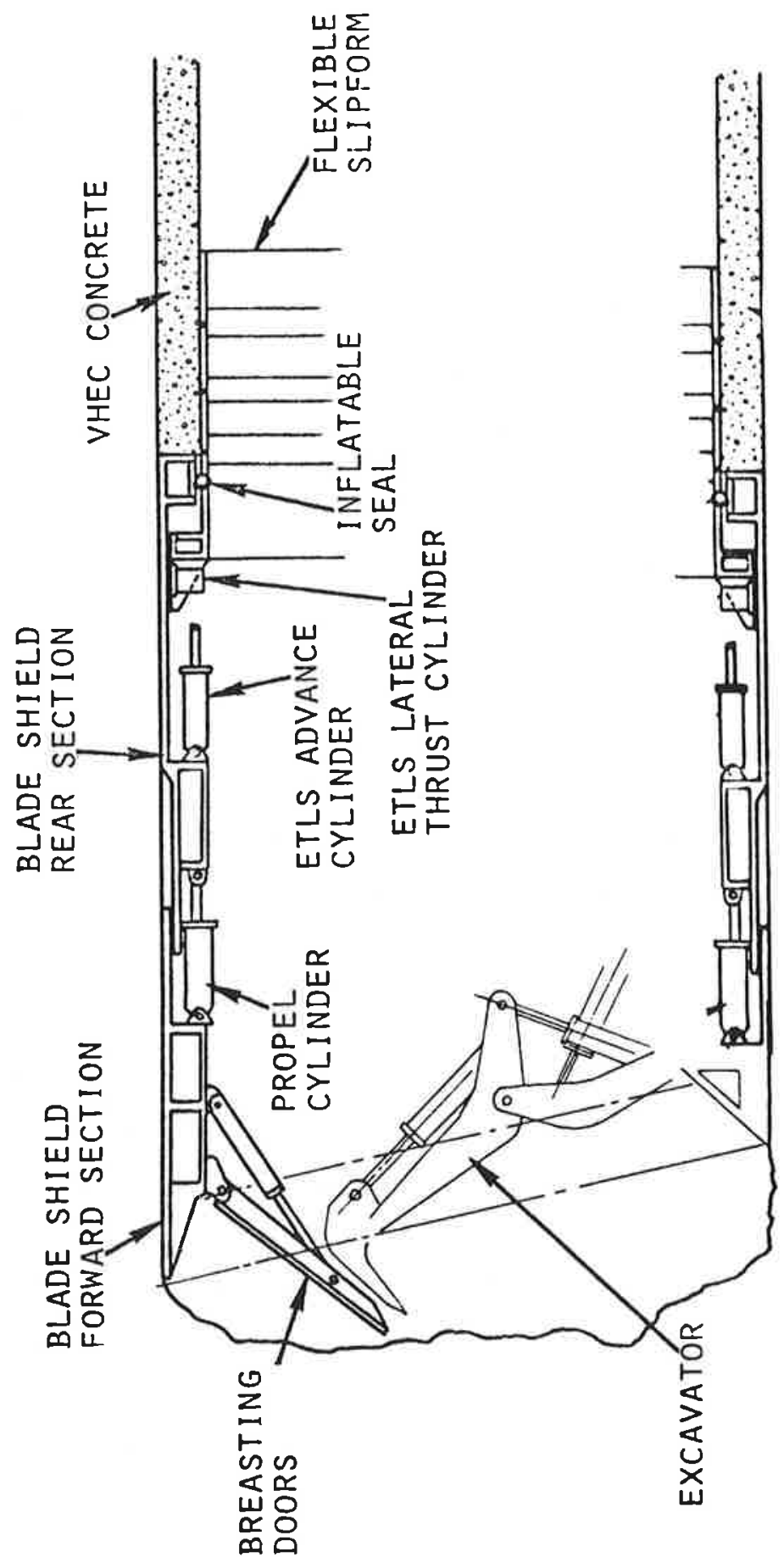

要

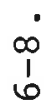

1
0
0
0
01
1 
by comparison with the overall cycle time. This permits concrete to be pumped during most of the cycle.

The pressure-drag balance which was observed during the later ETLS laboratory tests suggests that a system such as this would be workable. The advance of the shield rear section could be assisted slightly by pulling off the shield forward section in the event that concrete pressure alone is not enough. Shield skin friction could be varied to advantage by slotting the bottom of the shield sections and installing hydraulic cylinders to expand or contract the sections. The concrete pressure would also help to minimize subsidence.

It is the opinion of the authors that an ETLS could also be developed which would adapt to this type of tunneling machine.

\subsubsection{ETLS with Rotary Mechanical Shield}

Figure 6-9 shows a cross section of an ETLS integrated with a rotary mechanical shield. With a machine of this type, the greater portion of the cycle time is consumed in advancing the cutter head. The machine is then stopped briefly and the thrust ring is pulled forward to install precast concrete or steel liner segments.

It is difficult to adapt the ETLS to a machine of this type. The lining operation would have to proceed while the face is being advanced. Advancing the face by thrusting off the ETLS bulkhead would create concrete pressures of 200-300 psi (depending on liner thickness). For this reason the shield thrust would have to be transmitted through the slipform to a gripper section which reacts against the set concrete. This results in a complicated system. A system such as the Hochtief system (10) which transmits the load through stationary form rings is preferable. 


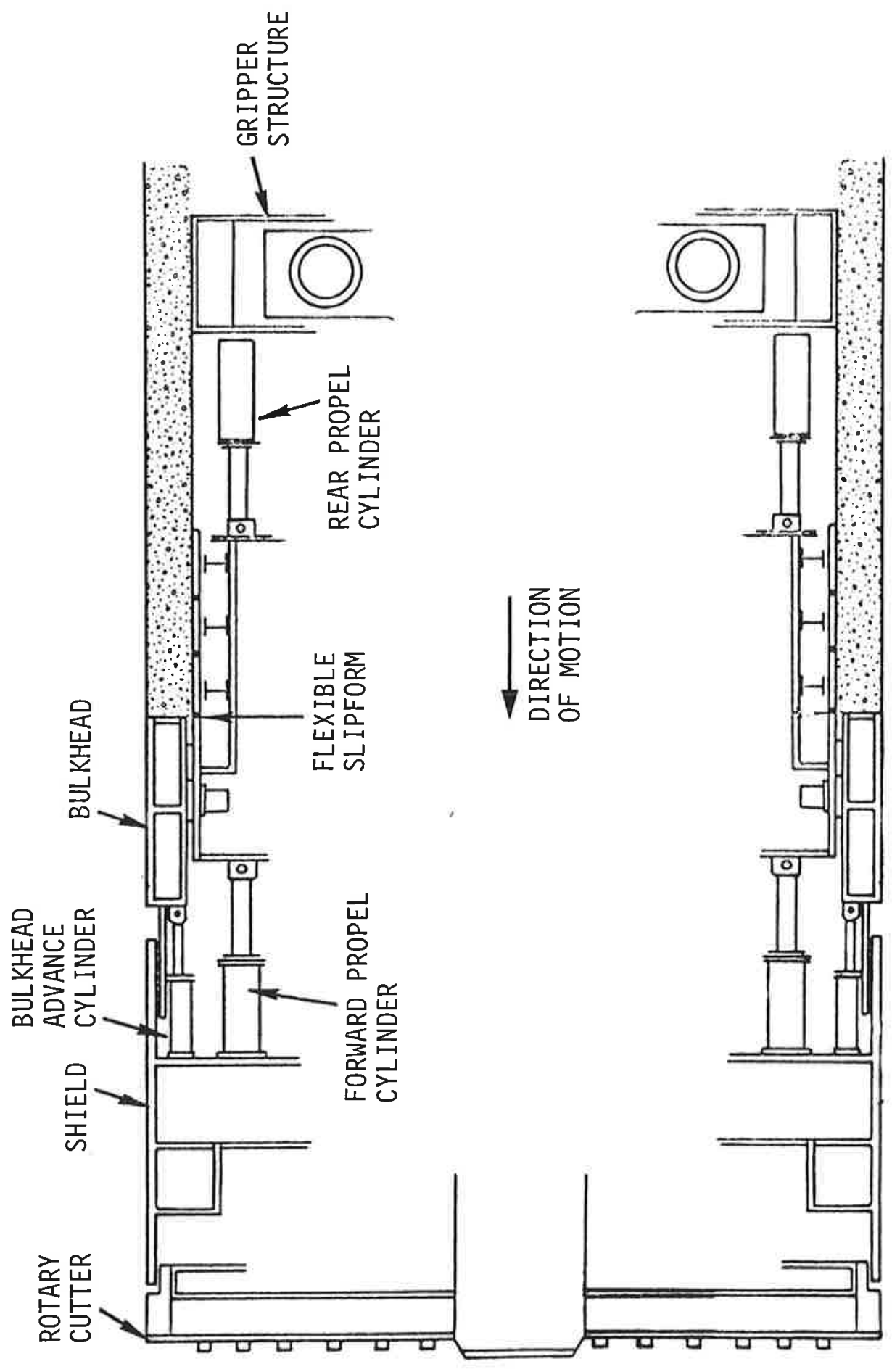

是

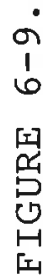


It is the opinion of the authors that to adapt the ETLS to a tunneling machine of this type would be difficult. 


\section{PROGRAM EVALUATION AND RECOMMENDATIONS}

This final section is divided into two parts. The first part describes the format, conclusions, and recommendations of two major industry reviews conducted during the course of the ETLS development program. The second section incorporates these conclusions and recommendations with those generated as a result of Foster-Miller's efforts and presents a set of final recommendations for future direction.

\subsection{PROGRAM EVALUATION}

Two external evaluations were organized by DOT during the course of this program. The first was followed at the request of UMTA following the completion of Phase I of the program. This evaluation was conducted by the Institute for Public Administration (IPA) and is referred to as the IPA review. The second evaluation was carried out at the end of the program and was organized by TSC. This evaluation solicited input from various members of the tunnel construction community and is referred to as the "peer review".

\subsubsection{The IPA Review}

The IPA review was conducted in November, 1979, and the report of this review was issued in December, 1979. The purpose of the review was to assess the merits of, and recommend directions for the ETLS program. The IPA had prior experience in conducting such reviews for major government development programs. The major thrust of its reviews had been to insure that the technology being developed could be implemented by the industry 
that it was intended to serve and to develop recommendations to support a plan for such implementation. The IPA approach was to formulate a Product Planning Team whose members would combine technical, marketing, and entrepreneurial experience in the relevant field - in this case, tunnel construction. The IPA Product Planning Team was instructed by UMTA to address the following major issues:

1. The practicability of the extruded tunnel lining concept

2. The potential for eventual industry acceptance of ETLS

3. What incentive strategy should UMTA follow to hasten industry adoption of ETLS?

4. How should UMTA's ETLS program be phased?

Two individuals represented technical societies - one, the American Society of Civil Engineers, and the other, the American Institute of Architects. The other three individuals were executives of major engineering and construction firms, heavily involved in tunneling.

The recommendations of the IPA Product Planning Team are summarized as follows:

1. Industry Acceptance of ETLS - Uncertainty exists concerning ETLS since it is still an embryonic technology: however, it is promising enough to warrant further development. UMTA should proceed with the hard rock ETLS, while also emphasizing the potential for adapting ETLS to soft ground. This will ensure the interest of the broadest potential market. 
2. Visibility - Foster-Miller and UMTA should start now to promote ETLS to the R\&D community as a promising technology being developed. This will establish a peer review which will provide useful engineering and marketing feedback from potential users; limit risk and liability through "prior discussion;" and familiarize owners, designers and contractors with ETLS. Both the overall concept of ETLS and the major new technical components should be presented in relevant professional and trade journals and in public forums of the tunneling and engineering community.

3. Program Plan - The Team approved Foster-Miller's proposed program plan for Phase II and III, with the recommendation that an in-ground demonstration be included. Neither owners nor contractors will be inclined to adopt ETLS based solely on a laboratory demonstration. The demonstration must resolve these issues: viability of seal versus rough rock, water leakage, quality control of the concrete mix and logistics of the TBM-ETLS operation.

4. Criteria for the Demonstration Site - The selection of the correct demonstration site is crucial. ETLS should initially be demonstrated under favorable conditions to prove the concept of continuously placing a concrete liner and to create a positive image of ETLS. UMTA should choose the site according to the Team's objective criteria, rather than for expediency, or for political or timing considerations.

5. Incentive Strategy for the Demonstration Program UMTA should guarantee completion of the tunnel, assume liability, and pay for design and lining costs to ensure 
the cooperation of the owner in specifying ETLS. The potential contractors should be pre-selected for technical competence and quality of management. The contract should be cost plus fixed fee due to the uncertainties involved; care should be taken in writing the contract, so as not to unnecessarily burden the contractor.

6. Incentive Strategy for Initial Applications - Further incentives will be needed to encourage the adoption of ETLS after the demonstration program. ETLS should be specified under an alternate bid procedure with the amount of the differential kept secret. After the initial applications, ETLS will become the "state of the art" and should readily be adopted by the tunneling construction industry.

7. Literature Search - Foster-Miller should undertake a more active and thorough literature search covering related and component technologies. This should include foreign technology as well. Foster-Miller can benefit from other's experience plus save time and money by adapting existing component technology to ETLS.

8. Potential Manufacturer for ETLS - UMTA should begin to identify potential manufacturers of ETLS, such as Robbins Co. or Ewing-Records, Co., since ETLS will not be deployed without a commercial manufacturer to produce and market it. UMTA does not have the in-house capabilities to handle this on its own.

The recommendations of the IPA reviewers resulted in the generation of an ETLS deployment plan, formulated by TSC and submitted to UMTA in March of 1980. This plan described a variety 
of activities to be carried on in parallel with, and subsequent to, the ETLS program described in this report. These activities were intended to lead to an underground demonstration of the ETLS system, which was identified as a major milestone for industry acceptance.

\subsubsection{The "Peer Review"}

As part of the completion of the ETLS program, TSC organized a "Peer Review" meeting which took place in June of 1982. The purpose of this meeting was to obtain feedback from the various segments of the tunnel construction community regarding the overall direction of the ETLS program. The peer review represented owners, designers, contractors, geotechnical engineers, and tunnel equipment manufacturers. The reviewers had the benefit of inspecting the full-scale test hardware developed during Phase II and of witnessing an ETLS test on videotape. They also presented conceptual designs for an underground ETLS system, as discussed in subsection 6.4 .

A list of attendees at the Peer Review meeting, along with their company or agency affiliation, and the segment of the industry they represent is presented in Table 7-1.

The reviewers commented orally following presentations by TSC and Foster-Miller personnel and were asked to submit written responses to a questionnaire at their convenience. The questions posed in the questionnaire are listed in Table 7-2.

Conclusions and recommendations of nine of the peer reviewers who submitted written responses to the questionnaire, along with their verbal comments, are summarized below. 


\section{TABLE 7-1. PEER REVIEWERS}

\begin{tabular}{|c|c|c|}
\hline Name & Affiliation & Segment \\
\hline $\begin{array}{l}\text { Volker Meldner } \\
\text { Stan Paul } \\
\text { Dave Thompson } \\
\text { Ken Schoeman }\end{array}$ & $\begin{array}{l}\text { Fruin Colnon Construction } \\
\text { University of Illinois } \\
\text { Haley and Aldrich, Inc. } \\
\text { U.S. Bureau of } \\
\text { Reclamation }\end{array}$ & $\begin{array}{l}\text { Contractor } \\
\text { University Research } \\
\text { Geotechnical Engineers } \\
\text { Owner }\end{array}$ \\
\hline Bruno Dietl & & Contractor \\
\hline Terrence McCusker & Self & Tunnel Consultant \\
\hline Hugh Cronin & S\&M Constructors & Contractor \\
\hline Greg Korbin & Self & Tunnel Consultant \\
\hline Daniel Hokens & $\begin{array}{l}\text { U.S. Army Corps of } \\
\text { Engineers }\end{array}$ & $\begin{array}{l}\text { Owner, Construction } \\
\text { Manager }\end{array}$ \\
\hline $\begin{array}{l}\text { Richard Flanagan } \\
\text { James Friant }\end{array}$ & $\begin{array}{l}\text { Goldberg Zoino Assoc. } \\
\text { The Robbins Co. }\end{array}$ & $\begin{array}{l}\text { Geotechnical Engineers } \\
\text { Tunnel Machine } \\
\text { Manufacturer }\end{array}$ \\
\hline Lynne Fitzpatrick & A.A. Mathews Co. & Designer \\
\hline Eugene Foster & UTDC & Consultant \\
\hline Harry Sutcliffe & Bechtel, Inc. & $\begin{array}{l}\text { Designer, Construction } \\
\text { Manager }\end{array}$ \\
\hline Glenn Traylor & Traylor Brothers & Contractor \\
\hline Don Rose & Tudor Engineering & Designers \\
\hline P. Dande & Jenny Engineering & $\begin{array}{l}\text { Tunne1 Equipment } \\
\text { Designers }\end{array}$ \\
\hline
\end{tabular}




\section{TABLE 7-2. QUESTIONNAIRE FOR ETLS PEER REVIEW COMMITTEE}

1. Will the ETLS, when fully developed and operational, find easy acceptance in the tunneling industry? Why?

2. What modifications to the present model and full-scale concept are needed to improve the ETLS's applicability?

3. What technical or operational factors have been overlooked or require significant further attention?

4. What institutional factors (union, labor, government, insurance, financing, etc.) need to be addressed?

5. How do the following affect the applicability of the ETLS?

1. Type of rock

2. Type of tunneling machine

3. Designed use of tunnel

6. What further development or test would be required before you would be able to recommend the use of the ETLS on one of your projects?

7. What specifications or conditions would you recommend be incorporated in an underground test and demonstration of a full-scale ETLS?

8. What future tunneling projects do you suggest be considered as possible sites for an underground test/demonstration of the ETLS?

9. At what stage in the development of the ETLS would/should the tunneling industry be willing to accept the responsibility for the further development and funding of the system? 
Table 7-3 summarizes the comments of the nine written responses to the questions posed in the questionnaire.

The responses to Question 1 , both written and oral, generally recognized the difficulty of introducing any new technology into tunnel construction. The industry representatives felt that they must see the ETLS work in the adverse tunnel environment and demonstrate its economical potential before they would accept it on one of their projects.

With respect to the overall design concept, questions were raised regarding the location of grippers relative to the location of the liner placement. It was felt that less competent rock would require immediate placement of the liner behind the TBM cutterhead and that the TBM would have to grip off of the set concrete. A question was raised regarding the use of a telescopinc shield in soft ground, which is incorporated in one of the soft ground ETLS concepts.

A number of technical issues requiring further attention were raised by the reviewers. The ability of the ETLs to handle water inflow and immediate rock loads was high on the list of technical concerns. The ability to seal the pressurized concrete when overbreak exceeds $3 \mathrm{in}$. was a concern for the rock application. Equipment performance, ability to negotiate curves and cracks which appeared in the concrete during one of the tests were also identified as areas to address. On the nontechnical side, oral comments during the meeting suggested that the cost/benefit analysis of the ETLS system needs to be updated to reflect both current data on lining techniques and the current state of knowledge regarding the potential performance of the ETLS system underground. 
TABLE 7-3. SUMMARY OF PEER REVIEWER'S RESPONSES $((9)=$ NUMBER OF RESPONSES )

\begin{tabular}{|c|c|}
\hline $\begin{array}{l}\text { 1. Ease of Industry Acceptance: } \\
\text { Only when economy is demonstrated underground } \\
\text { Industry is conservative and resists new developments } \\
\text { Only under limited conditions } \\
\text { After proven resistant to complication } \\
\text { Yes } \\
\text { No }\end{array}$ & $\begin{array}{l}(4) \\
(2) \\
(1) \\
(1) \\
(1) \\
(1)\end{array}$ \\
\hline $\begin{array}{l}\text { 2. Required Modifcations to Concept: } \\
\text { Liner must be placed ahead of gripper for true } \\
\text { application to incompetent rock } \\
\text { question use in conjunction with double shield }\end{array}$ & $\begin{array}{l}(2) \\
(1)\end{array}$ \\
\hline $\begin{array}{l}\text { 3. Areas Requiring Further Attention: } \\
\text { Overbreak beyond } 3 \mathrm{in.} \\
\text { Water inflow } \\
\text { Ground loads on liner } \\
\text { Equipment wear/breakdown } \\
\text { Curves } \\
\text { Cracks in liner } \\
\text { Long term verification of concrete performance }\end{array}$ & $\begin{array}{l}(2) \\
(4) \\
(4) \\
(2) \\
(1) \\
(1) \\
(1)\end{array}$ \\
\hline $\begin{array}{l}\text { 4. Institutional Factors: } \\
\text { Nothing significant }\end{array}$ & \\
\hline $\begin{array}{l}\text { 5. ETLS Applicability: } \\
\text { No question in competent rock } \\
\text { Needed in weak rock and soil } \\
\text { Question ability to deal with weak rock and soft ground }\end{array}$ & $\begin{array}{l}(4) \\
(3) \\
(3)\end{array}$ \\
\hline $\begin{array}{l}\text { 6. Recommended Development Prior to Application on Project: } \\
\text { Underground field test } \\
\text { Laboratory tests for specific issues (e.g., water) }\end{array}$ & $\begin{array}{l}\text { (9) } \\
(2)\end{array}$ \\
\hline $\begin{array}{l}\text { 7. Specifications for Field Tests: } \\
\text { Begin with ideal conditions (no curves, competent } \\
\text { rock, limited water, etc.) } \\
\text { Include problem conditions } \\
\text { Separate from TBM }\end{array}$ & $\begin{array}{l}(3) \\
(5) \\
(2)\end{array}$ \\
\hline $\begin{array}{l}\text { 8. Future Tunneling Projects: } \\
\text { Rochester sewer } \\
\text { USBR Tunnels }\end{array}$ & $\begin{array}{l}\text { (2) } \\
\text { (1) }\end{array}$ \\
\hline $\begin{array}{l}\text { 9. Milestone for Industry Acceptance: } \\
\text { Must see system and its technical and economic potential } \\
\text { demonstrated underground }\end{array}$ & (7) \\
\hline
\end{tabular}


Regarding the applicability of the ETLS system, there was a consensus that while the system would probably work in competent rock, it was most relevant, economically, to weak rock and soil. It was this latter application that raised the most serious doubts about the technical feasibility of the ETLS (for example, ability to support short-term loads).

The written responses unanimously agreed that an underground field test was required prior to an ETLS project application. There were differences of opinion regarding the specifications for such a test. Some reviewers felt that the initial conditions should be ideal to maximize the probability of initial success. Others felt that the test should incorporate the difficult conditions (water, overbreak, curves, etc.) that represented their specific concerns. It was suggested that the initial field tests be separated from the actual tunnel boring operation. It was also suggested that those technical issues that could be resolved in the laboratory should be addressed prior to the underground tests.

Suggestions of potential tunneling projects for ETLS application were limited to the Rochester sewer system and two U.S. Bureau of Reclamation tunnels.

\subsubsection{Summary of Reviews}

The IPA and peer reviewers concurred on the following issues:

1. While a competent rock ETLS is most likely to succeed, a soft ground ETLS has the greatest economical potential.

2. An underground demonstration must be carried out prior to industry's acceptance of the ETLS approach.

The IPA reviewers concurred with those peer reviewers who recommended favorable conditions for initial testing, followed by gradual adaptation to the more difficult conditions. These 
opinions support the developmental philosophy of "walk before you run," a philosophy that was established by DOT in organizing this program.

\section{2 RECOMMENDATIONS}

The following recommendations have been formulated based on the technical information generated by Foster-Miller during the course of this program and on the input from the IPA and peer reviewers.

1. Definitions of ETLS Application - It must be recognized that the ETLS, like any other tunneling system, will have limits to its applications. To date, the ETLS has been presented as a broadly applicable system and no clearly defined configuration for a specific type of project has been put forth. The competent rock system being developed for initial demonstration does not address the total market and thus, provides limited appreciation of significant benefit. Foster-Miller believes that many of the technical issues raised in the context of the applicability of the ETLS (e.g., ground loads, water inflow, etc.) can be resolved within the context of the proposed equipment and materials, or with minor modifications. For example, with the VHEC concrete it is possible to place the lining behind the cutterhead and grip off of the finished liner. FosterMiller recommends that conceptual studies be carried out to define the types of tunneling configurations that could benefit from the ETLS. Such studies should consider overall applicability to competent rock, incompetent rock, and a variety of soil applications. They should address questions such as the source of TBM/shield thrust, location of grippers or thrust cylinders, use of fiber-reinforced concrete for soft ground, and thrust and rock loads which must be supported by the newly-placed 
liner. Such studies should also address specific issues such as how the lining system will cope with curves, overbreak, high water inflow, equipment failures, etc. The results of these studies will lead to specifications for a complete system design, and would focus on specific problems that need to be resolved.

2. Cost/Benefit Analysis - In conjunction with the conceptual studies discussed above, the real benefit of the ETLS must be viewed in economic terms. An updated cost/benefit analysis, reflecting the type of tunneling conditions identified above, should be carried out. This analysis should address current tunneling cost elements and should recognize the increasing use and decreasing cost of precast concrete tunnel linings.

3. Laboratory Tests - Certain issues raised by the peer reviewers can be addressed economically in the laboratory. The influence of water inflow on the quality and competence of the extruded liner can be tested in a benchtop test rig utilizing a pressure and flowcontrolled water source on samples of concrete under simulated ETLS placement conditions.

The ability of the freshly placed concrete to sustain immediately imposed ground loads can also be lab tested. A number of organizations currently support test facilities for applying controlled loadings to laboratory scale concrete liners. Such facilities could be utilized to apply various predicted loads to freshly exposed ETLS concrete.

Foster-Miller recommends that such tests be designed and conducted for the following purposes:

- To provide information to support design concepts

- To address industry concerns

- To precede any field test that may encounter these conditions. 
4. Field Tests - Foster-Miller recommends an underground field test as the next major step in the ETLS development. Such a test should incorporate a sufficient length of lining so that the following system features are evaluated:

- Sustained operation

- Reliability and performance of equipment

- $\quad$ Startup/shutdown procedures

- Ability to adapt to unplanned events

- Control of advance rate and alignment

- Performance of seals

- Quality of finished liner.

Foster-Miller believes that the above issues will be best evaluated under ideal tunnel conditions, in a prebored tunnel without connection to a TBM. Once these features are evaluated and satisfactory equipment and operating procedures are implemented, we recommend that issues related to connection to TBM, water inflow, response to overbreak, and curve negotiation be addressed in (a) subsequent underground test(s). 
REFERENCES

1. Mayo, R.S., T. Adair, and R. Jenny, "Tunneling - The state of the Art," U.S. Department of Housing and Urban Development Contract report $\mathrm{H}-766$, January 1968 .

2. Arthur D. Little, Inc., and Fenix and Sissan, Inc., "A System Study of Soft Ground Tunneling," U.S. Department of Transportation, Federal Railroad Administration contract report DOT-FRAOHSGT-231, May 1970 .

3. Bechtel Corporation, "A Research Program for Meeting Tomorrow's Needs in Tunneling and Excavation," National Science Foundation Report, February 1974.

4. Snyder, Anya, "Update of the Cost Comparison for the Extruded Tunnel Lining system," DOT/TSC internal memo, January 1981.

5. U.S. National Committee on Tunneling Technology, "Demand Forecast of Underground Construction and Mining in the United States," National Academy of Sciences, Report NRC/AE/TT-81-1, 1981 .

6. Parker, H.W., et al., "Innovations in Tunnel Support systems," DOT/FRA report RT-72-17 (University of Illinois), 1971.

7. Halvorsen, G.T., C.E. Kesler, and S.L. Paul, "Concrete for Tunnel Liners: Mix Design Recommendations for Prototype Extruded Liner systems," Report FRA OR\&D 75-89 (University of Illinois) 1975.

8. Ounanian, D.W., J.S. Boyce, and K.R. Maser, "Development of an Extruded Tunnel Lining System," Rapid Excavation and Tunneling Conference, San Francisco, California, May 1981.

9. Magnus, W., "Stahlfaser-Pumpbeton in Tunnelbau," Tiefbau Ingenieurbau StraBenbau, September 1981. In German.

10. Martin, D., W.M. Braun, "Blade Shield Tunnelling Machine Extrudes its own Lining," Tunnels and Tunnelling, March 1982.

11. Paulson, B.C., et al., "Alternative Methods for Underground Station Construction in Japan," Report No. DOT/RSPA/DMA-50/83/14. Dept. of Civil Eng., Stanford University 
12. Maser, K.R., B. Doherty, and D.W. Ounanian, "Extruded Tunnel Lining System: Phase I - 'Conceptual Design' and Feasibility Testing," Report UMTA-MA-06-0100-79-11, September 1979.

13. Institute for Public Administration, "Final Report of the Product Planning Team for the UMTA Extruded Lining system," December 1979.

14. Transportation Systems Center, "A Deployment Plan for the Extruded Tunnel Lining system," Submitted to UMTA under PPA UM048, March 1980.

15. Torbin, Robert N. et al., "Development of a Continuous shaft Lining System," Report No. FE/14223, U.S. Department of Energy, May 1983. 